Portland State University

PDXScholar

Spring 5-4-2016

\title{
Cyclic Loading Behavior of CFRP-Wrapped Non- Ductile Reinforced Concrete Beam-Column Joints
}

Ali S. H. Zerkane

Portland State University

Follow this and additional works at: https://pdxscholar.library.pdx.edu/open_access_etds

Part of the Civil and Environmental Engineering Commons Let us know how access to this document benefits you.

\section{Recommended Citation}

Zerkane, Ali S. H., "Cyclic Loading Behavior of CFRP-Wrapped Non-Ductile Reinforced Concrete BeamColumn Joints" (2016). Dissertations and Theses. Paper 3000.

https://doi.org/10.15760/etd.3001

This Thesis is brought to you for free and open access. It has been accepted for inclusion in Dissertations and Theses by an authorized administrator of PDXScholar. Please contact us if we can make this document more accessible: pdxscholar@pdx.edu. 
Cyclic Loading Behavior of CFRP-Wrapped NonDuctile Reinforced Concrete Beam-Column Joints

by

Ali S. H. Zerkane

A thesis submitted in partial fulfillment of the requirements for the degree of

Master of Science

in

Civil and Environmental Engineering

Thesis Committee:

Franz Rad, Chair

Evan Kristof

Patrick McLaughlin

Portland State University

2016 


\begin{abstract}
Use of fiber reinforced polymer (FRP) material has been a good solution for many problems in many fields. FRP is available in different types (carbon and glass) and shapes (sheets, rods, and laminates). Civil engineers have used this material to overcome the weakness of concrete members that may have been caused by substandard design or due to changes in the load distribution or to correct the weakness of concrete structures over time specially those subjected to hostile weather conditions. The attachment of FRP material to concrete surfaces to promote the function of the concrete members within the frame system is called Externally Bonded Fiber Reinforced Polymer Systems. Another common way to use the FRP is called Near Surface Mounted (NSM) whereby the material is inserted into the concrete members through grooves within the concrete cover. Concrete beam-column joints designed and constructed before 1970s were characterized by weak column-strong beam. Lack of transverse reinforcement within the joint reign, hence lack of ductility in the joints, and weak concrete could be one of the main reasons that many concrete buildings failed during earthquakes around the world. A technique was used in the present work to compensate for the lack of transverse reinforcement in the beam-column joint by using the carbon fiber reinforced polymer (CFRP) sheets as an Externally Bonded Fiber Reinforced Polymer System in order to retrofit the joint region, and to transfer the failure to the concrete beams. Six specimens in one third scale were designed, constructed, and tested. The proposed retrofitting technique proved to be very effective in improving the behavior of non-ductile beam-column joints, and to change the final mode of failure. The comparison between beam-column joints before and after
\end{abstract}


retrofitting is presented in this study as exhibited by load versus deflection, load versus CFRP strain, energy dissipation, and ductility. 


\section{Acknowledgment}

I would like to I extend my thanks and gratitude to my academic advisor Professor Franz Rad for his effort represented by his supervision and support of this work. I want to thank the committee members: Professor Evan Kristof and Professor Patrick McLaughlin for serving on the thesis defense committee. I would like to give a special thank you Mr. Tom Bennett for his advice and help throughout the experimental work, and for his help in facilitating the data acquisition system set-up. Moreover, I express my gratitude to my friends who worked and supported me to finish this project: Hayder Alkhafaji, Yasir Saeed, Maysoun Hameed, Salih Mahmmod, Alaa Hameed, Mohamed Al-Saadi, Anas Yosefani, Omid Abbas, Wisam Aules, Ali Hafes, Ranj Rafeeq and Aqeel Al-Bahadli.

I am very grateful to my parents and my wife for their support and encouragement. Finally, I would like to extend my gratitude to my financial sponsor (The Higher Committee for Education Development in Iraq). 


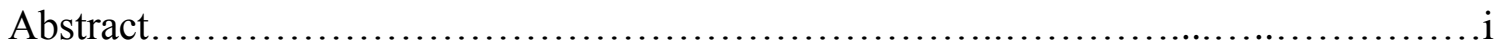

Acknowledgment..............................................................

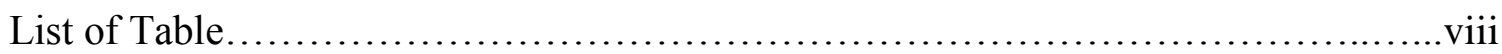

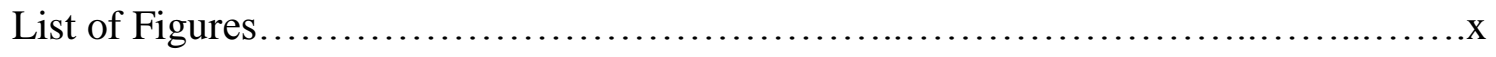

Notations.............................................................

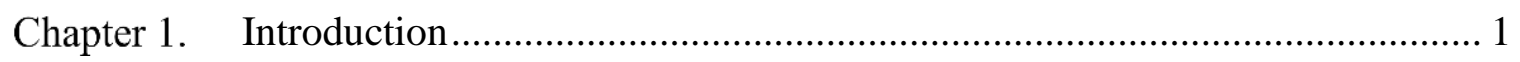

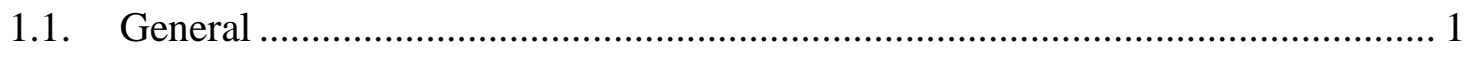

1.2. Beam-Column Joint............................................................................. 3

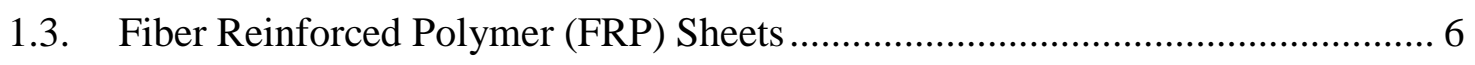

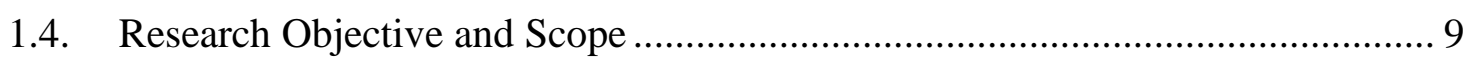

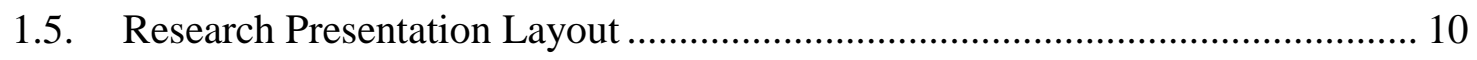

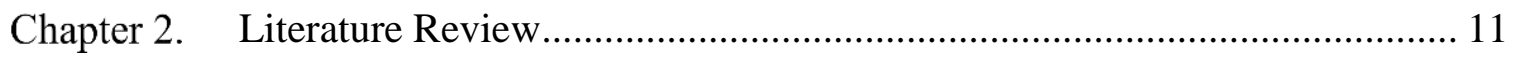

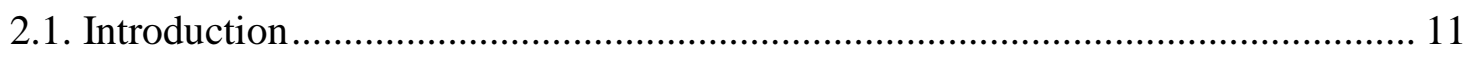

2.2. Retrofitting Techniques for Beam-Column Joint ......................................... 12

2.3. Seismic Behavior of the Concrete Beam Column Joint with Slab................... 51

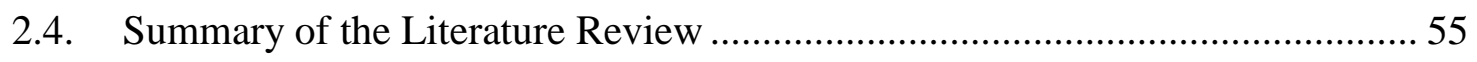

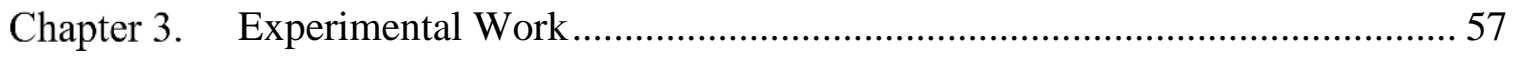

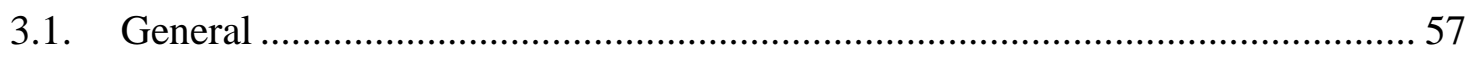


3.3. Details of Specimens ............................................................................. 58

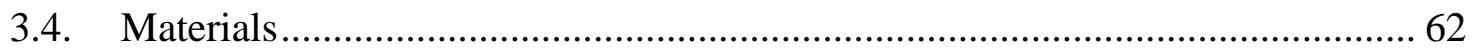

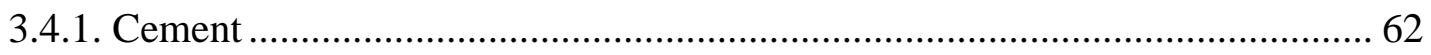

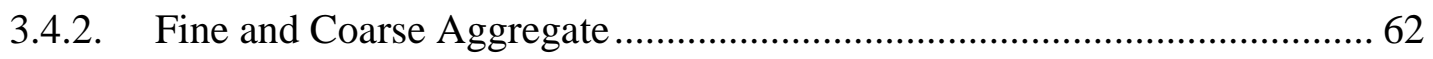

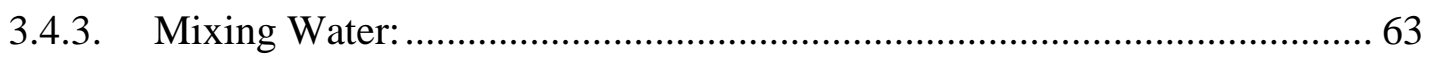

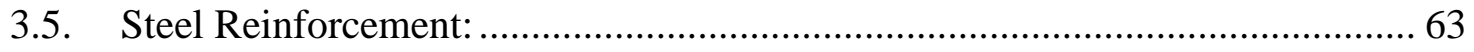

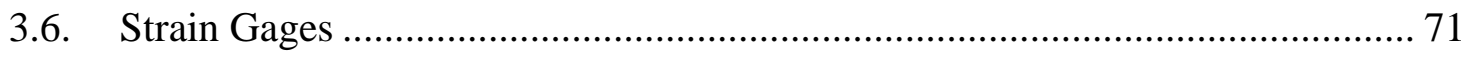

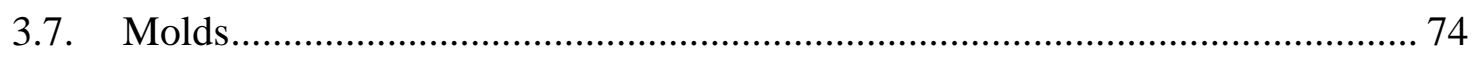

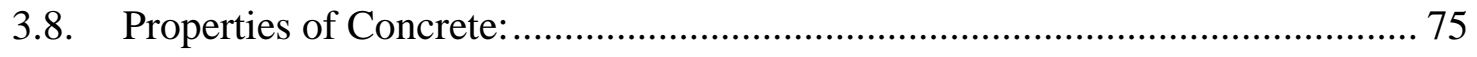

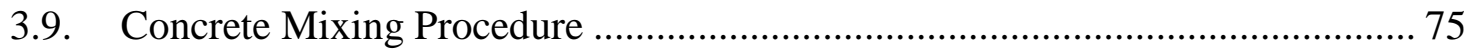

3.10. Curing Age of Specimens .................................................................. 78

3.11. Mechanical Properties of the Hardened Concrete ..................................... 79

3.11.1. Compressive Strength Testing ...................................................... 79

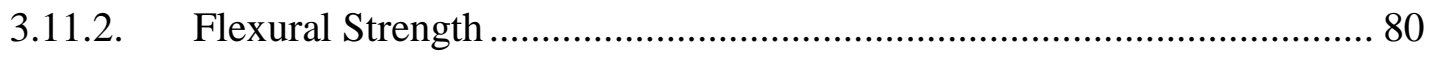

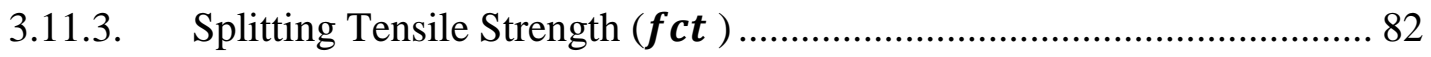

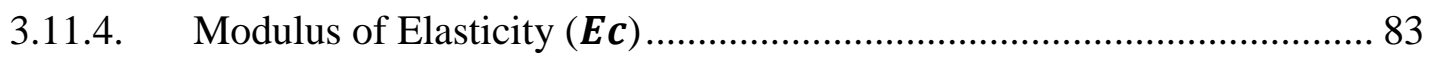

3.12. Carbon Fiber Reinforced Polymer (CFRP) Sheets ................................... 86

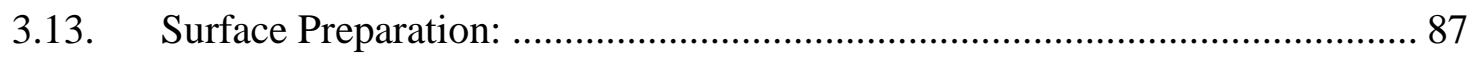




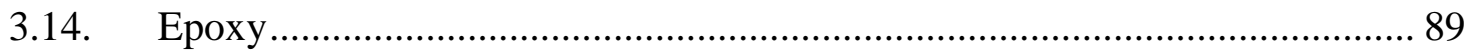

3.14.1. MasterBrace P 3500 or Primer Layer.................................................... 90

3.14.2. MasterBrace F 2000 or Putty Layer ........................................................ 91

3.14.3. MasterBrace SAT 4500 or Saturant Layer............................................... 93

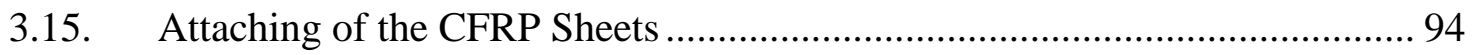

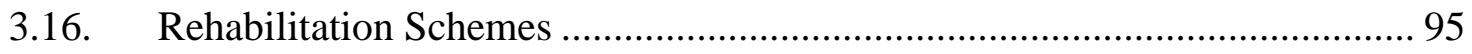

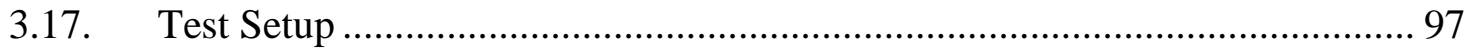

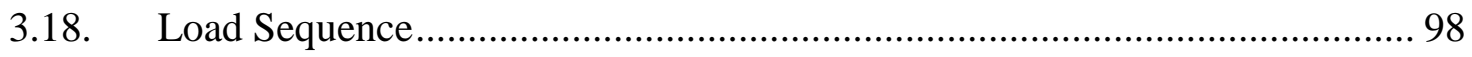

Chapter 4. Experimental Results .......................................................................... 100

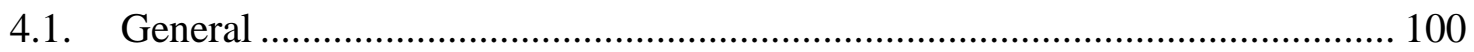

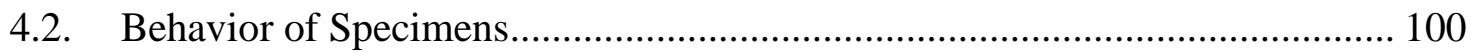

4.2.1. Ductile Specimen J1 ....................................................................... 100

4.2.2. Non-Ductile Specimen J2 ................................................................ 112

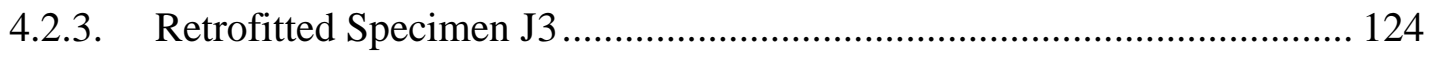

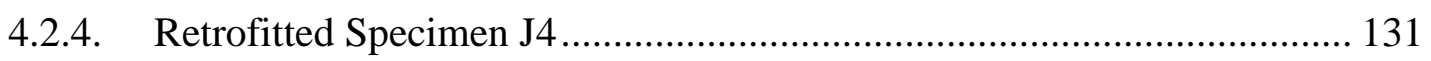

4.2.5. Retrofitted Specimen J5 and J6......................................................... 138

4.3. Effect of Carbon Fiber Reinforced Polymer (CFRP) Sheets on Joint's Strength 145

4.4. Load versus Displacement …………………........................................ 148 
4.5. Carbon Fiber Reinforced Polymer (CFRP) Sheet Strain

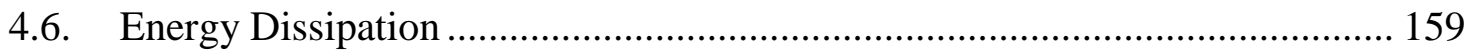

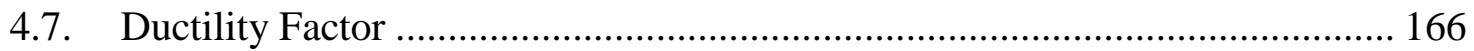

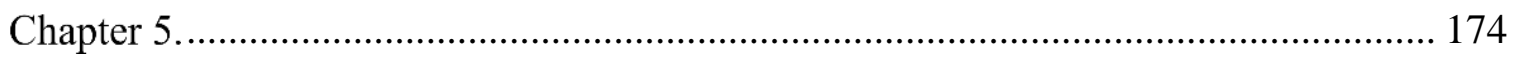

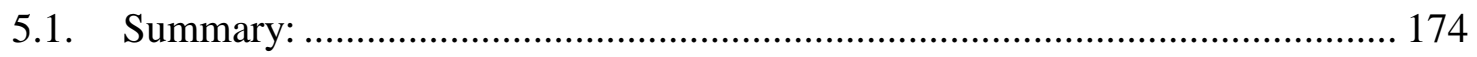

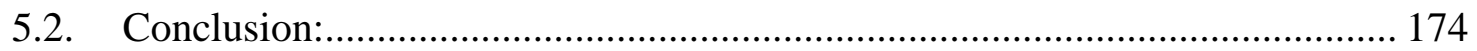

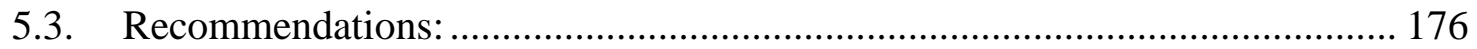

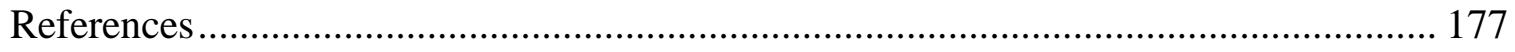

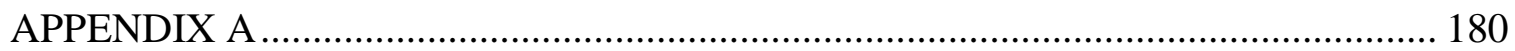

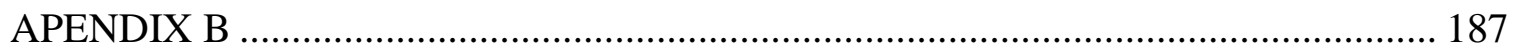




\section{List of Tables}

Table 2-1 First Group Test Results, Park, T. et al. (1973)............................................ 16

Table 2-2 Uniaxial Compressive and Spilt Strength of Concrete Cylinders .................... 21

Table 2-3 Reinforcing and Corrugated Steel Properties .................................................... 21

Table 2-4 Yield Strength of the Jacket Reinforcement Bars, Hakuto, S. et al. (2000)..... 27

Table 2-5 the Summary of the Test Results, Ghobarah, A. et al. (2005).......................... 31

Table 2-6 The Properties of Composite Materials, Prota, A. et al. (2000) ........................ 35

Table 2-7 The Reinforcing and Retrofitting Details, Prota, A. et al. (2000) ……............. 35

Table 2-8 The Properties of the Composite Material (Ghobarah, A. 2001) ...................... 39

Table 2-9 Properties of Composite Materials (El-Amoury, T. et al. (2001)) ................... 44

Table 2-10 Strengthening Techniques for All Specimens (Ghobarah, A.2002) ............... 48

Table 2-11 Reinforcement Details (Revathi R., 2014) ……………………………...... 52

Table 2-12 The Maximum Ductility Factor for Beam Column Joint without Slab.......... 53

Table 2-13 The Maximum Ductility Factor for Beam Column Joint with Slab ............... 53

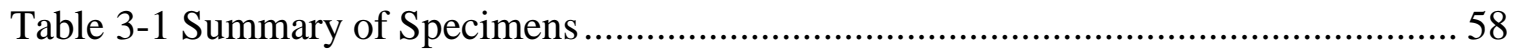

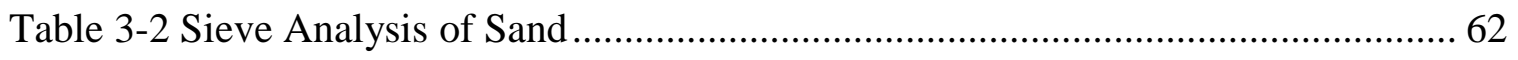

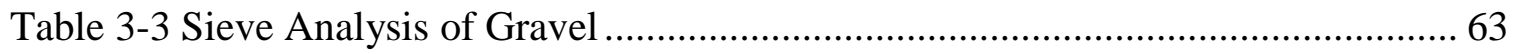

Table 3-4 The Reinforcing Steel Mechanical Properties ................................................... 64

Table 3-5 Strain Gage Properties ......................................................................... 71

Table 3-6 Properties of Mixture with 3000 Psi Compressive Strength ............................. 75

Table 3-7 Concrete Compressive Strength of the Specimens......................................... 80

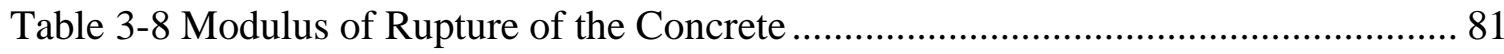


Table 3-9 Splitting Tensile Strength of the Concrete .................................................. 83

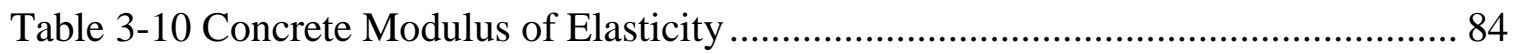

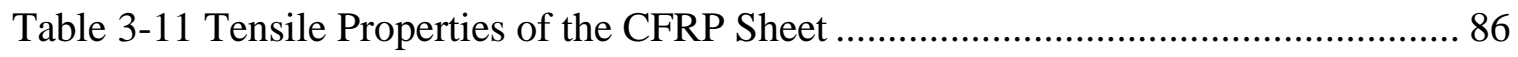

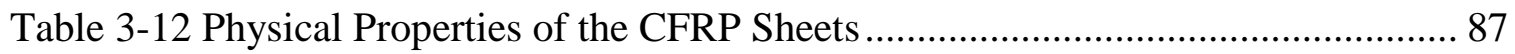

Table 3-13 Mechanical Properties of MasterBrace P 3500 ...................................... 91

Table 3-14 Mechanical Properties of MasterBrace F 2000 ........................................ 92

Table 3-15 Mechanical Properties of MasterBrace SAT 4500 …................................. 93

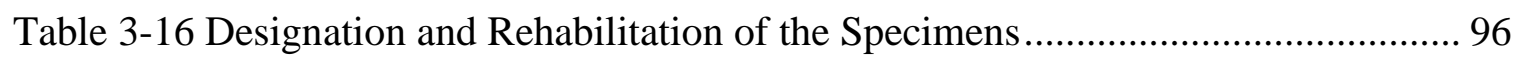

Table 4-1 The Maximum Values of the Loads and Displacements at Each Cycle, J1 .. 110

Table 4-2 The Values of the Loads and Displacements at Each Cycle, J2 ................... 123

Table 4-3 The Values of the Loads and Displacements at Each Cycle, J3 .................... 129

Table 4-4 The Values of the Loads and Displacements at Each Cycle, Specimen J4 ... 136

Table 4-5 Values of Loads and Displacements at Each Cycle, J5 .............................. 141

Table 4-6 Values of Loads and Displacements at Each Cycle, J6 ............................. 143

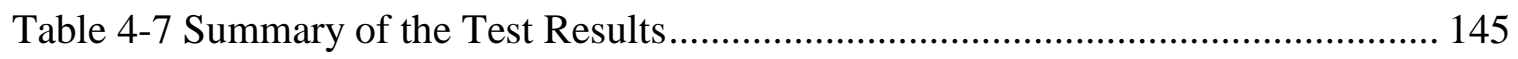

Table 4-8 Maximum Stress Developed in the CFRP Sheet ...................................... 159

Table 4-9 Maximum Ductility Factor for All Specimens ....................................... 167 


\section{List of Figures}

Figure 1-1 Beam-Column Joint Shear Failure, Kocaeli Earthquake ................................. 2

Figure 1-2 Joint Failure, Kocaeli Earthquake .............................................................. 2

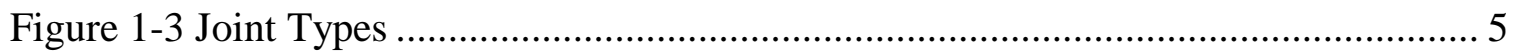

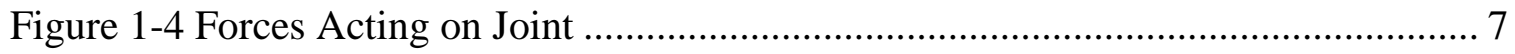

Figure 2-1 Action at an External Reinforced Concrete Joint, Park, T. et al. (1973) ........ 12

Figure 2-2 Details of First Group Specimens, Park, T. et al. (1973) ............................. 13

Figure 2-3 Details of the Second Group, Park, T. et al. (1973) ..................................... 14

Figure 2-4 The Applied Load versus the Ductility Factor for Specimen (M3), .............. 15

Figure 2-5 The Applied Loads versus the Beam Displacement, Specimen R3 ............... 17

Figure 2-6 The Applied Loads versus Beam Displacement, Specimen P3 .................... 17

Figure 2-7 Dimensions of Specimens, Biddah, A. et al. (1997) .................................... 18

Figure 2-8 Proposed Rehabilitation Technique, Biddah, A. et al. (1997) ....................... 19

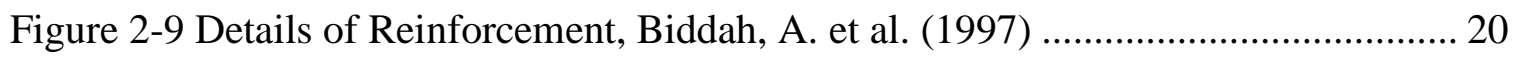

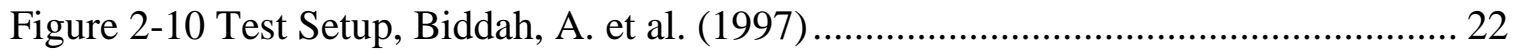

Figure 2-11 Cumulative Energy Dissipation, Biddah, A. et al. (1997) .......................... 23

Figure 2-12 The Dimensions and Reinforcement Details of the Specimens, Hakuto, S.

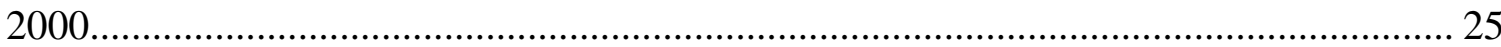

Figure 2-13 Test Setup for the External and Internal Beam-Column Joint, Hakuto, S.

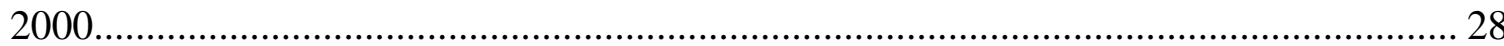

Figure 2-14 The Dimensions and Reinforcement Details of the Specimens, Ghobarah, A.

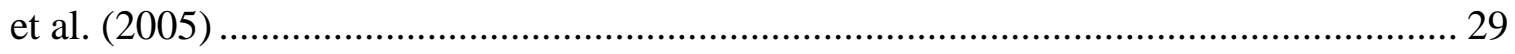


Figure 2-15 The Retrofitting Details of All Specimens, Ghobarah, A. et al. (2005)....... 30

Figure 2-16 Cumulative Energy Dissipation, Ghobarah, A. et al. (2005) ....................... 32

Figure 2-17 Stiffness Degradation, Ghobarah, A. et al. (2005) ................................... 33

Figure 2-18 Typical Test Specimen and Reinforcement Used by Prota, A. et al. (2000) 34

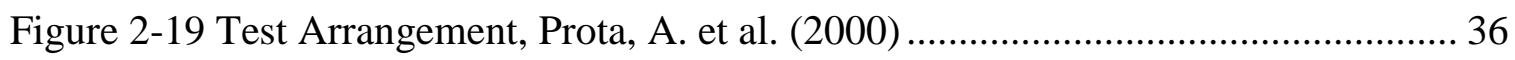

Figure 2-20 Compression between (1a and 1c) Specimens, Prota, A. et al. (2000) ......... 37

Figure 2-21 The Reinforcement Bar Details and The Dimensions............................... 38

Figure 2-22 The Test Setup and the Instrumentation (Ghobarah, A. (2001)).................. 40

Figure 2-23 Envelopes of the Beam Tip Load-Displacement Curves, (Ghobarah, A. 2001)

Figure 2-24 Energy Cumulative- Ductility Factor for Specimens (T1 and TR1),

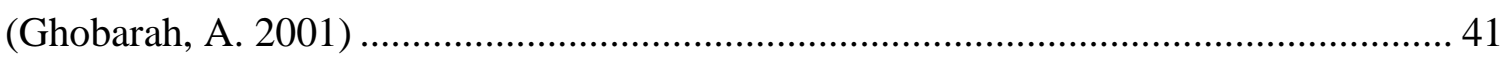

Figure 2-25 Specimens Dimensions and Reinforcement Details ............................... 42

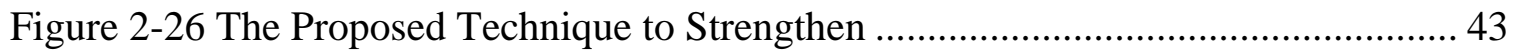

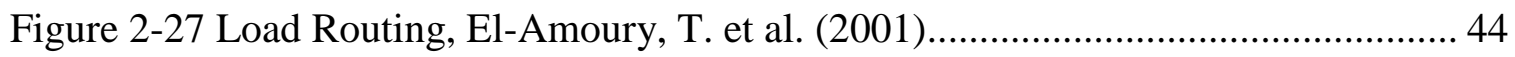

Figure 2-28 Apparatus Details for Testing Specimen (El-Amoury, T. et al. (2001)) ....... 45

Figure 2-29 Hysteretic Loop Envelopes of the Test Specimens, El-Amoury, T. (2001) . 46

Figure 2-30 Cumulative Energy Dissipation, El-Amoury, T. (2001) ............................. 46

Figure 2-31 Test Setup for Specimen TR1 (Ghobarah, A. 2002) .................................. 48

Figure 2-32 Envelop of the Hysteretic Loops, Ghobarah, A. (2002) ............................ 49

Figure 2-33 Cumulative Energy Dissipation, Ghobarah, A. (2002) ............................... 50

Figure 2-34 Failure Modes of Specimens, Ghobarah, A. (2002) ................................. 50 
Figure 2-35 Test Specimens with and without the Slab (Revathi R., 2014).................... 51

Figure 2-36 Energy Dissipation Curves for Beam-Column Joint without Slab .............. 53

Figure 2-37 Energy Dissipation Curves for Beam-Column Joint with Slab ................... 54

Figure 2-38 Cracks Patterns of the Specimens ......................................................... 54

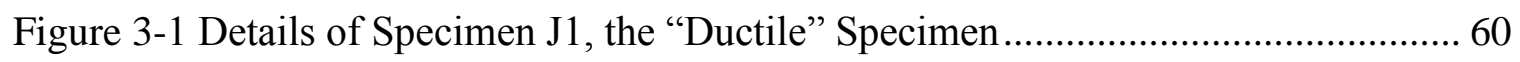

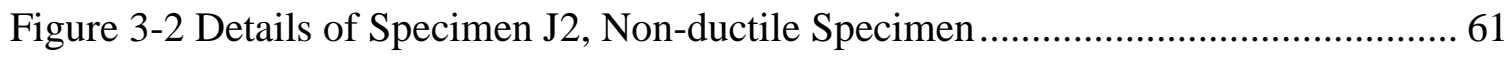

Figure 3-3 Stress-Strain Diagrams of the Reinforcement Bars ................................... 65

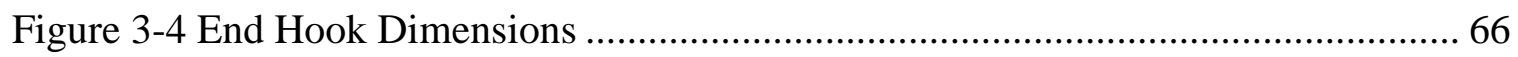

Figure 3-5 The Difference between Shear Reinforcement in Seismic and Non-Seismic

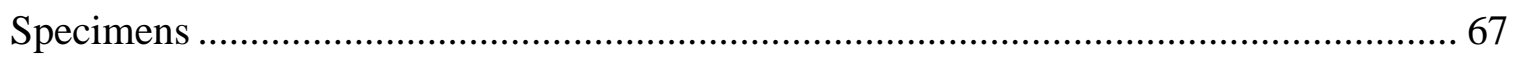

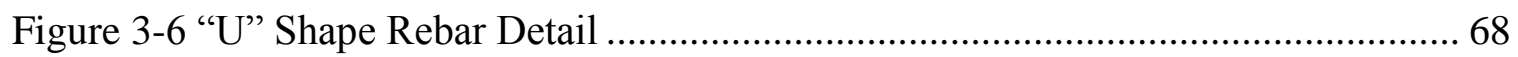

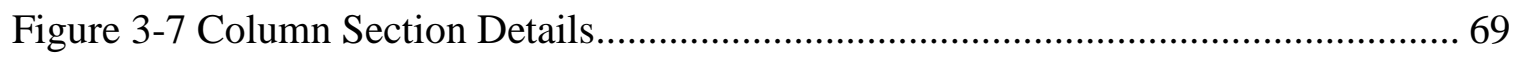

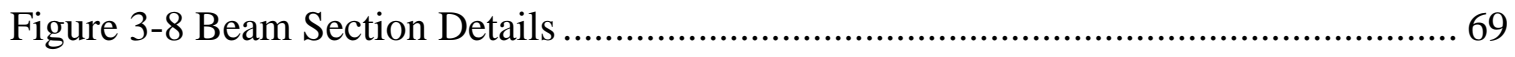

Figure 3-9 Reinforcement Cage of Specimen J1 .............................................. 70

Figure 3-10 Reinforcement Cage of Specimen J2 ….......................................... 70

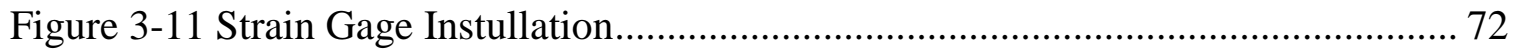

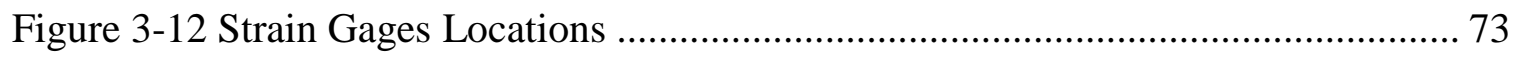

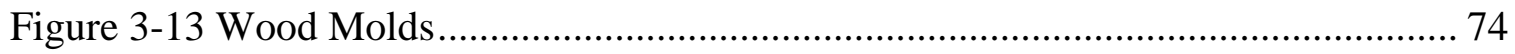

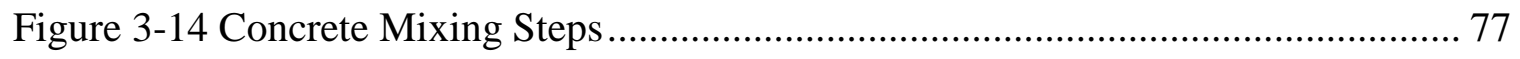

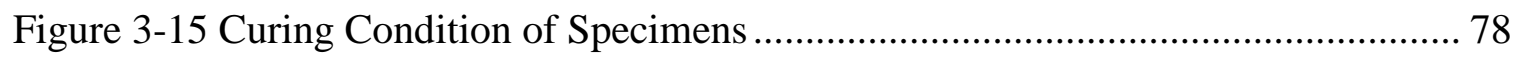

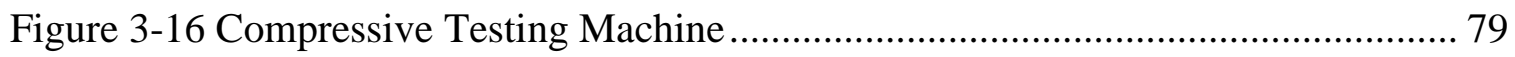

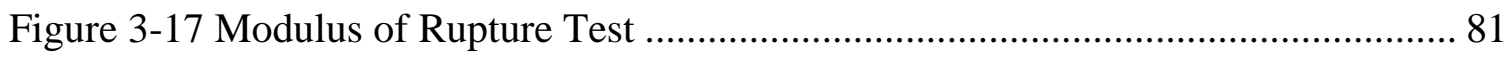




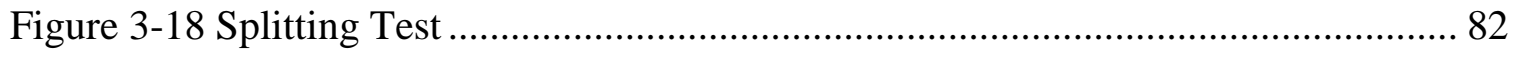

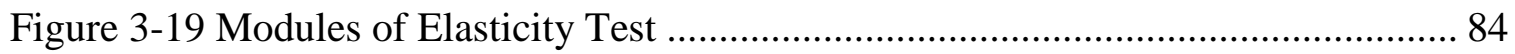

Figure 3-20 Stress-Strain Diagram of the Concrete............................................... 85

Figure 3-21 The Concrete Surface Preparations of the Specimens ............................... 88

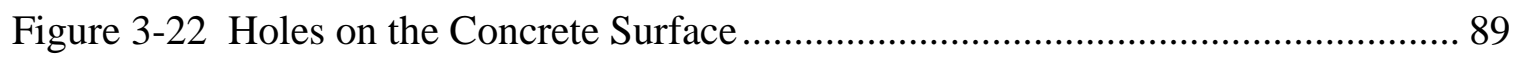

Figure 3-23 Applying the Prime Layer to the Concrete Surface ................................. 90

Figure 3-24 Applying the Putty Layer to the Concrete Surface .................................. 92

Figure 3-25 Specimen Wrapped by CFRP Sheets .................................................. 94

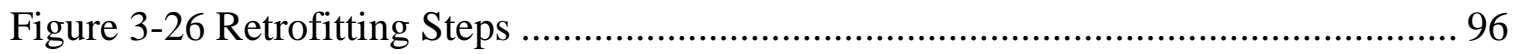

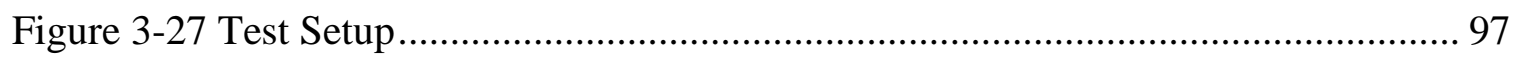

Figure 3-28 Load Sequence Diagram .................................................................. 99

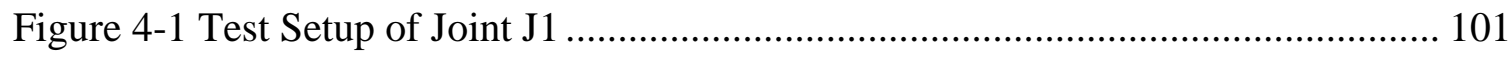

Figure 4-2 The Development of the First Cracks at the First Cycle, J1 ...................... 102

Figure 4-3 Development of the Flexural Cracks after Cycle 4, J1 ............................ 103

Figure 4-4 Specimen J1 at the End of First Set of Cycles...................................... 104

Figure 4-5 Crack Patterns Developed During Second Set of Applied Cyclic Load, J1 . 105

Figure 4-6 Crack Pattern of Cycle 1, Strain Control, J1 ......................................... 106

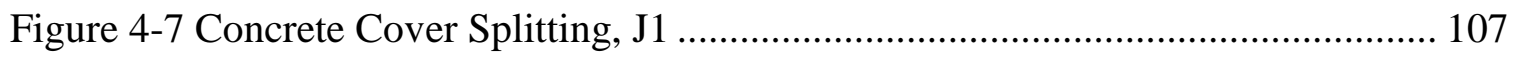

Figure 4-8 Specimen J1 (final crack pattern) .................................................. 108

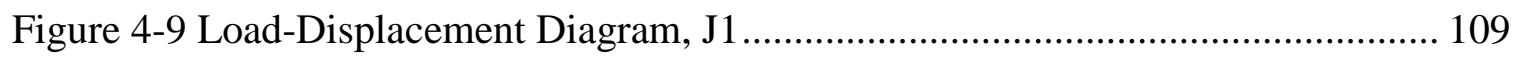

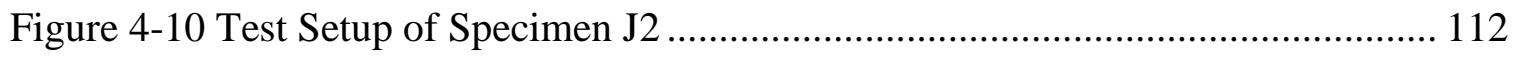

Figure 4-11 The Development of the First Crack, J2 .......................................... 113 


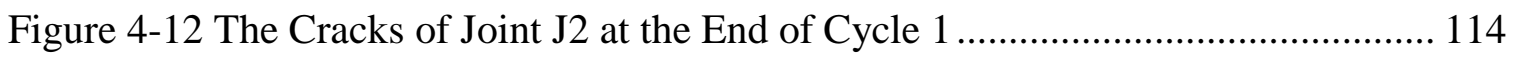

Figure 4-13 The Cracks of Joint $\mathbf{J} 2$ at the End of Cycle 2 ..................................... 115

Figure 4-14 The Backside of Joint J2 at the End of Cycle 2 .................................. 115

Figure 4-15 Developed Cracks at Cycle No. 4, J2 ................................................. 116

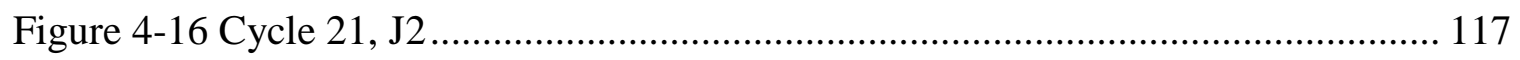

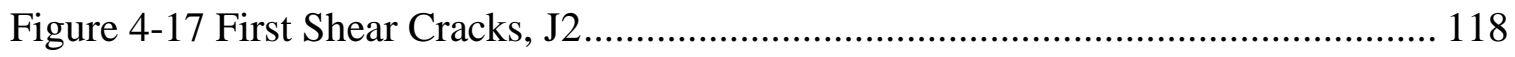

Figure 4-18 Developed Cracks within the Load Control Phase, J2 ............................ 119

Figure 4-19 The Failure Pattern of Specimen J2 ................................................ 121

Figure 4-20 Load - Displacement Diagram, J2 .................................................... 122

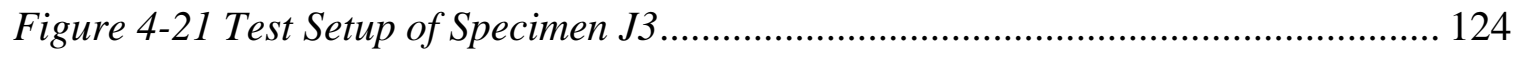

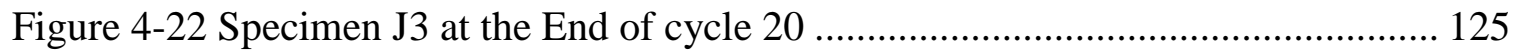

Figure 4-23 Specimen J3 at the End of Cycle 20, Strain Control Phase ...................... 126

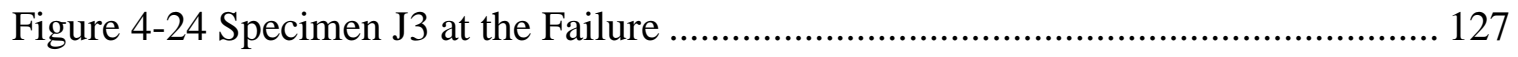

Figure 4-25 Load-Displacement Diagram, J3 ................................................... 128

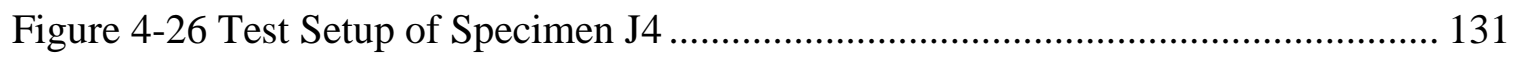

Figure 4-27 Specimen J4 at the End of Load Control ........................................... 132

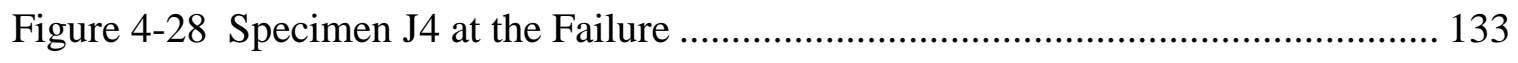

Figure 4-29 Areas under CFRP Sheets at the End of the Test, Specimen J4 ............... 134

Figure 4-30 Load versus Displacement, J4 ................................................... 135

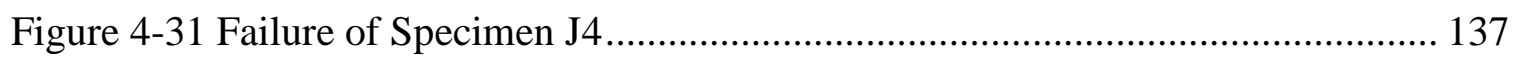

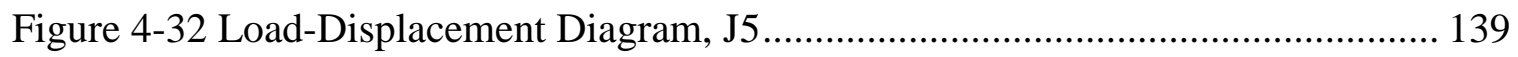

Figure 4-33 Cyclic Load-Displacement, J6 ..................................................... 140 
Figure 4-34 Failure of Specimen J5 144

Figure 4-35 Failure of Specimen J6. 144

Figure 4-36 Maximum Moment at Face of the Column, Pushing Down Case..... 146

Figure 4-37 Envelop Cyclic Load- Vertical Displacement of the Ductile Specimen, J1 148 Figure 4-38 Envelop Cyclic Load- Vertical Displacement of the Non-Ductile Specimen,

$\mathrm{J} 2$ 149

Figure 4-39 Envelop Cyclic Load- Vertical Displacement, Specimen J3 149

Figure 4-40 Envelop Cyclic Load- Vertical Displacement of the Specimen, J4 ..... 150

Figure 4-41 Envelop Cyclic Load- Vertical Displacement of the Specimen, J5 150

Figure 4-42Envelop Cyclic Load- Vertical Displacement of the Specimen, J6 151

Figure 4-43 Cyclic Load- Vertical Displacement Relationship of All Specimens Tested Under Same Axial Loads (20\% of the Column Capacity) 152

Figure 4-44 Cyclic Load- Vertical Displacement Relationship of Specimens (J3 and J5)

Tested under a Different Axial Load (20\% and 40\% of the Column Capacity) 154

Figure 4-45 Cyclic Load- Vertical Displacement Relationship of Specimens (J4 and J6)

Tested under a Different Axial Load (20\% and 40\% of the Column Capacity) ............. 155

Figure 4-46 CFRP Joint Strain versus Load for Specimen J3 ................................. 156

Figure 4-47 CFRP Joint Strain versus Cyclic Load for Specimen J4 .......................... 157

Figure 4-48 CFRP Joint Strain versus Cyclic Load for Specimen J5 ......................... 157

Figure 4-49 CFRP Joint Strain versus Cyclic Load for Specimen J6 .......................... 158

Figure 4-50 The Cumulative Energy Dissipation of Specimen J1 ............................ 160

Figure 4-51 The Cumulative Energy Dissipation of Specimen J2 ........................... 160 
Figure 4-52 The Cumulative Energy Dissipation of Specimen J3 ............................ 161

Figure 4-53 The Cumulative Energy Dissipation of Specimen J4 ............................ 161

Figure 4-54 The Cumulative Energy Dissipation of Specimen J5 ............................ 162

Figure 4-55 The Cumulative Energy Dissipation of Specimen J6 ............................. 162

Figure 4-56 The Cumulative Half Cycle Energy Dissipation of Specimens J1, J2, J3, and

J4 .. 163

Figure 4-57 Compare between the Cumulative Energy Dissipation for Specimens J3 and J5 165

Figure 4-58 Compare between the Cumulative Energy Dissipation for Specimens J4 and J6 165

Figure 4-59 Ductility Factor Diagram (Half Cycle) of Specimen, J1 .......................... 168

Figure 4-60 Ductility Factor Diagram (Half Cycle) of Specimen, J2 ......................... 168

Figure 4-61 Ductility Factor Diagram (Half Cycle) of Specimen, J3 ......................... 169

Figure 4-62 Ductility Factor Diagram (Half Cycle) of Specimen, J4 .......................... 169

Figure 4-63 Ductility Factor Diagram (Half Cycle) of Specimen, J5 .......................... 170

Figure 4-64 Ductility Factor Diagram (Half Cycle) of Specimen, J6.......................... 170

Figure 4-65 Compare of Ductility (Half Cycle) for Specimens J1, J2, J3, and J4 ........ 171

Figure 4-66 Comparison of Ductility for Specimens J3 and J5 .............................. 173

Figure 4-67 Comparison of Ductility for Specimens J4 and J6 ............................. 173 


\section{Notations}

\begin{tabular}{|c|c|c|}
\hline NSM & $=$ & Near Surface Mounted Retrofitting Technique. \\
\hline CFRP & $=$ & Carbon Fiber Reinforced Polymer. \\
\hline GFRP & $=$ & Glass Fiber Reinforced Polymer. \\
\hline GLD & $=$ & Gravity Load Design. \\
\hline IS & $=$ & Indian Standards. \\
\hline$\rho$ & $=$ & Reinforcement Ratio for the Concrete Section. \\
\hline$\rho_{\min }$ & $=$ & Min. Reinforcement Ratio for the Concrete Section. \\
\hline$d_{b}$ & $=$ & Bar Diameter. \\
\hline$f_{y}$ & $=$ & Steel Yielding Stress. \\
\hline$\varepsilon$ & $=$ & Steel Strain. \\
\hline$f_{f u}$ & $=$ & CFRP Ultimate Tensile Stress. \\
\hline$M_{n}$ & $=$ & Flexural Moment Capacity of the Concrete Beam. \\
\hline$f_{c}^{\prime}$ & $=$ & Concrete Compressive Strength. \\
\hline$V_{u}$ & $=$ & Shear Force. \\
\hline$V_{c}$ & $=$ & Concrete Shear Strength. \\
\hline$A_{v}$ & $=$ & Shear Reinforcement Area. \\
\hline
\end{tabular}




\begin{tabular}{|c|c|c|}
\hline$A_{b}$ & $=$ & Shear Reinforcement Bar Area. \\
\hline$V_{s}$ & $=$ & Demanded Shear Force. \\
\hline$E_{c}$ & $=$ & Modulus of Elasticity for Concrete. \\
\hline $\mathrm{S}$ & $=$ & Space Between Stirrups or Ties. \\
\hline$E_{s}$ & $=$ & Steel Modulus of Elasticity. \\
\hline$A_{g}$ & $=$ & Cross Sectional Area. \\
\hline$l_{o}$ & $=$ & Confinement Length. \\
\hline$A_{s}$ & $=$ & Cross Sectional Area of Tensile Steel Reinforcement. \\
\hline$A_{s h}$ & $=$ & $\begin{array}{l}\text { Total Cross Sectional Area of Rectangular Hoop } \\
\text { Reinforcement. }\end{array}$ \\
\hline $\mathrm{C}$ & $=$ & The Depth of Compressive Concrete Section. \\
\hline$d_{t}$ & $=$ & The Depth of Tensile Steel Reinforcement. \\
\hline$M_{c}$ & $=$ & Concrete Bending Moment Capacity. \\
\hline$M_{p r}$ & $=$ & Approximate Joint Moment. \\
\hline$A_{j}$ & $=$ & Cross Sectional Area of the Joint. \\
\hline$f_{r}$ & $=$ & Concrete Flexural Strength. \\
\hline$f_{c t}$ & $=$ & Concrete Splitting Tensile Strength. \\
\hline
\end{tabular}


FEM = Finite Element Model.

CSA A23.3-94 = Canadian Concrete Design code 1994.

LVDT $=$ Linear Variable Differential Transformer. 


\section{Chapter 1. Introduction}

\subsection{General}

The annual average of successful concrete frames constructed world-wide is on the order of hundreds of thousands. On the other hand, there are a large number of these frames that are unsafe in seismic resistance capacity, especially the buildings that were constructed prior to the 70s. Evidence shows that from earthquakes such as the one in Kocaeli, Turkey, 1999, and the one in Chi-Chi, Taiwan, 1999, that there has been severe damages or complete collapse in these kinds of buildings that were designed and built prior to modern building codes. Most of the buildings designed and constructed based on the earlier codes were characterized by non-ductile performance during the earthquakes because the earlier codes did not include the required reinforcement details for ductility. As a result, non-ductile behavior of these buildings during the earthquakes was expected. Figure 1-1 and 1-2 show an example of this sort of damage that happened after Kocaeli earthquake.

Most older buildings were designed to carry the gravity loads and resist wind lateral loads. The results of the examination of the collapsed buildings during earthquakes have shown the weakness of these buildings to resist the lateral loads created by earthquakes. Furthermore, it has been observed that the weakest part in such structures was the beamcolumn joints as shown in Figure 1-1 and 1-2, where the beams and columns were intact whereas the joints were crushed. 
According to earlier codes most beam-column joints in the existing buildings that were constructed before the 1970s were characterized by non-ductile reinforcement details where inadequate or no shear reinforcement was provided in the joint region. Moreover, the design of the strong beam caused high shear force on the joint and this may have caused a brittle shear failure at the joint regions.

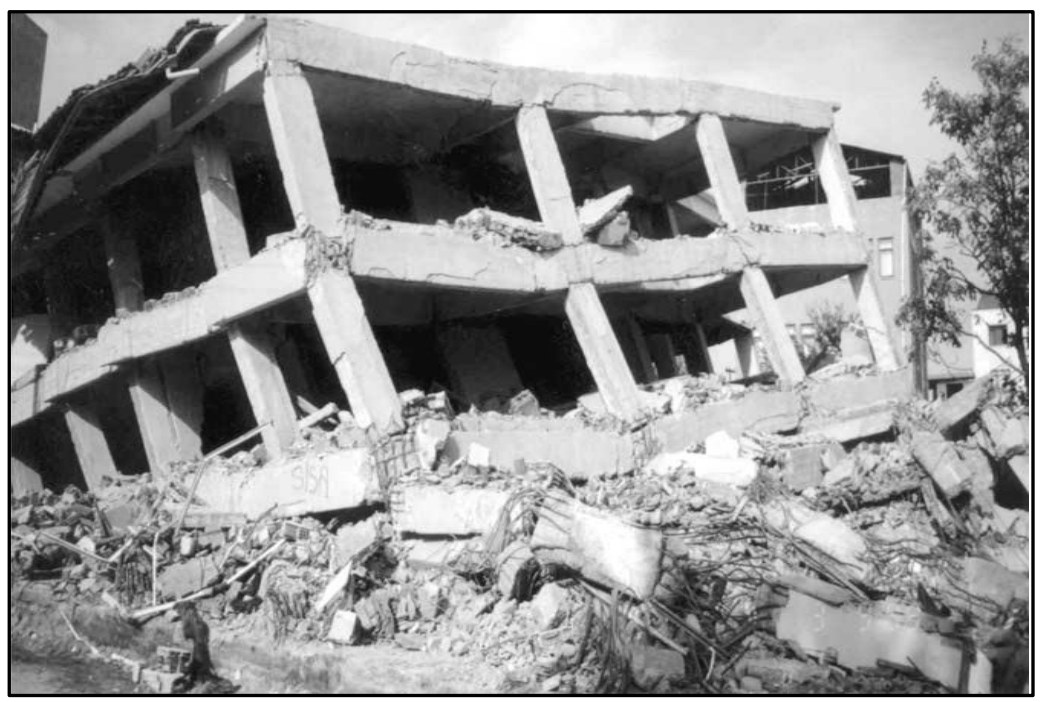

Figure 1-1 Beam-Column Joint Shear Failure, Kocaeli Earthquake

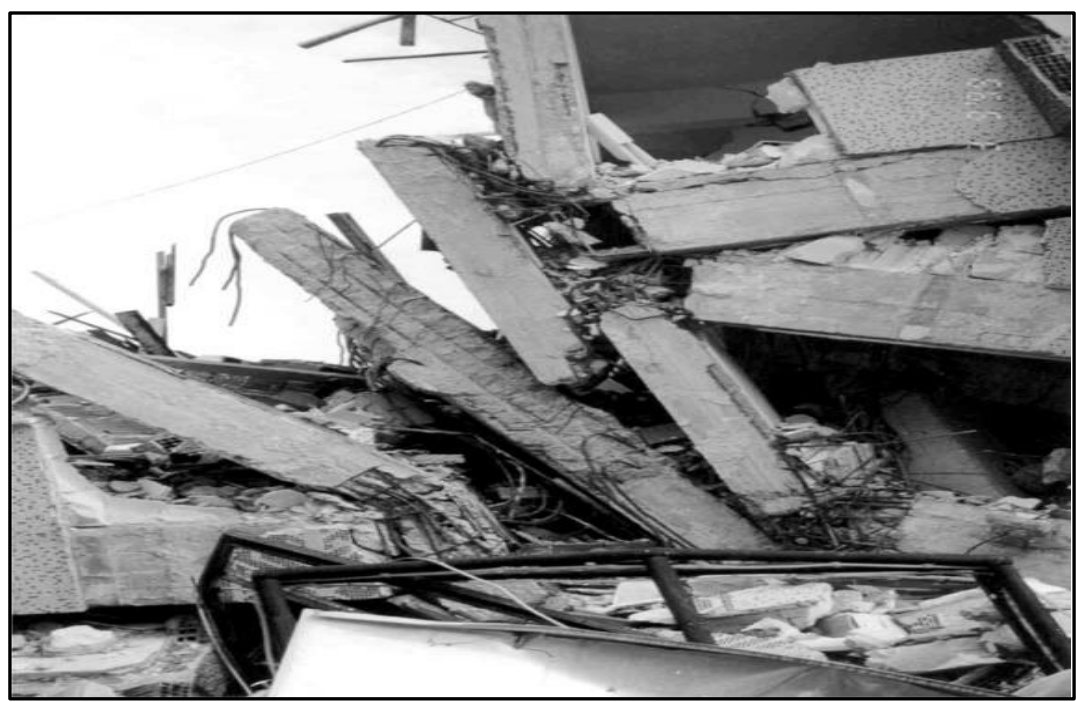

Figure 1-2 Joint Failure, Kocaeli Earthquake 
The behavior of the joint region is one of the most important factors controlling the performance of the whole concrete structure. If the beam-column joints show non-ductile performance, then the whole frame will be weakened, even though its beams and columns may have adequate capacity.

\subsection{Beam-Column Joint}

A beam-column joint could be defined as "that portion of the column within the depth of the beam(s) that frame into column". In general, there are two types of joints (type I and II) based on the concrete frame type. If the concrete frame is designed to carry gravity loads and no inelastic deformations is required, then the joints are called type I. If the concrete frame is designed to carry the gravity loads and resist lateral loads and inelastic deformations required, then the joints are called type II. The earlier codes required the framing members of the joint to be designed according to their prevailing stresses, but the design of the joints was ignored in these codes. Many buildings were destroyed during earthquakes caused by deficiency of the shear reinforcement in the joint regions. Most type I joints have no reinforcement to resist the shear force through the joints that are characterized by:

1. Lack of transverse of reinforcement in the joint region.

2. Weak column-strong beam condition.

3. Weak concrete. 
Type II joints that are constructed in accordance with the modern codes are characterized by:

1. Adequate transvers reinforcement ties within the joint as shear reinforcement.

2. Adequate ductility in the joint rejoins.

3. Strong column-weak beam joints.

All these features will prevent or delay the failure in the beam-column joint and provide opportunity for the plastic hinge to form in the flexural member(s).

The beam-column joints could also be classified based on the joint position as internal and external joints or joint shape within the concrete frame. Figure 1-3 shows the different types of beam-column joints based on the shape and position. 


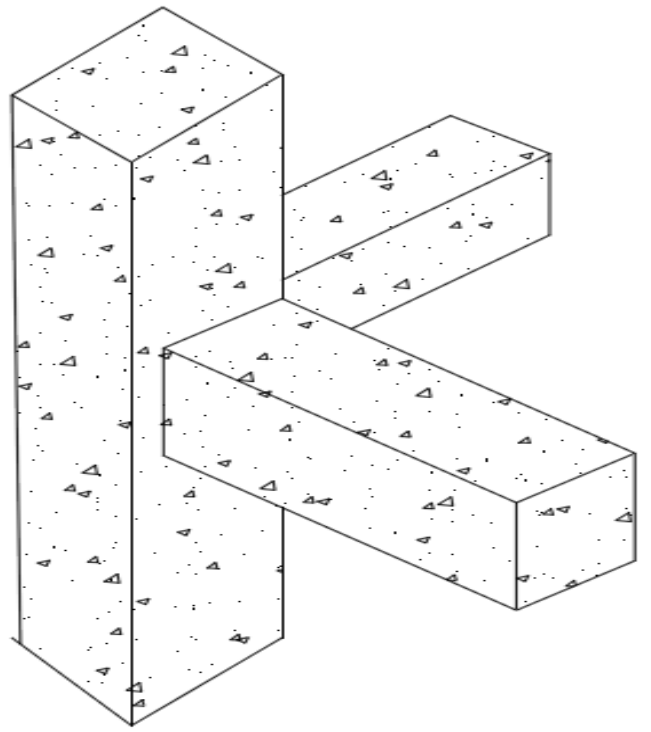

(a) Corner Joint

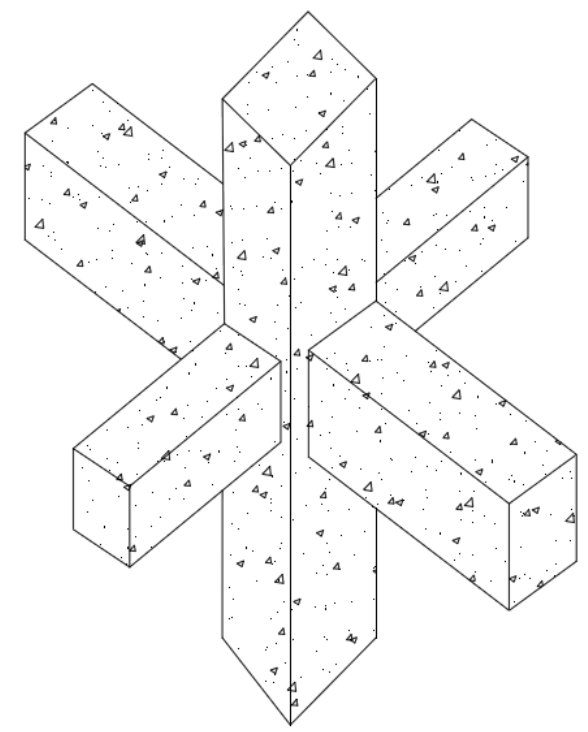

(b) Internal Joint

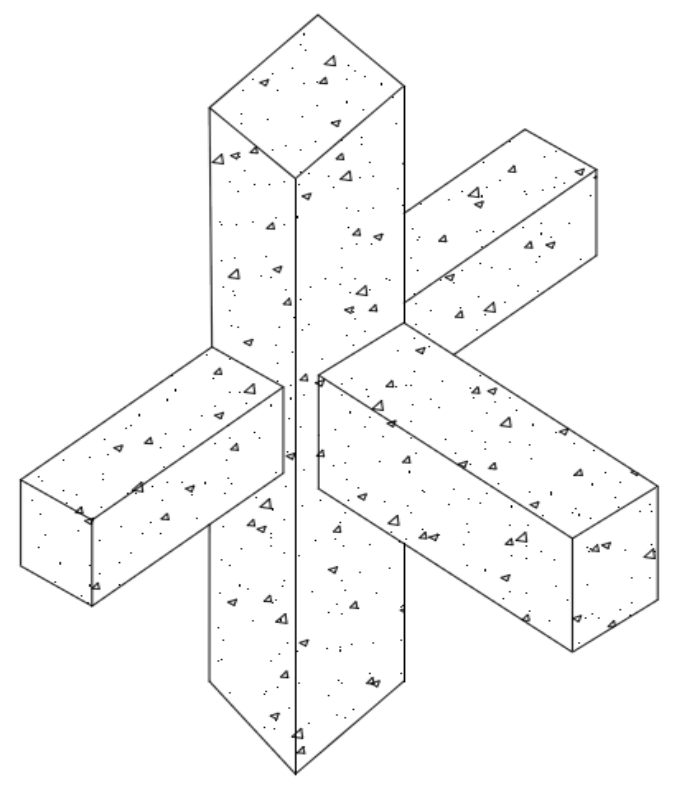

(c) External Joint

Figure 1-3 Joint Types 


\subsection{Fiber Reinforced Polymer (FRP) Sheets}

About two decades ago, a new material came onto the markets. This material is called "Fiber Reinforced Polymer" (FRP). These composite materials have been successfully used in a variety of industries. Civil engineers also used this material and found it could be a solution for many structural problems. The most common types of this material are Carbon Fiber Reinforced Polymer (CFRP) and Glass Fiber Reinforced Polymer (GFRP).

The fiber reinforced polymer (FRP) materials have a number of great features:

1. Lightweight and ease of installation.

2. Immunity to corrosion.

3. Extremely high tensile strength.

4. Available in many forms.

5. Short construction time.

In the civil engineering field, the Fiber Reinforced Polymer (FRP) sheets have been used extensively in the past decade as externally bonded reinforcement concrete and prestressed concrete structures. 
In order to gain a better understanding of the effects of CFRP sheets on the joint when the external forces were acting on it, it is useful to examine the general mechanism of the joint and the reasons that lead to failure of non-ductile joints. Per R. Park and T. Paulay (1973), the internal forces that are acting within the joint region as a result of the external actions from the beam and columns are shown in Figure 1-4.
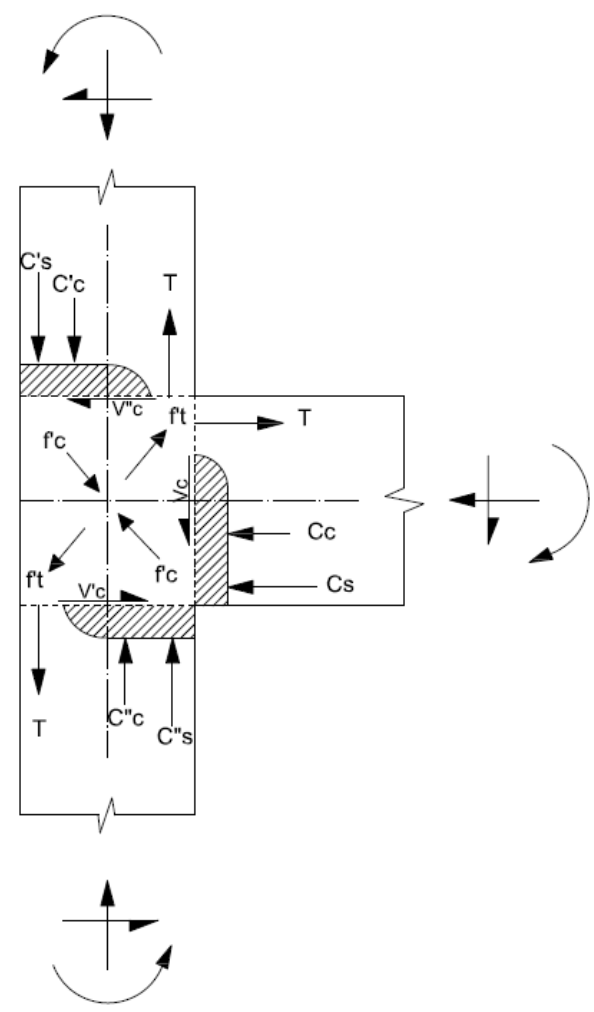

\section{force from beam and columns acting on the joint}

Figure 1-4 Forces Acting on Joint

Figure 1-4 shows that when lateral load acts on the concrete structure, compressive and tensile stresses are generated at the same time within the joint. When the tension forces are very high, the tensile stress within the joint was very high as well. By developing the 
ultimate moment capacity of the adjoining members, these tensile stresses are very high and cause diagonal cracks. At this stage of loading, the shear and compression forces are transferred by diagonal compression struts.

As known, concrete is strong in compression, but very weak tension where the compression strength of the concrete is approximately ten times larger than the tension strength. This is the key issue for those joints that were constructed prior to 1970s. In order to upgrade their behavior, one needs to understand how to reduce the tensile stresses acting on the joint region until one of the adjoining member (beam) reaches its ultimate capacity and fails. The technique used in this research included an "L" shape CFRP sheet attached to both sides of the beam in order to take most of the tension that came from one of the adjoining members, and transferred it to the other one out side of the joint. 


\subsection{Research Objective and Scope}

The problem in most of the existing beam-column joints in concrete frames that were designed before the development of the modern codes is that these joints lack shear strength, energy dissipation, and ductility required to resist earthquakes.

This study will focus the behavior of concrete beam-column joints. Three types of joints will be tested to investigate their behavior under cyclic loading:

1- A non-ductile joint representing a design based on older codes.

2- A ductile joint representing a design based on current (modern) codes.

3- A non-ductile joint a design based on older codes (same as case 1) but retrofitted with CFRP sheet.

Comparison of behavior of joints before and after retrofitting, as well as with the ductile joint designed based on modern codes, will be presented. Behavior will be investigated by load versus deflection, load versus CFRP strain, energy dissipation, and ductility. 


\subsection{Research Presentation Layout}

This Presentation includes the following chapters:

\section{Chapter One:}

Presents the introduction of the problem.

\section{Chapter Two:}

Reviews the available literature and research works that are related to the present study.

\section{Chapter Three:}

Deals with the properties of the construction materials used in the experiment, as well as the details of the experimental work.

\section{Chapter Four:}

Presents the analysis of the data from the experimental work.

\section{Chapter Five:}

Presents a summary and conclusions drawn from this study, and recommendations for further studies. 


\section{Chapter 2. Literature Review}

\subsection{Introduction}

In the earlier design codes, the principles of design and structural behavior of the main members, such as the columns and the beams are well established. As known the development of codes is always in progress. In the current, ACI 318-14 code, Chapter 18, deals with seismic issues by addressing the design requirements of structural members in order to provide ductility and strength to absorb and dissipate the seismic loads. Most buildings that were designed before the1970s did not have seismic reinforcement in the joints. Moreover, most of these buildings are characterized by a weak column-strong beam structure. It is clear that columns represent the overall strength and stability of the framed structures especially in multistory reinforced concrete structures. Moreover, the joints in these buildings are characterized by the deficiency of the shear reinforcements in the columns. These reasons lead one to expect a non-ductile behavior and severe consequences of failure.

Over the past two decades, Externally Bonded Reinforcement, along with several other techniques, have been used to strengthen the joint regions. Each technique has its pros and cons. For instance, the use of the steel jacketing to strength the joints provides flexural capacity in order to change brittle behavior to ductile behavior, but over time, steel may corrode which would be a disadvantage of this technique. 


\subsection{Retrofitting Techniques for Beam-Column Joint}

One of the earlier studies by Park, R. et al. (1973) was to test and analyze the behavior of the beam-column joint under simulated severe seismic loading. Thirteen specimens were constructed in full scale. The transverse joint reinforcement and the anchorage length of the beam reinforcement were the main parameters in this experiment. The ACI 318-71 was the main reference for the design of these specimens. The general shape of the specimens consisted of a column with a beam framing one side at mid-height. All of the specimens were tested under small or no axial loads on the column, and an applied cyclic load on the free end on the beam. The external and internal actions in the external beamcolumn joints are shown in Figure 2-1.
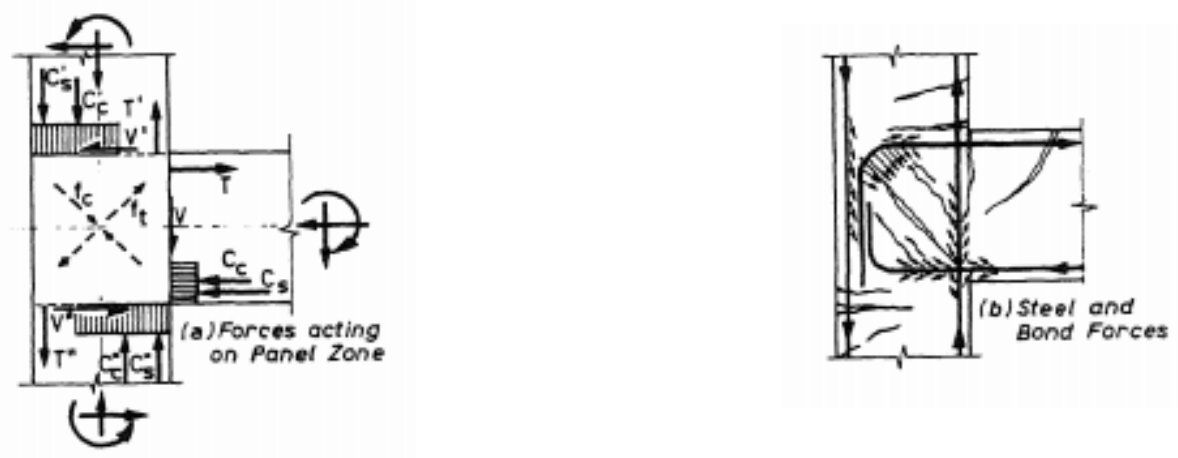

Figure 2-1 Action at an External Reinforced Concrete Joint, Park, T. et al. (1973)

The specimens were tested in two groups. The first group consisted of six specimens, where no axial load was applied to the column during the test. Figure 2-2 shows the dimensions and reinforcement details of this group of the specimens. In these specimens the flexural capacity of the beam was less than the flexural capacity of the column. As a consequence, the plastic hinge was expected to form in the beams. Also the concrete 
compressive strength of specimens $\left(\mathrm{M}_{1}, \mathrm{M}_{2}\right.$, and $\left.\mathrm{M}_{3}\right)$ was between 4 to $5 \mathrm{ksi}$ whereas the concrete compressive strength of specimens $\left(\mathrm{S}_{4}, \mathrm{~S}_{5}\right.$, and $\left.\mathrm{S}_{6}\right)$ was $3 \mathrm{ksi}$.

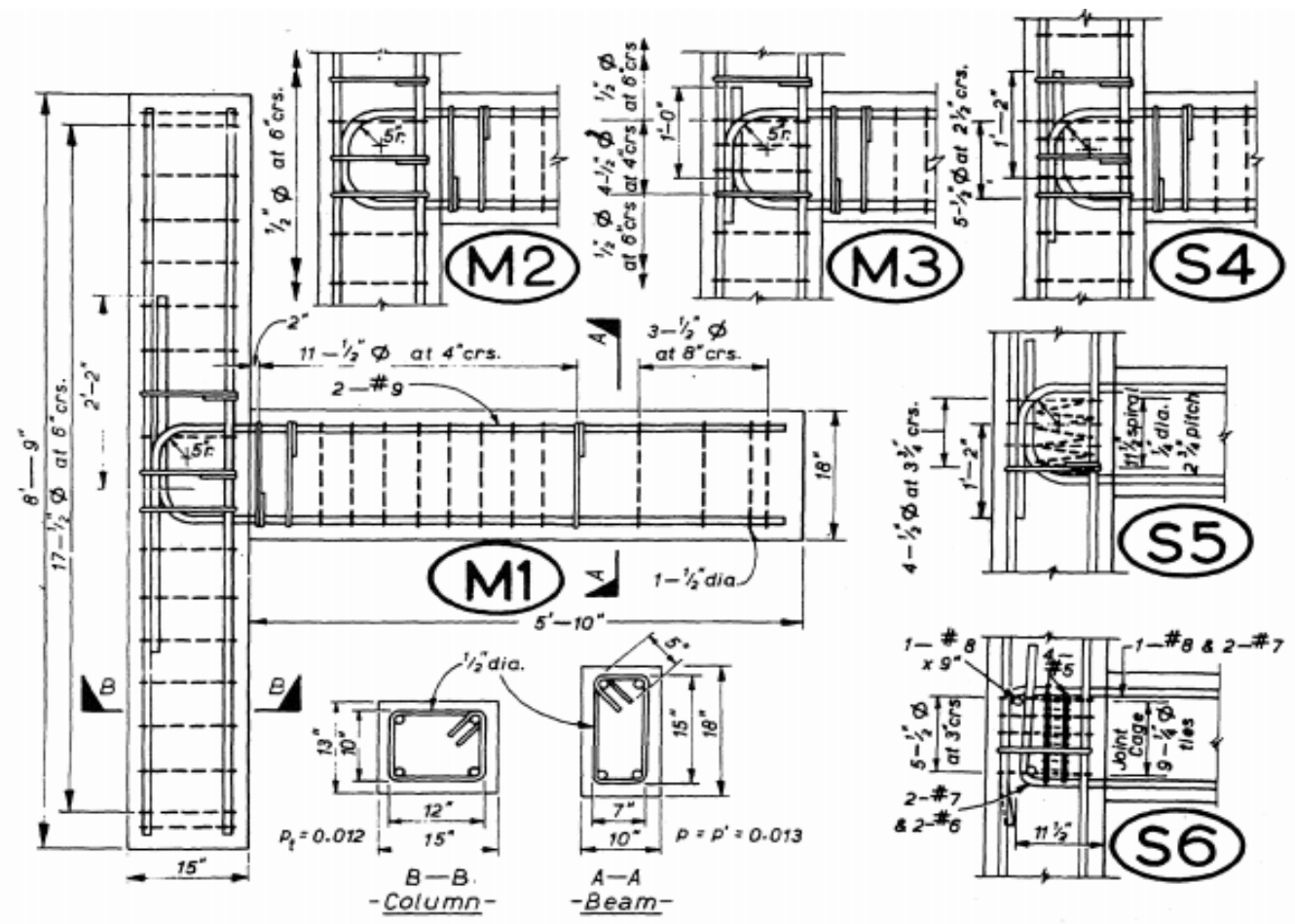

Figure 2-2 Details of First Group Specimens, Park, T. et al. (1973)

From Figure 2-2, it is clear that the transverse reinforcement within the joint region is different. M1 and M2 specimens had a normal amount of shear reinforcement within the joint according to ACI 318-71, whereas S4 and S6 specimens had a greater amount, and M3 and S5 specimens had less than the required amount. The second group consisted of seven specimens, and an axial load was applied to the column during the test equal to $16 \%$ of the axial load capacity of the column. Figure 2-3 shows the dimensions and reinforcement details of this group of specimens. These specimens were characterized by a flexural capacity of the column was less than the flexural capacity of the beam. As a consequence, the plastic hinge was expected to form in the column. The ties in specimen 
$\mathrm{R} 1$, and $\mathrm{R}_{2}$ were normal, based on ACI Code requirements, but spaces between ties were closer in the rest of the specimens $\mathrm{R}_{3}, \mathrm{R}_{4}, \mathrm{P}_{1}, \mathrm{P}_{2}$, and $\mathrm{P}_{3}$. Specimens $\mathrm{P} 1, \mathrm{P} 2$, and $\mathrm{P} 3$ had a back stub at the joint region from the back side of the column to give more room in order to add extra reinforcement. The concrete compressive strength of specimens was changed 3.4 to $5.6 \mathrm{ksi}$.

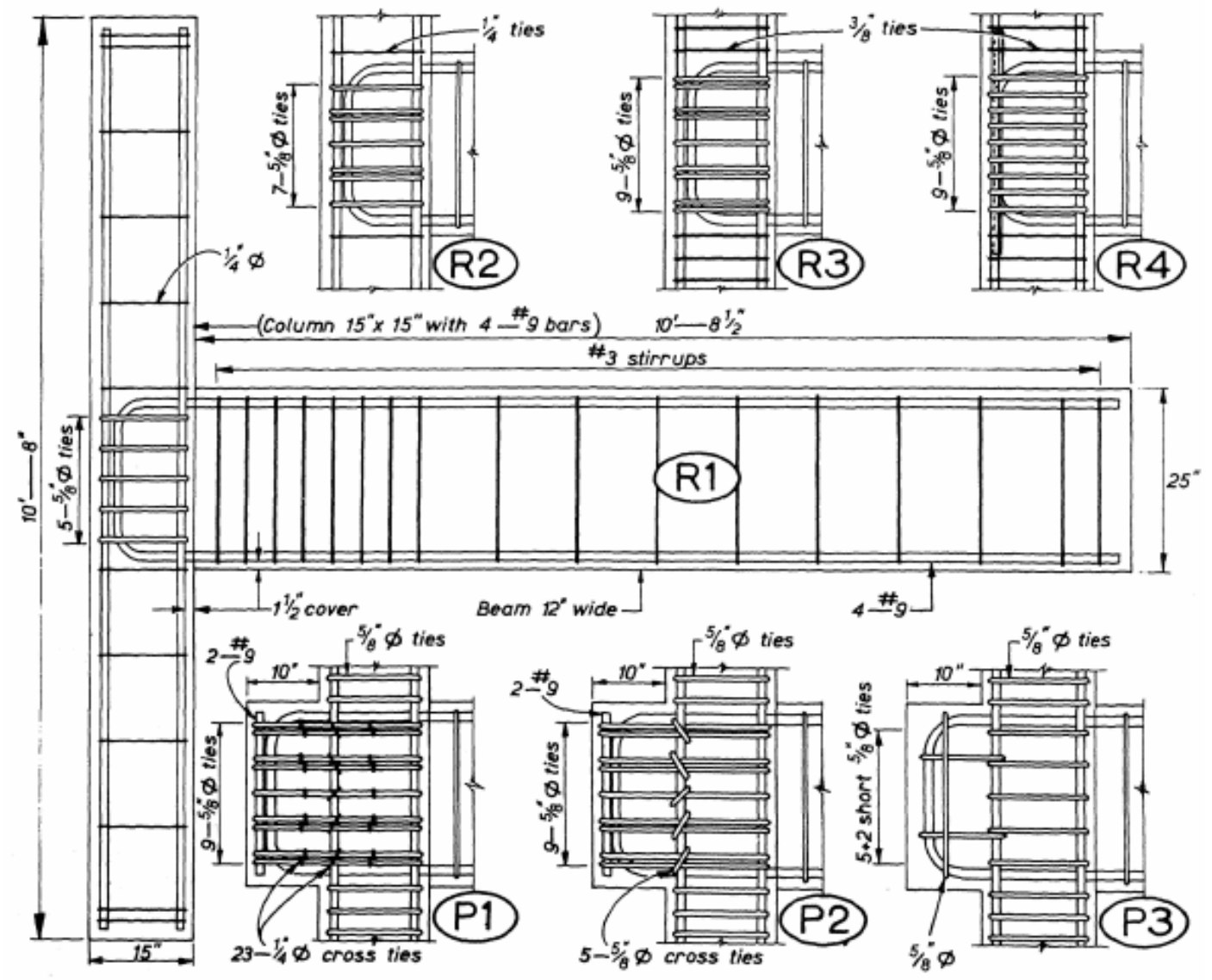

Figure 2-3 Details of the Second Group, Park, T. et al. (1973) 
The test results of first group showed poor behavior during the test cycles due to the deterioration of the moment capacity and anchorage breakdown. Figure 2-4 shows the relations between the applied loads versus the ductility factor for specimen $\mathrm{M}_{3}$, and Table 2-1 shows the maximum moment of each cycle versus the ductility factor of each specimen in the first group.

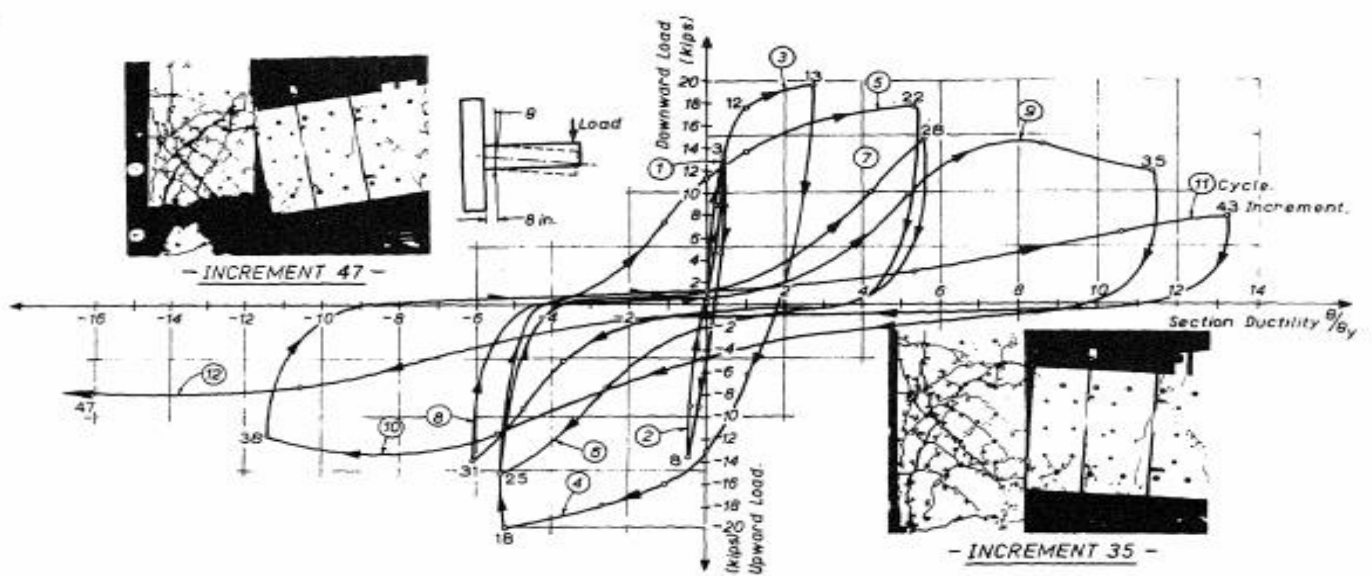

Figure 2-4 The Applied Load versus the Ductility Factor for Specimen (M3),

Park, T. et al. (1973) 
Table 2-1 First Group Test Results, Park, T. et al. (1973)

\begin{tabular}{|c|c|c|c|c|c|c|c|c|c|c|c|}
\hline Cycle & 3 & 4 & 5 & 6 & 7 & 8 & 9 & 10 & 11 & 12 & 13 \\
\hline Section & 2.5 & -5 & 5 & -5 & ----- & ---- & 10 & -10 & 13 & -25 & ---- \\
ductility & & & & & & & & & & & \\
\hline $\mathrm{M}_{1}$ & 0.98 & 1.08 & 1.05 & 0.89 & 0.72 & 0.72 & 0.67 & 0.61 & ----- & ------ & ---- \\
\hline $\mathrm{M}_{2}$ & 0.91 & 0.80 & 0.54 & 0.44 & 0.58 & 0.58 & ----- & ----- & ----- & ---- & ---- \\
\hline $\mathrm{M}_{3}$ & 1.03 & 1.05 & 0.94 & 0.74 & 0.71 & 0.71 & 0.47 & 0.63 & 0.35 & 0.32 & ----- \\
\hline Section & 2.5 & -5 & 5 & -5 & ------ & ----- & 10 & -10 & 15 & -15 & 20 \\
ductility & & & & & & & & & & & \\
\hline $\mathrm{S}_{4}$ & 1.04 & 0.97 & 0.85 & 0.65 & 0.53 & 0.62 & 0.66 & 0.55 & 0.32 & 0.47 & 0.31 \\
\hline $\mathrm{S}_{5}$ & 095 & 0.90 & 0.66 & 0.53 & ------ & ----- & 0.54 & 0.47 & 0.44 & 0.37 & 0.44 \\
\hline $\mathrm{S}_{6}$ & 1.04 & 0.98 & 1.05 & 0.78 & 0.74 & 0.73 & 1.11 & 0.79 & 0.79 & 0.61 & 0.55 \\
\hline
\end{tabular}

On the other hand, the results of the second group showed that the specimens $R_{1}, R_{2}$, and $\mathrm{R}_{3}$ reached $71-75 \%$ of the theoretical ultimate flexural capacity of the column whereas specimens $\mathrm{P}_{1}, \mathrm{P}_{2}$, and $\mathrm{P}_{3}$ reached $90 \%$ of the theoretical ultimate flexural capacity of the column. This means that the anchorage length of the beam reinforcement affected the joint performance. Figure 2-5 and 2-6 show the applied load versus displacement. 


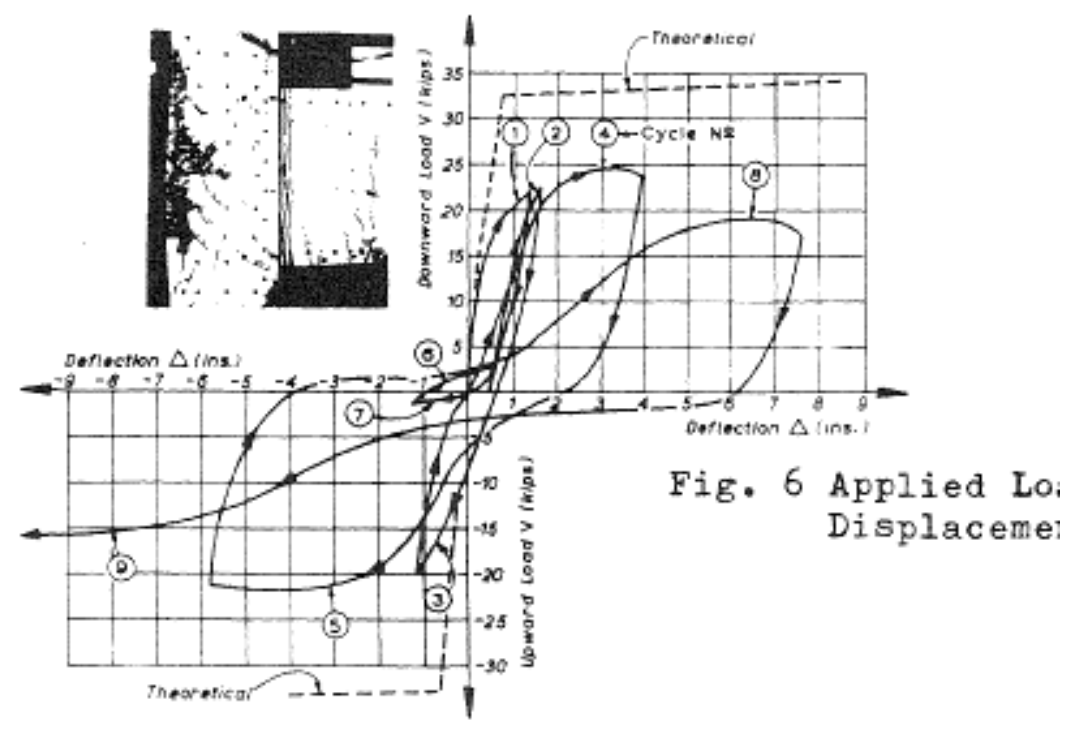

Figure 2-5 The Applied Loads versus the Beam Displacement, Specimen R3

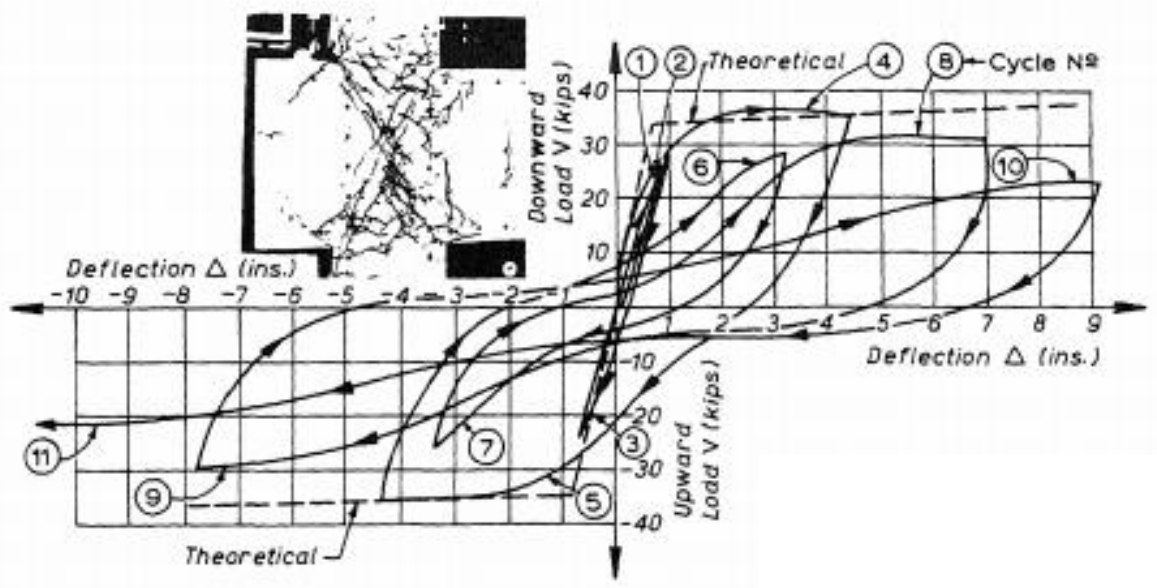

Figure 2-6 The Applied Loads versus Beam Displacement, Specimen P3 
After the observation of the failure modes and behavior, it was clear that the plastic hinge did not occur where designed, and that all failures occurred in the joint region. This could cause the collapse of the entire building.

Biddah, A. et al. (1997) constructed and tested six specimens in one-third scale under static cyclic loading. The specimens represented an external joint of a two story concrete frame in a nuclear power generation plant constructed in 1969. All of the specimen dimensions were identical. Figure 2-7 shows the general shape and the dimensions of the specimens.

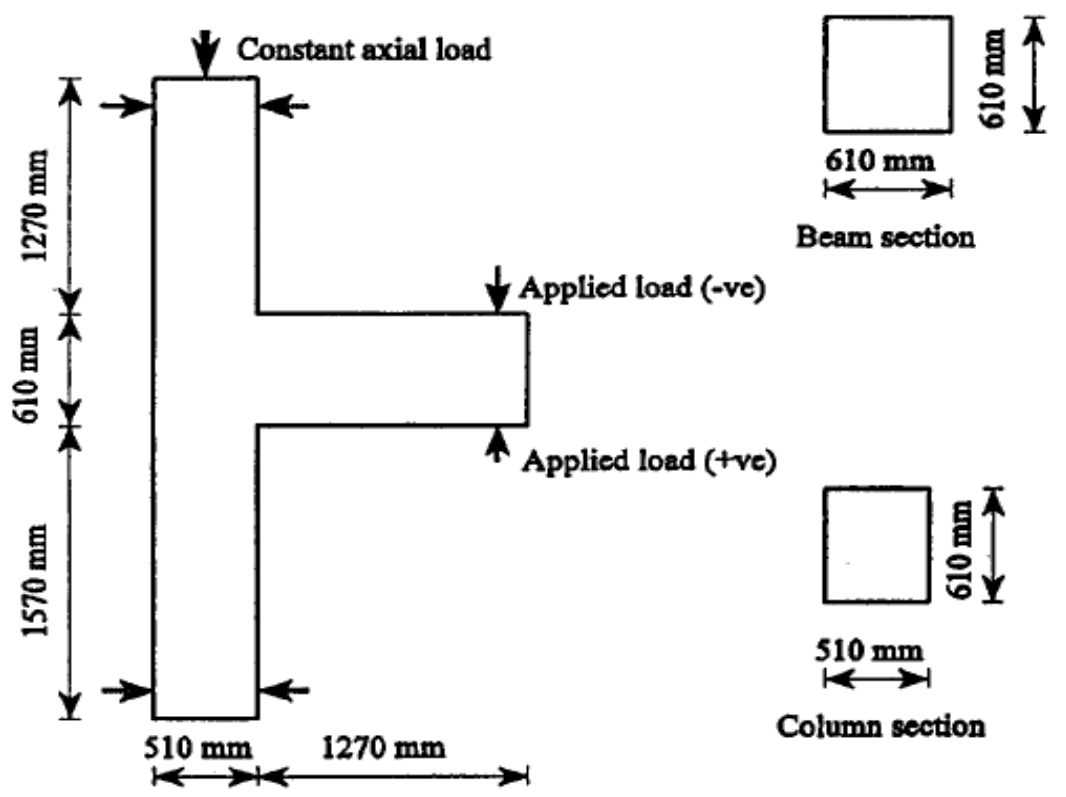

Figure 2-7 Dimensions of Specimens, Biddah, A. et al. (1997)

This experiment proposed a technique using corrugated steel to strengthen an external joint that was designed before the 1970s as shown in Figure 2-8. This technique could also be applied to undamaged joints. The parameters that were investigated in this 
experimental work the shear reinforcement in the joint, the development length of the beam longitudinal bars, the retrofitting plate thickness, and the retrofitting style.

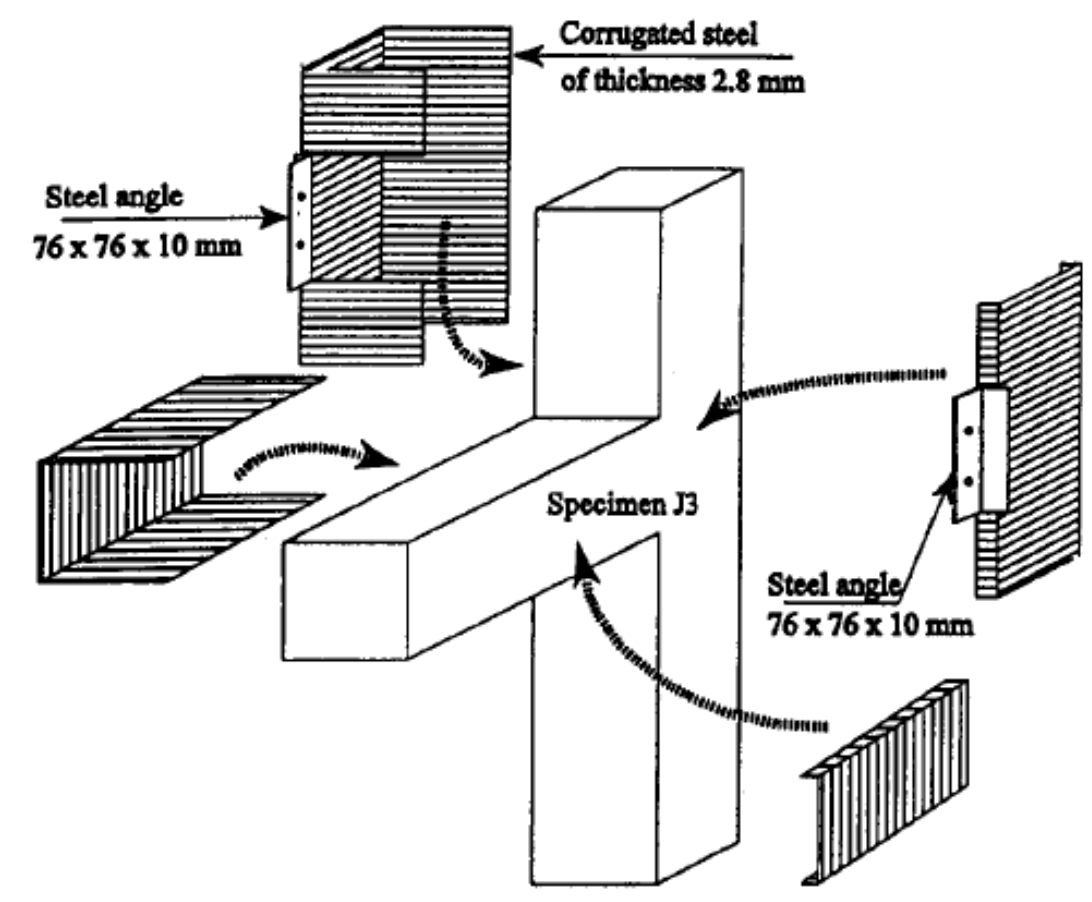

Figure 2-8 Proposed Rehabilitation Technique, Biddah, A. et al. (1997)

Specimens J1, J3, and J5 represented existing joints in terms of reinforcement details in the concrete frame. J3 was retrofitted by using the steel jacket to confine the column and beam, whereas J5 was retrofitted by using the steel jacket to confine the column only. In both specimens, the steel jacket thickness was $2.8 \mathrm{~mm}$. J2 was designed in accordance with CSA A23.3-94, where shear reinforcement was placed within the joint region. J4 and J6 were designed with no shear reinforcement in the joint region, and an inadequate development length of the positive beam reinforcement. J6 was retrofitted by using a steel jacket thickness of $3.5 \mathrm{~mm}$ around the column, in addition to two steel plates anchored between the beam and the joint. The longitudinal reinforcement of all 
specimens was identical, except for J4 and J6 where the bottom beam reinforcement had a shorter development length. The details of the stirrups are shown in Figure 2-9. The concrete cover was $30 \mathrm{~mm}$ in all specimens. Also non-shrink grout of $25 \mathrm{~mm}$ used to fill the gap between the concrete and steel jackets. Table 2-2 shows the compressive and tensile strength of the concrete, and Table 2-3 shows the reinforcing and the corrugated steel properties.

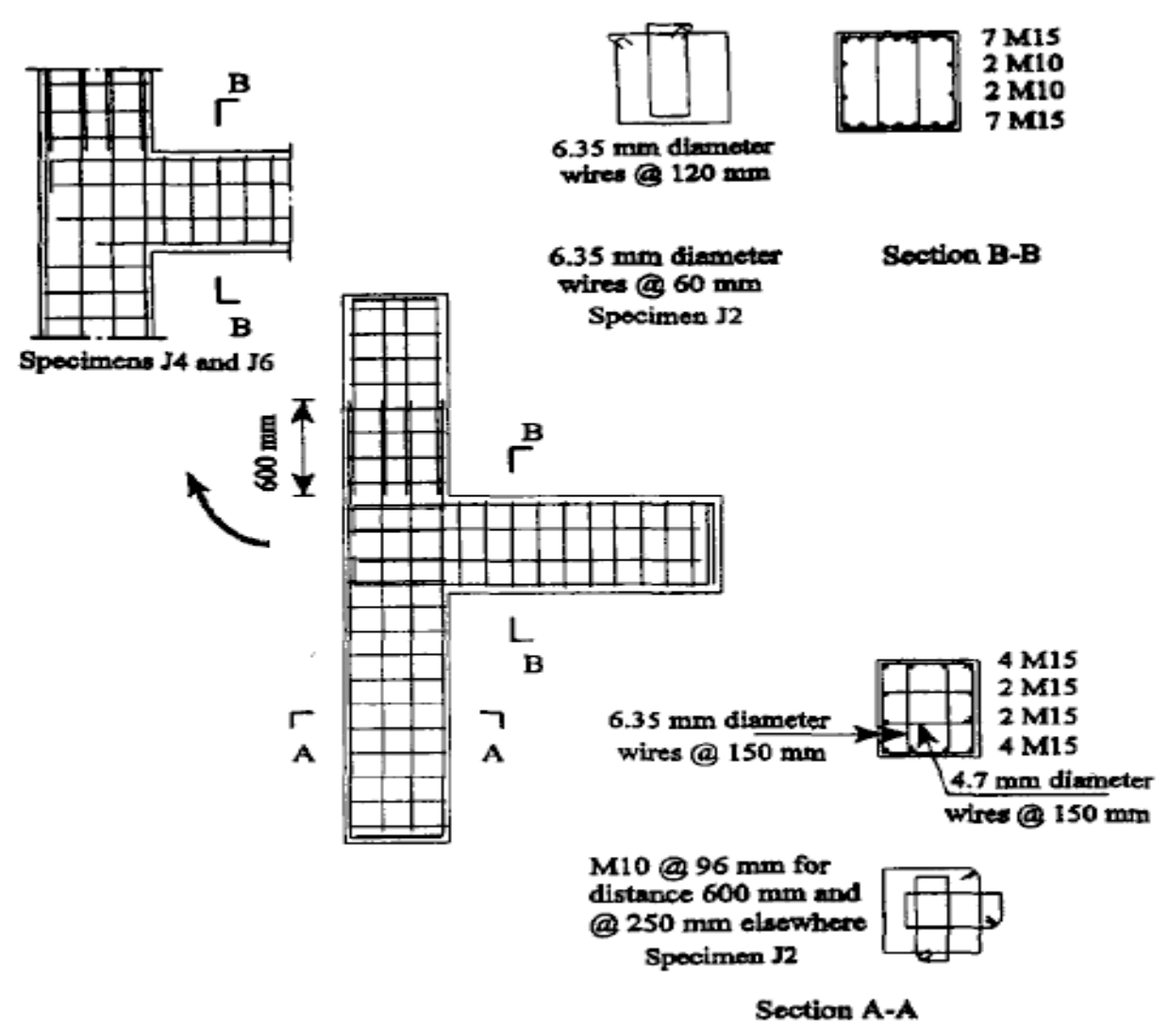

Figure 2-9 Details of Reinforcement, Biddah, A. et al. (1997) 


\section{Table 2-2 Uniaxial Compressive and Spilt Strength of Concrete Cylinders}

\begin{tabular}{|c|c|c|c|c|c|c|}
\hline \multicolumn{2}{|c|}{ Time } & \multicolumn{5}{c|}{ Specimen } \\
\cline { 2 - 8 } & $\mathrm{J} 1$ & $\mathrm{~J} 2$ & $\mathrm{~J} 3$ & $\mathrm{~J} 4$ & $\mathrm{~J} 5$ & $\mathrm{~J} 6$ \\
\hline Twenty-eight days compressive strength (Mpa) & 21.5 & 22.0 & 21.5 & 24.0 & 22.0 & 24.0 \\
\hline Twenty-eight days split tensile strength (Mpa) & 2.85 & 2.40 & 2.85 & 2.42 & 2.40 & 2.42 \\
\hline Compressive strength at time of test (Mpa) & 23.6 & 22.0 & 25.0 & 24.0 & 23.0 & 25.5 \\
\hline
\end{tabular}

Table 2-3 Reinforcing and Corrugated Steel Properties

\begin{tabular}{|c|c|c|c|}
\hline Item & $f_{y}(\mathrm{Mpa})$ & $\varepsilon_{u} \%$ & $f_{u}(\mathrm{Mpa})$ \\
\hline M10 rebar & 500 & 12.0 & 750 \\
\hline M15 rebar & 440 & 14.5 & 697 \\
\hline 6.35-mm-diameter smooth bar & 448 & 13.8 & 534 \\
\hline 4.7-mm-diameter smooth bar & 648 & 5.0 & 706 \\
\hline 2.8-mm-corrugated steel sheet & 363 & 2.8 & 397 \\
\hline 3.5-mm-corrugated steel sheet & 342 & 2.9 & 390 \\
\hline
\end{tabular}

The general set-up of the test is shown in Figure 2-10. A constant axial load of $505 \mathrm{KN}$ was applied to the column to simulate the gravity load, whereas the cyclic load was applied on the free end of the beam. After testing all specimens, the specimens representing the existing joints performed poorly under the cyclic load. The final failure mode was brittle at the joint. On the other hand, the joint that was designed according to CSA A23.3-94 exhibited considerable improvement in joint behavior, and the plastic hinge was formed within the beam section. Moreover, the energy dissipation of the 
specimen J3 was the highest, and the specimen J1 was the lowest as shown in Figure 211. In general, the proposed technique was considered effective because the undamaged retrofitted specimens showed desirable results in terms of shear strength and energy dissipation.

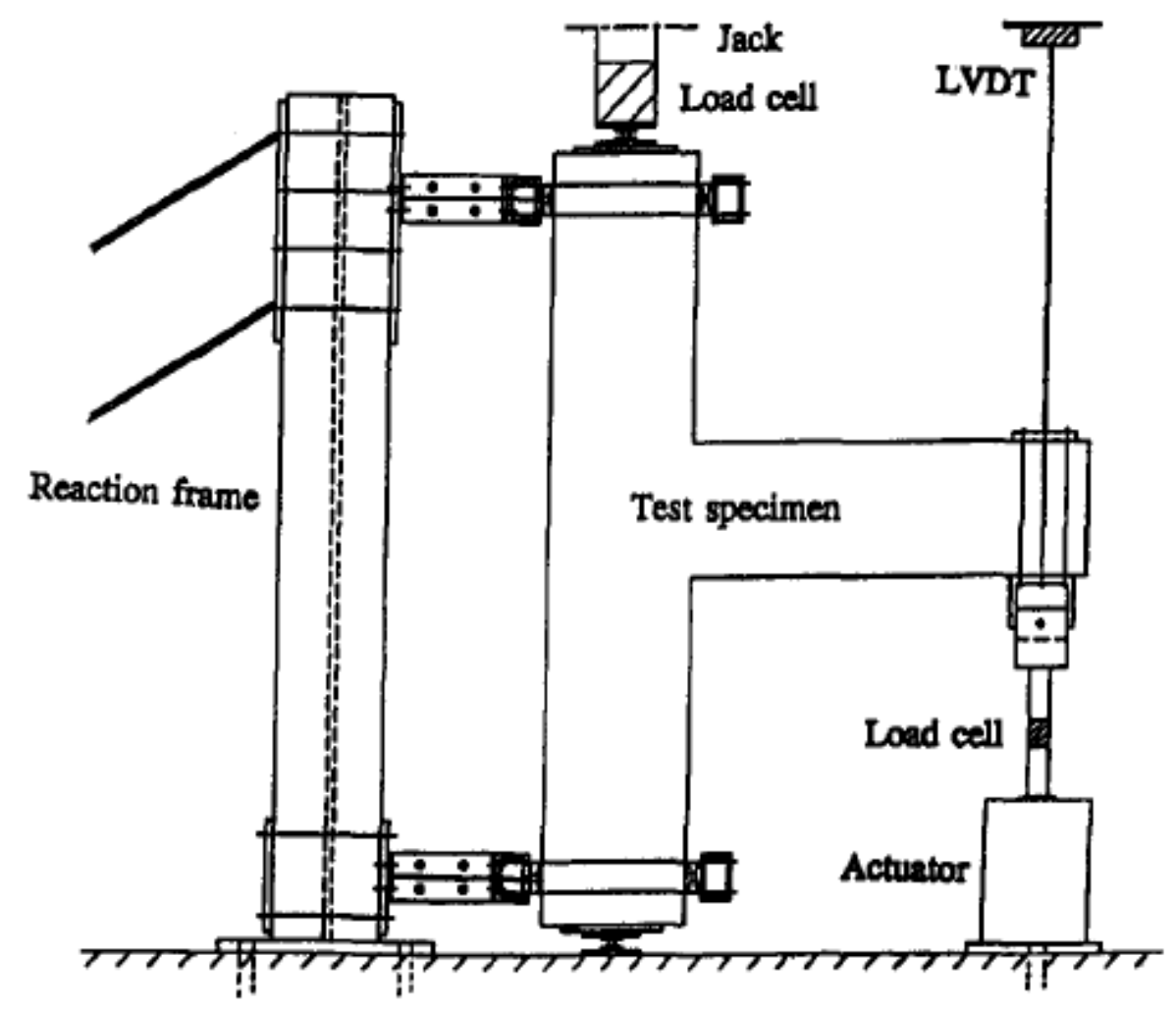

Figure 2-10 Test Setup, Biddah, A. et al. (1997) 


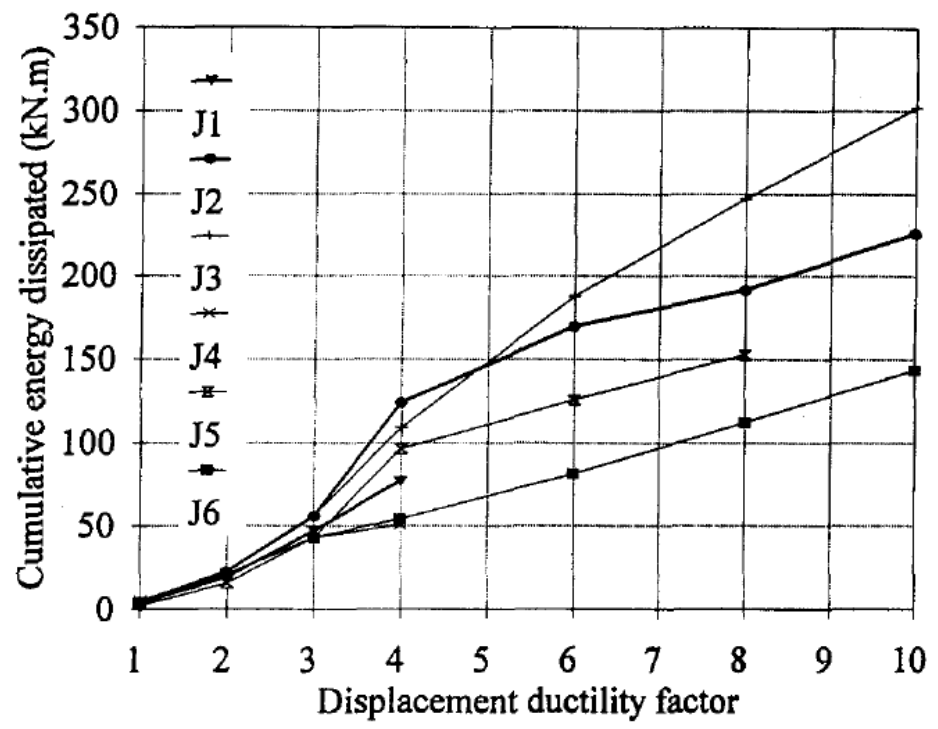

Figure 2-11 Cumulative Energy Dissipation, Biddah, A. et al. (1997)

Hakuto, S. et al. (2000) proposed and ran an analysis using concrete jacking to investigate the retrofitting of the exterior and interior joints of an existing seven story reinforced concrete building designed and built in New Zealand at the end of the 1950s. Eight specimens in full scale were constructed, where six specimens O1, R1, R2, R3, O4, and $\mathrm{O} 5$ represented the internal joints, and two specimens $\mathrm{O6}, \mathrm{O} 7$ represented the external joints. After the comparison between the old codes and the current codes, one of the main differences was the concept of weak beam-strong column. The design in the codes previous 1970s accounted for gravity loads and moderate wind loads. These buildings were characterized by a lack of ductility and shear strength at the joint regions. To change the existing buildings to conform to the current codes (New Zealand and U.S. standards), a comprehensive exam was conducted in order to propose an effective procedure to strengthen the joints, to achieve the concept of week beam-strong column, and to ensure that the plastic hinge will form in the desirable spot. This paper reported the 
results from testing some poorly detailed concrete interior and exterior beam-column joints. Tests on interior beam-column joints retrofitted by jacketing with new reinforced concrete were investigated in this study. The researchers analyzed the theoretical behavior of the joint before the experimental stage. Their results showed that after the tensile cracks occurred, the forces in the joint region were transferred by diagonal compressive struts. According to NZS 3101:1995 and ACI 318-95, the normal horizontal shear stresses should not exceed $0.2 f^{\prime}{ }_{c}$, so the researchers stated that the diagonal cracks is more likely to occur before the horizontal shear stresses in the joint reached $0.2 f^{\prime}{ }_{c}$. Their recommendation was to consider the diagonal cracks within the joint to be the failure citation instead of the horizontal shear stresses. With regard to the experimental work, the general parameters in the experimental portion were the behavior of the concrete joint that had been designed before the development of the current codes under seismic loads, the retrofitting of the existing beam-column joints before and after damage, and the anchorage of the longitudinal beam bars through the concrete joint core. Figure 2-12 shows the dimensions and reinforcement details of the specimens. 


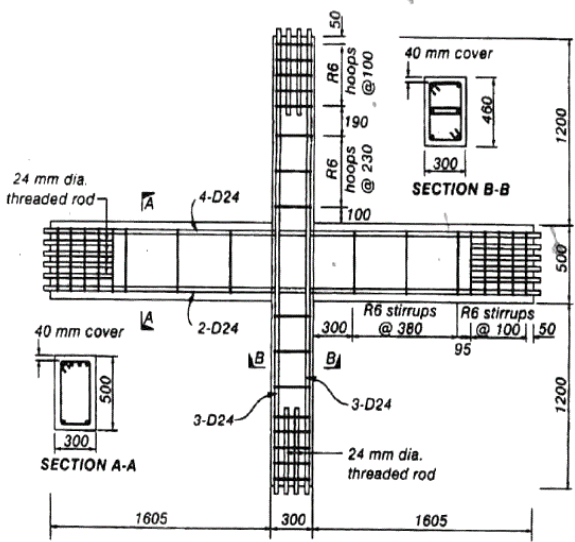

Specimen O1

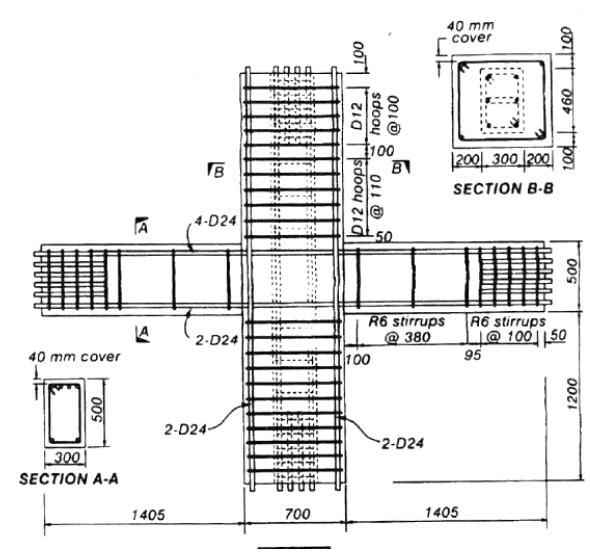

Specimen R3

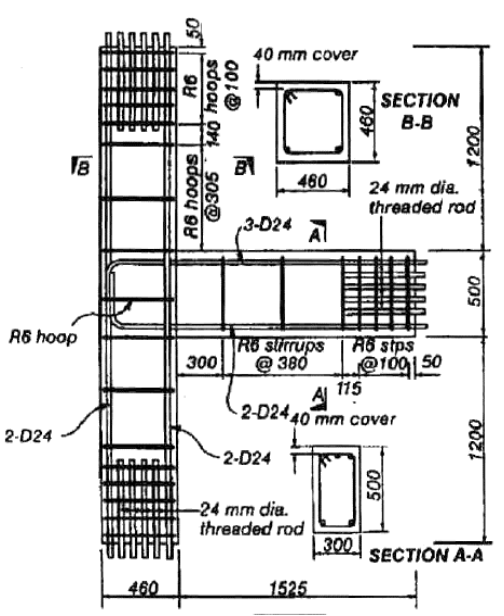

Specimen O6

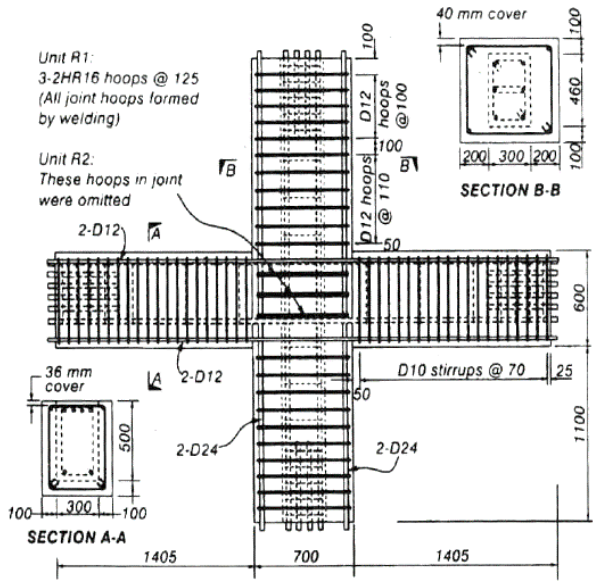

Specimen R1 and R2

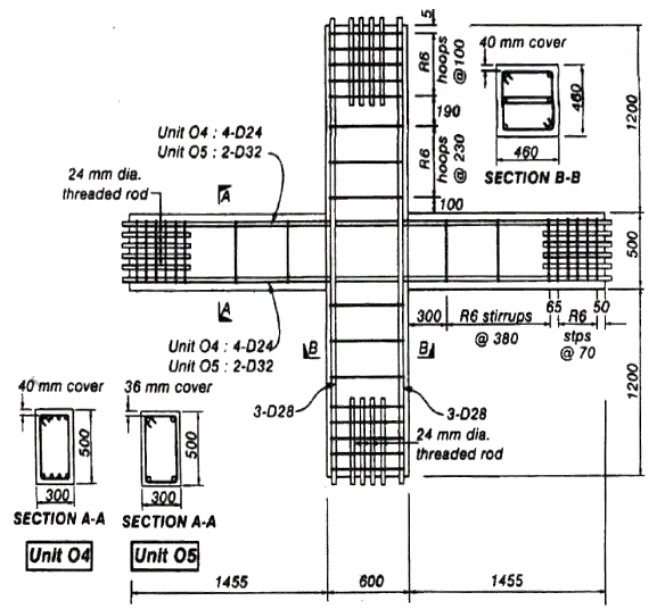

Specimen $\mathrm{O} 4$ and $\mathrm{O} 5$

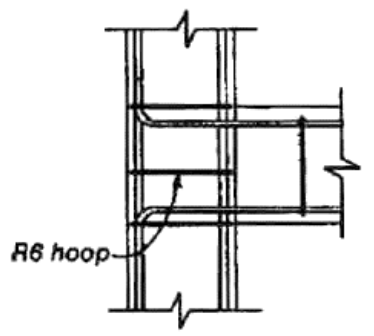

(All other dimensions and details are as for Unit O6)

\section{Specimen 07}

Figure 2-12 The Dimensions and Reinforcement Details of the Specimens, Hakuto, S. 2000 
The reinforcement details of specimen $\mathrm{O} 1$ were identical to the internal joint in that building. The theoretical flexural strength of the column represented $70 \%$ of the theoretical flexural strength of the beam, so the plastic hinge was expected to form in the column. The only difference between the actual and the model joints before the mid1960s, was that plain round bars were used as a longitudinal reinforcement, whereas in the experiment, the longitudinal reinforcement bars were deformed ( $f_{y}=47100$ psi), and the transverse reinforcement stirrups were plain round $\left(f_{y}=49200 \mathrm{psi}\right)$. Also, the concrete compressive strength of the specimen $\left(\mathrm{f}_{\mathrm{c}}^{\prime}\right)$ was 5950 psi. R1 and R2 specimens were similar to $\mathrm{O} 1$ in terms of the reinforcement details and dimensions, and the difference between R1 and R2 was that the damaged specimen $\mathrm{O} 1$ was retrofitted by jacketing the beam, column, and the joint with new reinforced concrete to become specimen R1. Specimens $\mathrm{O} 4$ and $\mathrm{O} 5$ were similar to $\mathrm{O} 1$ but with a bigger column section in order to exam how the ratio between diameter of the longitudinal beam bar to column section affected the performance of the joint. It should be noted that the increase of the column section led to expectation that the plastic hinge would be located within the beam instead of the column. The concrete compressive strength of specimens O4 and O5 were 7690 and 4790 psi respectively and the longitudinal reinforcement yield strength was $\left(f_{y}=\right.$ 44700 psi for 0.94 in diameter, 46500 psi for 1.10 in diameter, and 44400 psi for 1.26 in diameter) and the transverse reinforcement yield strength was $\left(f_{y}=57700 \mathrm{psi}\right)$. Specimens $\mathrm{O} 6$ and $\mathrm{O} 7$ represented the external column-beam joint. These two specimens were used to investigate the effect of the development length details on the general behavior of the external joints that were common in the design codes before the 1970s, in 
comparison with that of the current codes. The concrete compressive strength of specimens $\mathrm{O} 6$ and $\mathrm{O} 7$ was 4930 and 4500 psi respectively, the longitudinal reinforcement yield strength was $\left(f_{y}=44700 \mathrm{psi}\right)$, and the transverse reinforcement yield strength was $\left(\mathrm{f}_{\mathrm{y}}=57710 \mathrm{psi}\right)$.

The retrofitting of the external and internal beam-column joints by using concrete jacket required intensive labor. The concrete cover was chopped off to reach the original reinforcement in the joints and framing members. Moreover, to place the external ties in the joints, each tie consisted of two parts in "U" shape placed together through drilled holes in the beam, that were then welded together to form closed stirrups in the joint region. The yield strength of the bars used in the concrete jacket are summarized in Table $2-4$.

Table 2-4 Yield Strength of the Jacket Reinforcement Bars, Hakuto, S. et al. (2000)

\begin{tabular}{|c|c|c|c|}
\hline Member & $\begin{array}{c}\text { Yield strength of longitudinal } \\
\text { bars }\end{array}$ & $\begin{array}{c}\text { Yield strength of transverse } \\
\text { bars }\end{array}$ & Property \\
\hline Column & $67000 \mathrm{psi}$ & $43800 \mathrm{psi}$ & deform bar \\
\hline Beam & $43800 \mathrm{psi}$ & $47900 \mathrm{psi}$ & deform bar \\
\hline Joint & & $63200 \mathrm{psi}$ & $\begin{array}{c}\text { Plain round } \\
\text { bar }\end{array}$ \\
\hline
\end{tabular}

All of the specimens were tested in a vertical position with no axial applied load on the column. The general setup of the test is shown in Figure 2-13. The ends of the beams and the bottom of the column were pinned to fixed supports, and the upper end of the column was connected to a double acting actuator in order to apply the lateral horizontal load on the column. 


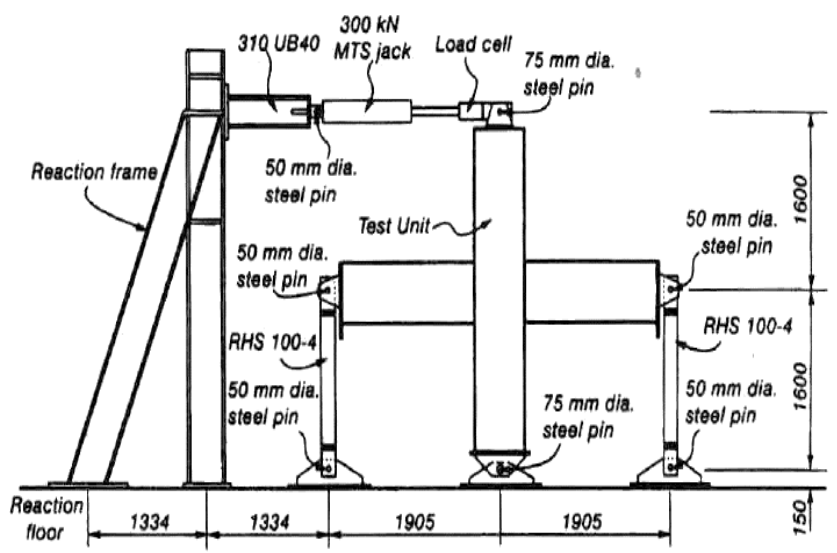

a- The Internal Joint

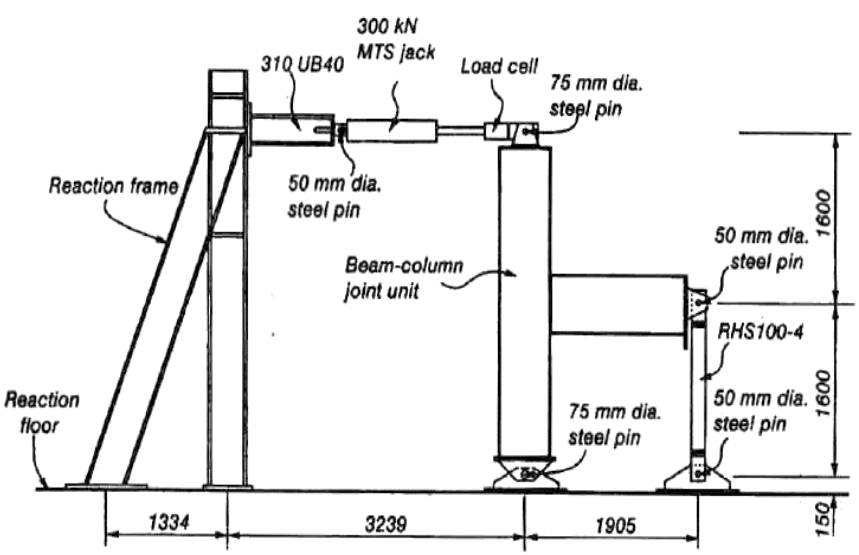

b- The External Joint

Figure 2-13 Test Setup for the External and Internal Beam-Column Joint,

Hakuto, S. (2000)

The test results showed that the existing joints that had been designed three decades ago behaved poorly under the cyclic loads because the design of these regions (joints) had been done to resist gravity loads only. There was no transverse reinforcement placed at this joint to resist the tension cracks that could affect the shear strength of the joint. The proposed retrofitting procedure to strengthen the joint by using concrete jacket was effective and applicable to enhance the strength, stiffness, and ductility of these joints, but it is difficult to do. 
Ghobarah, A. et al. (2005) tested six full-scale specimens representing the external beamcolumn joints designed according to the pre-1970 codes. The specimen shape and reinforcement details is shown in Figure 2-14, where three of the specimens represent the anchorage deficient joints and the rest of the specimens represent both the shear and the anchorage deficient joints. In Figure 2-14 all dimensions are in mm.
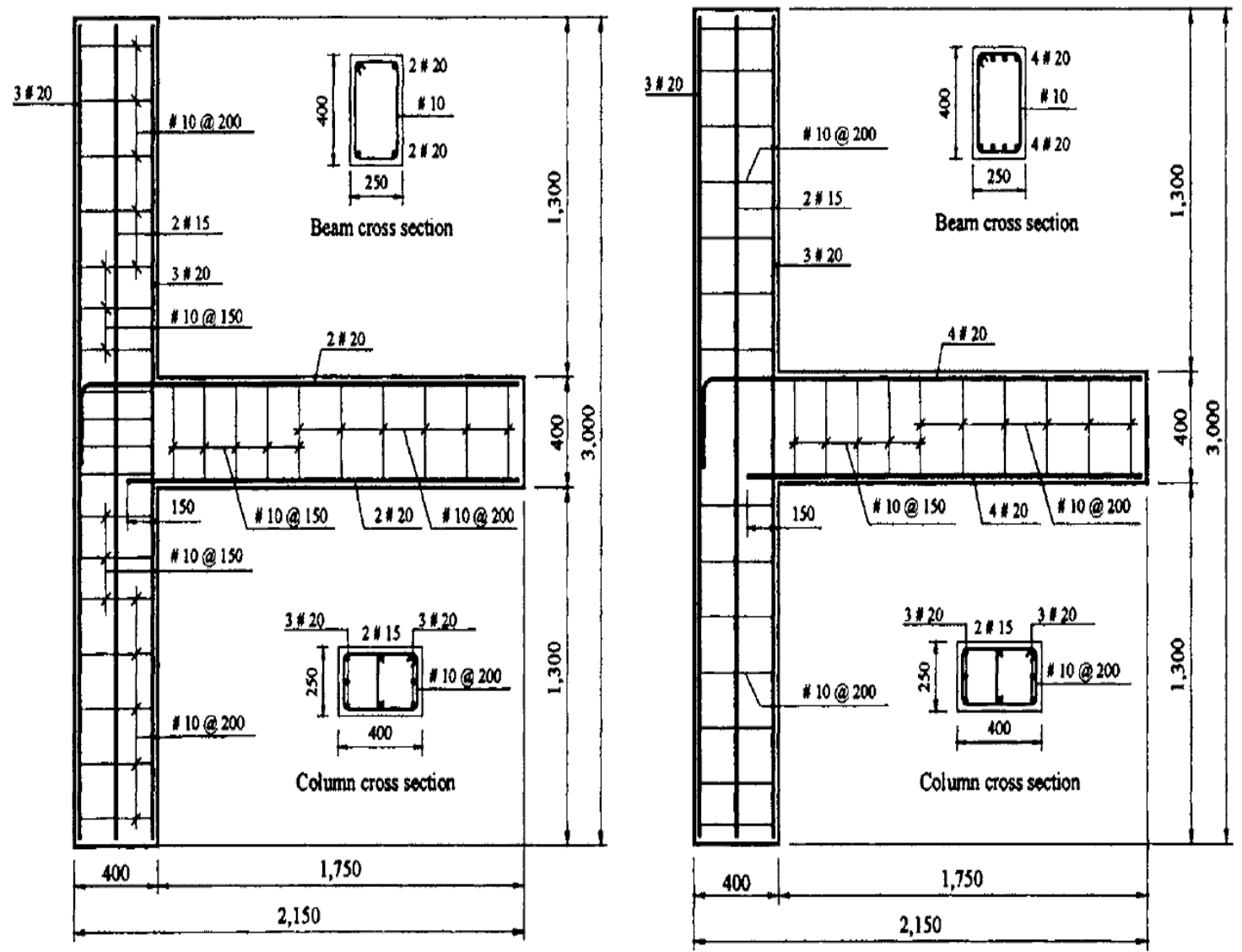

Figure 2-14 The Dimensions and Reinforcement Details of the Specimens, Ghobarah, A. et al. (2005) 
Two types of materials were used in order to retrofit these joints. Carbon Fiber

Reinforced Polymer (CFRP) type (CF130) and Glass Fiber Reinforced Polymer (GFRP) type (Tyfo BC and MBrace EG 900) were used as composite materials, and the rods and sheets were used for the steel materials. Figure 2-15 shows the techniques used to retrofit these specimens in order to change the general behavior of the joints from brittle (nonductile) to ductile, and to compensate for the lack in the reinforcement details and their names. Specimens (T-B10 and T-SB3) were tested as the control specimens.

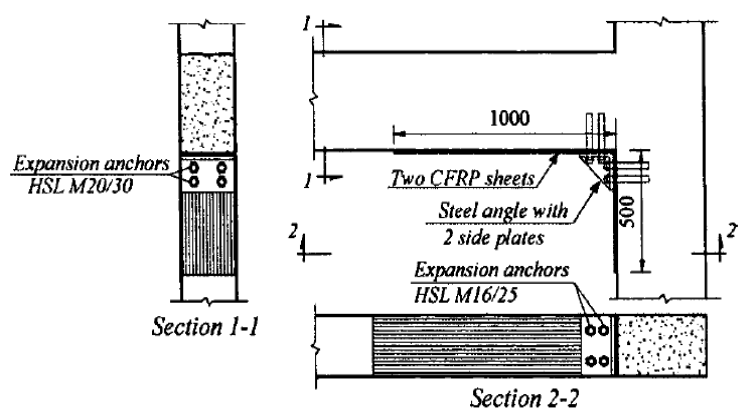

Joint T-B12

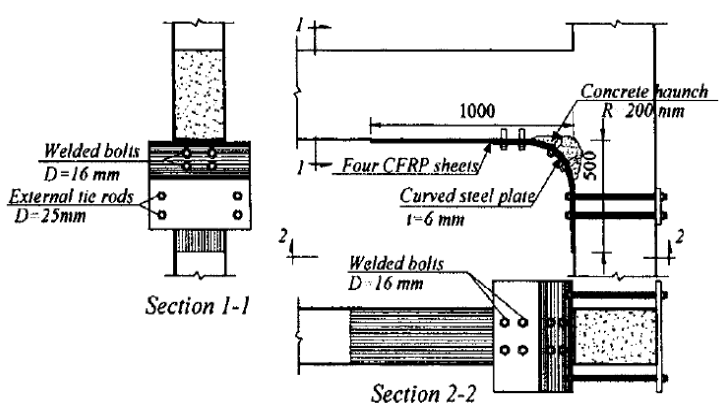

Joint T-B11

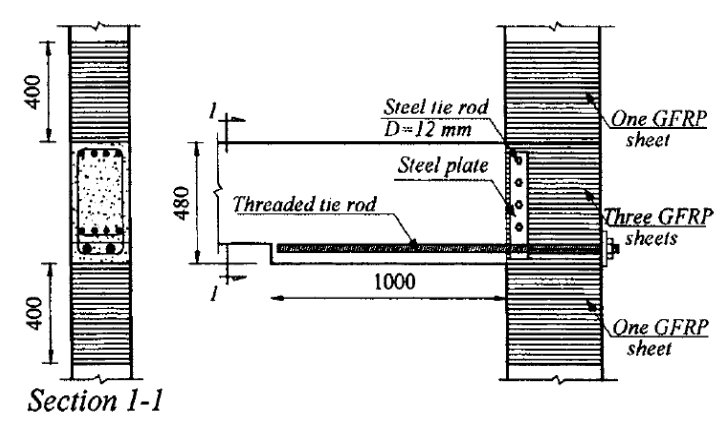

Joint T-SB8

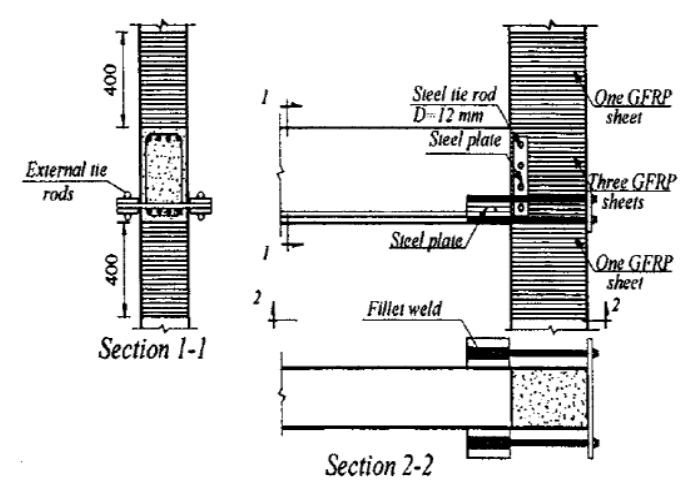

Joint T-SB7

Figure 2-15 The Retrofitting Details of All Specimens, Ghobarah, A. et al. (2005)

The specimens were tested in the vertical position. There was an axial constant load equal to $\left(0.2 \mathrm{Ag} \mathrm{f^{ \prime }}=600 \mathrm{KN}\right)$ applied to the top of the column, and the cyclic load was applied 
at the free end of the beam tip. The ultimate loads, story drifts, and failure modes are summarized in Table 2-5.

Table 2-5 the Summary of the Test Results, Ghobarah, A. et al. (2005)

\begin{tabular}{|c|c|c|c|c|}
\hline Joint & Failure mode & $\begin{array}{l}\text { Ultimate tip load } \\
(\mathrm{kN})\end{array}$ & $\begin{array}{c}\text { Story drift at } \\
\text { ultimate load } \\
(\%)\end{array}$ & $\begin{array}{c}\text { Maximum } \\
\text { story drift } \\
(\%)\end{array}$ \\
\hline \multicolumn{5}{|c|}{ (a) Anchorage-deficient joints } \\
\hline T-B10 & Bond slip & +52.9 and -61.5 & 0.99 & 4.93 \\
\hline T-B12 & FRP debonding & +46.8 and -55.0 & 1.95 & 4.86 \\
\hline T-B11 & Beam hinging & +86.0 and -80.0 & 1.68 & 11.17 \\
\hline \multicolumn{5}{|c|}{ (b) Shear/anchorage-deficient joints } \\
\hline T-SB3 & Bond and shear & +61.4 and -92.1 & 1.62 & 2.70 \\
\hline T-SB8 & Shear of rehab section & +152.0 and -127.6 & 2.43 & 4.86 \\
\hline T-SB7 & Fracture of rehab rods & +124.0 and -127.9 & 4.22 & 8.43 \\
\hline
\end{tabular}

The tests results of this experimental work showed that the joints that were designed before 1970s were characterized by the lack of shear reinforcement, and the lack of the anchorage length of the beam bottom longitudinal bars within the joints. Based on the results from the test, it was clear that Glass Fiber Reinforced Polymer (GFRP) provided shear strength and confinement to these joints, therefor avoided any brittle shear failure. On the other hand, Carbon Fiber Reinforced Polymer (CFRP) and the steel (sheets and rods) were very effective in compensating for the lack of the anchorage length of the beam bottom longitudinal bars. Also there was a significant increase in the energy dissipation and stiffness of these joints as shown in Figures 2-16 and 2-17. Researches considered all of these features in the proposed rehabilitation as an effective way to retrofit the joints. The final recommendation based on the analyzed data was that the joint reinforcement within the joint was not only needed to resist the shear but it was needed to maintain the concrete integrity as well for the anchored zone. 

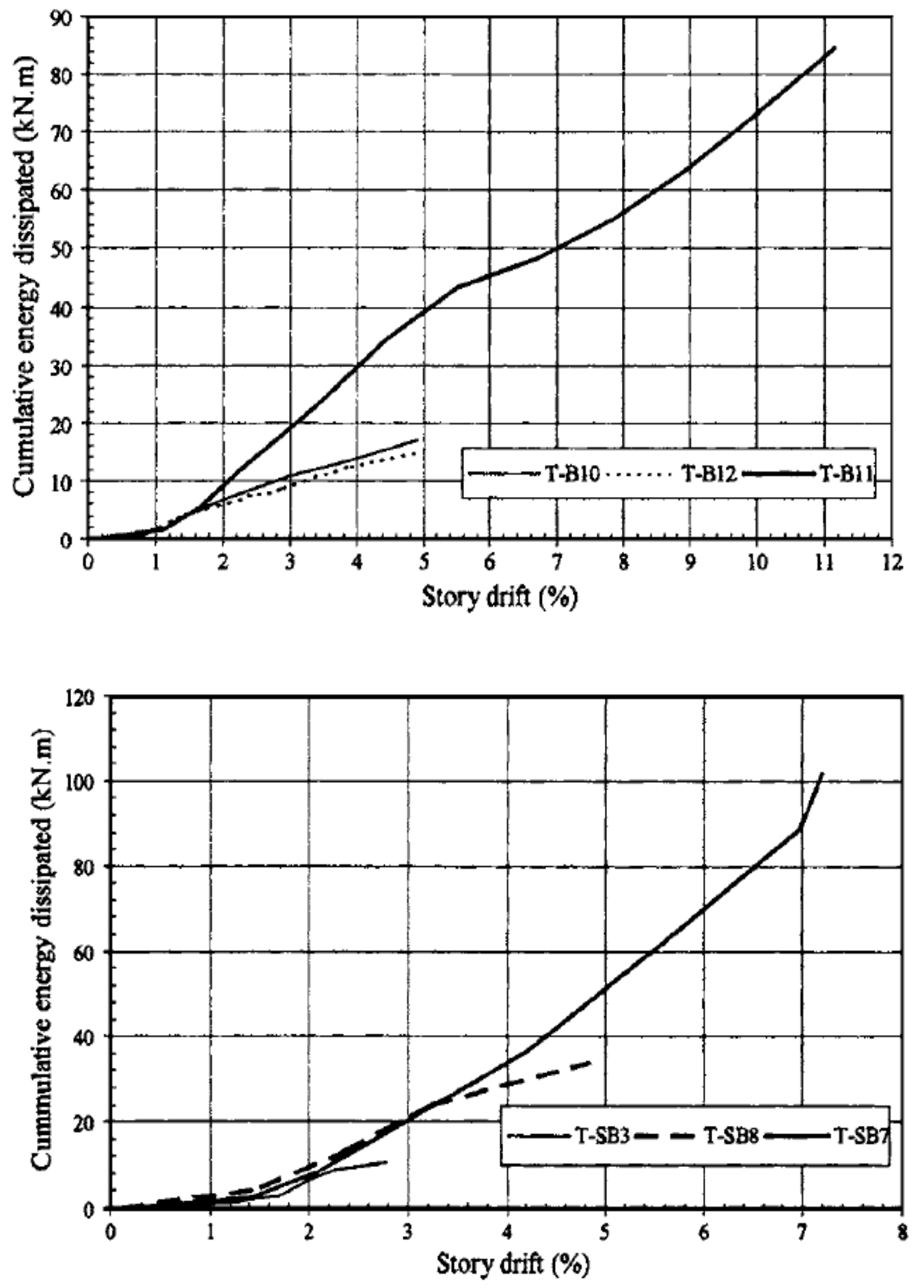

Figure 2-16 Cumulative Energy Dissipation, Ghobarah, A. et al. (2005) 

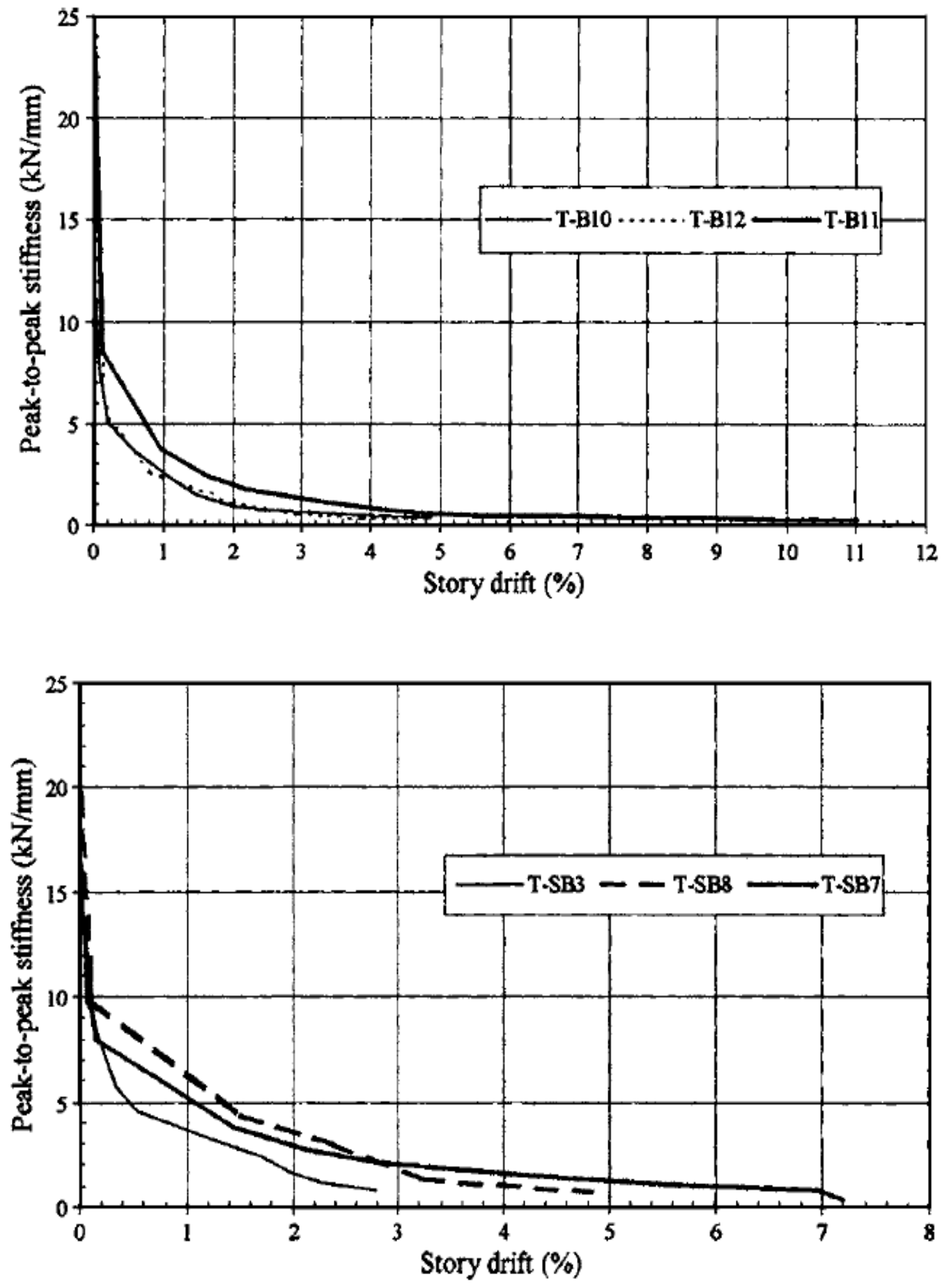

Figure 2-17 Stiffness Degradation, Ghobarah, A. et al. (2005) 
Prota, A. et al. (2000) used the composite materials Fiber Reinforced Polymer (FRP) in both forms (rods and sheets) to upgrade the existing beam-column concrete joints that were designed and constructed according to early codes ACI318-63. A new theory was investigated by this study. The theory was to use rods to increase the flexural strength of the column by following the near surface mounted technique (NSM), whereas the FRP was used as a jacket to increase the shear strength and the confinement at the joint. Two series of specimens were constructed. Figure 2-18 shows the typical test specimens and reinforcement details. All dimensions were chosen to represent a typical frame dimension.

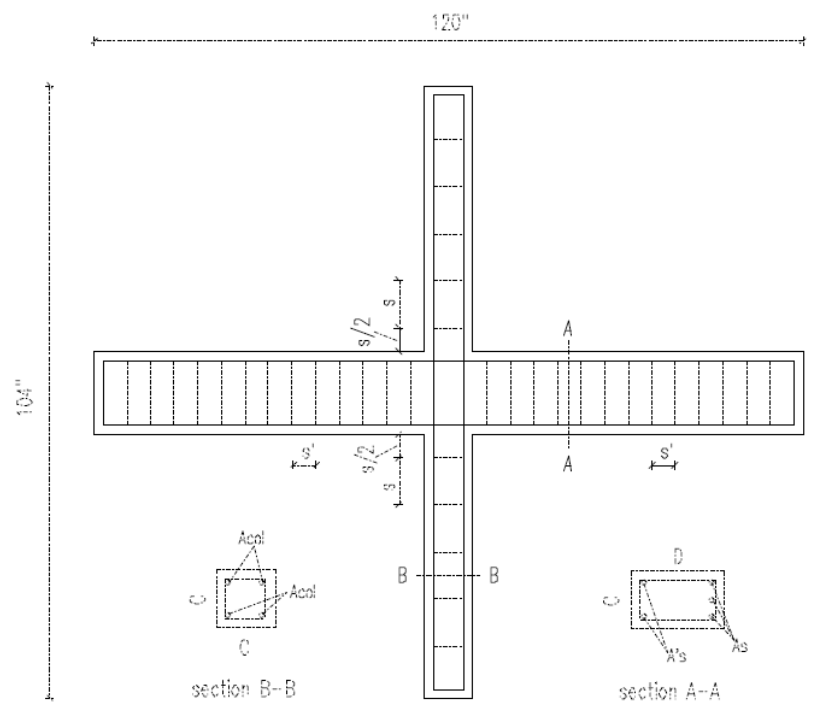

Figure 2-18 Typical Test Specimen and Reinforcement Used by Prota, A. et al. (2000)

The experiment program in this study consisted of twelve specimens divided into groups, where each group consisted of six specimens. The only difference between these two groups was the axial applied load. Table 2-7 includes these values of the axial loads. The 
concrete compressive strength $\left(\mathrm{f}^{\prime}{ }_{\mathrm{c}}\right)$ was $4530 \mathrm{psi}$ and the yield strength of the steel $\left(\mathrm{f}_{\mathrm{y}}\right)$ was 6000 psi. The following Table 2-6 shows the properties of composite materials.

Table 2-6 The Properties of Composite Materials, Prota, A. et al. (2000)

\begin{tabular}{|c|c|c|c|}
\hline Material & Size & $\begin{array}{c}\text { Modulus of Elasticity } \\
\left(\mathrm{E}_{\mathrm{fr}}\right)\end{array}$ & $\begin{array}{c}\text { Ultimate Tensile Strength } \\
\left(\mathrm{f}_{\mathrm{su}}\right)\end{array}$ \\
\hline CFRP Rod \#3 & $(0.375$ in. dia. $)$ & $15200 \mathrm{ksi}$ & $272 \mathrm{ksi}$ \\
\hline CFRP sheet & 0.0065 in. thick. & $32800 \mathrm{ksi}$ & $495 \mathrm{ksi}$ \\
\hline
\end{tabular}

All specimens were designed without any seismic details at the joint. Some specimens were retrofitted or strengthened by wrapping CFRP sheets around 15 in. of the column, and the others retrofitted by using both the rods and sheets. The retrofitting technique is summarized in the following Table 2-7.

Table 2-7 The Reinforcing and Retrofitting Details, Prota, A. et al. (2000)

\begin{tabular}{|c|c|c|c|c|c|c|c|c|c|c|c|c|c|c|}
\hline \multirow{3}{*}{ SET } & \multicolumn{7}{|c|}{ COLUMN } & \multicolumn{3}{|l|}{ PANEL } & \multicolumn{4}{|c|}{ BEAM } \\
\hline & Spec. & $\begin{array}{l}\text { Axial } \\
\text { Load }\end{array}$ & $\mathrm{C}$ & $\mathbf{A}_{\mathrm{col}}$ & $\mathrm{s}$ & $\begin{array}{c}\text { FRP } \\
\text { sheets }\end{array}$ & $\begin{array}{c}\text { FRP } \\
\text { NSMr }\end{array}$ & $\begin{array}{c}\text { upgraded } \\
\text { by }\end{array}$ & $\mathrm{C}$ & D & $\overline{\mathbf{A}_{\mathrm{s}}}$ & $\mathbf{A}_{\mathrm{s}}{ }^{\prime}$ & $\mathrm{s}^{\prime}$ & $\begin{array}{c}\text { FRP } \\
\text { sheets }\end{array}$ \\
\hline & & kips & in & bars & in. & layers & $\begin{array}{c}\text { rods } \\
\text { number }\end{array}$ & & in. & in. & rods & rods & in. & layers \\
\hline & $1 . \mathrm{a}$ & 56 & 8 & $2-\# 5$ & 8 & 0 & 0 & "-----. & 8 & 14 & $3-\# 7$ & $2-\# 6$ & 4 & 0 \\
\hline & $1 . \mathrm{b}$ & 56 & 8 & $2-\# 5$ & 8 & 2 & 0 & ------ & 8 & 14 & $3-\# 7$ & $2-\# 6$ & 4 & 0 \\
\hline 1 & $1 . c$ & 56 & 8 & $2-\# 5$ & 8 & 2 & $8-\# 3$ & ---.-- & 8 & 14 & $3-\# 7$ & $2-\# 6$ & 4 & 0 \\
\hline & 1.d & 56 & 8 & $2-\# 5$ & 8 & 2 & $8-\# 3$ & sheets & 8 & 14 & $3-\# 7$ & $2-\# 6$ & 4 & 0 \\
\hline & 1.e & 56 & 8 & $2-\# 5$ & 8 & 2 & $8-\# 3$ & $\mathrm{sh}+\mathrm{NSMr}$ & 8 & 14 & $3-\# 7$ & $2-\# 6$ & 4 & 0 \\
\hline & 1.f & 56 & 8 & $2-\# 5$ & 8 & 2 & $8-\# 3$ & sh. $+\mathrm{NSMr}$ & 8 & 14 & $3-\# 7$ & $2-\# 6$ & 4 & 2 \\
\hline & $2 . a$ & 28 & 8 & $2-\# 5$ & 8 & $\overline{0}$ & $\overline{0}$ & -..-- & 8 & 14 & $3-\# 7$ & $2-\# 6$ & 4 & $\overline{0}$ \\
\hline & $2 . b$ & 28 & 8 & $2-\# 5$ & 8 & 2 & 0 & ------ & 8 & 14 & $3-\# 7$ & $2-\# 6$ & 4 & 0 \\
\hline 2 & 2.c & 28 & 8 & $2-\# 5$ & 8 & 2 & $8-\# 3$ & ------- & 8 & 14 & $3-\# 7$ & $2-\# 6$ & 4 & 0 \\
\hline & 2.d & 28 & 8 & $2-\# 5$ & 8 & 2 & $8-\# 3$ & sheets & 8 & 14 & $3-\# 7$ & $2-\# 6$ & 4 & 0 \\
\hline & 2.e & 28 & 8 & $2-\# 5$ & 8 & 2 & $8-\# 3$ & $\mathrm{sh}+\mathrm{NSMr}$ & 8 & 14 & $3-\# 7$ & $2-\# 6$ & 4 & 0 \\
\hline & $2 . f$ & 28 & 8 & $2-\# 5$ & 8 & 2 & $8-\# 3$ & $\mathrm{sh}+\mathrm{NSMr}$ & 8 & 14 & $3-\# 7$ & $2-\# 6$ & 4 & 2 \\
\hline
\end{tabular}


These specimens were tested in the horizontal position. A plywood sheet was placed between the specimen and the floor in order to limit the friction, and to allow for the free movement of the beam and column. Figure 2-19 shows the test arrangement.

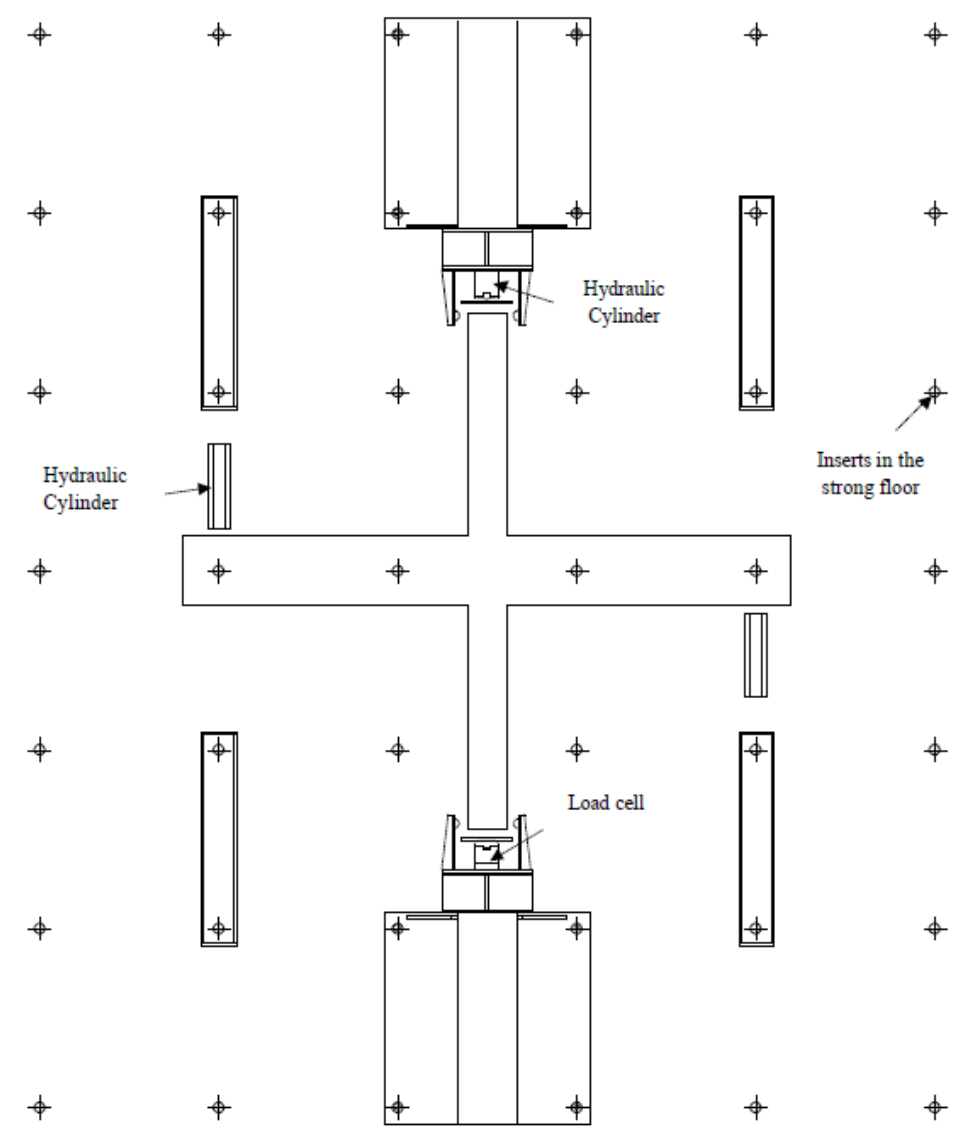

Figure 2-19 Test Arrangement, Prota, A. et al. (2000)

The loading process started by applied the axial load to the column at a constant value. As shown in Figure 2-19, two actuators were used to apply the cyclic load on each end of the transverse beam in order to generate the shear force and flexural moment in the column. 
It was confirmed by this experimental study that the combined action of FRP jacketing and NSM rods was a successful technique to retrofit the connections in gravity load designed (GLD) buildings. The retrofitting techniques could be adopted in more than one way to get the desirable failure mode. Figure 2-20 shows the increase of column strength between the control specimen (1a) and the retrofired specimen (1c). The ultimate column shear strength (1c) increased $1.6 \%$ compared to the control specimen (1a).

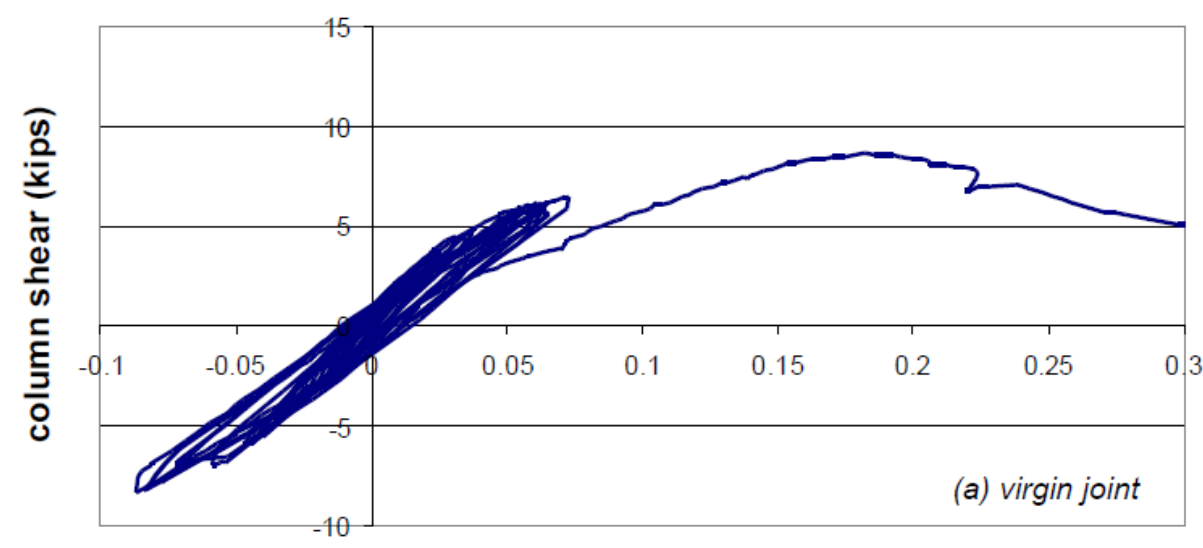

average recorded displacement (inches)

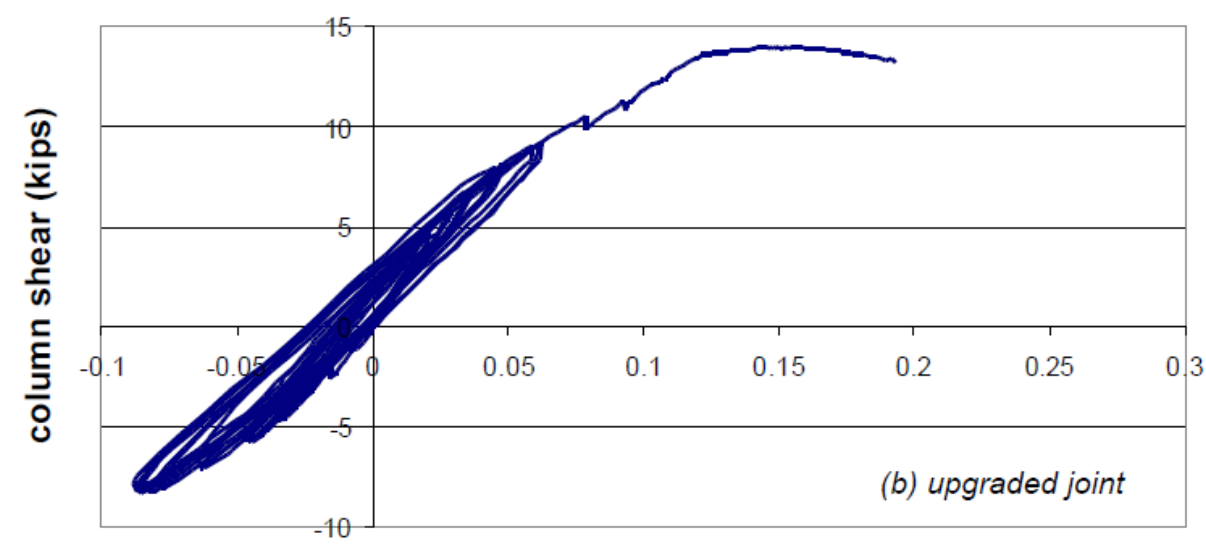

(1c)

average recorded displacement (inches)

Figure 2-20 Compression between (1a and 1c) Specimens, Prota, A. et al. (2000) 
Ghobarah, A. et al. (2001) used the Glass Fiber Reinforced Polymer (GFRP) laminates as a retrofitting material to retrofit the external beam-column joint. One specimen in full scale was constructed in the experimental work with no shear reinforcement within the joint region. It was expected that the joint would fail before the plastic hinge formation. The reinforcement bar details and the dimensions of this specimen are shown in Figure 221. The compressive strength of the concrete was $30.8 \mathrm{Mpa}^{1}$ and the yield strength of the reinforcement bars was (454 and $425 \mathrm{Mpa}$ ) for M10 and M20 ${ }^{2}$ bars, respectively.

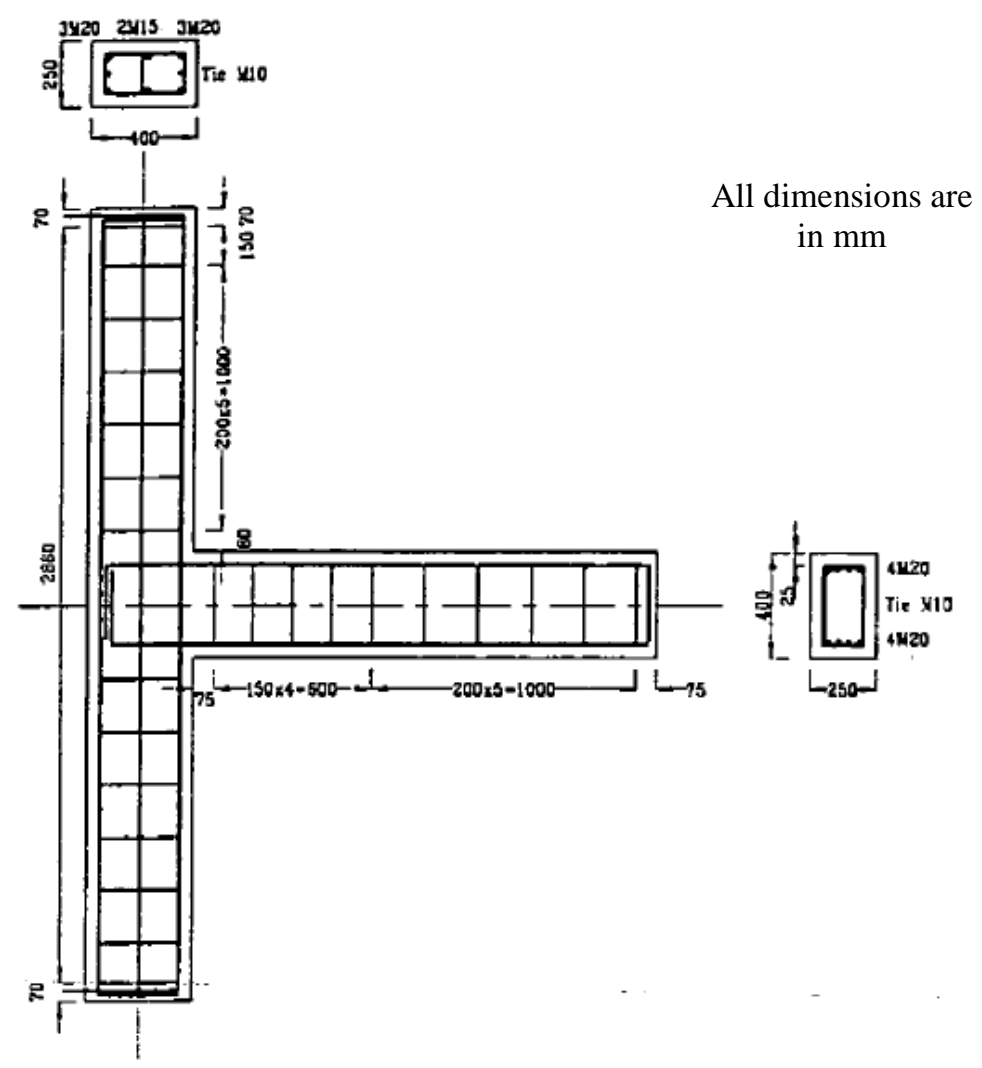

Figure 2-21 The Reinforcement Bar Details and The Dimensions

(Ghobarah, A. et al. (2001))

${ }^{1} \mathrm{Mpa}=145$ psi.

${ }^{2} \mathrm{M} 10=11.3 \mathrm{~mm}, \mathrm{M} 20=19.5 \mathrm{~mm}$. 
The objective of this work was to use the Glass Fiber Reinforced Polymer (GFRP) laminates as a seismic reinforcement to strength beam-column joint by providing the lateral confinement and shear resistance to the joint. The properties of the composite material is shown in the Table 2- 8 .

Table 2-8 The Properties of the Composite Material (Ghobarah, A. 2001)

\begin{tabular}{|c|c|c|c|c|}
\hline GFRP & $\begin{array}{c}\text { Ultimate } \\
\text { Tensile } \\
\text { Strength, Mpa }\end{array}$ & $\begin{array}{c}\text { Ultimate } \\
\text { Elongation, \% }\end{array}$ & $\begin{array}{c}\text { Elastic Modulus, } \\
\text { Mpa }\end{array}$ & $\begin{array}{c}\text { Thickness, } \\
\mathrm{mm}\end{array}$ \\
\hline $\begin{array}{c}\text { Bi-directional (in } \\
\text { the } 45^{\circ} \\
\text { direction) }\end{array}$ & 552 & $1.7-4.0$ & 27579 & 1.1 \\
\hline
\end{tabular}

The load sequence consisted of two phases. The first phase was the load control, where two cycles at $15 \%$ of the estimated strength of the beam followed by two cycles at the cracking load of the beam were applied to the load. This phase started from the beginning of the test until the yield point of the longitudinal beam reinforcement. Then the displacement control phase followed where two cycles were applied at each ductility level $(2,2.5,3, \ldots$ etc. $)$.

The beam-column joint specimen named T1 was the control specimen. After testing specimen $\mathrm{T} 1$, the specimen was repaired by removing the crashed concrete, and recasting it again by using concrete with compressive strength of $38 \mathrm{Mpa}$. The composite material GFRP was used to retrofit the joint area, and did not extend out to the joint region in a "U" shape. The free ends of the GFRP were anchored by using the steel plates and bolts in order to develop the maximum strength of the composite material. This specimen was 
named T1R. Both the control and retrofitting specimens were tested in the vertical position, where the axial load represented $0.2 A_{g} f^{\prime}{ }_{c}$ applied to the column and the cyclic load applied at the free end of the beam. Figure 2-22 shows the test setup and the instrumentation.

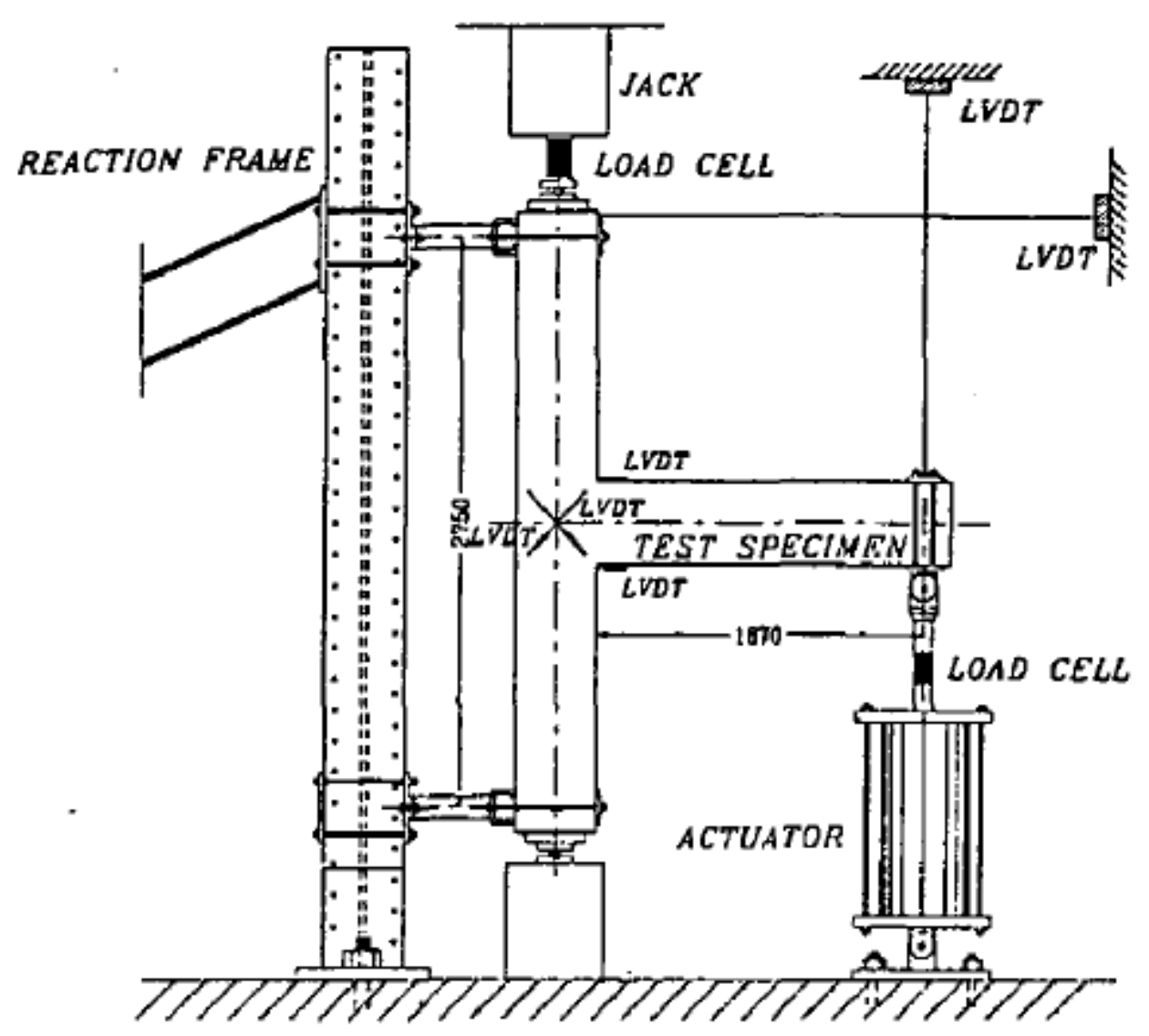

Figure 2-22 The Test Setup and the Instrumentation (Ghobarah, A. (2001))

The test results showed that the control specimen $\mathrm{T} 1$ exhibited a very high rate of shear deterioration represented by brittle shear failure in the joint whereas the retrofitted specimen T1R showed an increase in the shear resistance, a higher ductility (increased by 60\%), and it developed the plastic hinge in the beam as shown in Figure 2-23 . Regarding 
the energy dissipation, the repaired specimen T1R showed improvement compared to the un-retrofitted specimen T1. Figure 2-24 shows the energy dissipation of two specimens.

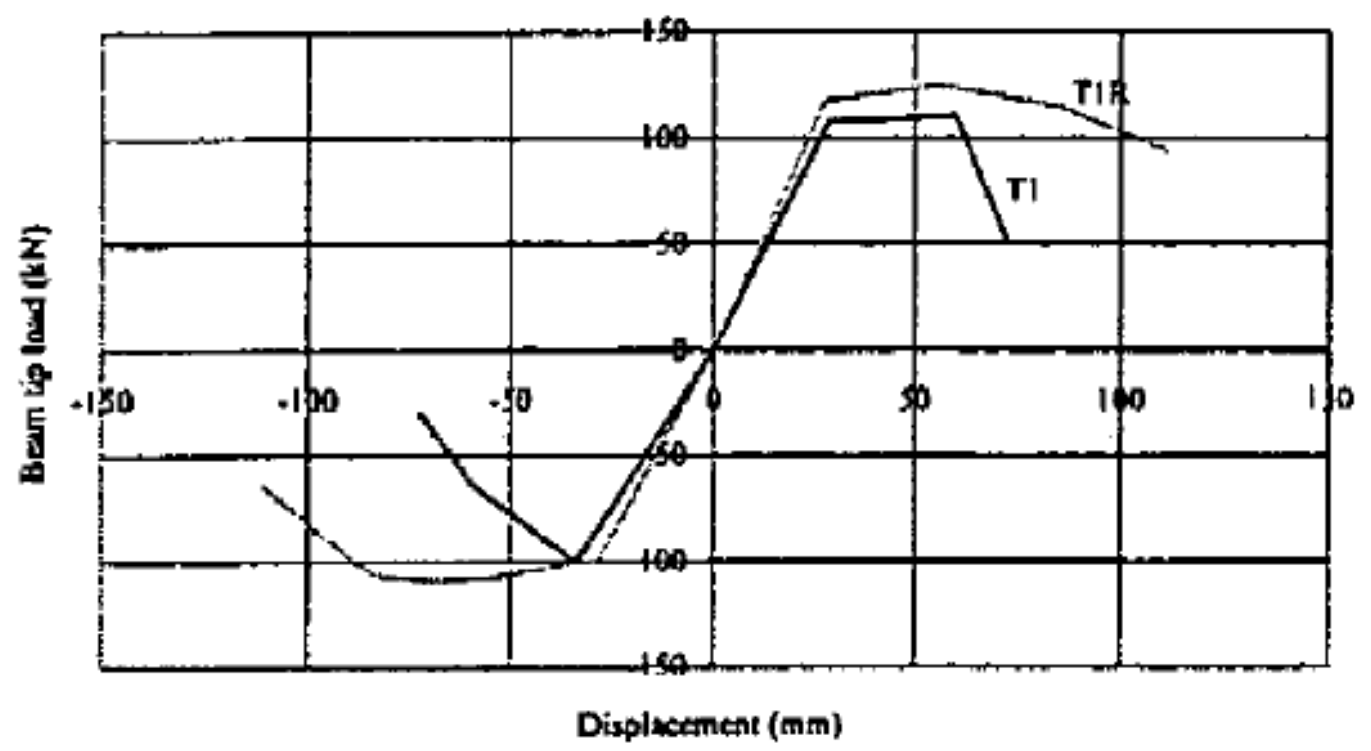

Figure 2-23 Envelopes of the Beam Tip Load-Displacement Curves, (Ghobarah, A. 2001)

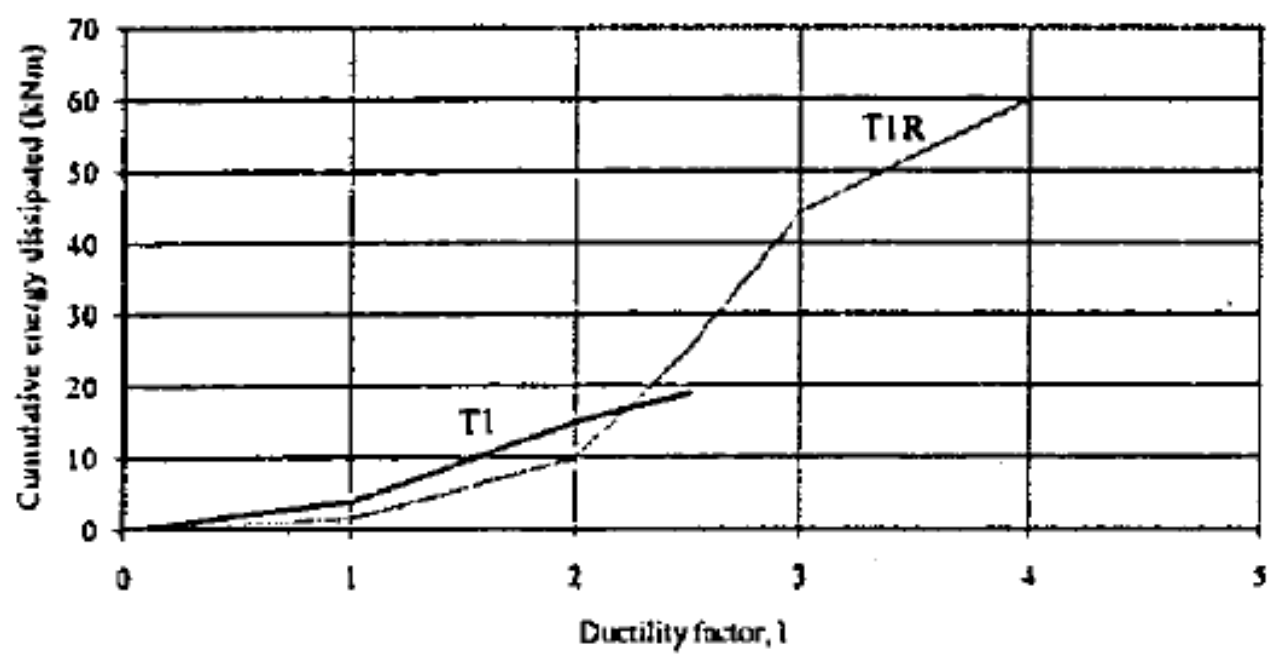

Figure 2-24 Energy Cumulative- Ductility Factor for Specimens (T1 and TR1), (Ghobarah, A. 2001) 
El-Amoury, T. et al. (2001) proposed a new technique to strengthen the exterior beamcolumn joint by using Glass Fiber Reinforced Polymer (GFRP) sheets as a jacket because the exterior beam-column joints were more vulnerable to seismic deformation than interior joints. Three specimens in full scale were designed according to pre- 1970s codes to resist the gravity loads and light lateral loads. These specimens were characterized by a lack of shear strength and by a deficiency in the development length of the beam longitudinal reinforcement. Specimen T0 represented the control specimen while the others TR1 and TR2 represented the retrofitted specimens. There was no difference between TR1 and TR2 in terms of dimensions and reinforcement details as shown in Figure 2-25. The yield strength of steel bars \#10, \#15, and \#20 ${ }^{3}$ was 450,408 , and 425 Mpa respectively and the concrete compressive strength was 30.6, 43.5, and 39.5 Mpa for T1, TR1, and TR2 respectively.

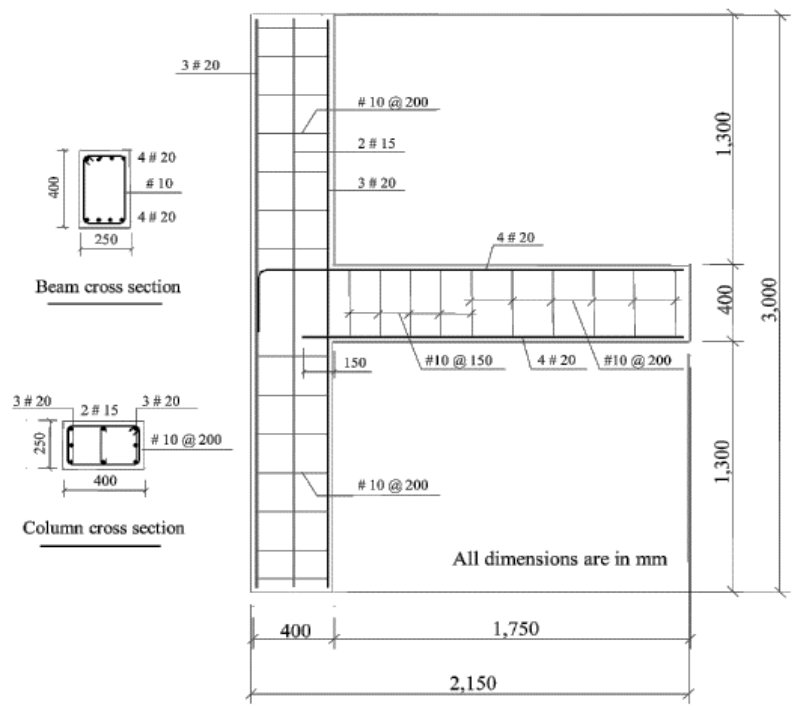

Figure 2-25 Specimens Dimensions and Reinforcement Details

(El-Amoury, T. et al. (2001))

${ }^{3} \# 10=9.5 \mathrm{~mm}, \# 15=15 \mathrm{~mm}, \# 20=20 \mathrm{~mm}$ 
TR1 was a damaged specimen. After testing specimen T0, the cracked concrete was removed from the joint region and the adjoining members. The specimen was laid inside the wooden form again and new concrete was poured to replace the removed materials. The specimen was retrofitted and tested again as TR1, whereas TR2 was the undamaged specimen which was already retrofitted and tested. The proposed technique to retrofit these specimens by using the Glass Fiber Reinforced Polymer (GFRP) sheets is shown in Figure 2-26, and the properties of the fiber sheets given by the manufacturer are given in Table 2-9. Two layers were used to confine the joint. The first layer was a bi-directional sheet, and the second layer was a unidirectional sheet.
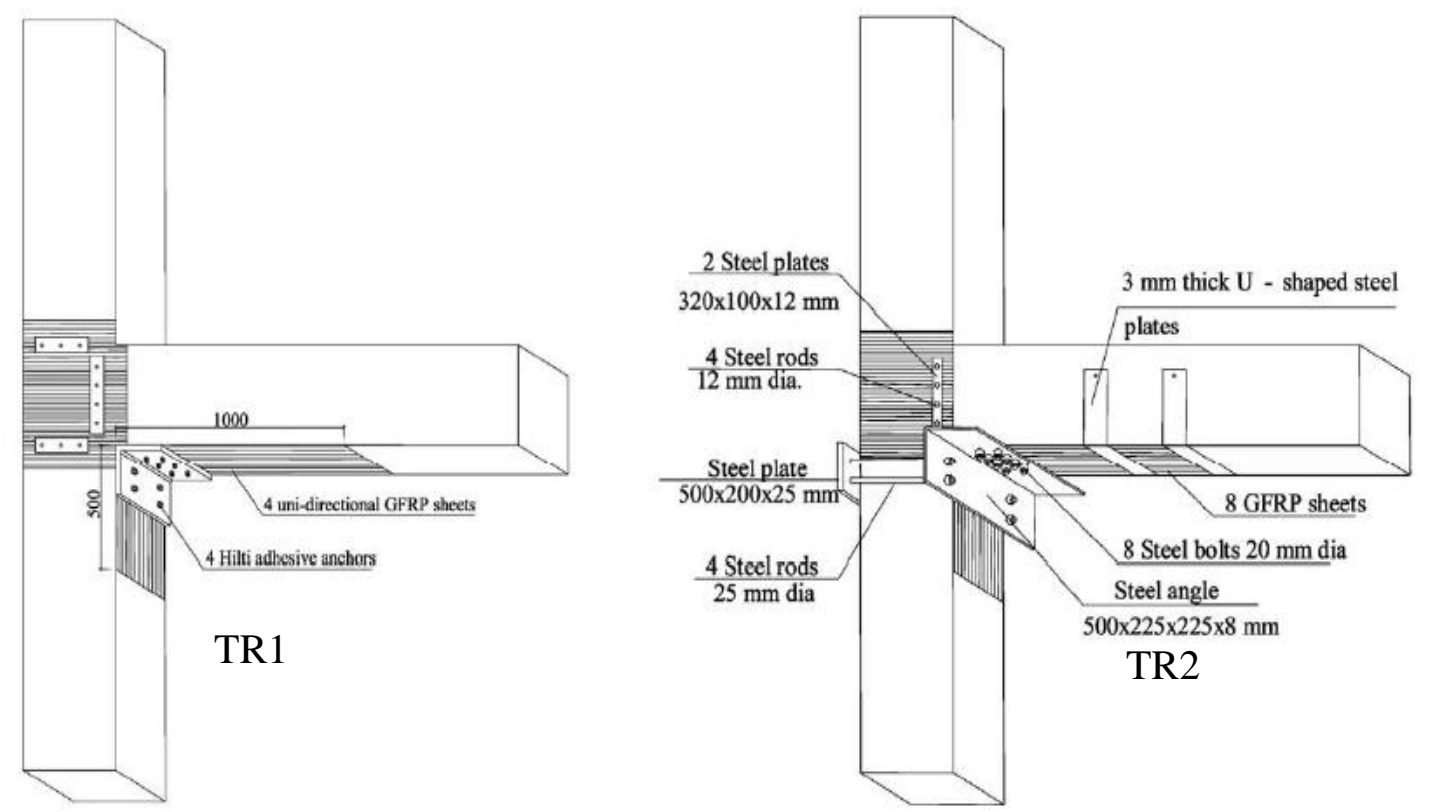

Figure 2-26 The Proposed Technique to Strengthen the Specimens (El-Amoury, T. et al. (2001)) 
Table 2-9 Properties of Composite Materials (El-Amoury, T. et al. (2001))

\begin{tabular}{lllll}
\hline GFRP & Tensile strength in $0^{\circ}$ direction $(\mathrm{MPa})$ & Elongation at break (\%) & Tensile modulus (GPa) & Thickness (mm) \\
\hline Bi-directional $\left( \pm 45^{\circ}\right)$ & 279 & 1.5 & 19 & 0.864 \\
Unidirectional & 1700 & 2 & 71 & 0.353 \\
\hline
\end{tabular}

The load sequence that used in this test consisted of two phases as shown in the Figure 227. Figure $2-28$ shows the general test setup in this experimental work. The specimens were tested in the vertical position, where the specimen was pinned at the end of columns. An axial load was applied to the top of the column and this load was constant and equal to $0.2 \mathrm{Ag} \mathrm{f}^{\prime}$. At the free end of the beam, the static cyclic load was applied and required data were recorded.

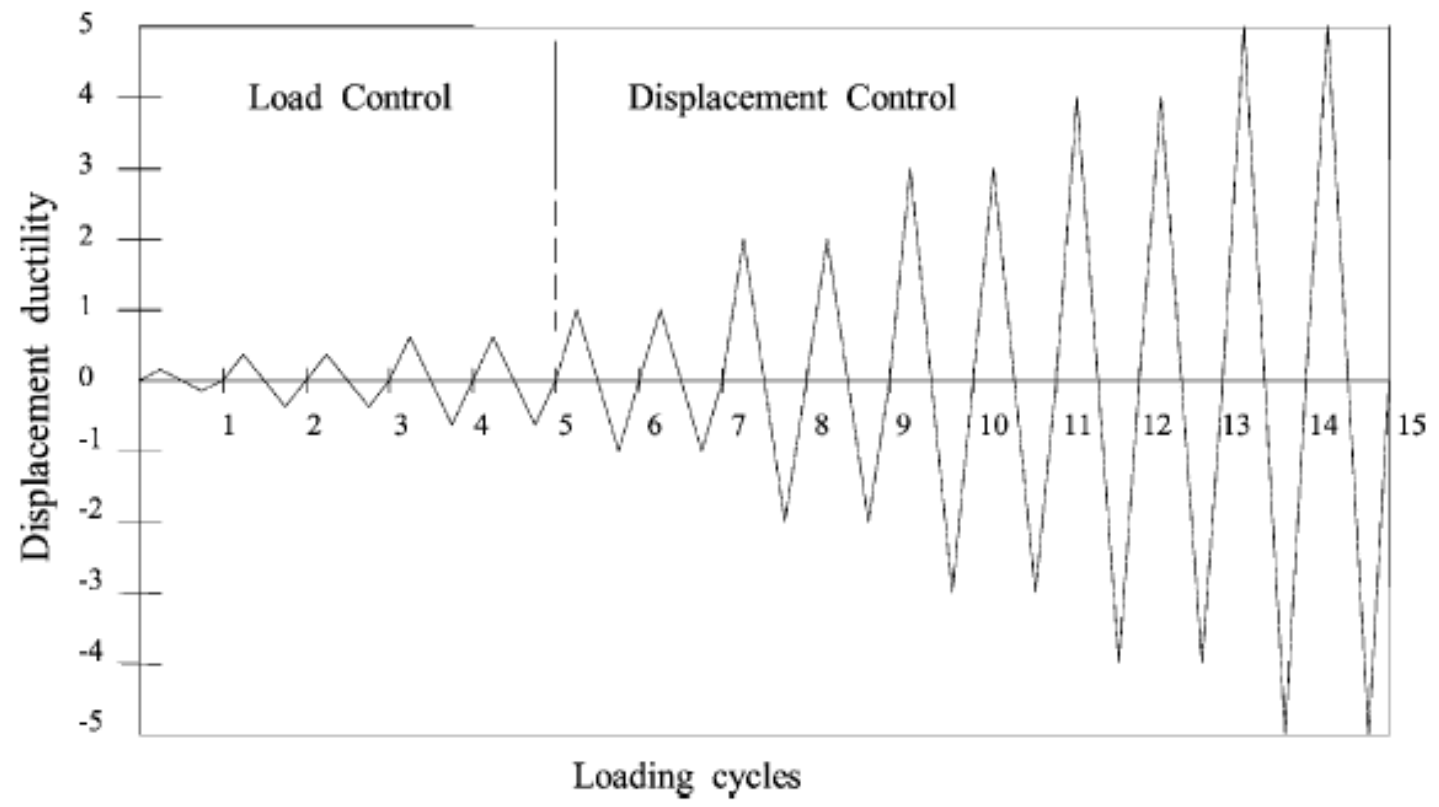

Figure 2-27 Load Routing, El-Amoury, T. et al. (2001) 
After the test, the results showed that the control specimen exhibited two types of failures as expected. This failure was represented by a brittle joint shear failure and slippage of the beam bottom bars. On the other hand, the retrofitted specimens showed a change in the general behavior of the joint in comparison with the control one, where the brittle joint shear failure was eliminated and slippage of the beam bottom bars was delayed with the improvement in the load carrying capacity. Moreover, the use of the GFRP jacket increased the energy dissipation of the joint by six times, and reduced the stiffness degradation. Figures 2-29 and 2-30 show the differences between specimens.

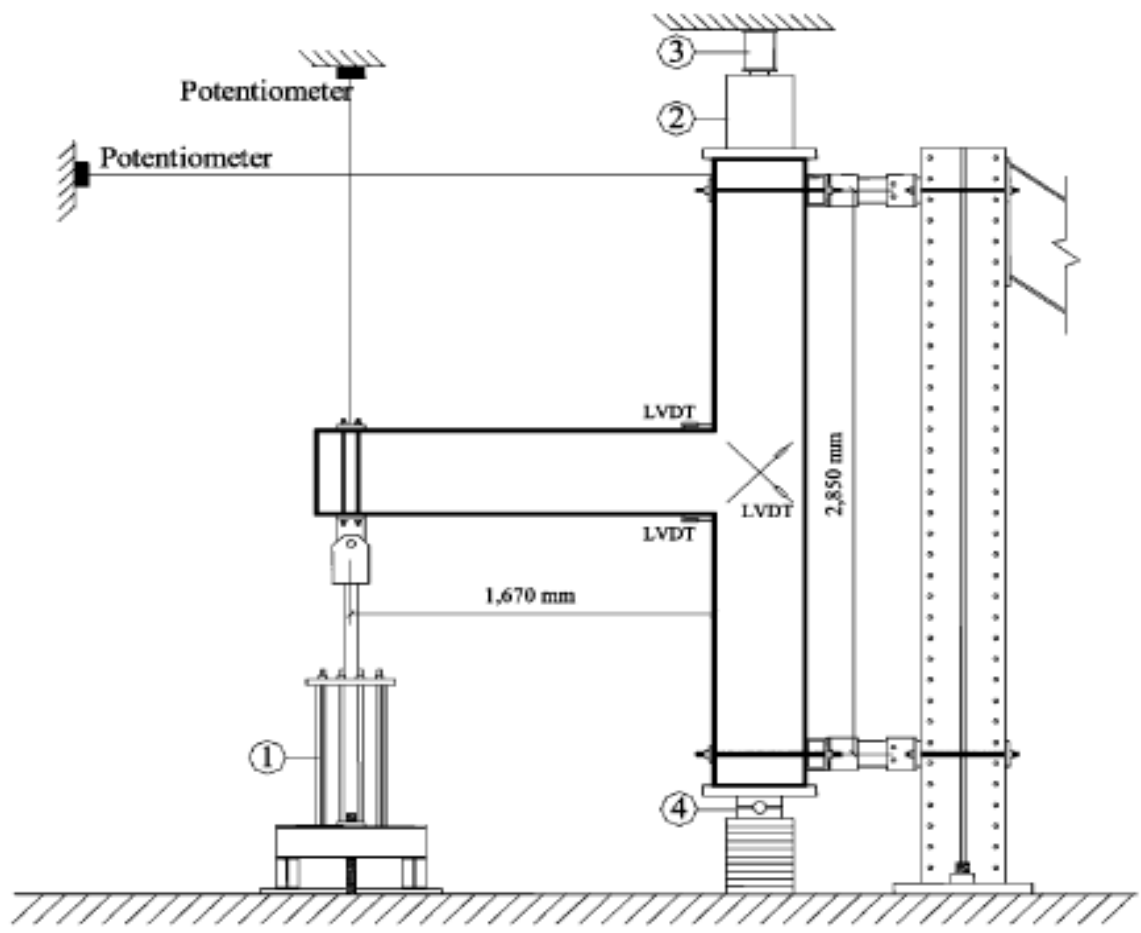

(1) Cyclic loading actuator

(2) Axial load hydraulic jack
(3) Load cell

(4) Bottom hinge

Figure 2-28 Apparatus Details for Testing Specimen (El-Amoury, T. et al. (2001)) 


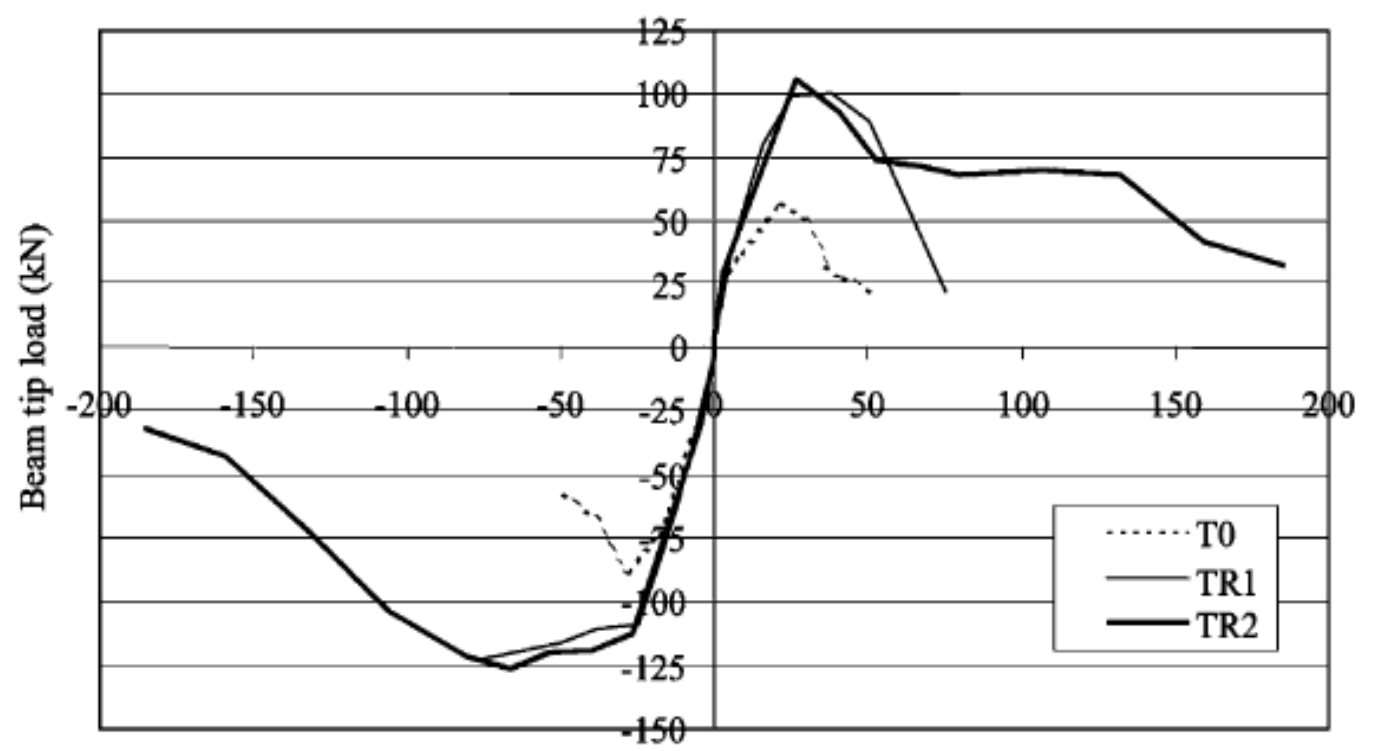

Beam tip displacement (mm)

Figure 2-29 Hysteretic Loop Envelopes of the Test Specimens, El-Amoury, T. (2001)

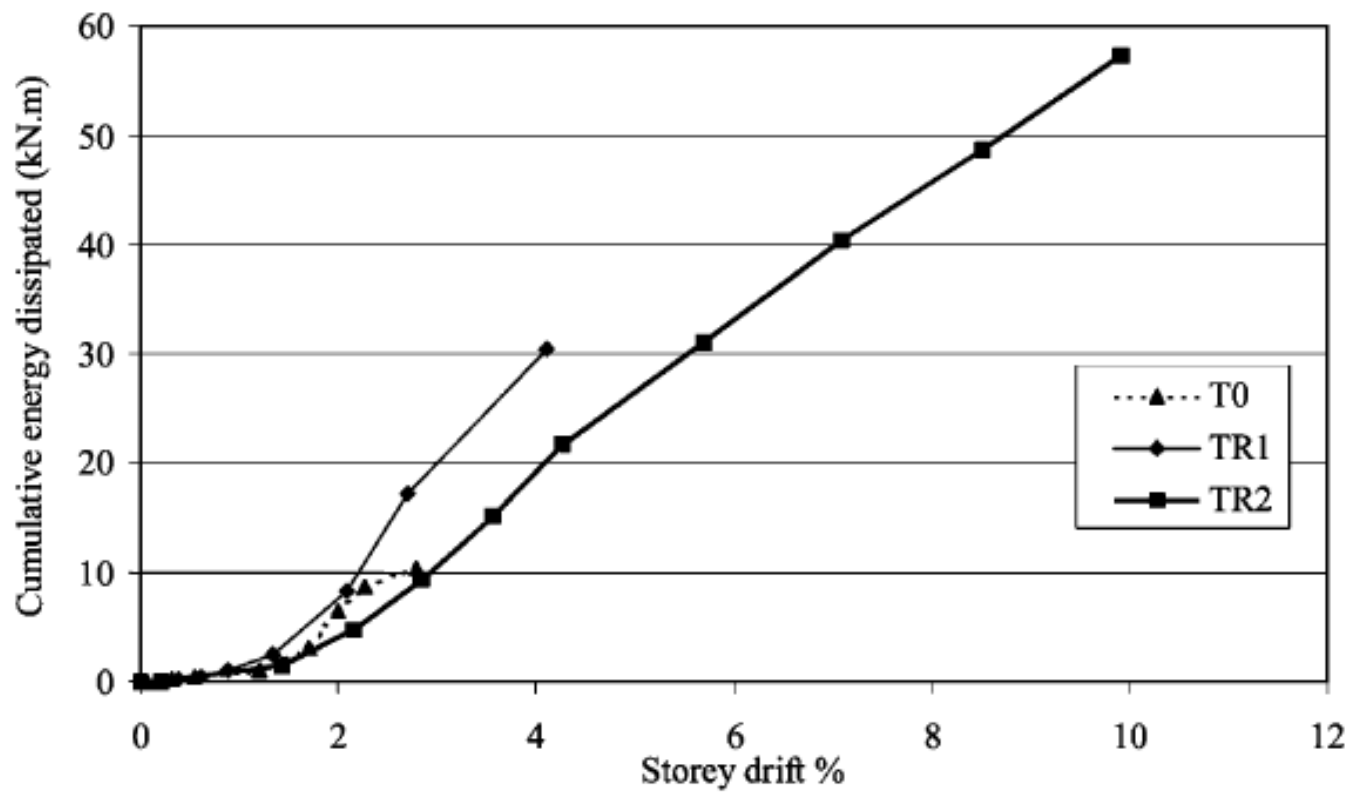

Figure 2-30 Cumulative Energy Dissipation, El-Amoury, T. (2001) 
Ghobarah, A. et al. (2002) suggested a new technique to strengthen the beam-column joint that was simple to install, and create minimum disruption to the function of building. Four beam-column joints in full scale were constructed representing the pre1970s design, where these specimens were characterized by strong beam-weak column, and no transverse reinforcement was provided within the joint region. The column cross section was $250 \times 400 \mathrm{~mm}$ and $3000 \mathrm{~mm}$ height, whereas the beam cross section was 250×400 mm and 1750 length from the column face. Six \#20 bars used as the longitudinal bars in the column, in addition to two \#15 bars. Rectangular closed ties \# 10 with a single \# 10 central leg were used as shear reinforcement in column. In the beam, four \# 20 bars used as the longitudinal bars in each beam and \#10 rectangular stirrups were used as a shear reinforcement. Within the joint region, there was no reinforcement placed to simulate the existing joints. The concrete compressive strength was $25 \mathrm{Mpa}$. These specimens were named as T1, T2, T4, and T9. The specimens $\mathrm{T} 1$ and $\mathrm{T} 2$ were the control specimens, where the only difference between them was the axial applied load on the column. In specimen T1, the axial applied load on the column was $600 \mathrm{KN}(\mathrm{KN}=$ $224.8 \mathrm{Ib}$ ) representing $20 \%$ of the column section capacity, and in the specimen $\mathrm{T} 2$, the axial applied load on the column was $300 \mathrm{KN}$ representing $10 \%$ of the column section capacity. The two control specimens were repaired after the testing and rehabilitated and tested again as TR1 and TR2. Two layers of GFRP sheets were used as a jacket to retrofit these specimens with anchored steel plates at the free ends of the composite material. The general technique is summarized in Table 2-10 for all specimens. 
Table 2-10 Strengthening Techniques for All Specimens (Ghobarah, A.2002)

\begin{tabular}{ll}
\hline Specimen designation & Test conditions and retrofit schemes using GFRP \\
T1 & $\begin{array}{l}\text { Control (column axial load of } 600 \mathrm{kN} \text { ). } \\
\text { T2 }\end{array}$ \\
T1R & $\begin{array}{l}\text { Reptrol (column axial load of } 300 \mathrm{kN} \text { ). } \\
\text { height as the joint with added cover plates and anchors through the joint, }\end{array}$ \\
T2R & $\begin{array}{l}\text { Repaired specimen T2 after control test, then rehabilitated with two "U" shaped GFRP layers extending above and } \\
\text { below the joint with added cover plates and anchors through the joint, }\end{array}$ \\
T4 & $\begin{array}{l}\text { Rehabilitated using one bi-directional "U" shaped GFRP sheet, same height as the joint, similar to T1R shown in Fig. } \\
\text { T9 but without cover plates and anchors through the joint. }\end{array}$ \\
\hline
\end{tabular}

All of the specimens were tested in the vertical position as shown in Figure 2-31 where the vertical load was applied directly to the column, while the cyclic load was applied at the free end of the beam.

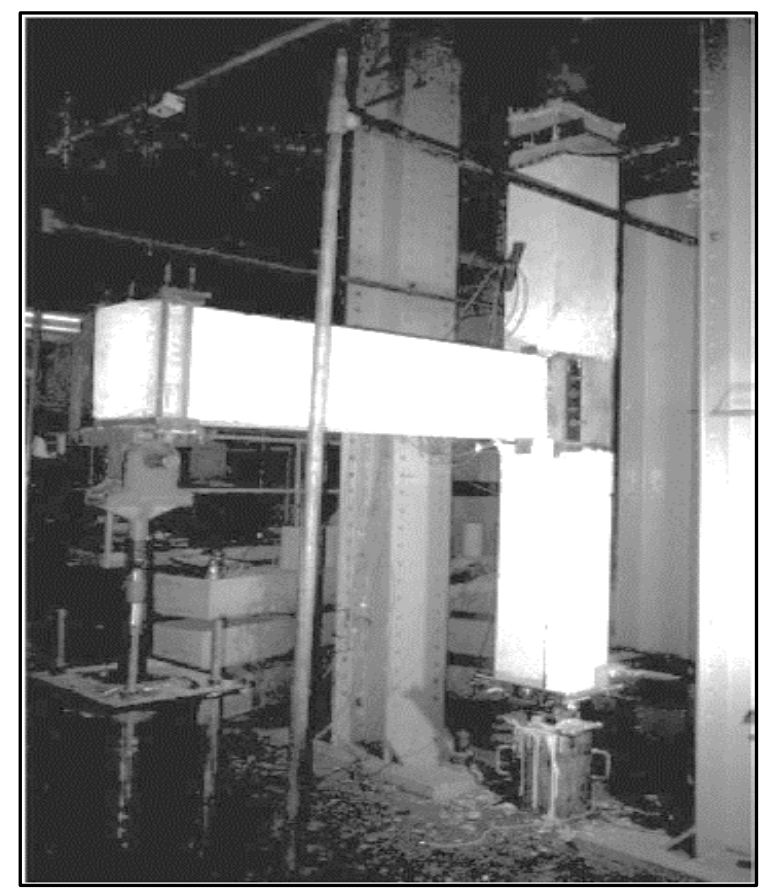

Figure 2-31 Test Setup for Specimen TR1 (Ghobarah, A. 2002) 
Figures 2-32 and 2-33 show the results of this experiment, where the retrofitting technique by using Glass Fiber Reinforced Polymer (GFRP) as a jacket to the beamcolumn joint successfully improved the behavior of the joints, and moved the failure from the joint region to the beam as shown in Figure 2-34. This gave the plastic hinge opportunity to form in the beam, thereby increasing the shear strength of the joint and providing the confinement of the column. The only issue in the experimental test was the bulging of the GFRP sheets because this effect allowed cracks to form under the fiber sheets. The control specimens T1 and T2 that were tested under two different axial loads exhibited exactly the same kind of the shear failure at the joint at a relatively low ductility factor comparing to retrofitted specimens.

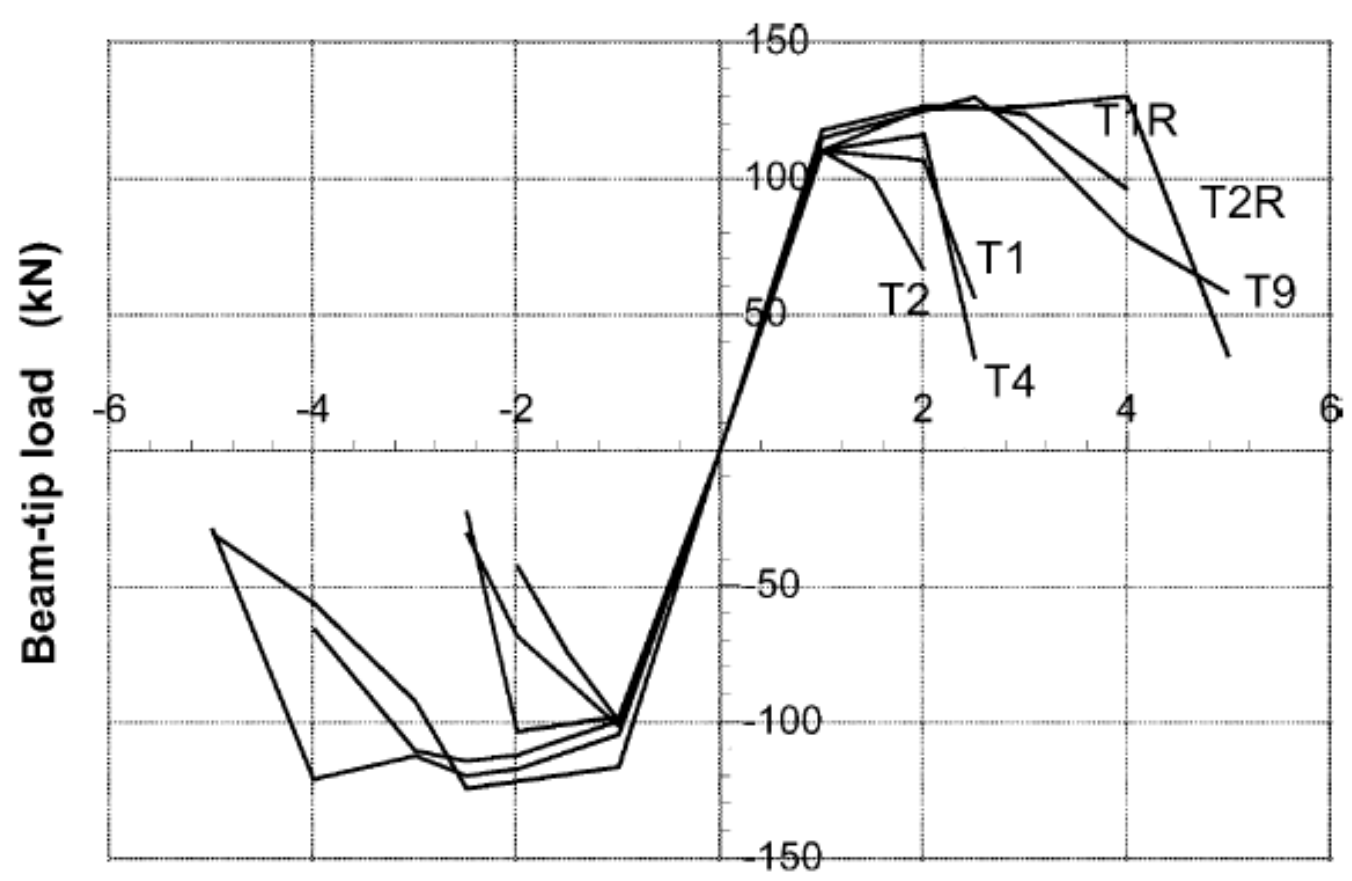

\section{Displacement ductility factor}

Figure 2-32 Envelop of the Hysteretic Loops, Ghobarah, A. (2002) 


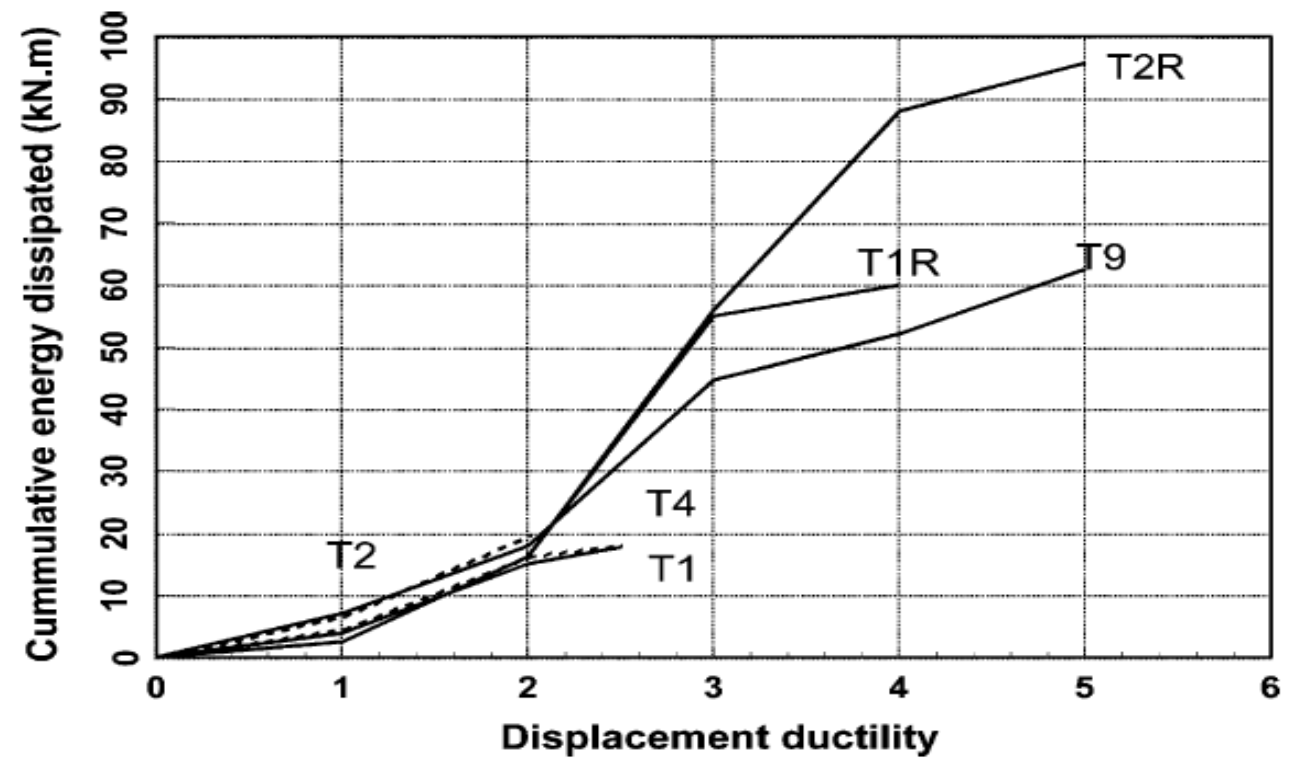

Figure 2-33 Cumulative Energy Dissipation, Ghobarah, A. (2002)

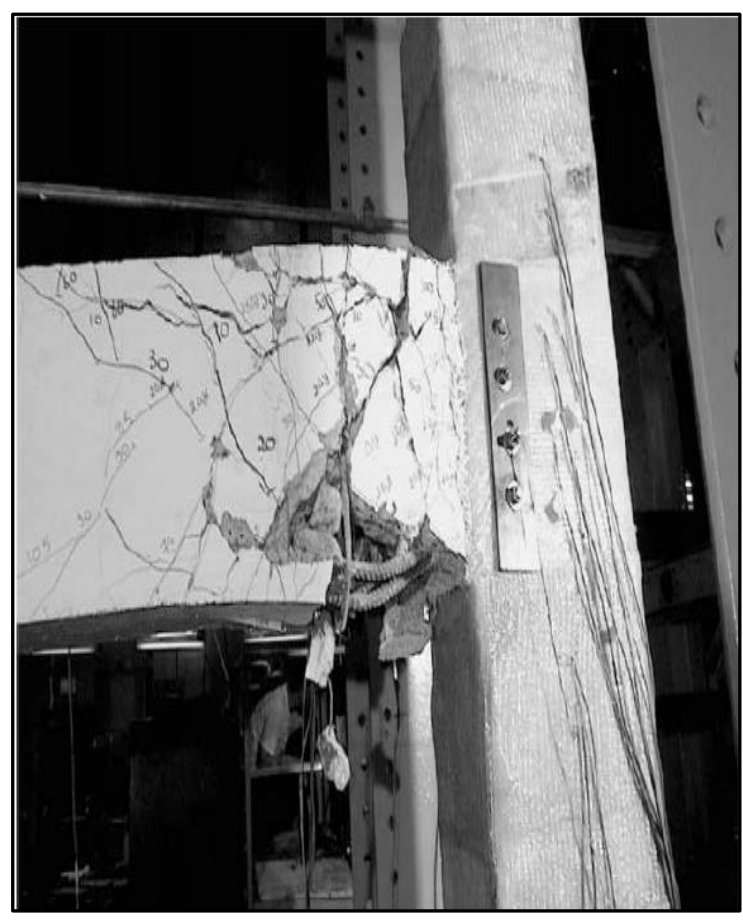

Failure Mode of Joint T2R

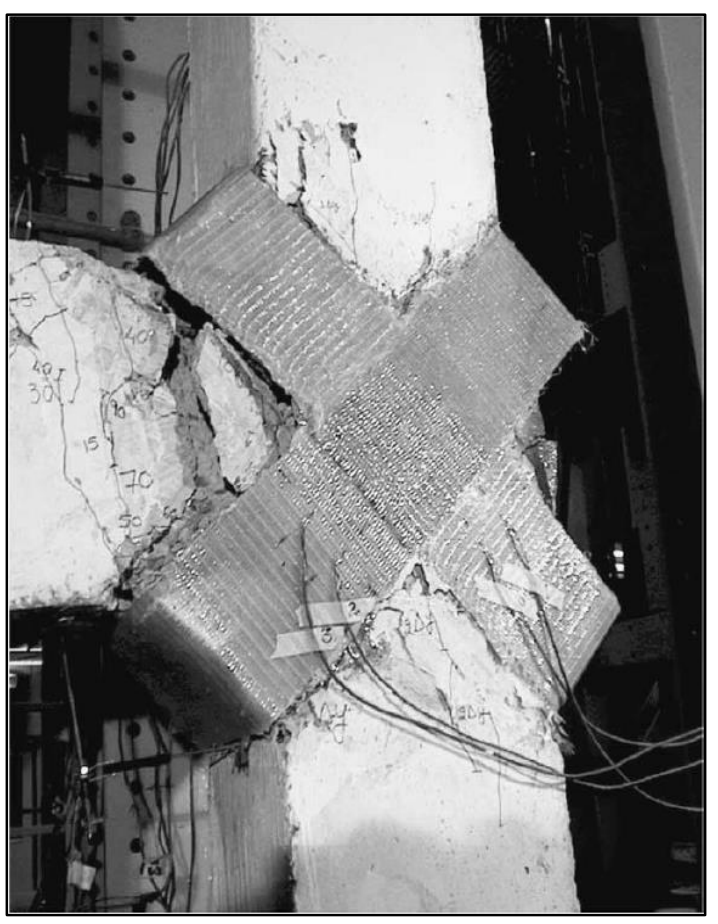

Failure Mode of Joint T9

Figure 2-34 Failure Modes of Specimens, Ghobarah, A. (2002) 


\subsection{Seismic Behavior of the Concrete Beam Column Joint with Slab}

According to the ACI 318-83 code under service loads, the slab worked as an integral part of the beam, and this led to an increase in the load capacity of the beam. On the other hand, in order to investigate the effects of the slab on the seismic performance, Revathi, R. et al. (2014) constructed and tested two specimens in one fourth scale. The reinforced concrete corner with the slab was called BCJS, and the reinforced concrete corner without the slab was called BCJ. These specimens were designed in accordance with Indian standards (IS) 1893(part1), 2002 and (IS) 13920: 1993.

The general shape of each specimen was comprised of column and two beams. The first beam connected to the joint at the north side and the second beam connected with the joint from east side as shown in Figure 2-35. The beam and column section dimensions were $100 \times 100 \mathrm{~mm}$, and the slab thickness was $40 \mathrm{~mm}$.

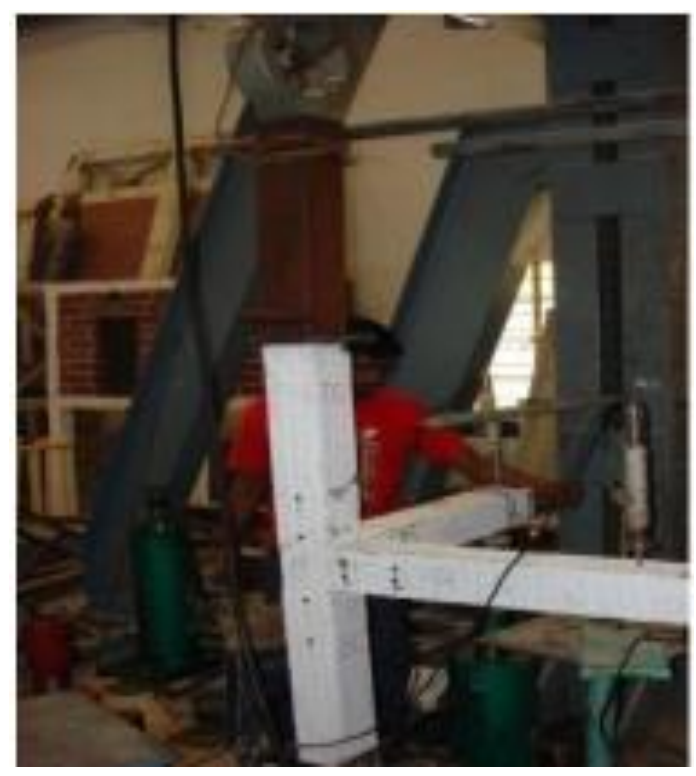

Specimen BCJ

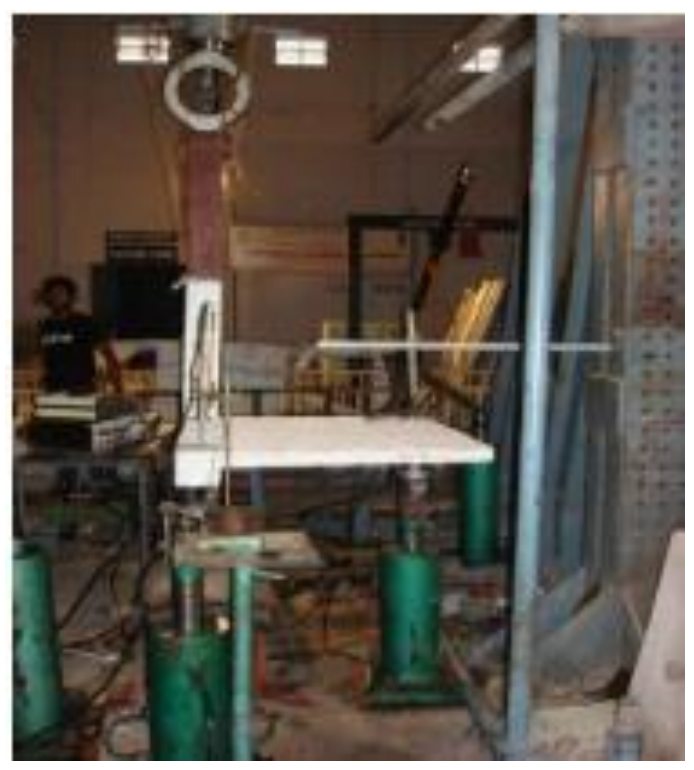

Specimen BCJS

Figure 2-35 Test Specimens with and without the Slab (Revathi R., 2014) 
The reinforcement details of these two specimens are summarized in Table 2-11.

Table 2-11 Reinforcement Details (Revathi R., 2014)

\begin{tabular}{|c|c|c|c|c|}
\hline Member & $\begin{array}{c}\text { Longitudinal } \\
\text { Bar Size }\end{array}$ & $\begin{array}{c}\text { Number of } \\
\text { Bars }\end{array}$ & $\begin{array}{c}\text { Transverse } \\
\text { Bar Size }\end{array}$ & $\begin{array}{c}\text { Spacing between } \\
\text { Stirrups }\end{array}$ \\
\hline North Beam & $8 \mathrm{~mm}$ & 4 & $6 \mathrm{~mm}$ & $50-150 \mathrm{~mm}$ \\
\hline East Beam & $8 \mathrm{~mm}$ & 4 & $6 \mathrm{~mm}$ & $50-150 \mathrm{~mm}$ \\
\hline Column & $10 \mathrm{~mm}$ & 4 & $6 \mathrm{~mm}$ & $40 \mathrm{~mm}-60 \mathrm{~mm}$ \\
\hline
\end{tabular}

Figure 2-35 also shows the test setup of these specimens, where the column was pinned at both ends. The specimens were subjected to an axial load equal to $50 \mathrm{KN}$, and the cyclic loads were applied to the free ends of the beams. The load versus displacement, the energy dissipation, and the crack pattern were checked during the test. All resulting data showed that the slab presence improved the behavior of the corner beam-column joint. Based on the acquired test results shown in Figures 2-36 until 2-38 and Tables 2-12 and 2-13, Revathi, R. recommended that the slab effects on the behavior of the concrete beam-column joints should be considered and included in the Indian Standards. 
Table 2-12 The Maximum Ductility Factor for Beam Column Joint without Slab

\begin{tabular}{|c|c|c|c|c|}
\hline \multirow{2}{*}{ No. } & \multirow{2}{*}{ Direction } & \multicolumn{3}{|c|}{ Displacement } \\
\cline { 3 - 5 } & North & 4 & 14.5 & 3.63 \\
\hline 1 & At Yield (mm) & $\begin{array}{c}\text { At Ultimate } \\
(\mathrm{mm})\end{array}$ & $\begin{array}{c}\text { Ductility } \\
\text { Factor }\end{array}$ \\
\hline 2 & East & 3.8 & 15.3 & 4.03 \\
\hline
\end{tabular}

Table 2-13 The Maximum Ductility Factor for Beam Column Joint with Slab

\begin{tabular}{|c|c|c|c|c|}
\hline \multirow{2}{*}{ No. } & \multirow{2}{*}{ Direction } & \multicolumn{3}{|c|}{ Displacement } \\
\cline { 3 - 5 } & At Yield (mm) & $\begin{array}{c}\text { At Ultimate } \\
(\mathrm{mm})\end{array}$ & $\begin{array}{c}\text { Ductility } \\
\text { Factor }\end{array}$ \\
\hline 1 & North & 5.2 & 33.3 & 6.4 \\
\hline 2 & East & 5.4 & 32.8 & 6.63 \\
\hline
\end{tabular}
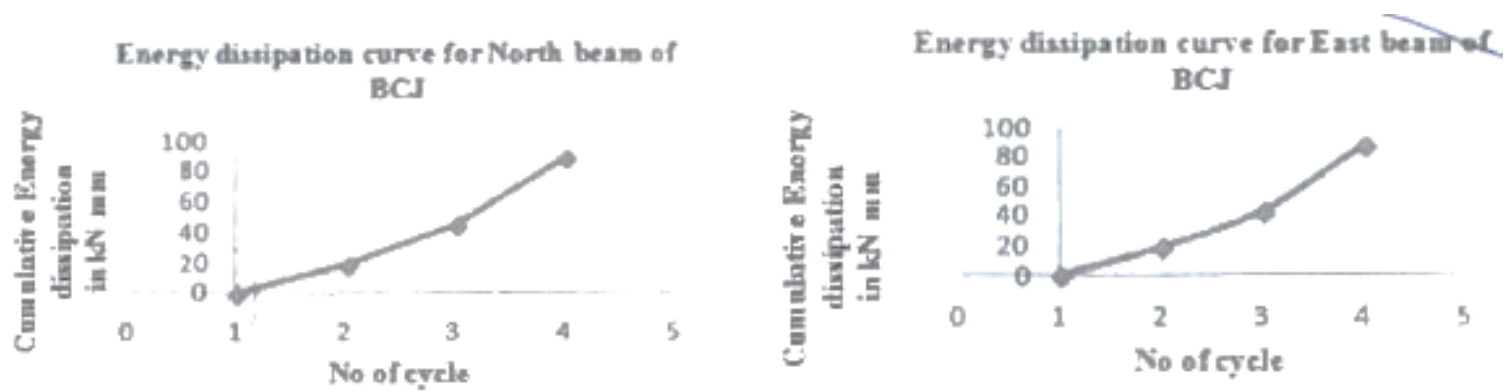

Figure 2-36 Energy Dissipation Curves for Beam-Column Joint without Slab 

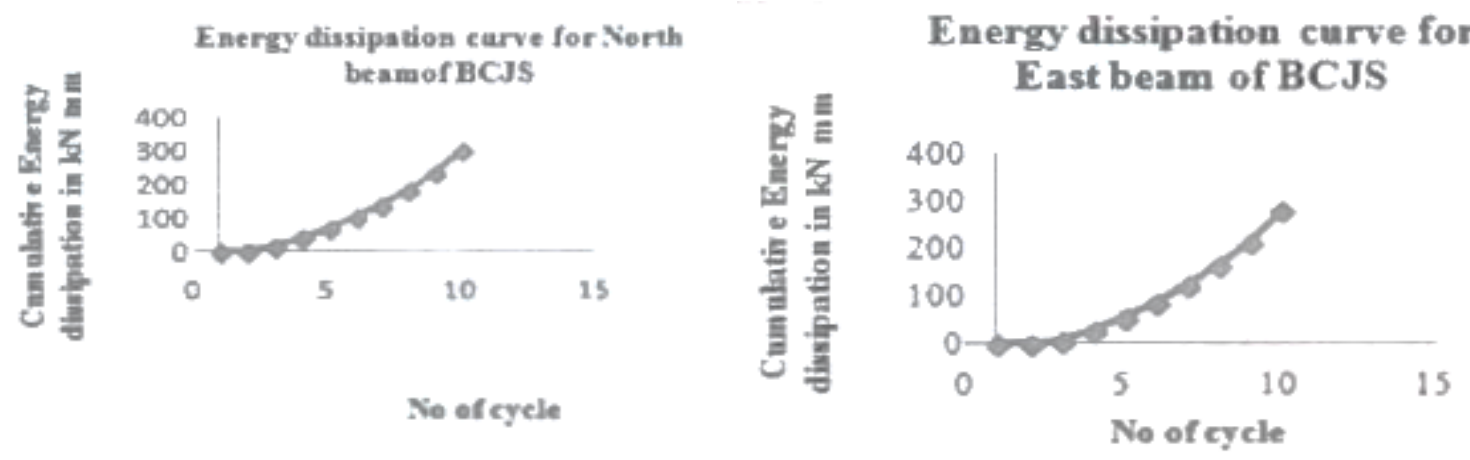

Figure 2-37 Energy Dissipation Curves for Beam-Column Joint with Slab

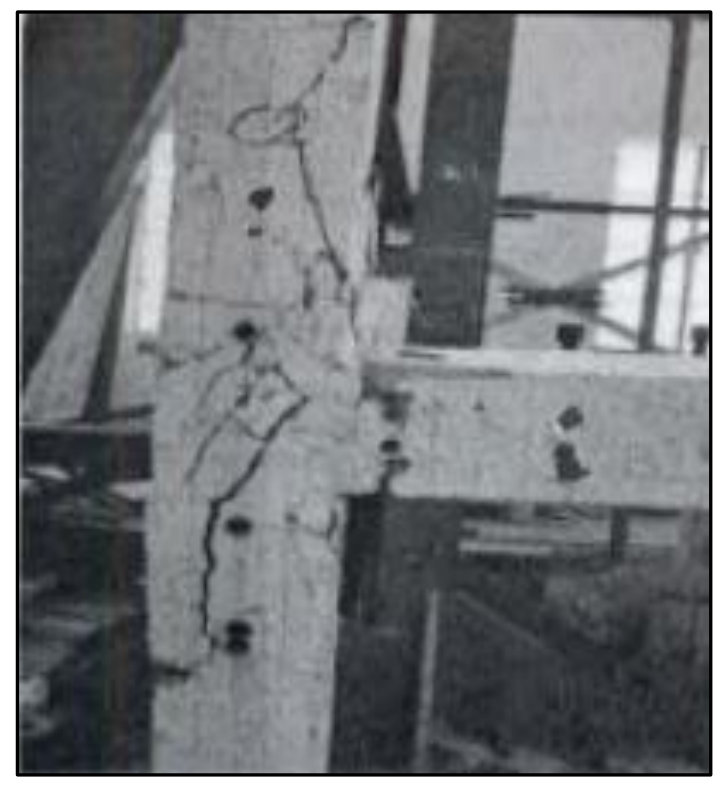

a- Beam-Column Joint without Slab

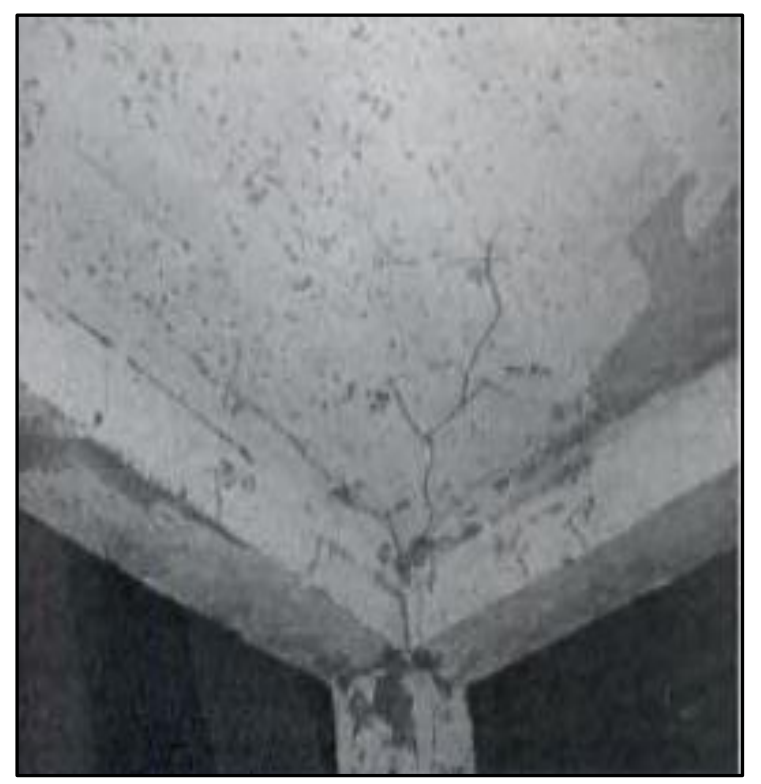

b- Beam-Column Joint with Slab

Figure 2-38 Cracks Patterns of the Specimens 


\subsection{Summary of the Literature Review}

Based on the literature review, it was clear that, many techniques and materials have been used to rehabilitate column-beam joints since 1970. Column-beam joints designed before 1970s that were used in concrete frames were the weakest link in a structure, and this weakness could cause building failure during the earthquakes because these joints were characterized by non-ductile behavior due to a lack of shear reinforcement in these regions. The first material that was as external reinforcement was steel plates as steel jackets. These jackets consisted of flat or corrugated steel plates. This technique was successful in increasing the flexural capacity within limited range by attaching the steel plates to the concrete surface with epoxy or bolts, but there were disadvantages in using it due to the cost and the availability of steel in some countries, the corrosion exposure, and the fact that it wasn't fireproof. The other technique used to change the non-ductile behavior of the beam-column joint was concrete jacketing. Many experimental tests were performed using concrete and reinforcement bars in order to confine the joints. But in the field, reinforced concrete jacketing needed an extensive labor with specialized skills. Moreover, concrete jackets increased the dimensions and the weight of the structures. More than two decades ago, the use of Fiber Reinforced Polymer (FRP) as an externally bonded reinforcement to retrofit the beam-column joint was proposed. The main feature of this material is the flexural strength. FRP composites have high strength, which makes them suitable for this purpose. The use of Fiber Reinforced Polymer (FRP) to retrofit the concrete beam-column joints offers many advantages: it is fast to apply, light weight, 
resistant to corrosion, does not affect the function of the buildings, requires simple skills to do the retrofitting, and the cost and availability are not a problem in many countries. 


\section{Chapter 3. Experimental Work}

\subsection{General}

The experimental research, including the specimens' design, materials properties, mix proportions, casting techniques, curing conditions, test setup, and instrumentation is discussed in this chapter. Experimental tests were performed in the South Greenhouse Lab at Portland State University.

\subsection{Design of Specimens}

The objective of this study was to investigate the behavior of a retrofitted concrete beamcolumn joint that was designed and constructed prior to the 1970s, with a deficiency of shear reinforcement within the joint region. Retrofitting was accomplished by using Carbon Fiber Reinforced Polymer (CFRP) sheets as an exterior bonded reinforcement. Because these types of joints are more vulnerable to failure during earthquakes, both the beam and column were designed according to ACI 318-14 to resist the gravity loads, and the shear reinforcement within the joint region was eliminated in order to ensure that the majority of the cracking and damage would occur within the joint region.

In this experimental work, six specimens in one third- scale were designed to represent a joint in a typical multi-story concrete building. Table 3-1 shows a summary of the six specimens. 
Table 3-1 Summary of Specimens

\begin{tabular}{|c|c|}
\hline Specimen & Comments \\
\hline J1 & Control Specimen, joint designed according to ACI 318-14, Chapter 18 \\
\hline J2 & Control Non-Ductile Specimen, joint designed according to old codes \\
\hline J3 & Non-Ductile Specimen Retrofitted by Using One Layer of the CFRP Sheet \\
\hline J4 & Non-Ductile Specimen Retrofitted by Using Two Layers of the CFRP Sheet \\
\hline J5 & Non-Ductile Specimen Retrofitted by Using One Layer of the CFRP Sheet \\
\hline J6 & Non-Ductile Specimen Retrofitted by Using Two Layers of the CFRP Sheet \\
\hline
\end{tabular}

All specimens contained beams 5 in. wide $\times 6$ in. deep, and square columns 5 in. $\times 5$ in. cross sections.

All specimens had identical dimensions. The general shape of the specimen was a " $T$ " shape, where the two columns connected with a transverse beam at mid height to form the exterior joint because these types of joints are more vulnerable to fail during the earthquakes.

\subsection{Details of Specimens}

The six specimens in one third scale were named as $\mathrm{J} 1, \mathrm{~J} 2, \mathrm{~J} 3, \mathrm{~J} 4$, $\mathrm{J} 5$, and $\mathrm{J} 6$ represented an exterior beam-column joint in multi-story building, and were constructed and tested under a constant axial load and cyclic flexural loading. All specimens had the same shape. The J1 specimen was different from the others in terms of the reinforcement details. The J1 specimen was designed in accordance with ACI 318-14, Chapter 18. The seismic provisions were included and were represented by using the shear reinforcement 
in the joint region and the confinement within the beam and columns. This specimen was considered as a "ductile" specimen, and the plastic hinge was expected to form in the beam since the confinement was provided by adding the closed ties in the columns and joint. Also, this joint represents one of the control specimens, and its general behavior represented the behavior of a ductile seismic joint. Figure 3-1 shows the dimensions and the reinforcement details of the specimen J1. On the other hands, the rest of the specimens $\mathrm{J} 2$, J3, J4, J5, and J6 were designed in accordance with older ACI codes (prior to 1970s) to resist the gravity loads only and the failure was expected to occur in the joints due to lack of confinement in the joint. Specimen J2 represented a control specimen J2, and represented the behavior of the non-ductile joint. Figure 3-2 shows the dimensions and the reinforcement details of the specimens $\mathrm{J} 2$.

The beam had a cross section of $5 \times 6$ in and the transverse beam length was $20 \mathrm{in}$, whereas the column section had a cross section of $5 \times 5$ in and the total length of the column was 46 in where the beam connected to the column at the mid-height to form the joint. 


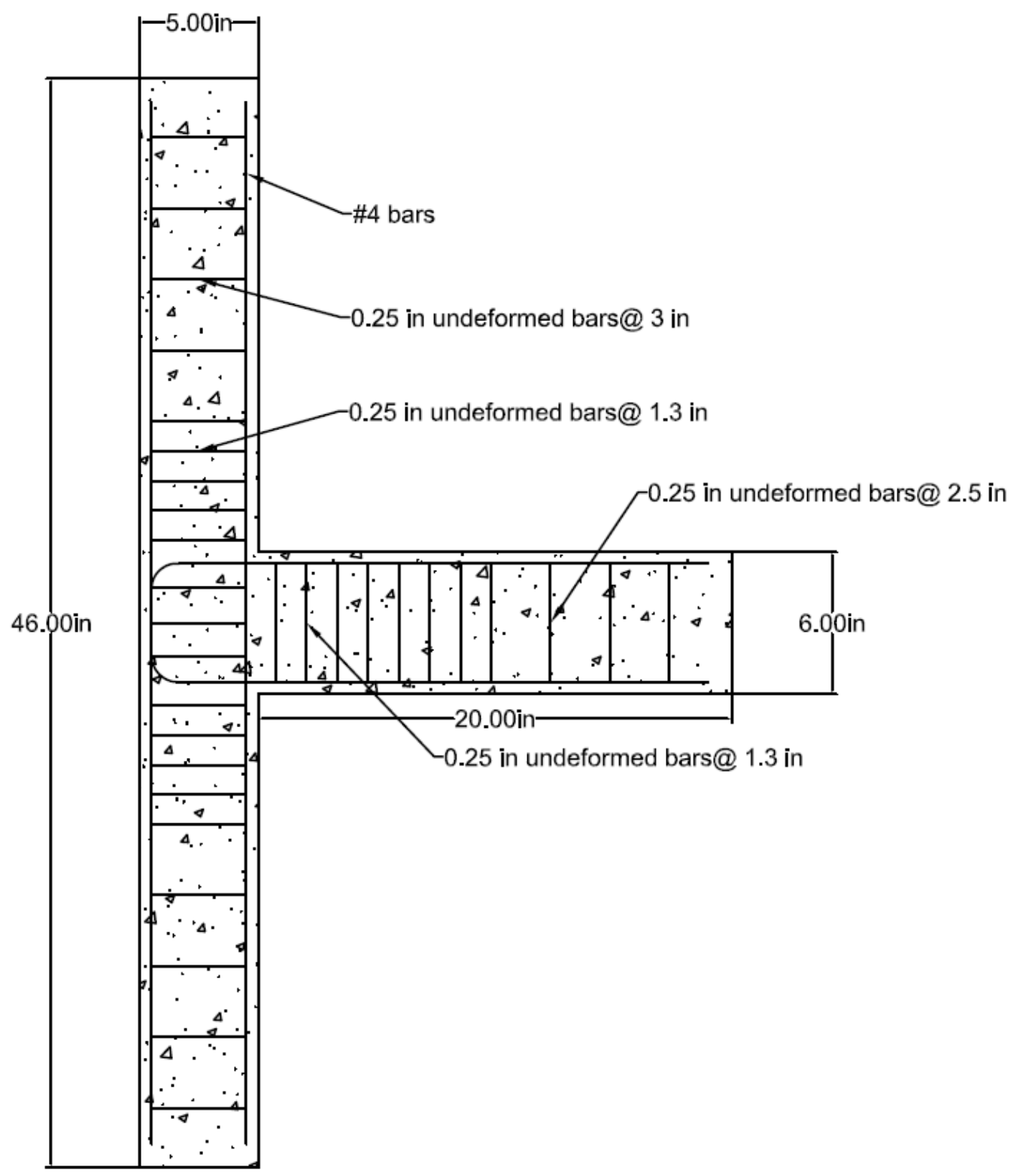

Figure 3-1 Details of Specimen J1, the "Ductile" Specimen 


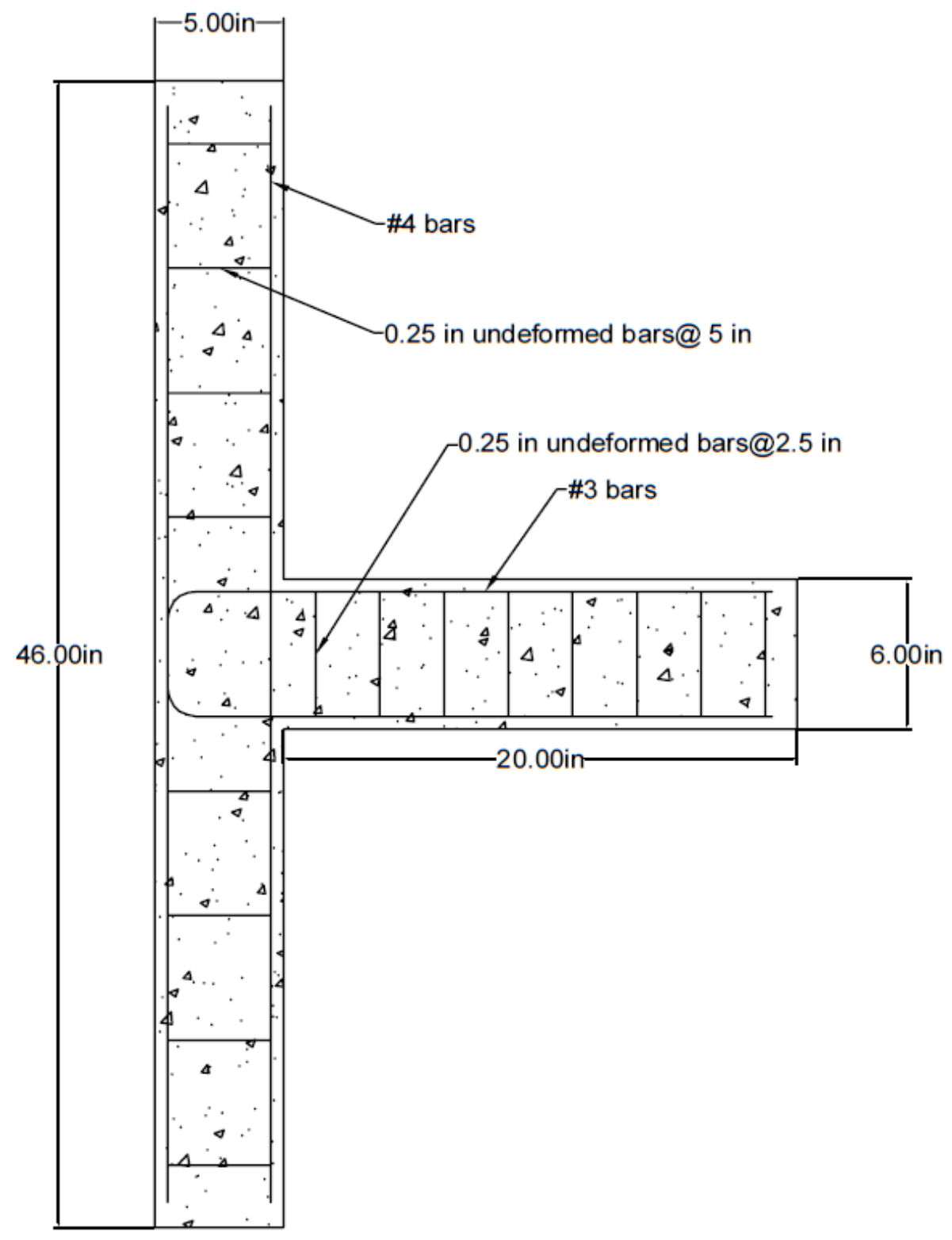

Figure 3-2 Details of Specimen J2, Non-ductile Specimen 


\subsection{Materials}

\subsubsection{Cement}

Ordinary Portland Cement Type (II) provided by (Mason Supply Company) was used throughout this study. It was stored in air-tight plastic container at the Greenhouse Lab to avoid exposure to humidity.

\subsubsection{Fine and Coarse Aggregate}

Sand from Mason Supply was used. The grading of the sand is shown in Table 3-2. Uncrushed gravel with maximum size $3 / 8$ in. was used. The grading of coarse aggregate is shown in Table 3-3.

\section{Table 3-2 Sieve Analysis of Sand}

\begin{tabular}{|c|c|c|}
\hline No. & Sieve size & \% passing of coarse aggregate \\
\hline 1 & $4.75 \mathrm{~mm}$ sieve (\#4) & $97.81 \%$ \\
\hline 2 & passing $2.00 \mathrm{~mm}(\# 10)$ & $84.67 \%$ \\
\hline 3 & $0.85 \mathrm{~mm}(\# 20)$ & $72.99 \%$ \\
\hline 4 & $0.425 \mathrm{~mm}(\# 40)$ & $49.64 \%$ \\
\hline 5 & $0.150 \mathrm{~mm}(\# 100)$ & $5.11 \%$ \\
\hline 6 & $0.075 \mathrm{~mm}(\# 200)$ & $0.73 \%$ \\
\hline
\end{tabular}


Table 3-3 Sieve Analysis of Gravel

\begin{tabular}{|c|c|c|}
\hline No. & Sieve size & \% passing of coarse aggregate \\
\hline 1 & $19 \mathrm{~mm}(0.75 \mathrm{in})$. & $100 \%$ \\
\hline 2 & $12.5 \mathrm{~mm}(1 / 2 \mathrm{in})$. & $99.36 \%$ \\
\hline 3 & $4.75 \mathrm{~mm}(3 / 8 \mathrm{in})$. & $1.32 \%$ \\
\hline 4 & $4.25 \mathrm{~mm}(\# 4)$ & $0.54 \%$ \\
\hline
\end{tabular}

\subsubsection{Mixing Water:}

Tap water was used to cast and cure all specimens during the 28 maturation period.

\subsection{Steel Reinforcement:}

The longitudinal bars in all of the specimens were deformed bars grade 60 , and were represented by \#4 bars as longitudinal reinforcement in the column, and \#3 bars as longitudinal reinforcements in the beam in each specimen. Steel bar size \#2 (0.25 in. diameter unreformed) was used as a transverse reinforcement in both beam and column in each specimen. Tensile tests were performed on three samples of each bar size to determine the reinforcing steel mechanical properties. The tensile strength and modulus of elasticity were obtained by testing $3 \mathrm{ft}$ specimens according to ASTM for \#3 and \#4 bars and 9 in. for \#2 bars. For \#3 and \#4 specimens, the specimens were prepared with strain gages at the middle to obtain the tensile stress-strain diagram, and tests were performed using MTS machine in the iSTAR laboratory. The \#2 bar specimens were 
tested in the Infrastructure Materials Lab, Room 370 in the Engineering Building at PSU.

Table 3-4 shows the steel properties. Figure 3-3 shows stress-strain diagrams of bars.

Table 3-4 The Reinforcing Steel Mechanical Properties

\begin{tabular}{|c|c|c|c|c|c|}
\hline Bar size & Diameter (in) & Area (in $\left.{ }^{2}\right)$ & $f y(\mathrm{Ksi})$ & $\varepsilon y$ & Es \\
\hline \#4 bar & $0.375(3 / 8)$ & 0.11 & 74 & 0.0027 & 27407 \\
\hline \#3 bar & $0.5(4 / 8)$ & 0.4 & 74 & 0.0027 & 27407 \\
\hline Wire gage (0.25 in.) & 0.25 & 0.049 & 38 & 0.00214 & 20416 \\
\hline
\end{tabular}



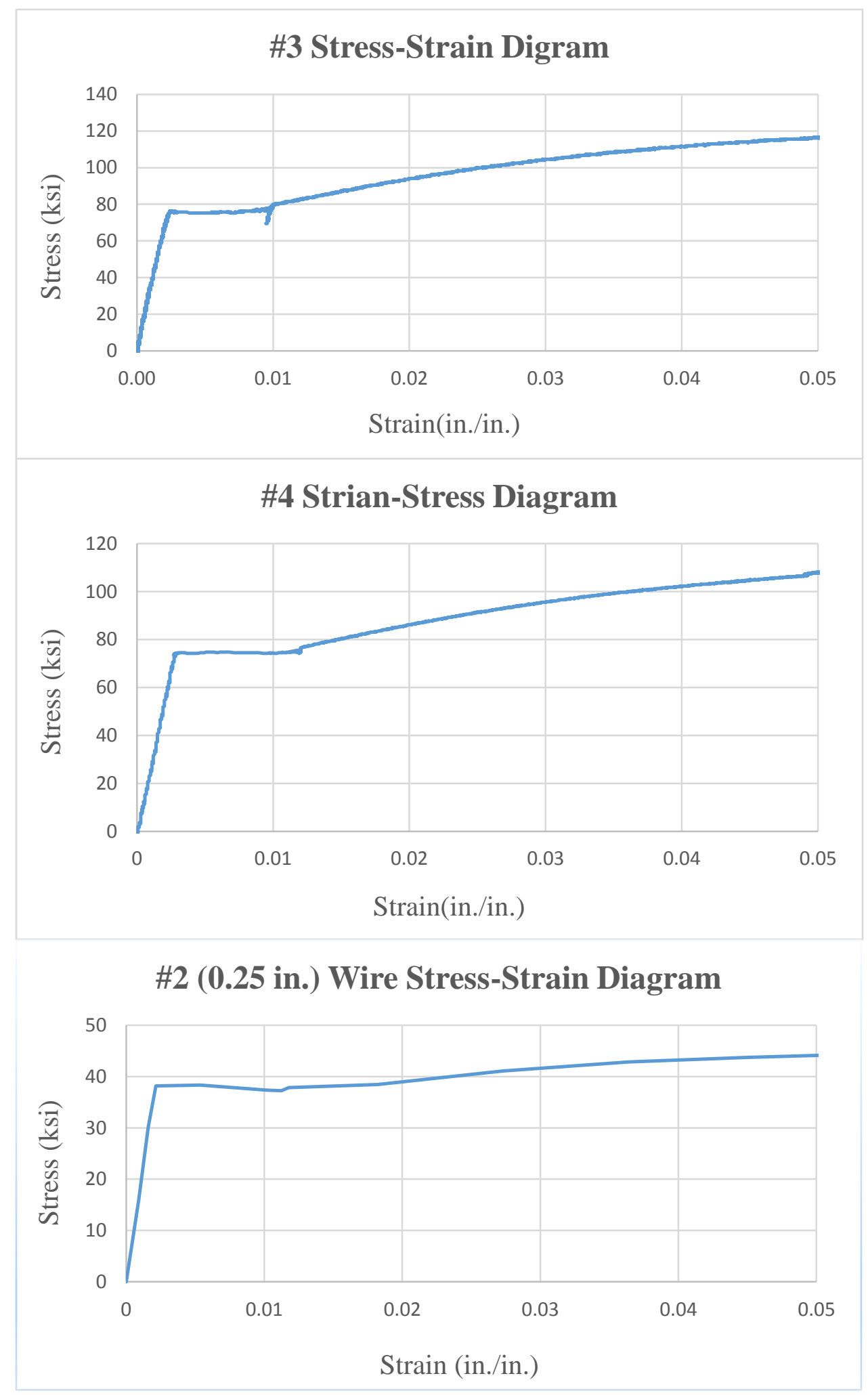

Figure 3-3 Stress-Strain Diagrams of the Reinforcement Bars 
Since the design represented an external beam-column joint, the longitudinal reinforcement of the beam was bent at the ends at the intersection region between the beam and the column where the upper rebar bent down and the lower rebar bent up. The hook length was 6 in. according to the ACI 318-14 as shown in Figure 3-4.

\section{STANDARD HOOK DETAILS in accordance with $\mathrm{ACl} 318$ Building Code \\ All gredes of steal (minimum yeid strengths)}

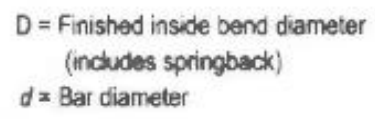

$\mathrm{ACl} 318 \mathrm{~min}$ bend diameter: $6 d$ for $\# 3$ through $\# 8$ $8 d$ for $\# 9$, \#10 and $\$ 11$ $10 d$ for $\# 14$ and $\# 18$
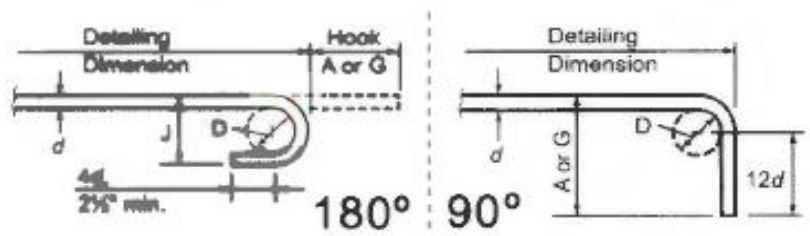

RECOMMENDED END HOOK DIMENSIONS

\begin{tabular}{|c|c|c|c|c|c|}
\hline \multirow{2}{*}{$\begin{array}{l}\text { BAR } \\
\text { SIZE }\end{array}$} & \multirow[b]{2}{*}{ D } & \multicolumn{2}{|c|}{$180^{\circ}$ HOOKS } & \multirow{2}{*}{$\begin{array}{c}90^{\circ} \text { HOOKS } \\
\text { A or G }\end{array}$} & \multirow{3}{*}{ Used end hooked } \\
\hline & & $A$ or $G$ & $J$ & & \\
\hline 43 & $2 \%^{*}$ & 0.5 & $0 \cdot 3^{-}$ & $0^{\circ}-6^{-}$ & \\
\hline 4 & $3-$ & $0^{\circ} \cdot 6^{-}$ & 0.4 & 0.8 & \\
\hline$\# 5$ & $3 \%$ & $0:-7$ & $0^{\circ}-5^{\prime}$ & $0^{\circ}-10^{\circ}$ & \\
\hline \#6 & $4 \%-$ & $0 .-8$ & $0.6-$ & $1: 0^{-}$ & \\
\hline$\% 7$ & $51 / 4^{-}$ & $0^{\circ}=10^{-}$ & $0: 7$ & $1^{\prime}=2^{\prime \prime}$ & \\
\hline \#8 & $\theta^{-}$ & $0.11^{\prime}$ & $0.8^{2}$ & $1=4^{-}$ & \\
\hline *9 & $9 \%$ & $1 \div 3^{-}$ & $0:-11 \%$ & $1^{\prime}=7^{\prime}$ & \\
\hline$\# 10$ & $10 \%=$ & $1-5$ & $1 \cdot 11 / 4$ & $1 \cdot-10^{\prime}$ & \\
\hline *11 & $12^{\prime}$ & $1 \div 7$ & $1.2 \% \%^{2}$ & $2^{\prime} \cdot 0^{-}$ & \\
\hline$* 14$ & $18 \%^{-}$ & $2 \cdot 3^{-}$ & $1 \cdot 9 \%=$ & $2 \cdot 7^{\prime}$ & \\
\hline$* 18$ & 24 & $3.0^{\circ}$ & $2-4 \%-$ & $3 \div-5$ & \\
\hline $\begin{array}{l}\text { STEEL } \\
\text { TYPE }\end{array}$ & $\begin{array}{l}\text { BAR SIZE } \\
\text { RANGE }\end{array}$ & GRADE & $\begin{array}{l}\text { MINIMUM } \\
\text { YIELD (ksi) }\end{array}$ & $\begin{array}{c}\text { MINIMUM } \\
\text { TENSILE (ksi) }\end{array}$ & \\
\hline \multirow{4}{*}{$\begin{array}{l}\text { Carbon } \\
\text { A615 }\end{array}$} & \multirow{2}{*}{$\# 3-\# 6$} & 40 & 40 & 60 & \\
\hline & & 60 & 60 & 90 & \\
\hline & $43-11$ & 75 & 75 & 100 & \\
\hline & $* 3-\# 18$ & 80 & 80 & 105 & \\
\hline \multirow{2}{*}{$\begin{array}{l}\text { Low-Alloy } \\
\text { A706 }\end{array}$} & $* 3-* 18$ & 60 & 60 & 80 & \\
\hline & $13-18$ & 80 & 80 & 100 & \\
\hline \multirow{3}{*}{$\begin{array}{c}\text { Rail \& Axle } \\
\text { A996 }\end{array}$} & *3- & 40 & 40 & 70 & \\
\hline & $43-18$ & 50 & 50 & 80 & \\
\hline & $* 3-* 8$ & 60 & 60 & 90 & \\
\hline
\end{tabular}

Figure 3-4 End Hook Dimensions 
Figures 3-7 to 3-10 show the reinforcement details of all specimens that had been designed and tested throughout this experimental work. The longitudinal reinforcement bars in all specimens were the same, and the differences between the specimens were represented by the spacing between the transverse reinforcement bars and the stirrup's end hook details. In the non-seismic specimens, the space between the ties in the column was 5 in., and the space between the stirrups in the beam was 2.5 in. In seismic specimen, the space between the ties in the column within the confinement length was $1.3 \mathrm{in}$. and 3 in. out the confinement length. The space between the stirrups in the beam within the confinement length (hinge zone) was 1.3 in. and 2.5 in. outside of the confinement length. Figure 3-5 shows the details of shear reinforcement in seismic and non-seismic specimens where the length of hooked ends was equal to $6 \mathrm{~d}_{\mathrm{b}}$.
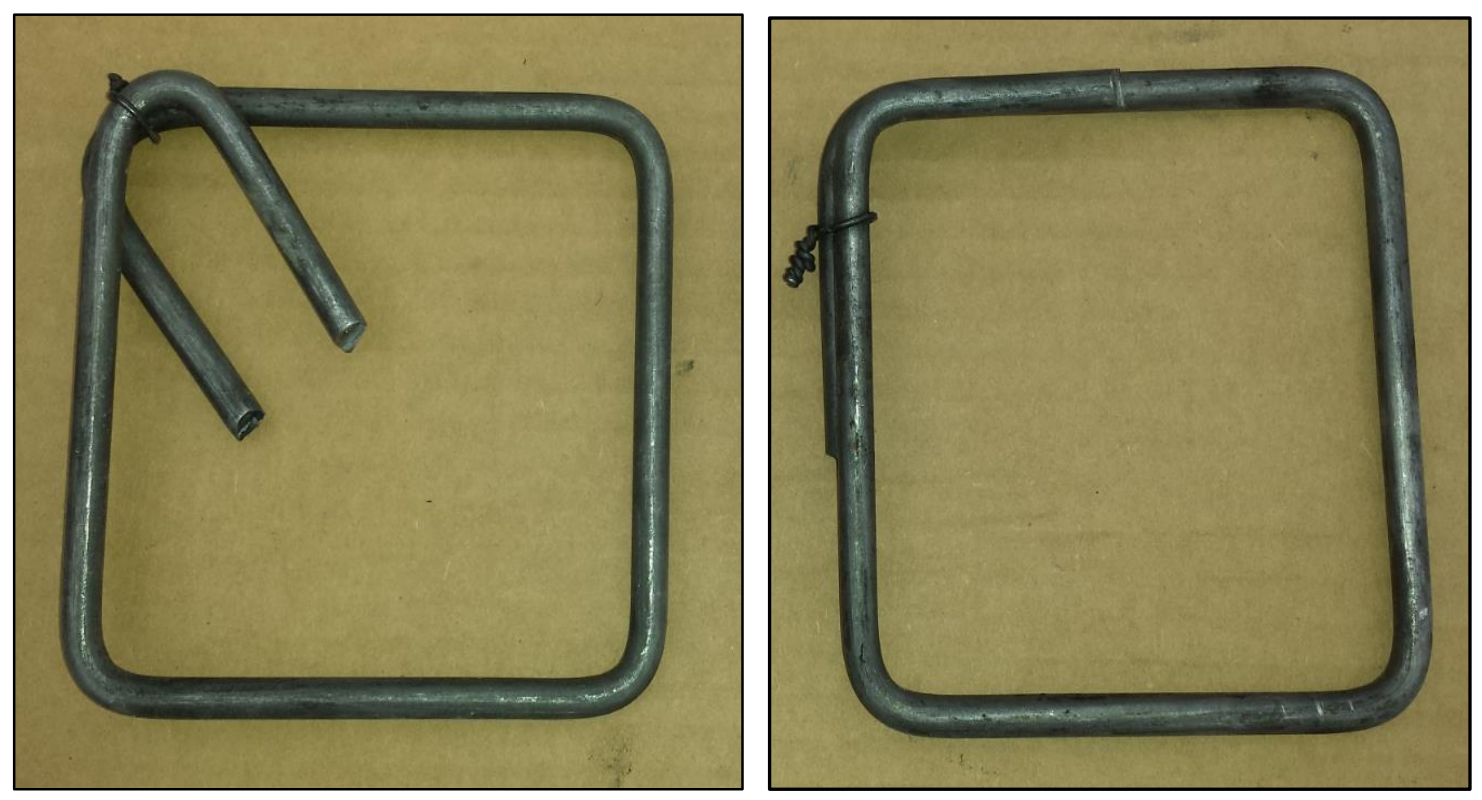

Figure 3-5 The Difference between Shear Reinforcement in Seismic and Non-Seismic Specimens 
In order to avoid unexpected failure by lack of development length, a special " $U$ " shape \#3 rebar was used at the end of the longitudinal beam rebar to insure that this bar would develop the tensile strength as shown in the Figure 3-6.

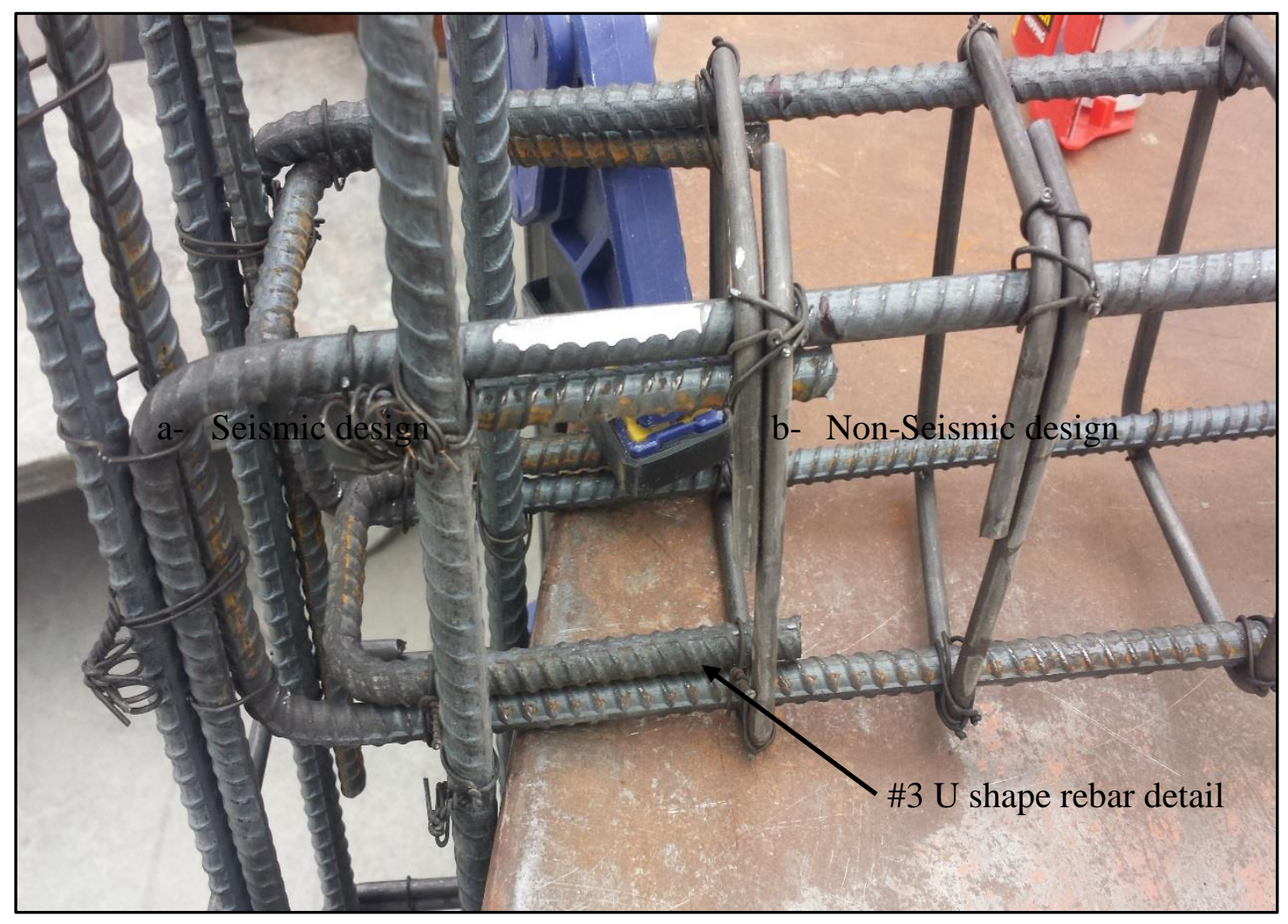

Figure 3-6 "U” Shape Rebar Detail 


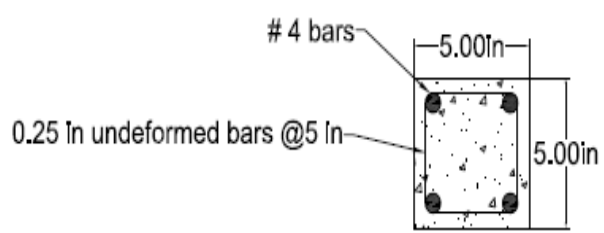

column section

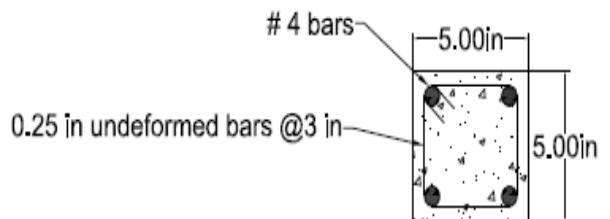

column section out the confinement length

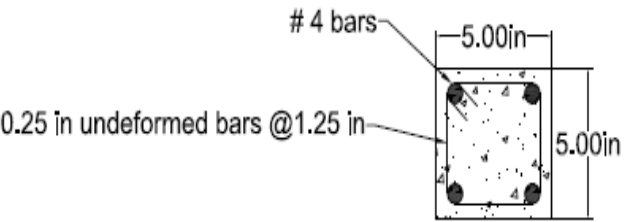

column section within the confinement length

Section details of Non-seismic column

Section details of seismic column

Figure 3-7 Column Section Details
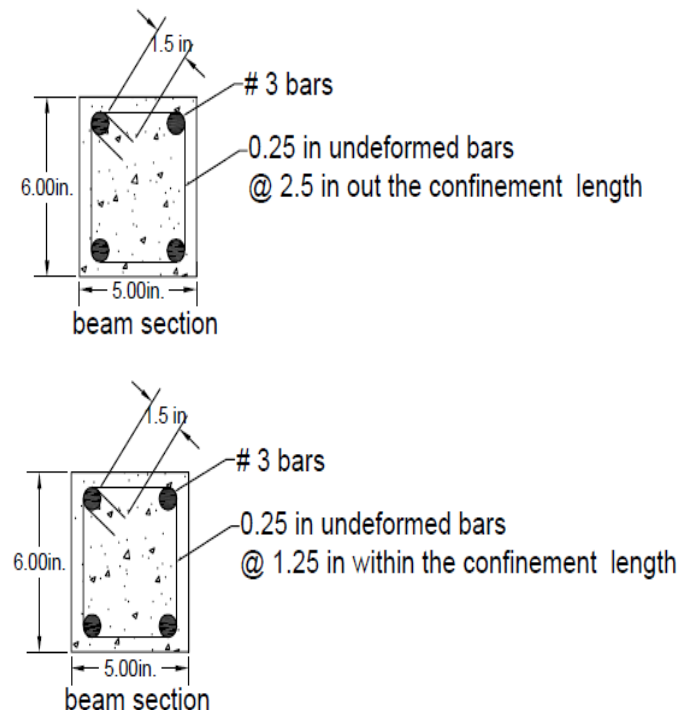

Section details of seismic beam

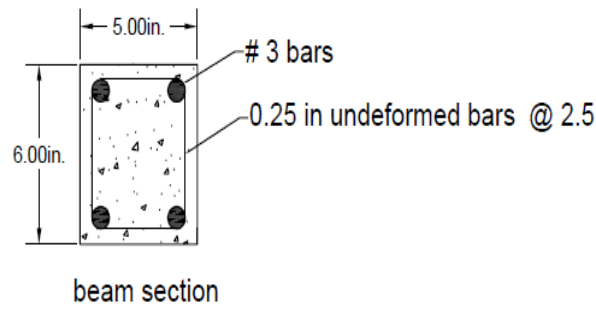

beam section

Section details of non-seismic beam

Figure 3-8 Beam Section Details 


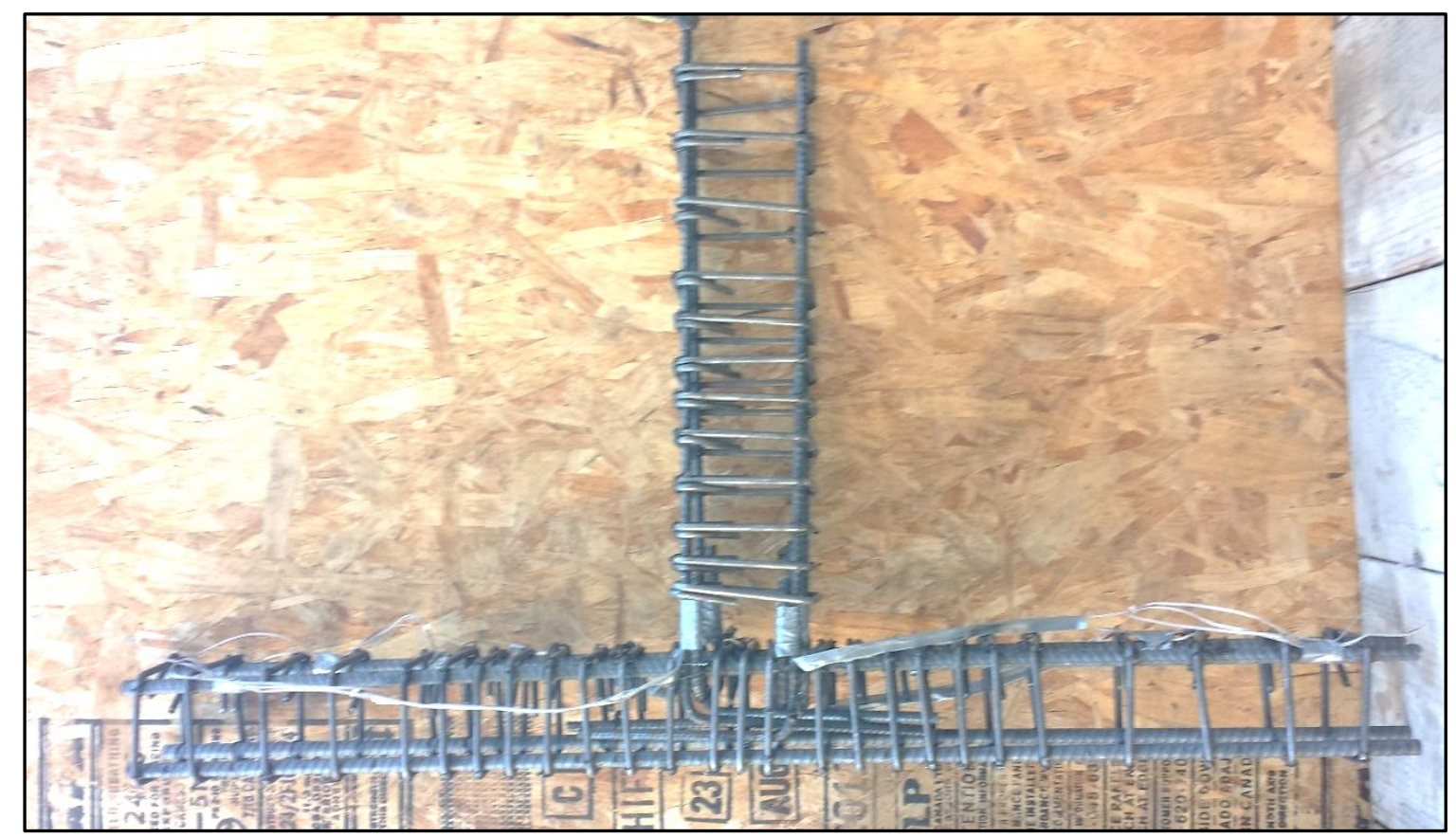

Figure 3-9 Reinforcement Cage of Specimen J1

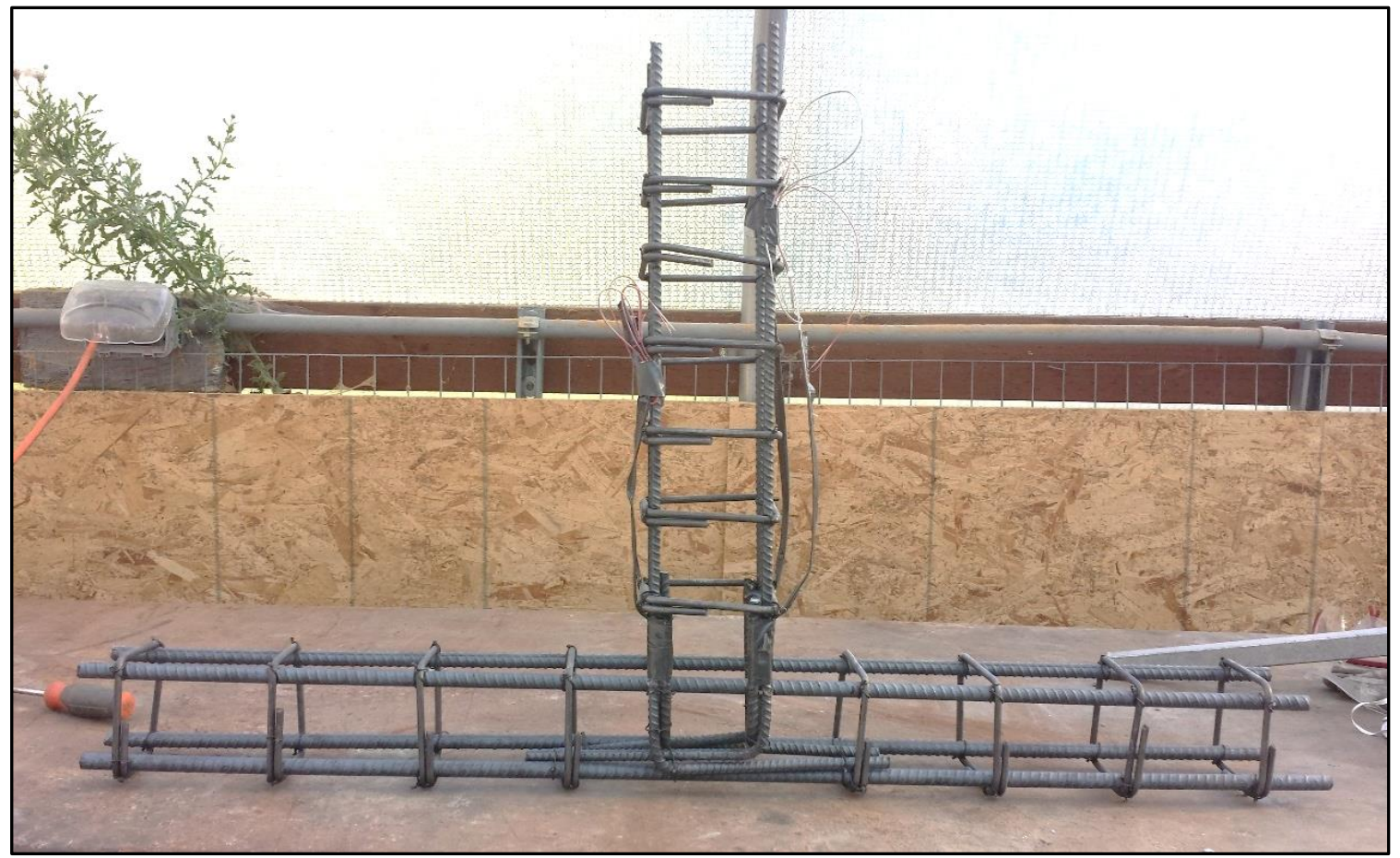

Figure 3-10 Reinforcement Cage of Specimen J2 


\subsection{Strain Gages}

When the reinforcement cages were ready, for the control specimens $\mathrm{J} 1$ and $\mathrm{J} 2$, four steel strain gages were attached to the beam longitudinal reinforcement of each one. The strain gage types "KFH-20-120-C1-11L1M2R" were purchased from Omega Engineering, Inc. The properties of these strain gages as provided by the company are shown in Table 3-5. Steel bar surface preparation was done by using a manual grinder and sand paper to ensure that the proper bonding of the strain gage was done perfectly. Epoxy glue was used to attach the strain gages to the steel bars, then duct tape was used to wrap both the strain gages and bars to protect them. A voltmeter was used to check these strain gages regularly to detect any potential problem before the casting of the concrete. There were six steel strain gages in each of retrofitted specimens. Four steel strain gages were attached to the beam longitudinal reinforcement, and the other two gages were attached directly to the Carbon Fiber Reinforced Polymer (CFRP) sheets (one on each side of the joint) in order to measure the CFRP strain up to the failure. Figures 3-11 and 3-12 show strain gage locations, preparation and attaching.

Table 3-5 Strain Gage Properties

\begin{tabular}{|c|c|c|c|}
\hline Strain Gage Types & Resistance & Gage Factor (K) & Transverse \\
& & & Sensitivity \\
\hline KFH-20-120-C1-11L1M2R & $120.4 \Omega \pm 0.35 \%$ & $2.07 \pm 1.0 \%$ & $-0.6 \%$ \\
\hline
\end{tabular}




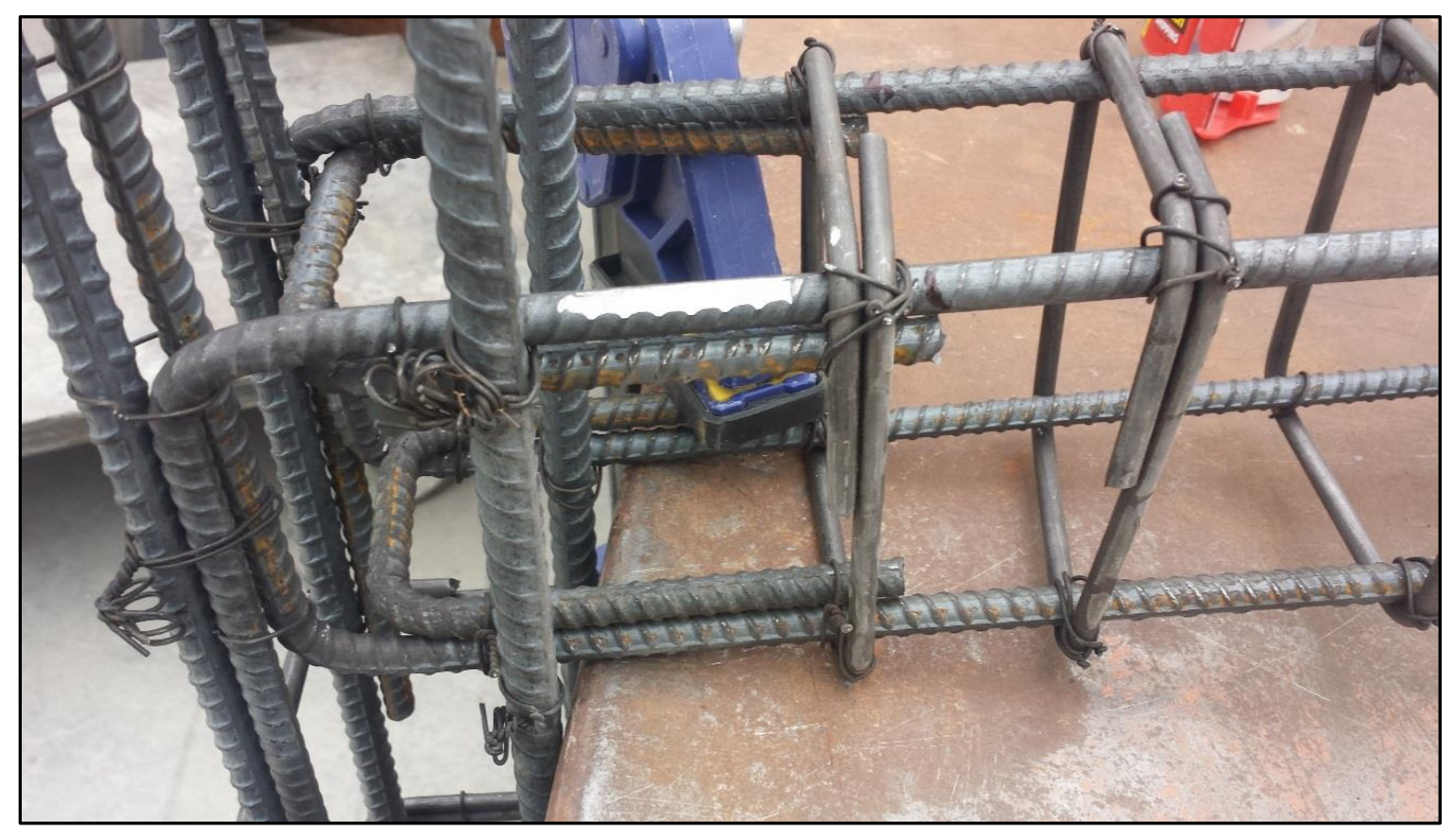

a- Surface Preparation

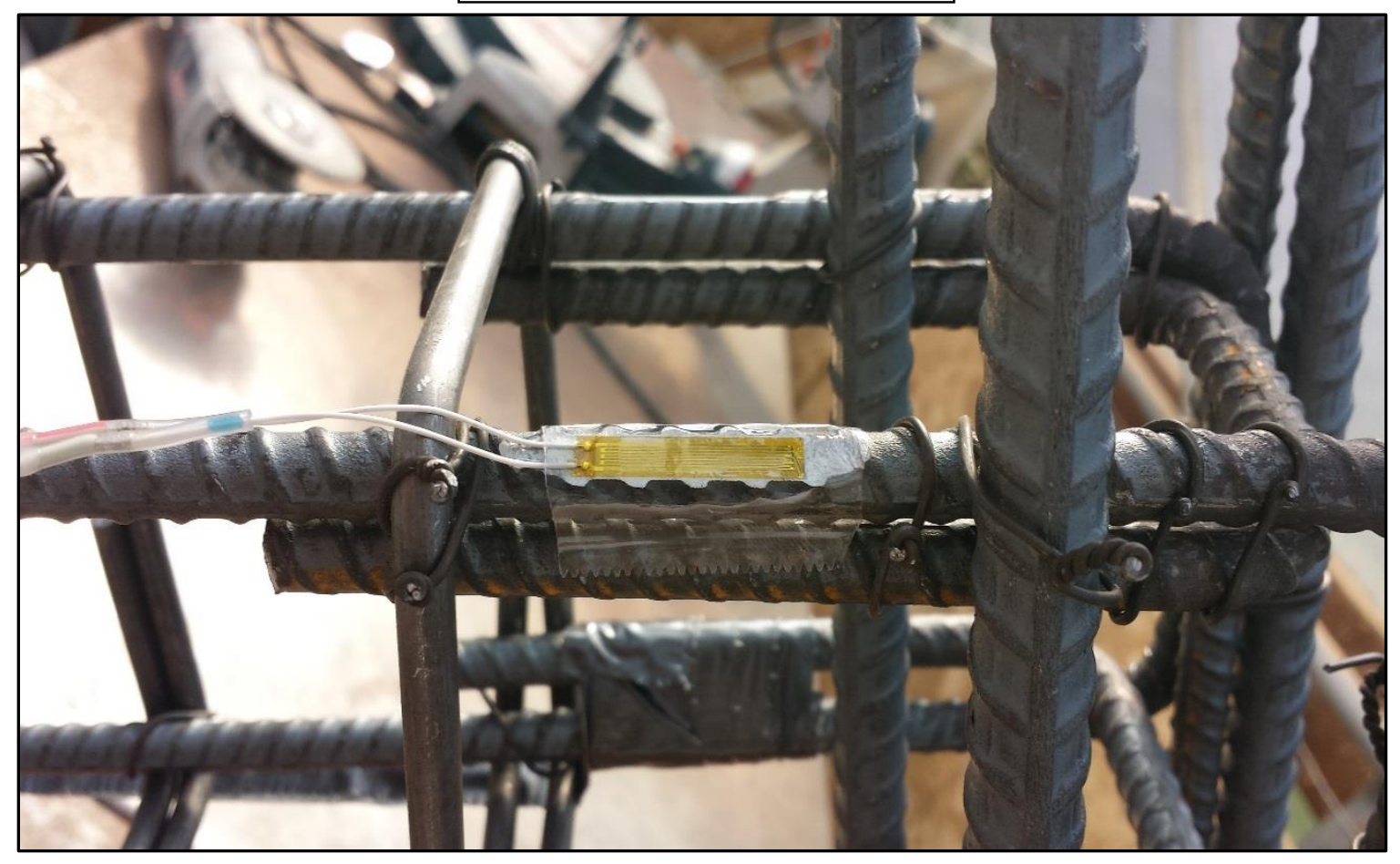

b- Strain Attachment

Figure 3-11 Strain Gage Instullation 


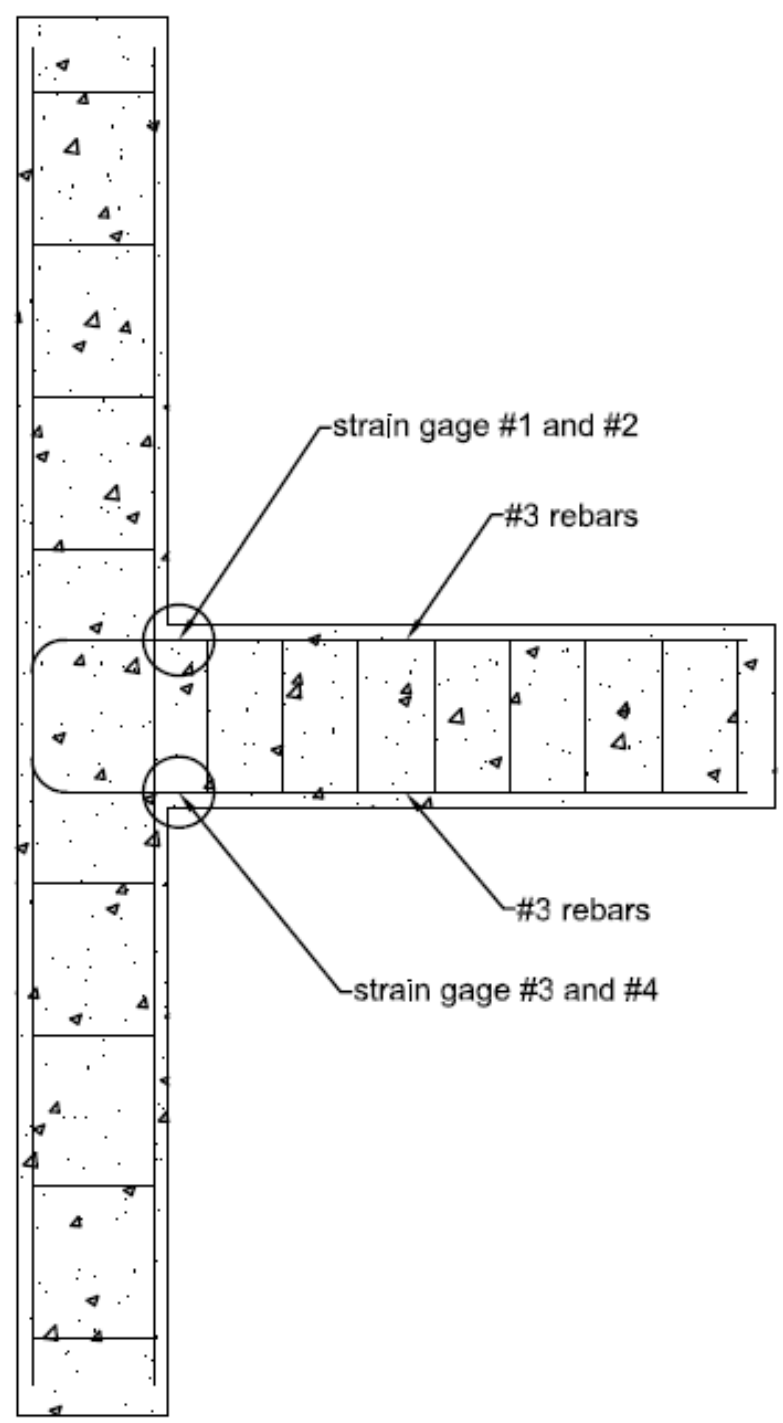

Figure 3-12 Strain Gage Locations 


\subsection{Molds}

Six wood molds were used to cast all of the specimens, all at one time at the Greenhouse Lab. The molds were manufactured from 1.5 in. thickness lumber purchased from Home Depot Inc. Figure 3-13 shows one of these molds. In order to avoid any unnecessary drainage of the water during the casting process, these molds were cleaned by an air compressor and then (DAP) waterproof silicone was used to fill the joints in the molds.

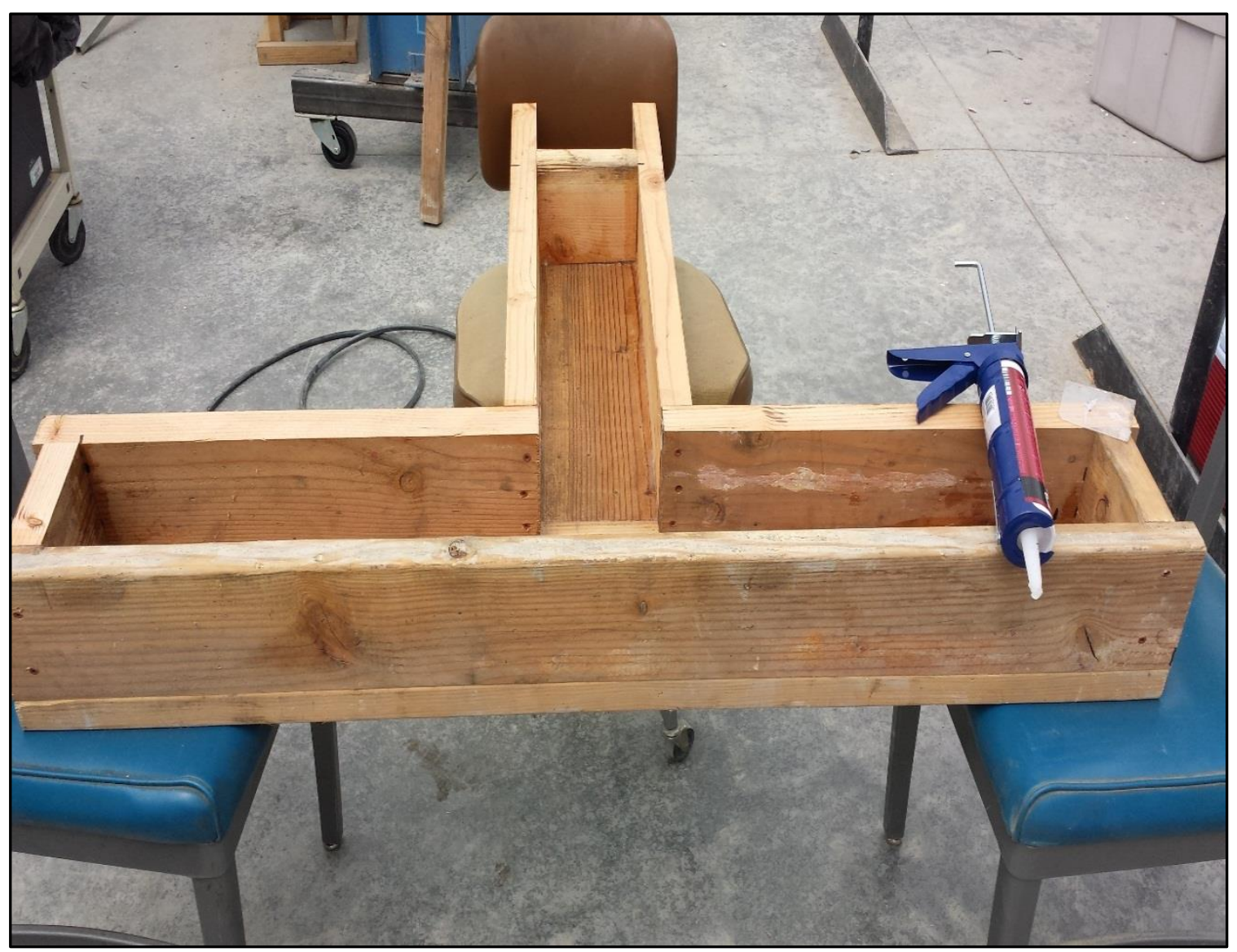

Figure 3-13 Wood Molds 


\subsection{Properties of Concrete:}

The concrete mix was designed in accordance with the Design and Control of Concrete Mixture, 14th Edition, Portland Cement Association (PCA). The mix was designed for a compressive strength of $3000 \mathrm{psi}$ at 28-day of age. Mixtures details are given in Table 36.

Table 3-6 Properties of Mixture with 3000 Psi Compressive Strength

\begin{tabular}{|c|c|c|}
\hline No. & Parameter & Weight $\left(\mathrm{Ib} \mathrm{per} \mathrm{ft}^{3}\right)$ \\
\hline 1 & Water / cement ratio & 0.67 \\
\hline 2 & Water $\left(\mathrm{Ib} / \mathrm{ft}^{3}\right)$ & 12 \\
\hline 3 & Cement $\left(\mathrm{Ib} / \mathrm{ft}^{3}\right)$ & 18 \\
\hline 4 & Sand $\left(\mathrm{Ib} / \mathrm{ft}^{3}\right)$ & 61 \\
\hline 5 & & 46 \\
\hline
\end{tabular}

\subsection{Concrete Mixing Procedure}

When the wood molds were ready, the reinforcement cages were placed inside of the molds. All of the molds were then placed in the front yard of the lab on the ground as shown in Figure 3-14. A concrete mixer of $2.25 \mathrm{ft}^{3}$ capacity available in the South Greenhouse Lab was used. The interior surface of the mixer was cleaned and moistened before placing the materials inside. While the mixer was running, half of the coarse aggregates were put in, and then the water was added to the aggregate. After 30 seconds, 
the cement was added to the mixture followed by half of the sand amount. One and a half minutes later, the rest of the coarse aggregate was added and same procedure was repeated. After all of the materials were put into the mixer, it took about three minutes for the mixture to be ready for slump test, which was done in order to check the workability of the mixture before casting the concrete in molds. The desired slump was 7-8 in., which was achieved by the mixtures. 


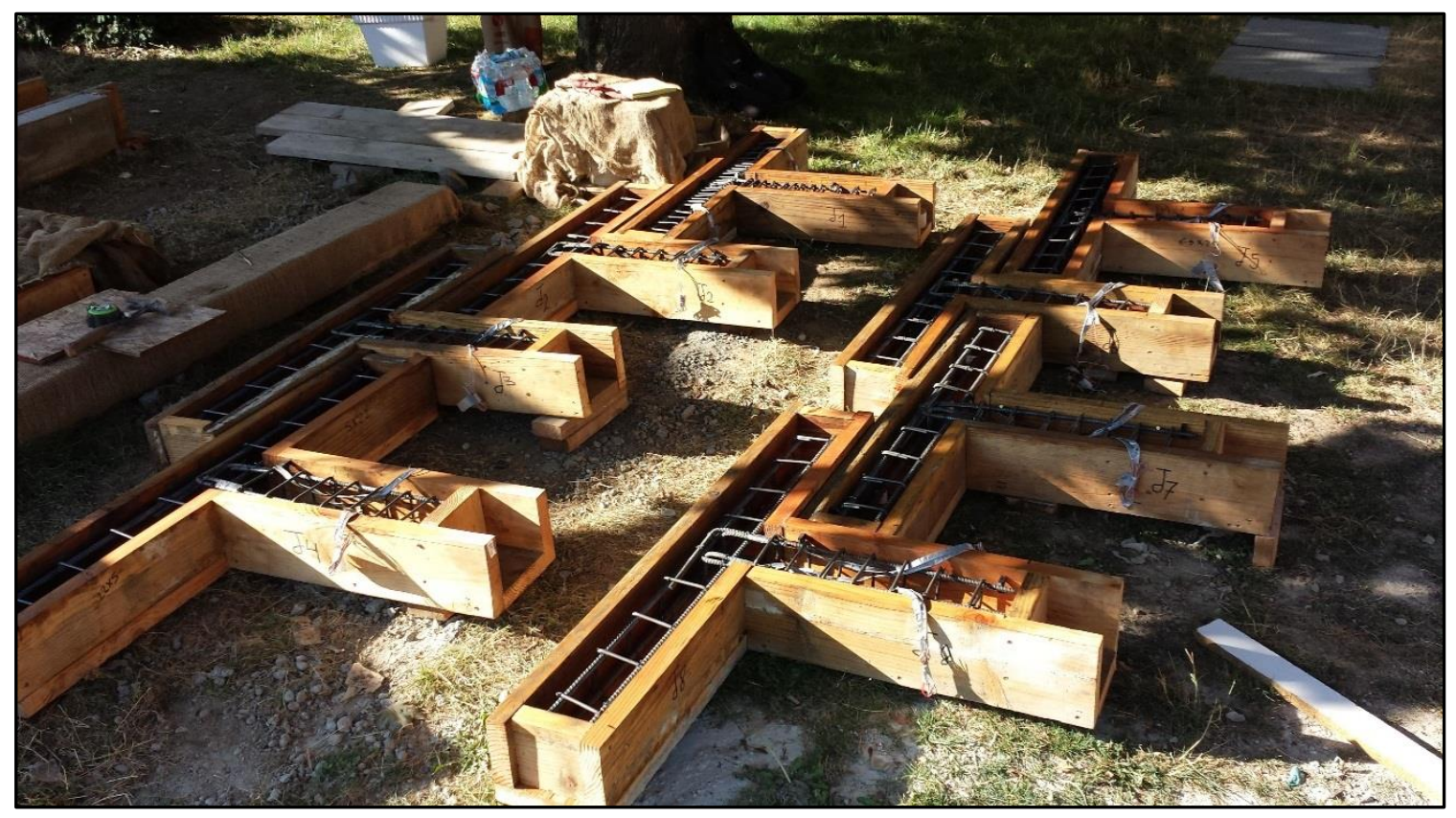

a- Preparing the molds for casting

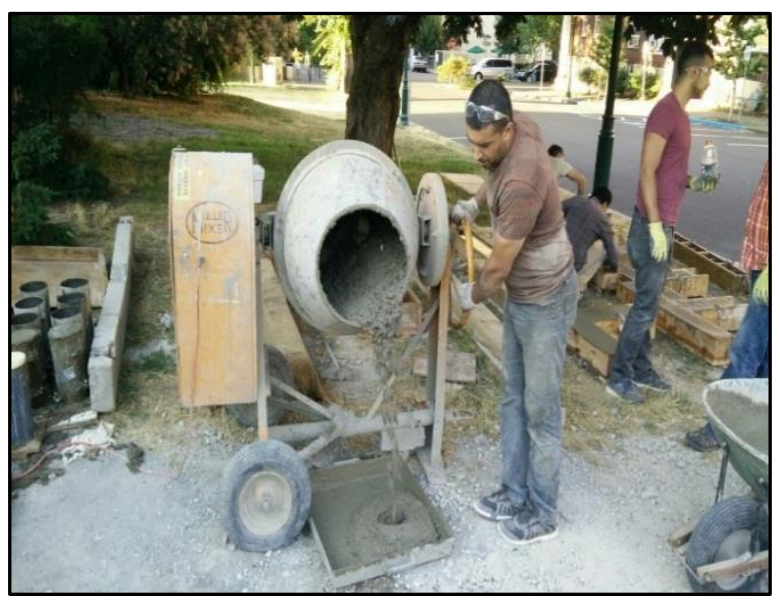

b- Mixing

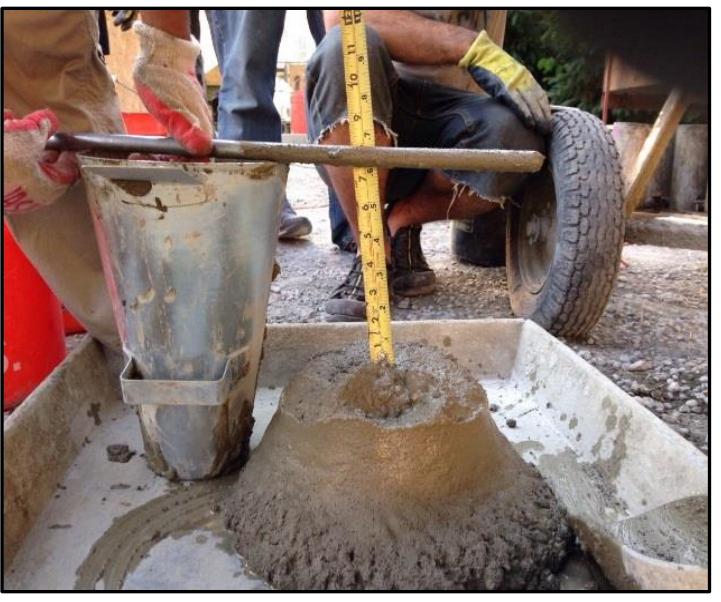

c- Slump test

Figure 3-14 Concrete Mixing Steps 


\subsection{Curing Age of Specimens}

The temperature was $99 \mathrm{~F}^{\circ}$ at casting time and the humidity was 55\%. Right after casting the specimens and cylinders, three layers of natural burlap and one layer of plastic sheets were used to cover all specimens in order to keep the moisture as long as possible. After five days, the wood molds were removed and all of the cylinders and flexural samples were placed beside the specimens to subject them to the same weather conditions as shown in Figure 3-15. Tap water was used to spray the specimens twice a day. This process continued up to first month age of specimens then the curing depended on the humidity of the atmosphere where all of the specimens and cylinders were placed inside the Greenhouse Lab.

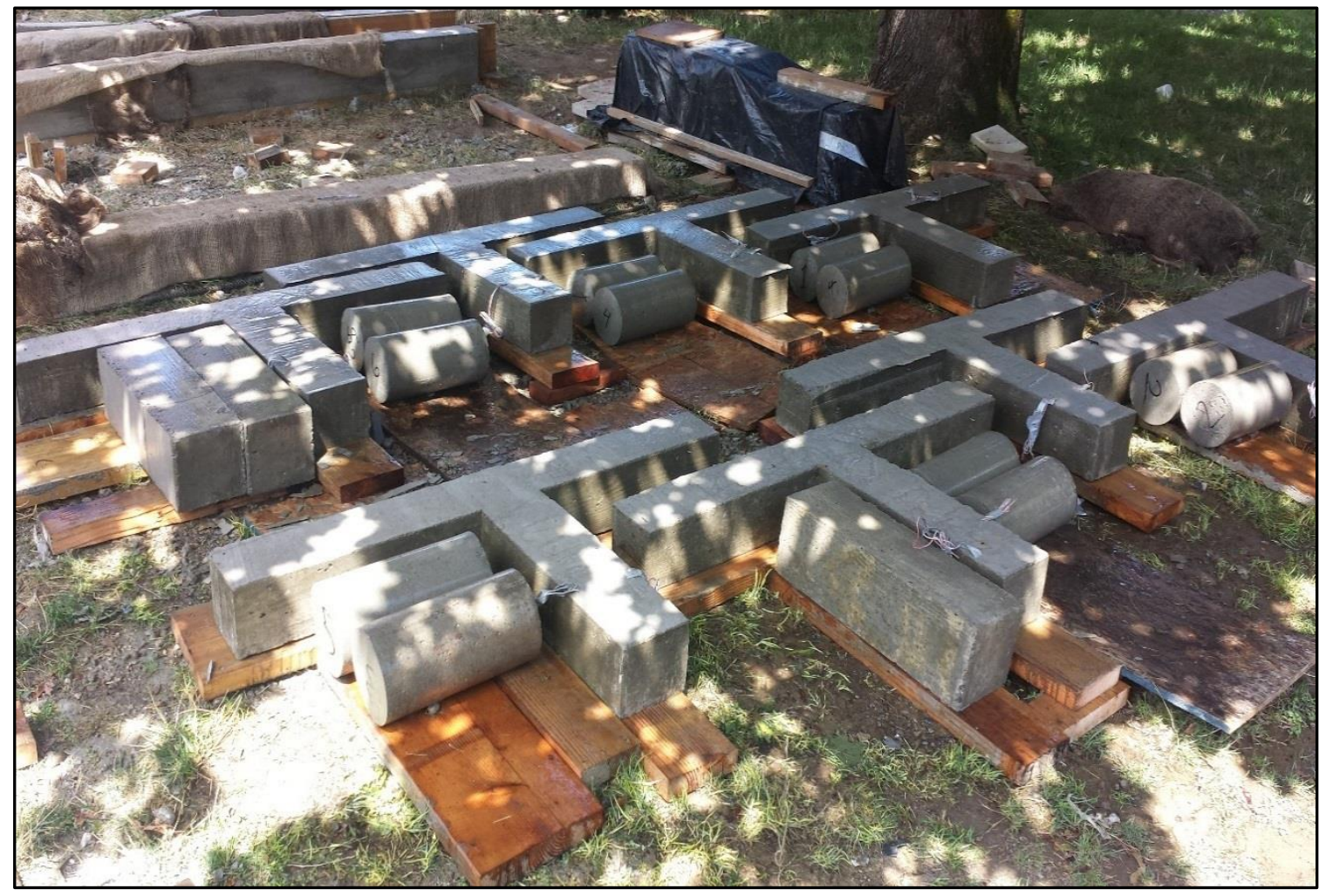

Figure 3-15 Curing Condition of Specimens 


\subsection{Mechanical Properties of the Hardened Concrete}

\subsubsection{Compressive Strength Testing}

The compressive strength of concrete was carried out in accordance with ASTM-C39 using $6 \times 12$ in. concrete cylinders loaded uniaxial by a compressive strength machine as shown in Figure 3-16. This was available at South Greenhouse Lab where the maximum compressive capacity of the machine is 250 kips. For each specimen, one cylinder was tested on the same day of the test. The results are given in Table 3-7.

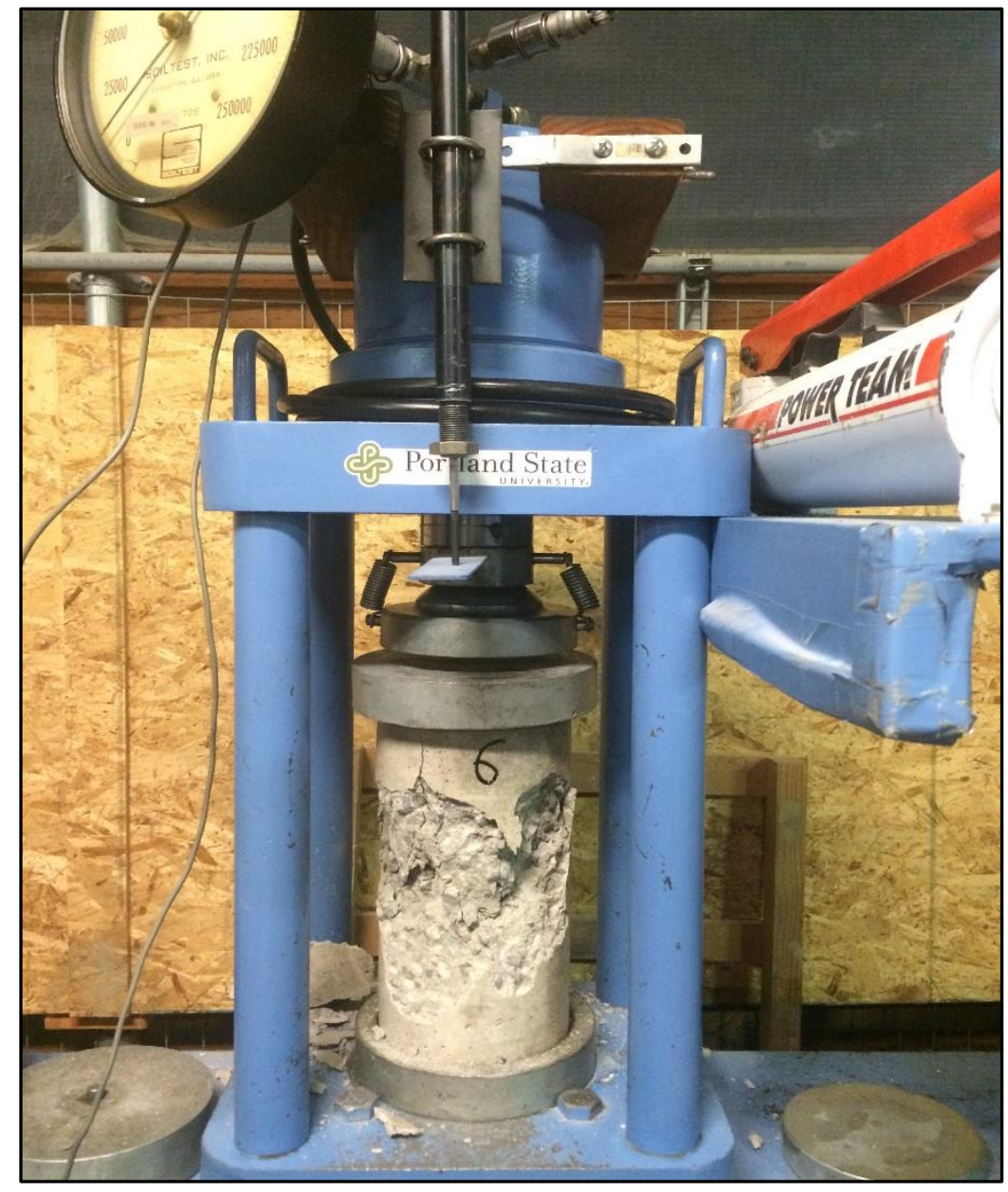

Figure 3-16 Compressive Testing Machine 
Table 3-7 Concrete Compressive Strength of the Specimens

\begin{tabular}{|c|c|c|c|}
\hline No. & Age of the Test (day) & Compressive Peak Load (kips) & Compressive Stress (ksi) \\
\hline 1 & 29 & 80.35 & 2.80 \\
\hline 2 & 39 & 91 & 3.14 \\
\hline 3 & 96 & 124.9 & 4.4 \\
\hline 4 & 110 & 126 & 4.46 \\
\hline 5 & 145 & 124 & 4.4 \\
\hline 6 & 150 & 1125 & 4 \\
\hline
\end{tabular}

\subsubsection{Flexural Strength}

Flexural strength (modulus of rupture) tests were carried out on three normal concrete specimens in accordance with ASTM- C 78. These specimens were casted and cured under the same conditions as the main specimens at the Greenhouse Lab and were tested after 42 days. The flexural strength tests are made on $6 \times 6 \times 18$ in. simple beam specimens loaded at third points. The experimental results are shown in Table 3-8 where all of the failures occurred within the middle third of span length of the beams as shown in Figure 3-17. Moreover, Table 3-8 also shows the comparison between the experimental and theoretical results. The theoretical calculations were done by using the ACI 318 equation:

$f_{r}=7.5 \lambda \sqrt{f^{\prime}{ }_{c}}$ 
Table 3-8 Modulus of Rupture of the Concrete

\begin{tabular}{|c|c|}
\hline Specimen No. & Experimental Result (ksi) \\
\hline$f_{r 1}$ & 0.391 \\
\hline$f_{r 2}$ & 0.417 \\
\hline$f_{r 3}$ & 0.450 \\
\hline
\end{tabular}

Experimental Average Flexural Strength $=0.42 \mathrm{ksi}$

Theoretical Result based on ACI $=0.41 \mathrm{ksi}$

Experimental $/$ Theoretical $=1.02$

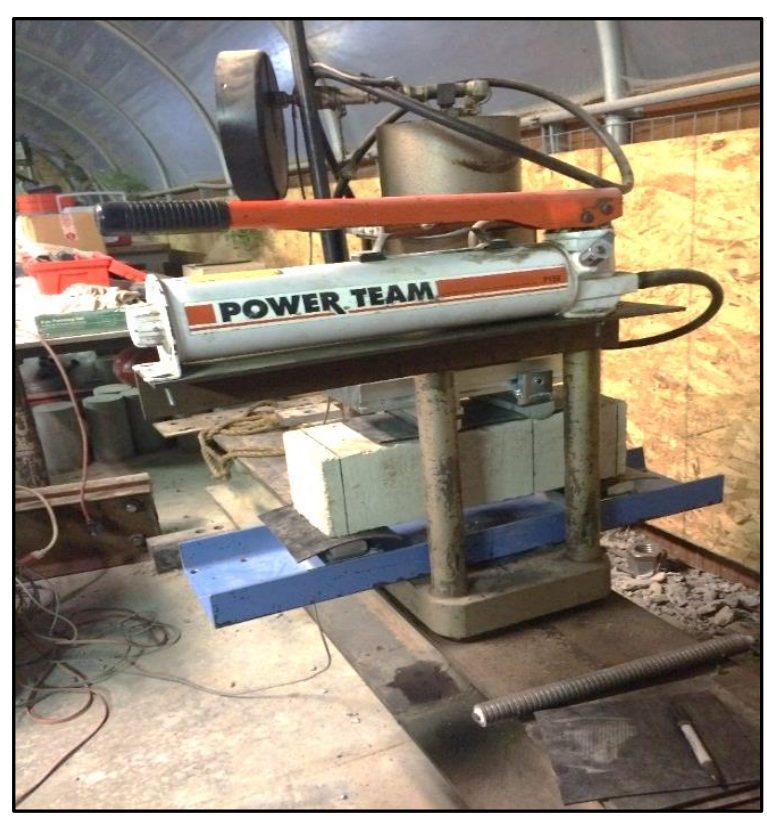

a- Test Setup

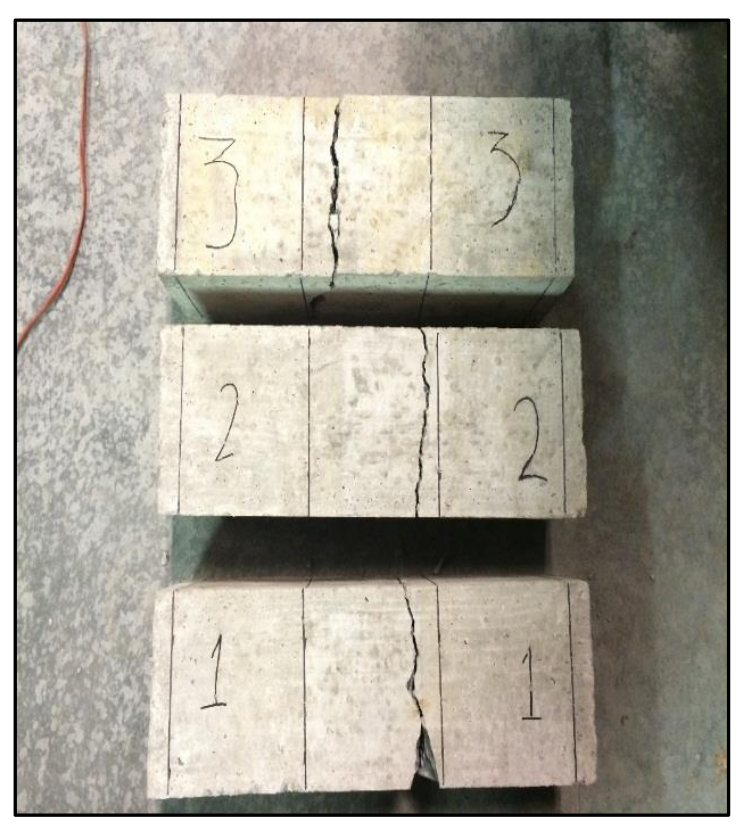

b- Failure Modes

Figure 3-17 Modulus of Rupture Test 


\subsubsection{Splitting Tensile Strength $\left(f_{c t}\right)$}

The indirect tensile strength (splitting tensile strength) tests were carried out in accordance with ASTM- C 496 by using the compressive machine that is available at the iSTAR Lab. Splitting tensile strength tests were made on $6 \times 12$ in. (diameter $\times$ height) cylinders as shown in Figure 3-18. Table 3-9 summarizes the splitting tensile strength of concrete and shows the comparison between the theoretical and experimental tests. The following equation was used to estimate the experimental splitting strength:

$$
f_{c t}=\frac{2 p}{\pi l d}
$$

Where: $f_{c t}$ : splitting tensile strength,psi

P: max. applied load

1: length, in

d: diameter, in
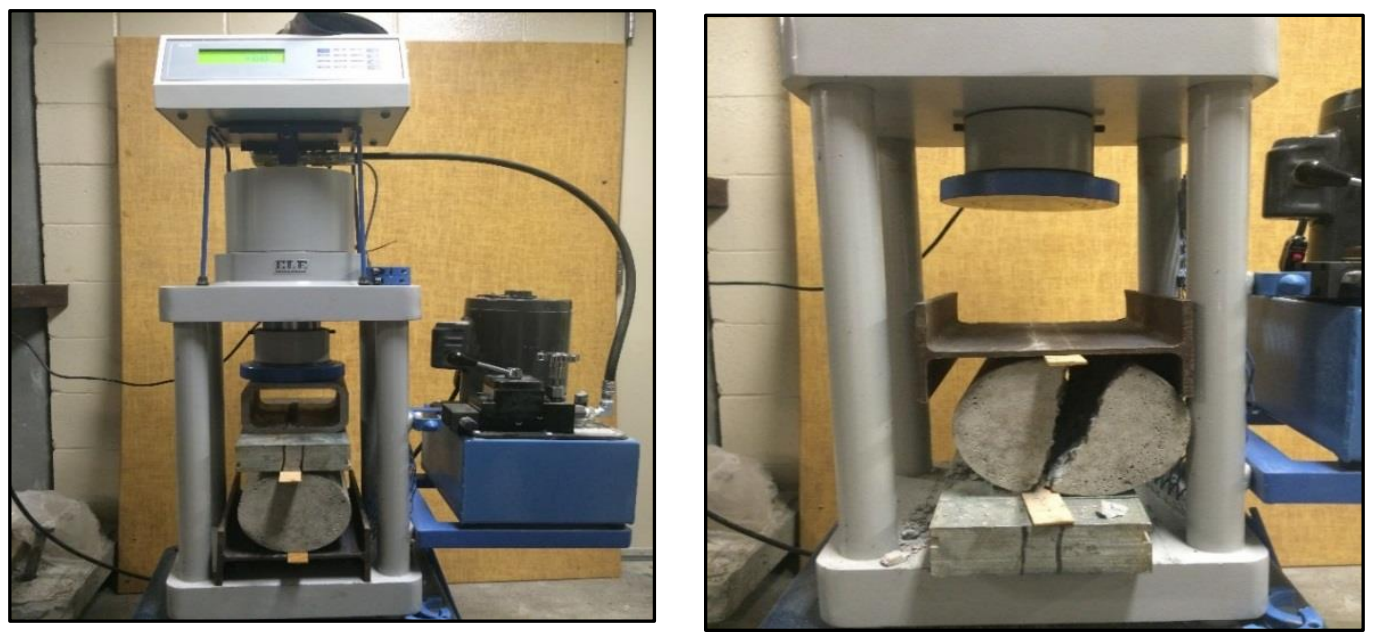

Figure 3-18 Splitting Test 


\begin{tabular}{|c|c|c|c|}
\hline \multirow{2}{*}{ Age (day) } & \multicolumn{2}{|c|}{$f_{c t}(p s i)$} & \multirow{2}{*}{ Deviation } \\
\cline { 2 - 4 } & Experimental & Theoretical & \\
\hline 55 & 387 & 374 & $3.5 \%$ \\
\hline 150 & 442 & 424 & $4.25 \%$ \\
\hline
\end{tabular}

\subsubsection{Modulus of Elasticity $\left(E_{c}\right)$}

Measurement of static modulus of elasticity of concrete $\left(E_{c}\right)$ was carried out in accordance with ASTM-C 469, using $6 \times 12$ in. concrete cylinders tested in compression at constant strain rate as shown in Figure 3-19. The same testing machine, which is employed in compressive strength tests of concrete, was used in this test. Two displacement transducers (LVDTs) were used to measure the deformation in the concrete cylinders as shown in the Figure 3-19. The theoretical values were determined by using the ACI code equation, $57000 \sqrt{f^{\prime}}$. Table 3-10 summarizes the modulus of elasticity of the concrete and the stress-strain diagrams are shown in Figure 3-20. 


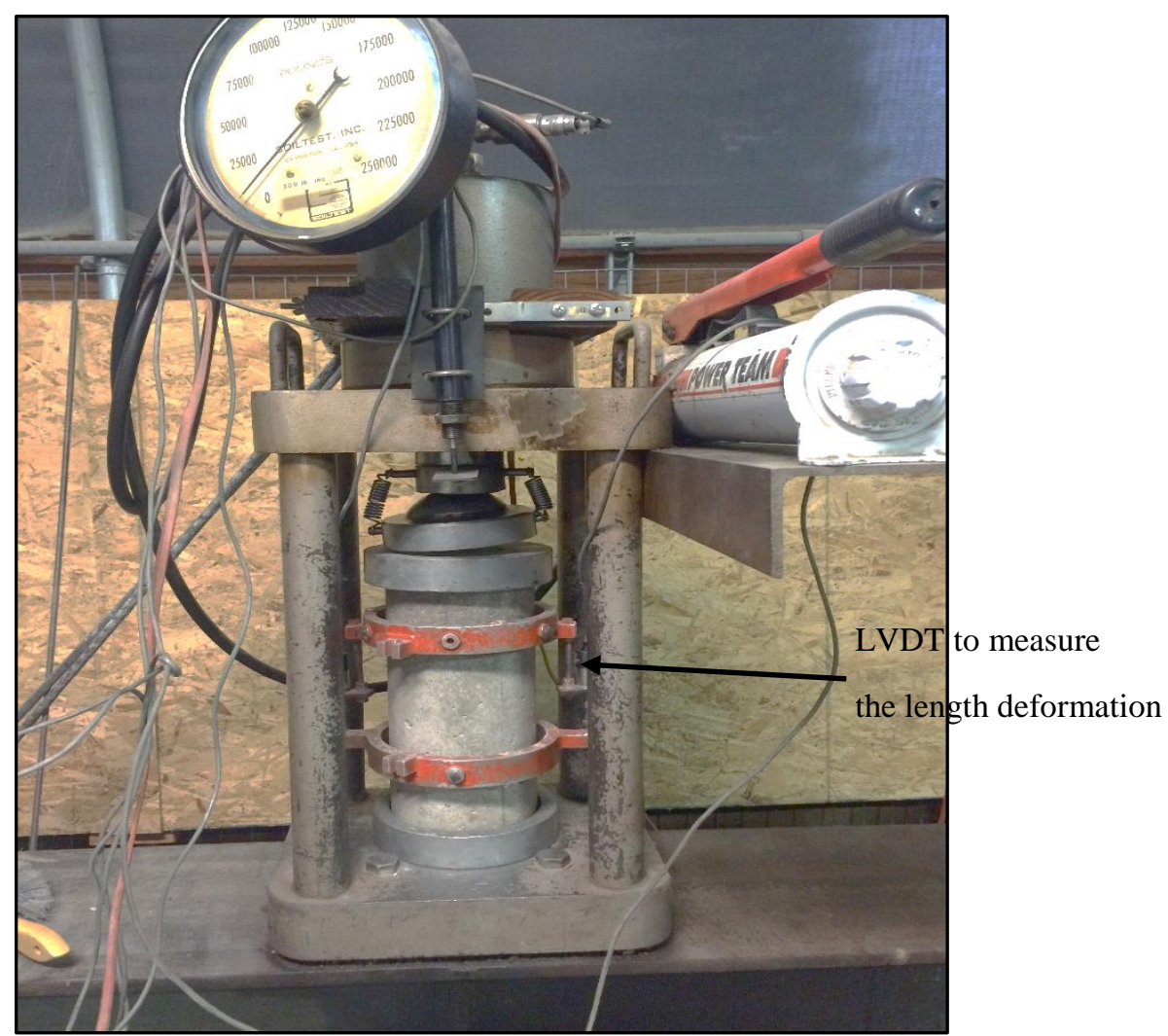

Figure 3-19 Modules of Elasticity Test

Table 3-10 Concrete Modulus of Elasticity

\begin{tabular}{|c|c|c|c|c|}
\hline \multirow{2}{*}{ No. } & \multirow{2}{*}{$\begin{array}{c}\text { Age of the } \\
\text { Concrete at the }\end{array}$} & \multicolumn{2}{|c|}{ Concrete Modulus of Elasticity $\left(E_{c}\right), \mathrm{ksi}$} & \multirow{2}{*}{ Deviation } \\
\cline { 3 - 4 } & Test (Days) & Theoretical & Experimental & \\
\hline 1 & 39 & 3122 & 3350 & $7 \%$ \\
\hline 2 & 150 & 3605 & 3420 & $5 \%$ \\
\hline 3 & 150 & 3605 & 3242 & $10 \%$ \\
\hline
\end{tabular}




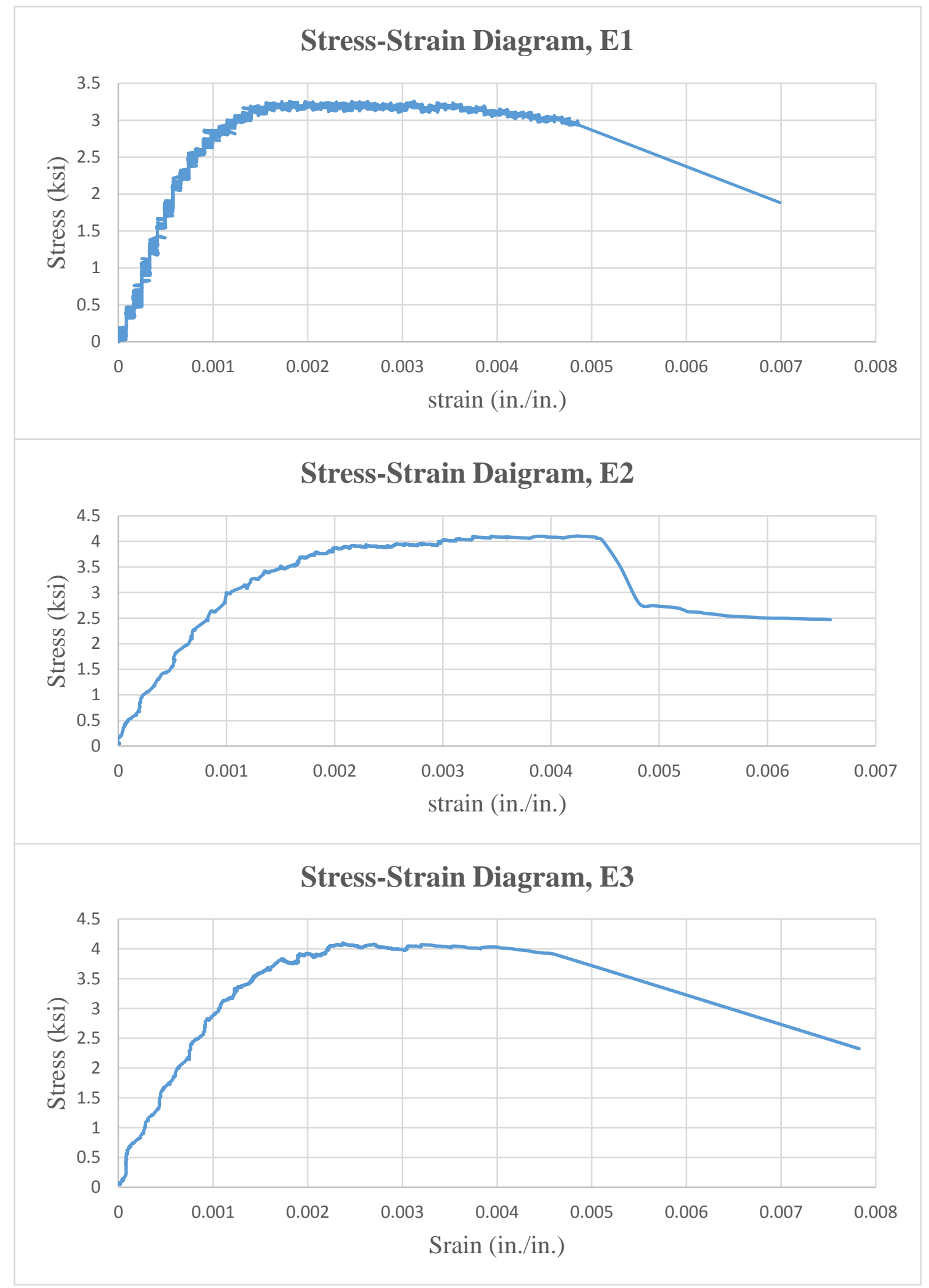

Figure 3-20 Stress-Strain Diagram of the Concrete 


\subsection{Carbon Fiber Reinforced Polymer (CFRP) Sheets}

CFRP sheets were used as an exterior bonded reinforcement to compensate for the missing reinforcement within the joint rejoin. FRP in general is very strong in tensile strength in the longitudinal direction and it is relatively weak in the transverse direction. In this experimental work, the MasterBrace FIB 300/50 CFS, CFRP unidirectional high strength carbon fiber sheets were purchased from BASF Company. The tensile properties of these sheets are shown in Table 3-11, and the physical properties are shown in Table 3-12 as described by the manufacturer.

\section{Table 3-11 Tensile Properties of the CFRP Sheet}

\begin{tabular}{|c|c|c|}
\hline No. & Property & Requirement \\
\hline 1 & Ultimate tensile strength,$\left(f_{f u}\right)$ & $550 \mathrm{ksi}$ \\
\hline 2 & Tensile modulus, $\left(E_{f}\right)$ & $33000 \mathrm{ksi}$ \\
\hline 3 & Ultimate tensile strength per unit width, $\left(f_{f u} t_{f}\right)$ & $3.57 \mathrm{kips} / \mathrm{in} / \mathrm{ply}$ \\
\hline 4 & Tensile modulus per unit width, $\left(E_{f} t_{f}\right)$ & $215 \mathrm{kips} / \mathrm{in} / \mathrm{ply}$ \\
\hline 5 & & $1.67 \%$ \\
\hline
\end{tabular}


Table 3-12 Physical Properties of the CFRP Sheets

\begin{tabular}{|c|c|c|}
\hline No. & Property & Requirement \\
\hline 1 & Fiber material & High strength carbon \\
\hline 2 & Fiber tensile strength & $720 \mathrm{ksi}$ \\
\hline 3 & Areal weight & 0.062 \\
\hline 4 & Fabric width & 20 in. \\
\hline 5 & Nominal thickness, $t_{f}$ & 0.0065 in. \\
\hline
\end{tabular}

In order to verify the provided properties, the tensile tests was performed in Material Science Lab, Mechanical and Materials Engineering Department at Portland State University. Seven identical specimens were tested in accordance with ASTM D 3039/ D 3039M, and the results are summarized in Appendix B.

\subsection{Surface Preparation:}

Four of the non-seismic specimens were strengthened by using CFRP sheets, where the sheets were attached to the specimens by a special epoxy recommended by the manufacturer. In order to achieve the best bond between the concrete surface and the CFRP sheet, a special preparation of the concrete surface was needed. The concrete surface preparation was done by using a manual grinder. The concrete surface was roughened, as shown in the Figure 3-21, in order to gain the highest adhesion between the 
concrete and the CFRP sheets. The sharp corners of the column were rounded to a 0.75 in. radius by using a grinder to avoid any unnecessary fractures in the sheets caused by the sharp corners as shown in the same figure. When the grinding was done, a few small holes appeared on the concrete surface, as shown in Figure 3- 22. A simple mortar consisting of 2:1 cement to sand (by volumetric ratio) was used to fill these holes.
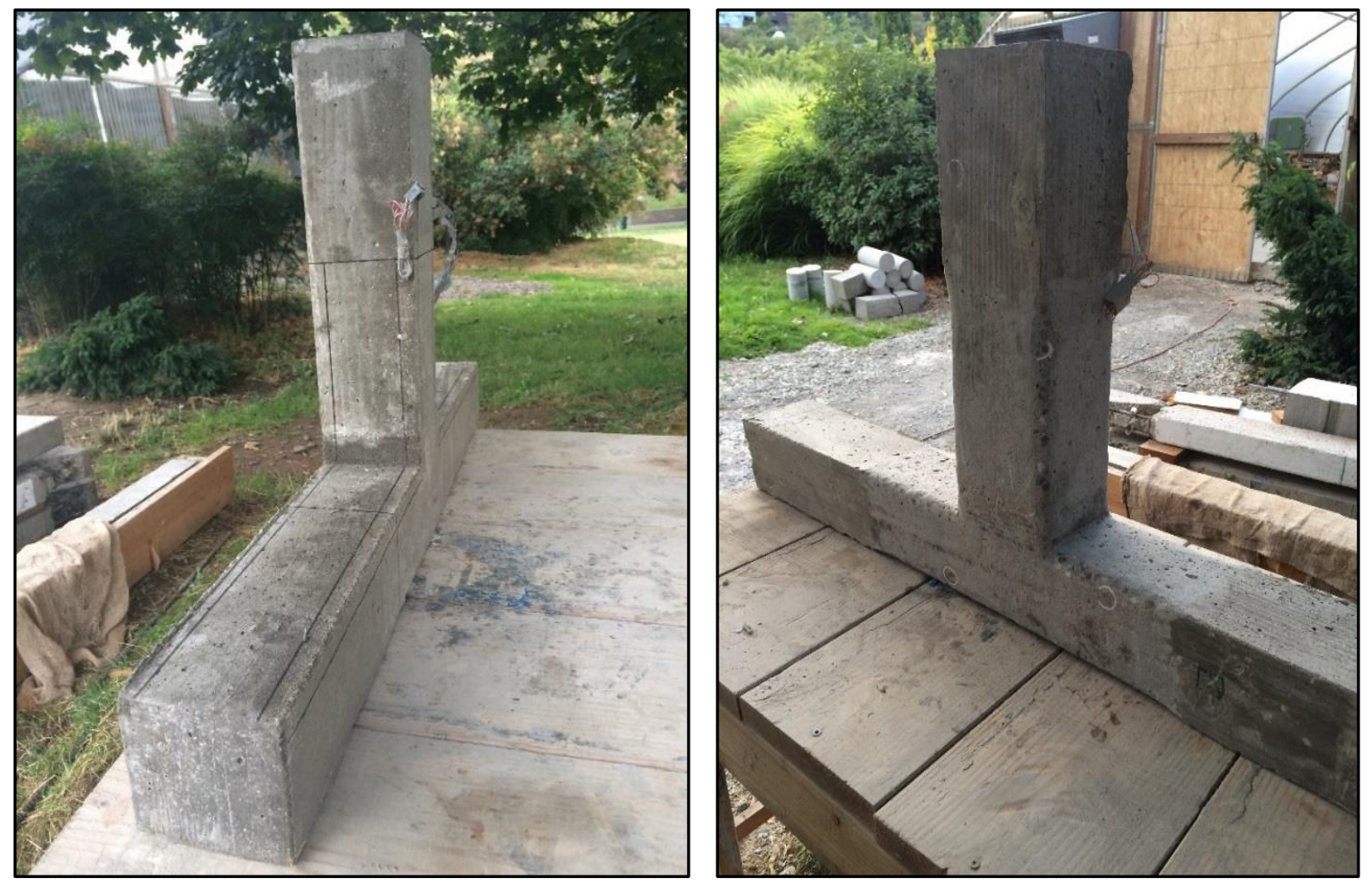

a- Before the grinding

b- After the grinding

Figure 3-21 The Concrete Surface Preparations of the Specimens 

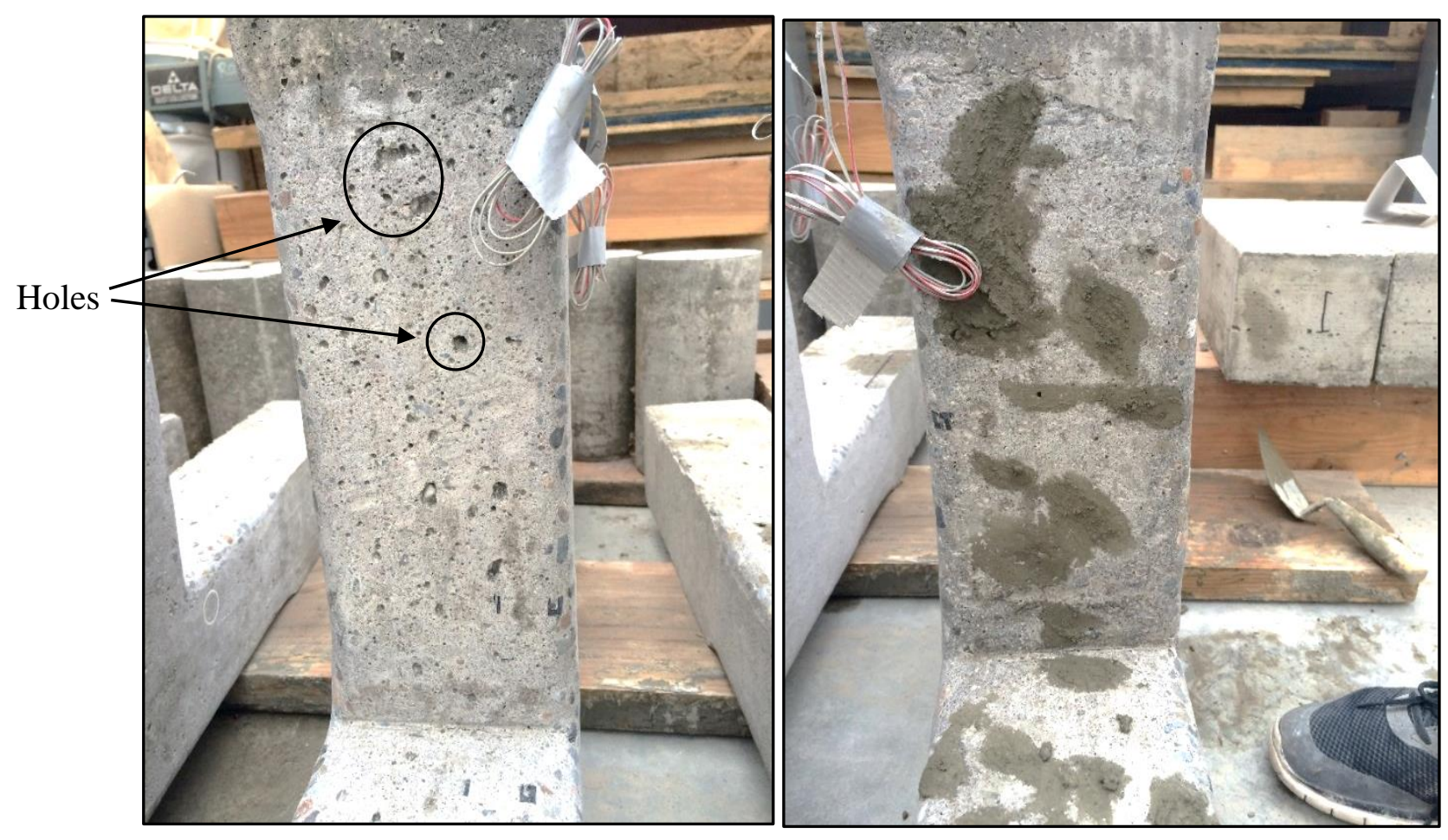

Figure 3-22 Holes on the Concrete Surface

\subsection{Epoxy}

The epoxy that was used to attach the CFRP sheets to the concrete surface was recommended by the CFRP manufacturer. The epoxy is usually sold together with CFRP sheets in order to provide the highest tensile strength. The epoxy consisted of three layers. These layers are described below. Each one of them has different properties. The instructions for use it also came from the same source (BASF Company), and all epoxy layers were applied after the preparation of the concrete surfaces. 


\subsubsection{MasterBrace P 3500 or Primer Layer}

After the preparation of the concrete member was done as recommended by the manufacturer, the primer layer, which is the first layer of the MasterBrace System, was applied to the concrete member. The primer layer was applied in order to provide good adhesion between the MasterBrace System and the member, as shown in Figure 3-23. The mechanical properties were provided by the manufacturer as shown in the Table 313.

This layer consists of two parts A and B. These parts were mixed based on the provided mix ratio of 3:1 (part A to part B) by volume or 100:30 (part A to part B) by weight. Before the mixing process, the concrete surface was cleaned with water, and then sundried. On the day of application, the concrete member was cleaned by using an air compressor that was available at the Greenhouse Lab, then the MasterBrace P 3500 was applied by using a paint brush. Spray paint is not recommended with this product. The recommended curing time for this layer was twenty four hours.

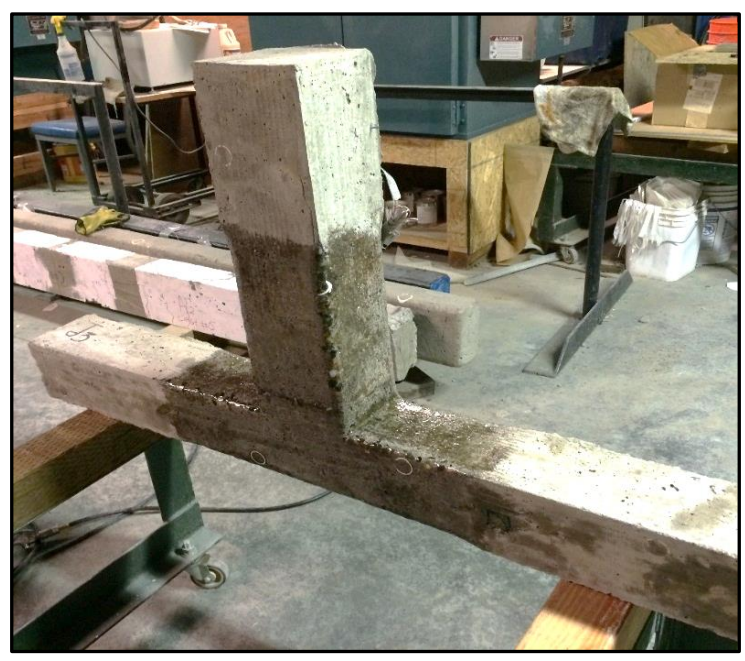

Figure 3-23 Applying the Prime Layer to the Concrete Surface 
Table 3-13 Mechanical Properties of MasterBrace P 3500

\begin{tabular}{|c|c|c|c|}
\hline No. & Property & Compressive & Tensile \\
\hline 1 & Yield strength (psi) & 3800 & 2100 \\
\hline 2 & Strain at yield & $4.0 \%$ & $2.0 \%$ \\
\hline 3 & Elastic modulus (ksi) & 97 & 105 \\
\hline 4 & Ultimate strength (psi) & 4100 & 2500 \\
\hline 5 & Rupture strain & $10 \%$ & $40 \%$ \\
\hline 6 & Poisson's ratio & N/A & 0.48 \\
\hline
\end{tabular}

\subsubsection{MasterBrace F 2000 or Putty Layer}

After twenty four hours, the second layer of the MasterBrace F 2000 was applied over the primer layer. The main purpose of this layer was to level out the small surface defects, and to provide a smooth surface where the MasterBrace System was attached to the specimen, as shown in Figure 3-24. The mechanical properties were provided by the manufacturer as shown in the Table 3-14. This layer also consists of two parts A and B. These parts were mixed based on the provided mix ratio of 3:1 (part A to part B) by volume or 100:30 (part A to part B) by weight. The MasterBrace F 2000 was applied by using a steel trowel. The recommended curing time for this layer was twenty four hours. 


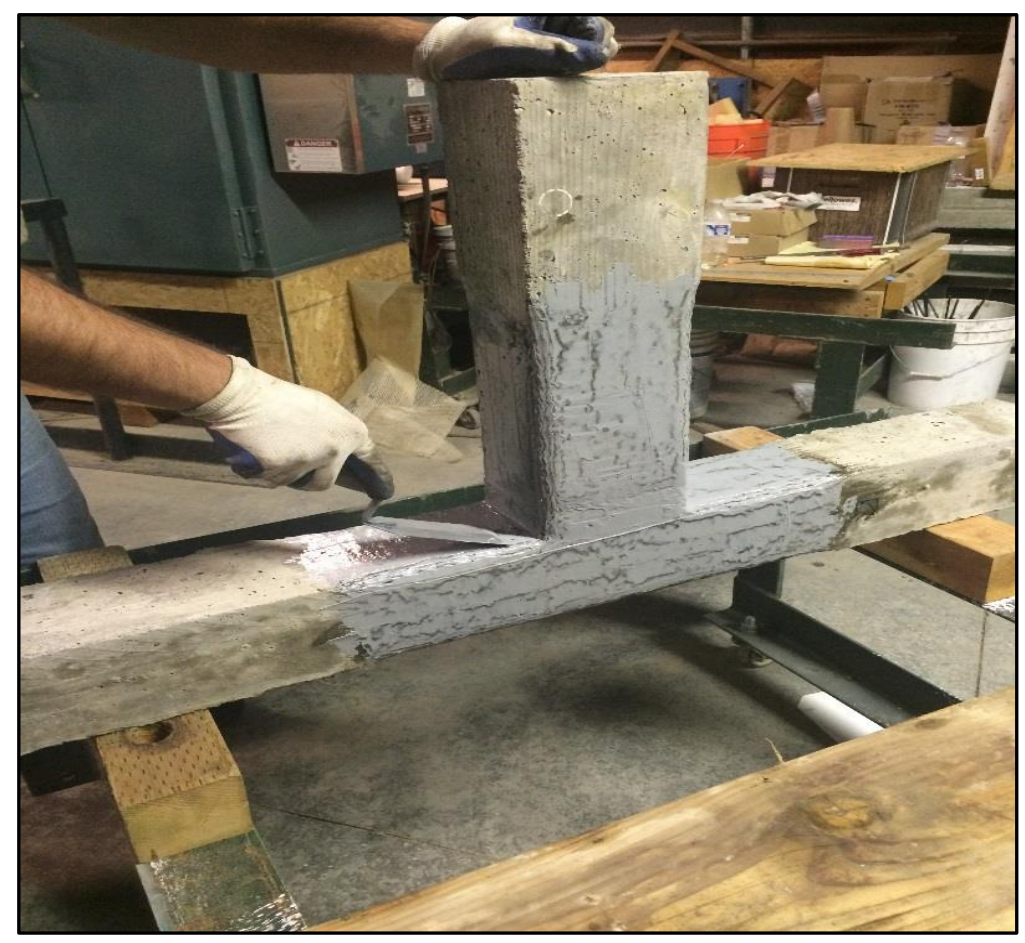

Figure 3-24 Applying the Putty Layer to the Concrete Surface

Table 3-14 Mechanical Properties of MasterBrace F 2000

\begin{tabular}{|c|c|c|c|}
\hline No. & Property & Compressive & Tensile \\
\hline 1 & Yield strength (psi) & 3300 & 1800 \\
\hline 2 & Strain at yield & $4.0 \%$ & $1.5 \%$ \\
\hline 3 & Elastic modulus (ksi) & 155 & 260 \\
\hline 4 & Ultimate strength (psi) & 3300 & 2200 \\
\hline 5 & & & $7 \%$ \\
\hline 6 & Rupture strain & $10 \%$ & 0.48 \\
\hline
\end{tabular}




\subsubsection{MasterBrace SAT 4500 or Saturant Layer}

At this point the concrete beam-column joint was ready to be covered with the CFRP sheets. The sheets were pre-cut and prepared for the installation at the required dimensions. After the first coat of the MasterBrace SAT 4500, which was mixed by using the exact same mixing ratio that was used for the first two layers, was applied to the joint by using a 3/8" roller, a dry sheet of CFRP was applied at the joint region. The rolling started until there was visible bleeding through the sheets. The mechanical properties were provided by the manufacturer as shown in the Table $3-15$. The most important factor that was considered during the installation of the CFRP sheets was the ambient temperature as recommended by the manufacturer should be between $50^{\circ} \mathrm{F}$ and $120^{\circ} \mathrm{F}$.

Table 3-15 Mechanical Properties of MasterBrace SAT 4500

\begin{tabular}{|c|c|c|c|}
\hline No. & Property & Compressive & Tensile \\
\hline 1 & Yield strength (psi) & 12500 & 7900 \\
\hline 2 & Strain at yield & $5.0 \%$ & $2.5 \%$ \\
\hline 3 & Elastic modulus (ksi) & 380 & 440 \\
\hline 4 & Ultimate strength (psi) & 12500 & 8000 \\
\hline 5 & Rupture strain & $5 \%$ & $3.5 \%$ \\
\hline 6 & Poisson's ratio & N/A & 0.40 \\
\hline
\end{tabular}




\subsection{Attaching the CFRP Sheets}

The process that was used to attach the CFRP sheets for all of the retrofitted specimens was similar. After the preparation of the concrete surface, as described in the previous section, applying the CFRP sheets was the final step of this process. This step started by using the Saturant layer to paint the areas to be strengthening. After the painting these areas with MasterBrace SAT 4500, the CFRP sheets were attached to the concrete surface. A plastic roller was used to make sure that all of the CFRP sheets were attached to the concrete surface, and that the leftover epoxy bled through the CFRP fibers. The CFRP sheets were left to cure for at least seven days at room temperature. The previous procedure was followed for one layer of the Carbon Fiber Reinforced Polymer (CFRP) sheet. In order to use two layers or more, the same procedure is usually used. Figure 3-25 shows the wrapped specimen that was retrofitted and left for curing as recommended by the manufacturer.

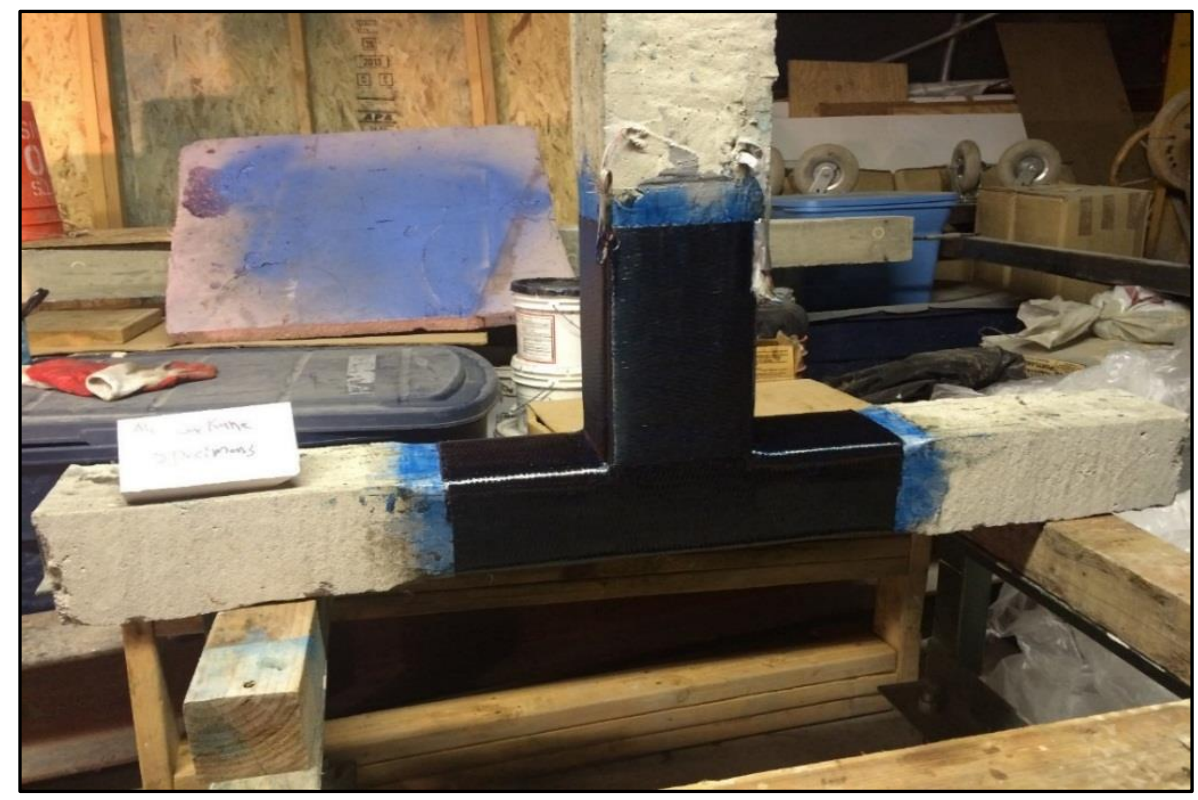

Figure 3-25 Specimen Wrapped by CFRP Sheets 


\subsection{Rehabilitation Schemes}

In adding CFRP sheets to the joint, one rehabilitation technique used consisted of adding an "L" shape of CFRP sheets at the corners on both sides of the beam in order to compensate the missing leg of the ties at the interface between the beam and column joint. The column was then wrapped with one layer of CFRP sheet at $0^{\circ}$ with the horizontal beam axis in "U"-shape form. Finally, CFRP sheets were wrapped around the beam to provide $100 \%$ confinement and to delay any unexpected deboning. For all specimens, the technique was the same as the first one, but the number of layers used was different. Table 3-16 shows the rehabilitation of the joints and Figure 3-26 shows the details of the technique used to retrofit the joints. The reason for attaching the CFRP sheets at $0^{\circ}$ with the horizontal beam axis at the joint region was to simulate the shear reinforcement position in the joint. 
Table 3-16 Designation and Rehabilitation of the Specimens

\begin{tabular}{|c|c|c|}
\hline No. & Designation & Rehabilitation schemes \\
\hline 1 & J1 & Control specimen ( ductile seismic specimen) \\
\hline 2 & J2 & Control specimen ( non-ductile specimen) \\
\hline 3 & J3 & Rehabilitated using one CFRP sheet \\
\hline 4 & J4 & Rehabilitated using two CFRP sheets \\
\hline 5 & J5 & Rehabilitated using one CFRP sheets \\
\hline 6 & J6 & Rehabilitated using two CFRP sheets \\
\hline
\end{tabular}

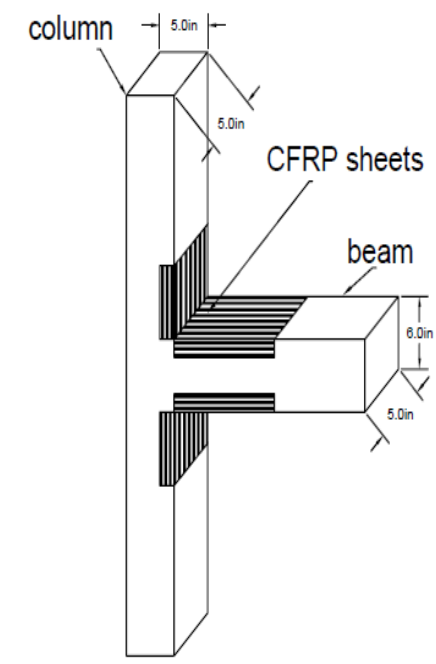

A- apply L- shape

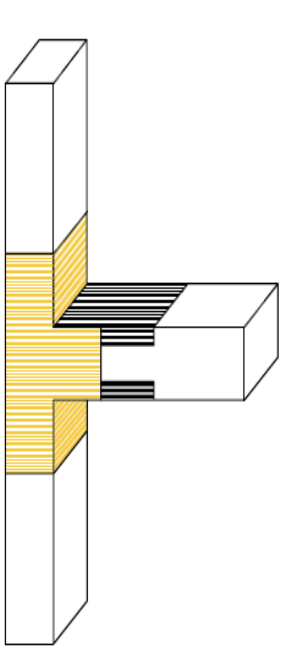

B- column confinement

C- beam \& column confinement

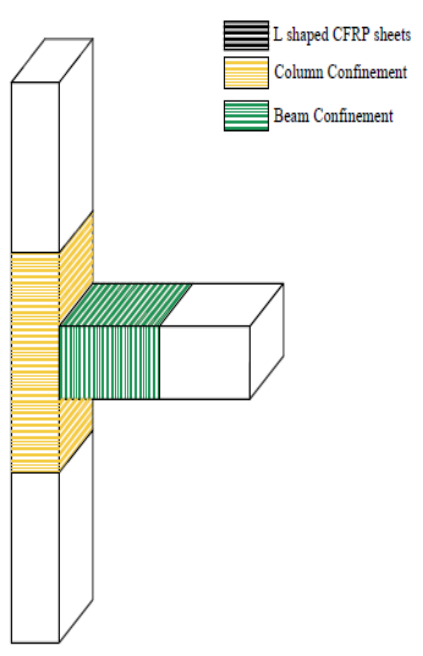

Figure 3-26 Retrofitting Steps 


\subsection{Test Setup}

All beam-column joints were tested in the South Greenhouse Lab at Portland State University by modifying the Blue Frame. Each specimen was pinned at the ends of column vertically. A constant axial load represented by $0.2 f^{\prime}{ }_{c} A_{g}$ of the compressive strength of the column (15 kips) was applied to specimens J1, J2, J3 and J4 and $0.4 f^{\prime}{ }_{c} A_{g}$ of the compressive strength of the column (30 kips) was applied to specimens J5 and J6 by using a 37 kip hydraulic cylinder connected to a manual pump. A load cell was used to record this load. The cyclic load was applied at the free end of the beam by using a 50kip double acting actuator connected to a manual pump. Two pressure sensors (2000 psi capacity) purchased from Omega Engineering Company were used to measure the applied cyclic load. The general test setup is shown in Figure 3-27. Two displacement sensors (LVDTs) were used to measure the displacement at the beam tip. Two horizontal supports were used to take any horizontal force at the ends of the columns of each specimen.

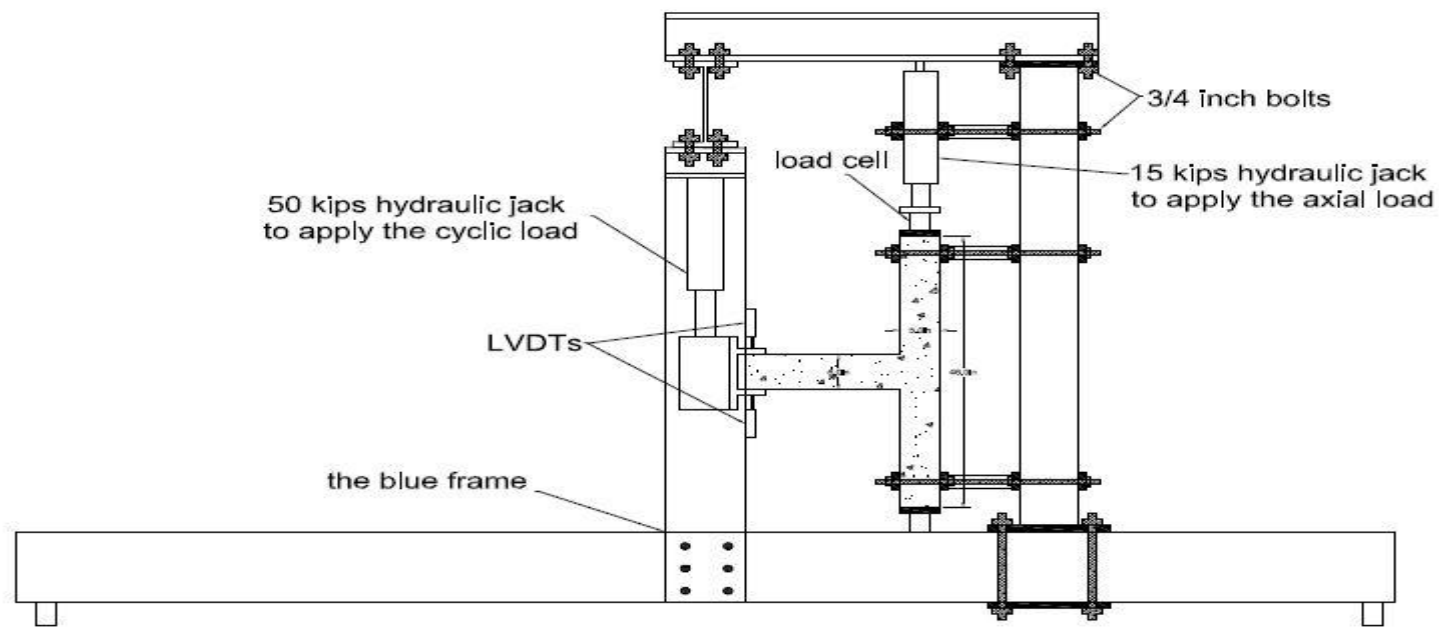

Figure 3-27 Test Setup 


\subsection{Load Sequence}

The selected load history consists of two phases. The first phase was load-controlled followed by a strain -controlled phase. The first phase consisted of twenty "full" cycles. "Full Cycle" refers to producing both positive and negative moments in one cycle. In the first ten cycles, a 2.4-kip load, which created $75 \%$ of the maximum theoretical flexural capacity of the beam, was applied at each load cycle. For the second ten cycles, a 2.8-kip load, which represented $90 \%$ of the maximum theoretical flexural capacity of the beam, was applied at each load cycle. Then the second phase (strain controlled) started. For the strain controlled phase of the load sequence, the cyclic load was applied in each direction until the strain in the longitudinal flexural beam bars was $0.4 \%$ in twenty cycles. This strain corresponding to twice the yield strain. The applied cyclic load was then increased until the strain reached $0.6 \%$ (representing 3 times the yield strain). Figure 3-28 shows the load sequence. During the test of each specimen, the axial load was applied and maintained at the upper end of the column. The cyclic load was applied at the free end of the beam, which was represented by pushing the free end down and releasing, then up and releasing for each cycle. The applied force and deflection at each cycle were recorded in addition to the strain gages readings. 


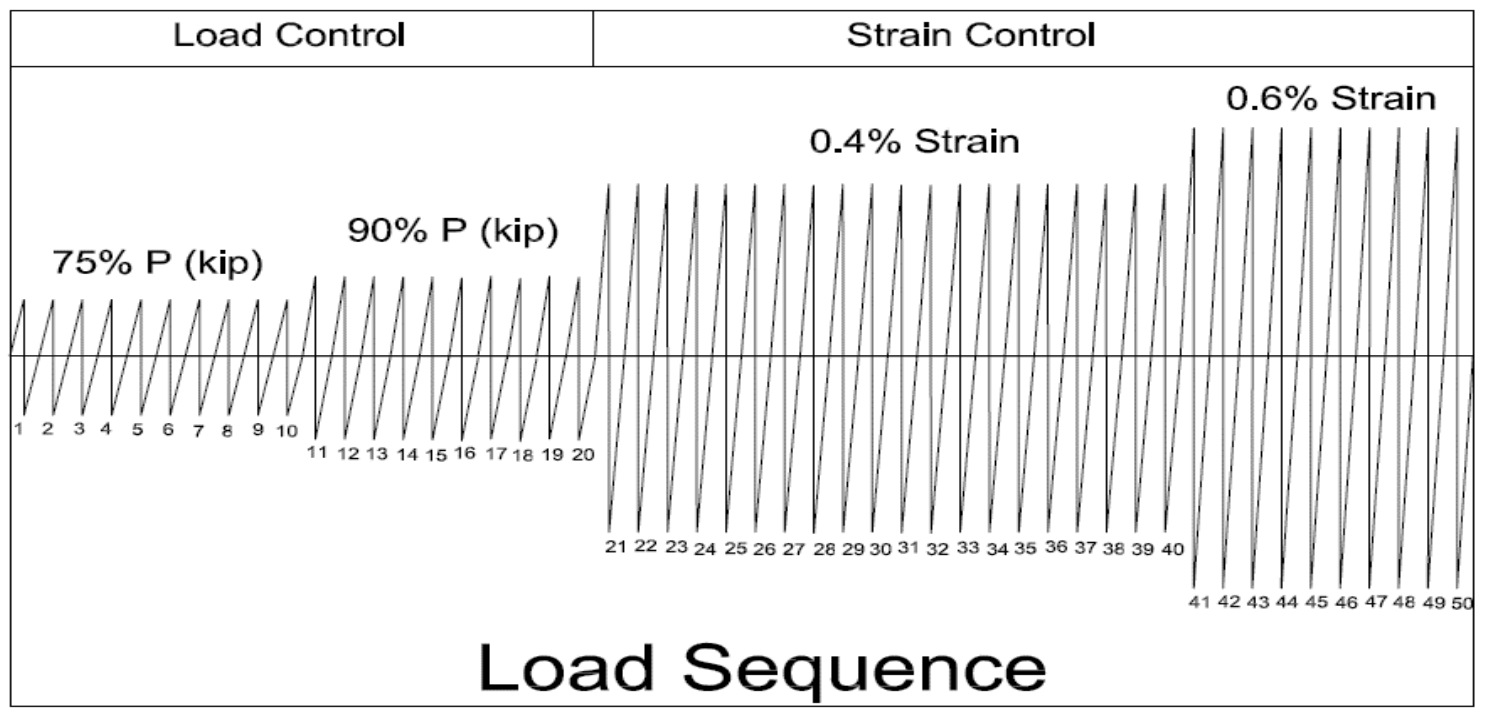

Figure 3-28 Load Sequence Diagram 


\section{Chapter 4. Experimental Results}

\subsection{General}

This chapter presents the data collected throughout the experimental tests of specimens described in Chapter Three. To evaluate the proposed retrofitting technique of using CFRP sheets, the behavior of the control and retrofitted specimens are described in terms of applied beam load versus displacement. This provides the information about the strength, energy dissipation, and ductility of the joints. Moreover, the failure modes and crack patterns are expressed by drawings and photographs.

\subsection{Behavior of Specimens}

\subsubsection{Ductile Specimen J1}

The general behavior of the seismic joint $\mathrm{J} 1$ which was the control specimen representing a ductile joint that designed based on the seismic provisions in the current code (ACI 318-14). As described in previous chapters, this specimen was prepared and cast at Greenhouse Lab at Portland State University and tested two and half months after casting. All specimens were tested using the Blue Frame that was first modified to have the loading system to perform the tests. Loading system was designed to simulate the type of stress that the joint would be subjected to during an earthquake. Figure 4-1 shows how the specimen was placed in the frame and set for the test. 


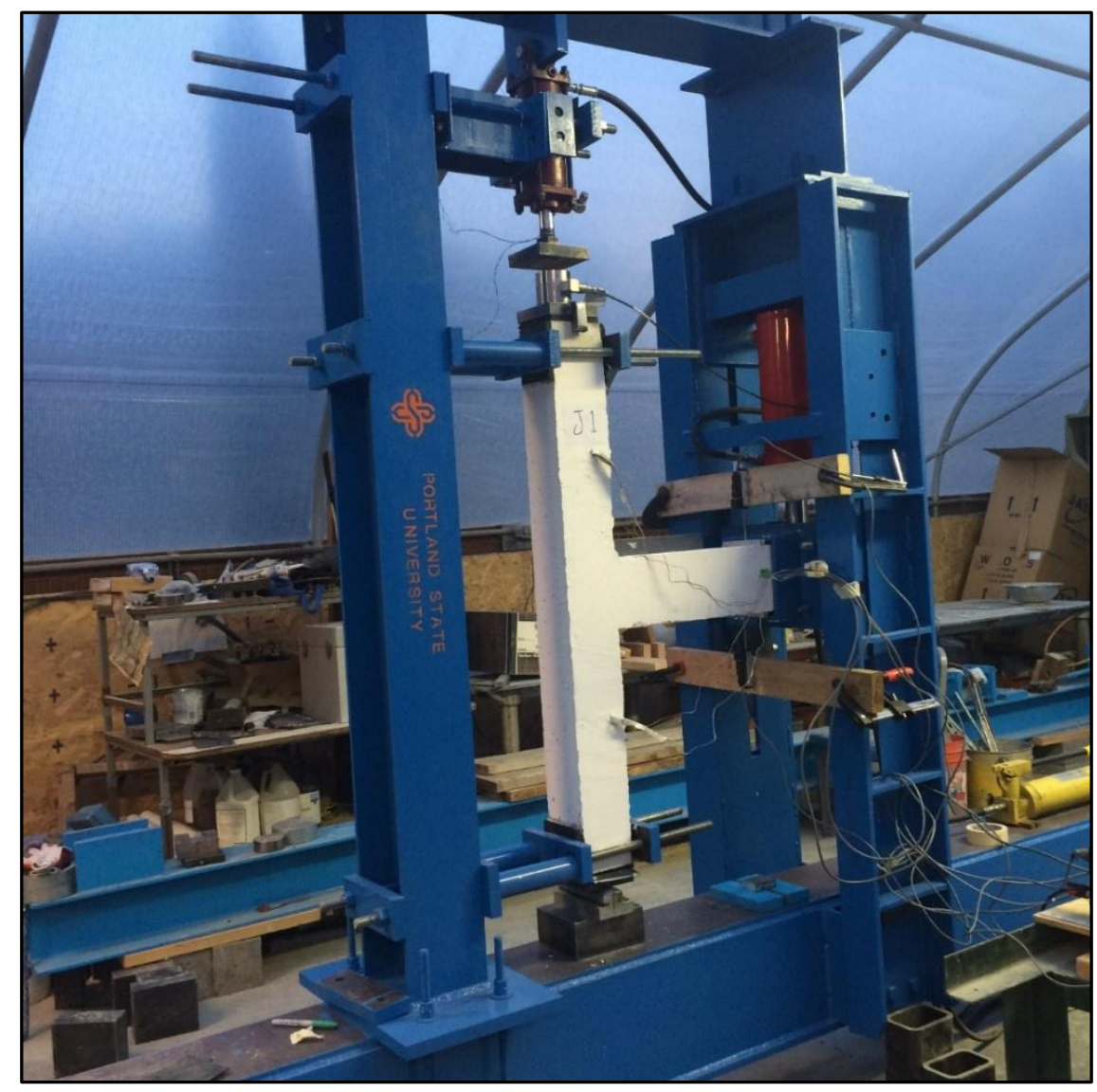

Figure 4-1 Test Setup of Joint J1

After the specimen was placed in the Blue Frame, and all of the wires connected to the data acquisition system, the specimen was ready to test. A systematic procedure for the load sequence was used to test the specimen. For specimen J1, the test started by applying an axial load of 15 kips (representing 0.2f'c Ag) on the top of the column, and the load was kept constant during the test. Beam load was then applied and cycled to produce positive and negative beam moments. After applying the first load cycle, a few flexural cracks developed along the hinge region of the beam starting from the interface between the column and the beam, as shown in Figure 4-2. The largest crack in terms of 
the length and the width was the one closest to the column face. The crack width was 1 $\mathrm{mm}$ and $0.5 \mathrm{~mm}$ at the loading and at the release respectively.

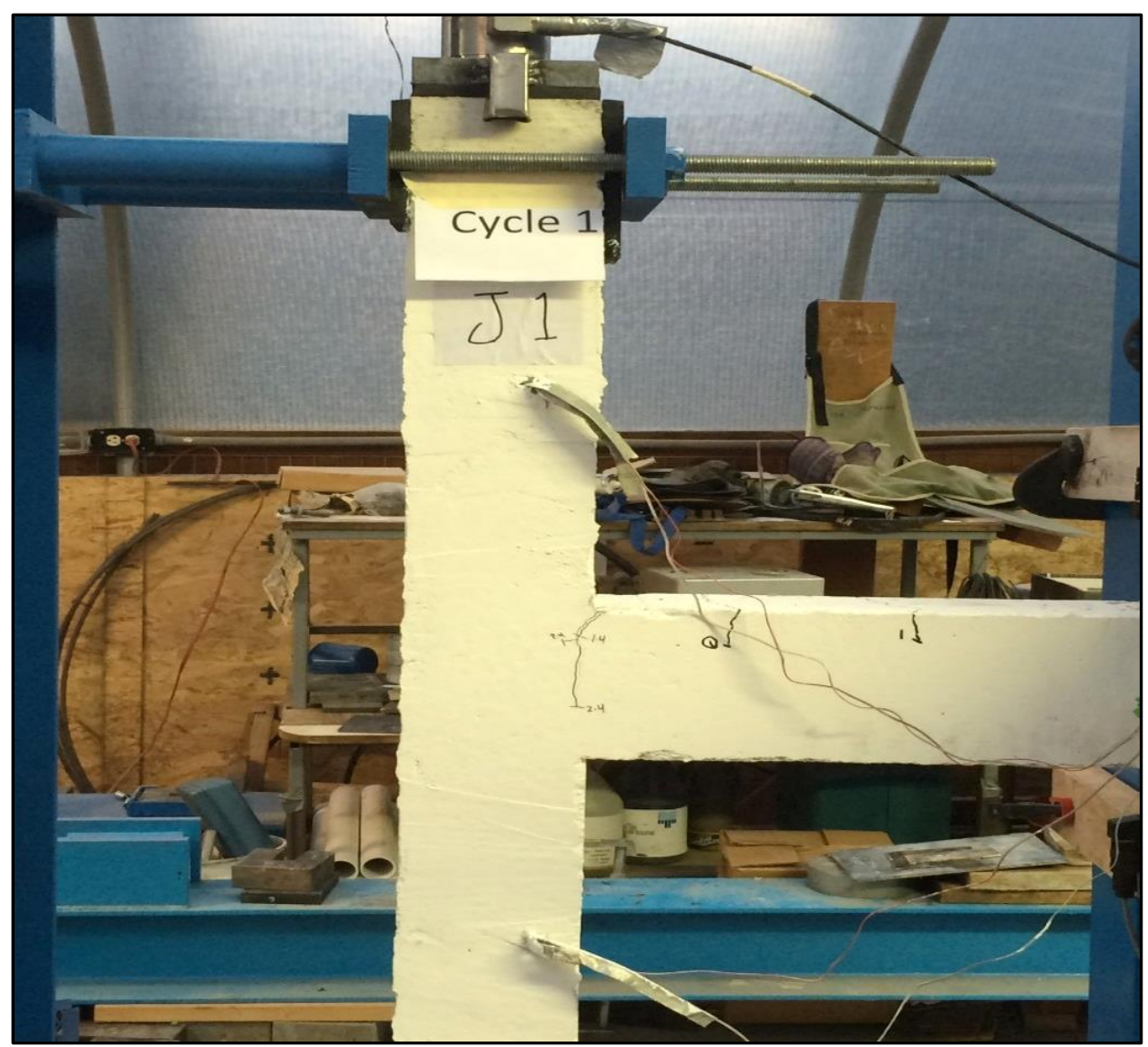

Figure 4-2 The Development of the First Cracks at the First Cycle, J1

For the next three cycles, a few more flexural cracks developed within the same beam region. The crack width increased to $1.2 \mathrm{~mm}$ and $0.9 \mathrm{~mm}$ at loading and at the release respectively. The same crack pattern formed on the lower beam face, and these cracks proceeded toward the middle of the beam depth. A few hairline cracks formed during these four cycles because the applied cyclic load at second cycle was accidentally increased to $10 \%$ greater than the maximum theoretical strength of the beam. Figure 43 shows the cracks that developed in the first four cycles. 


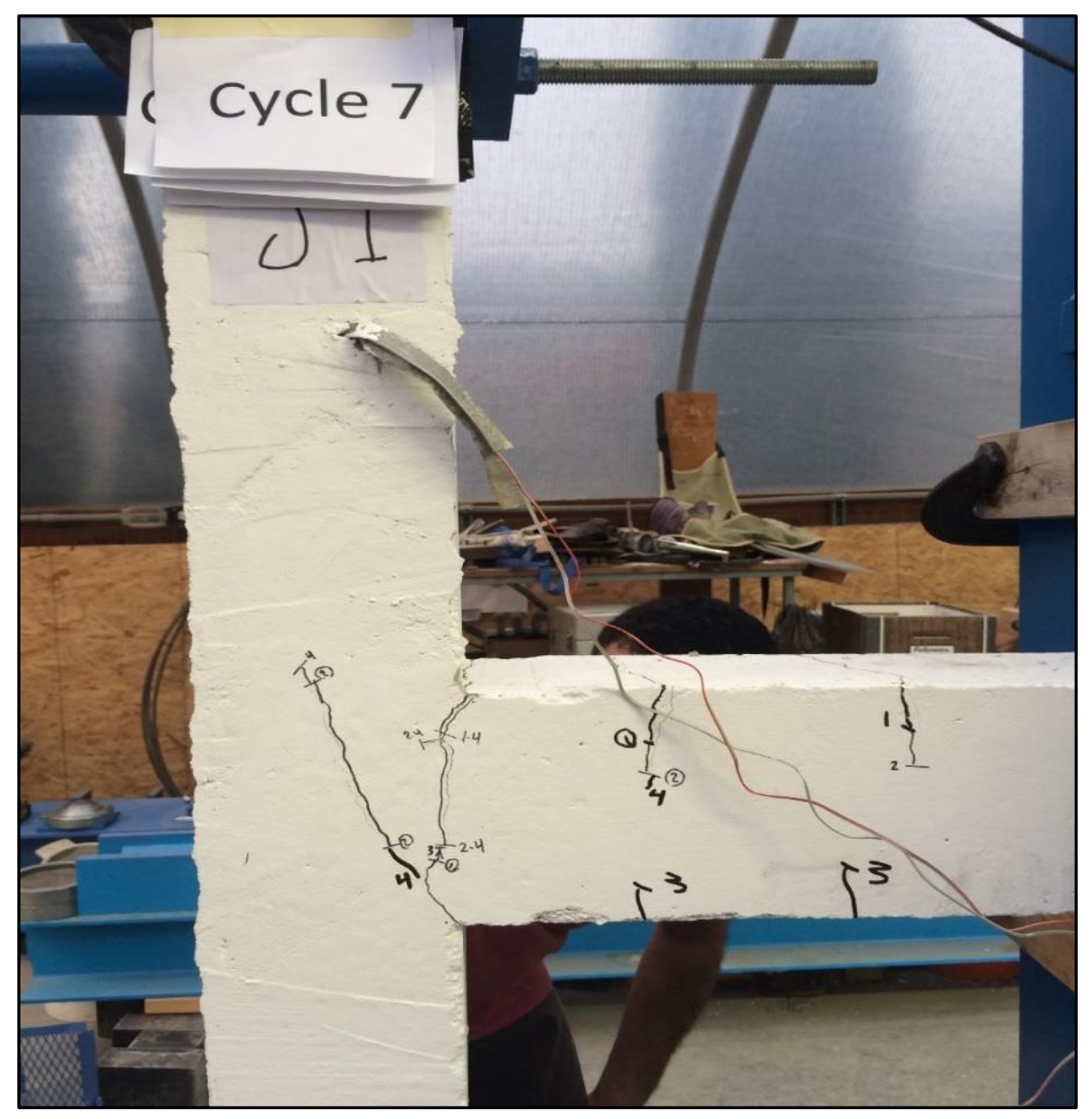

Figure 4-3 Development of the Flexural Cracks after Cycle 4, J1

For the rest of the first set of cycles, no new cracks developed. The only change was in crack widths, especially in the crack that formed at the interface between the beam and column. This crack width was $1.6 \mathrm{~mm}$ by the end of cycle 10 within the load control. Figure 4-4 shows the specimen $\mathrm{J} 1$ at the end of first set of load cycles. 


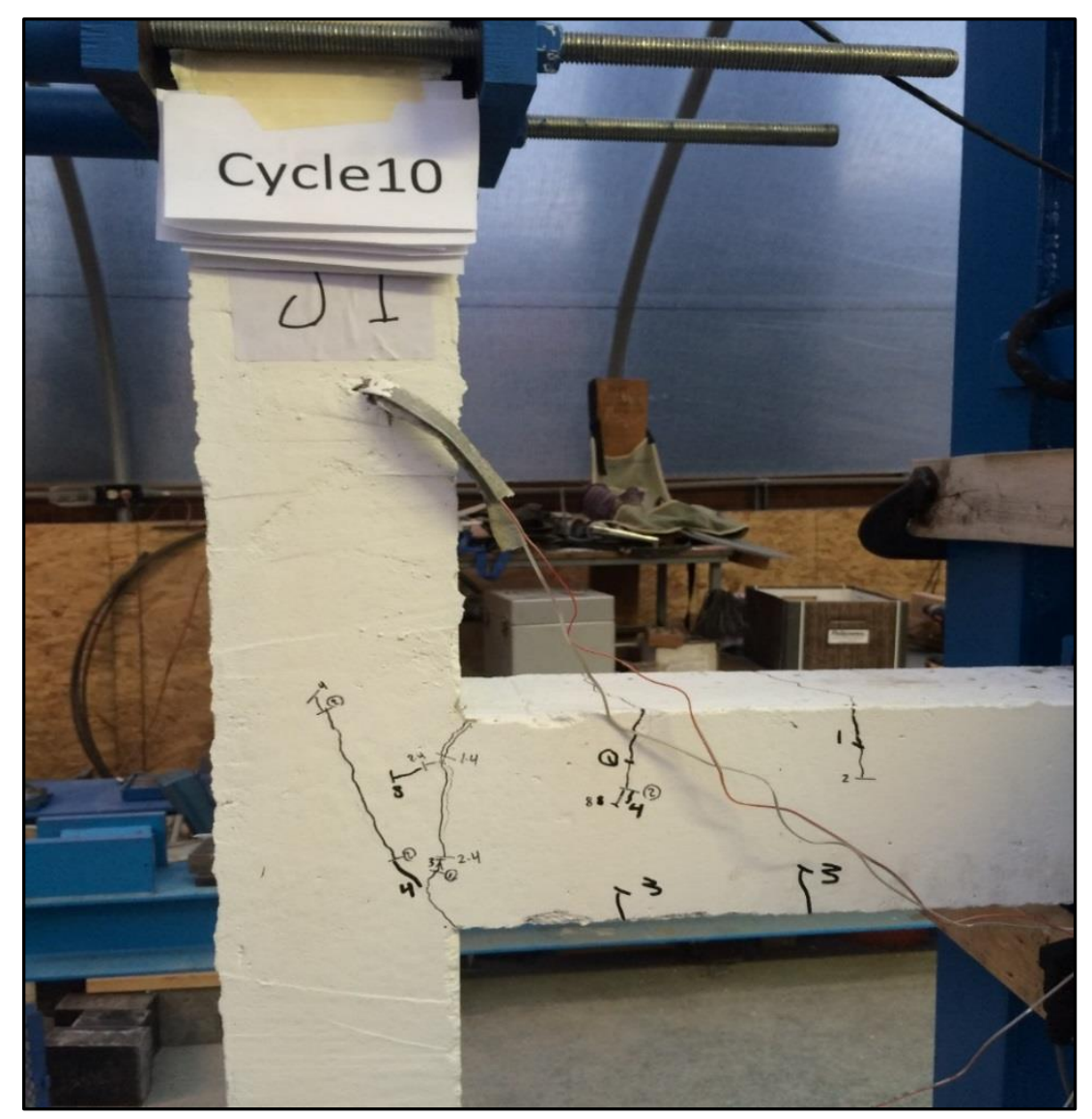

Figure 4-4 Specimen J1 at the End of First Set of Cycles.

In order to visually recognize the new cracks within the second set of cycles, red colored markers were used to highlight the cracks, whereas a black marker was used for the first set. Similar to the previous test procedure, the applied cyclic load on the free end of the beam in the second set was equal to $90 \%$ of the maximum theoretical load of the beam capacity. As expected in these cycles, the joint did not show any degradation in strength despite showing a few cracks within the joint region. Some of the existing cracks in the beam developed further, as shown in Figure 4-5. 

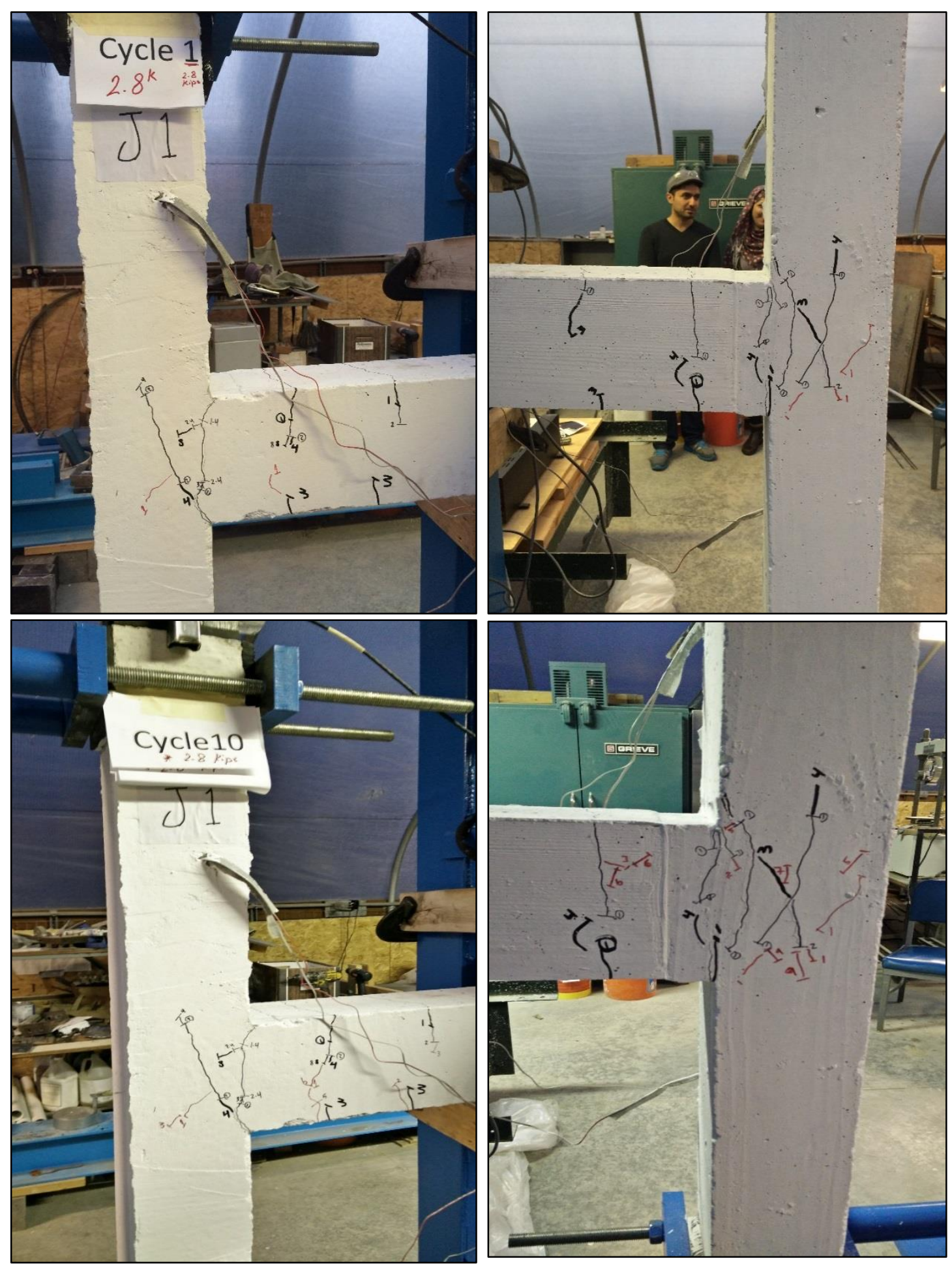

Figure 4-5 Crack Patterns Developed During Second Set of Applied Cyclic Load, J1 
In the first two sets of cycles (from cycle 1 until cycle 20), the specimen behavior showed that there was no degradation in the strength of the joint.

The next set of cycles represented the strain control where the cyclic load was applied to the free end of the beam until the strain was two times the yield strain to find out how the specimen would behave under severe earthquake effects. The first cycle in this phase developed the cracks within the joint region and formed diagonal cracks in " $\mathrm{X}$ " shape on both sides of the joint. The average cyclic load used in this phase was two times greater than used in the first set of load ( $75 \%$ maximum theoretical beam capacity). Blue Markers were used to highlight these cracks. Figure 4-6 shows the crack pattern at the first cycle within strain control phase.
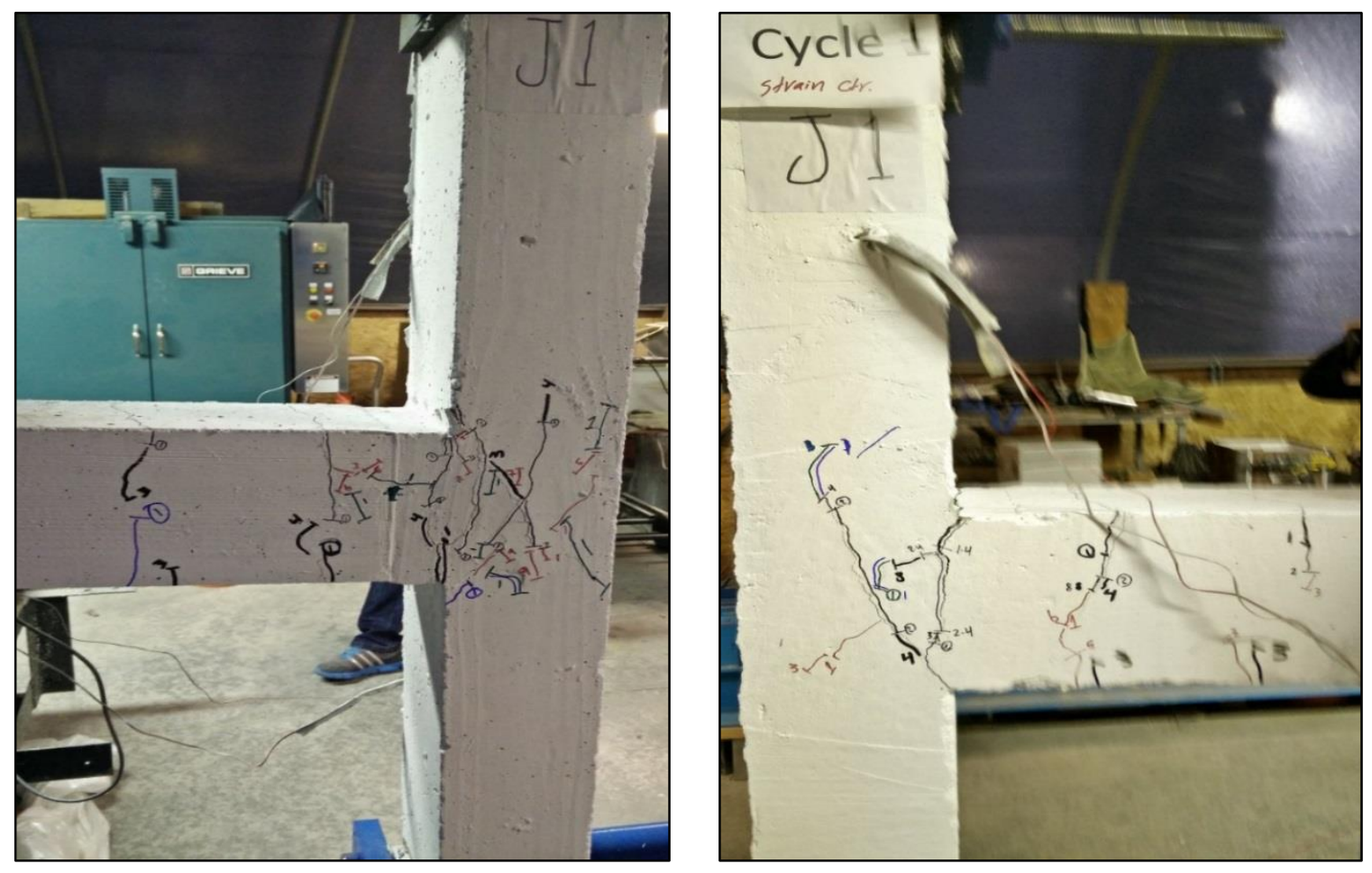

Figure 4-6 Crack Pattern of Cycle 1, Strain Control, J1 
As the strain control cycles progressed, the flexural crack that developed at the interface between the column and the beam became wider. Meanwhile, the side concrete covers started to gradually crack on both sides, especially at the seventh cycle in this set. Figure 4-7 shows cracking of concrete within the joint region.

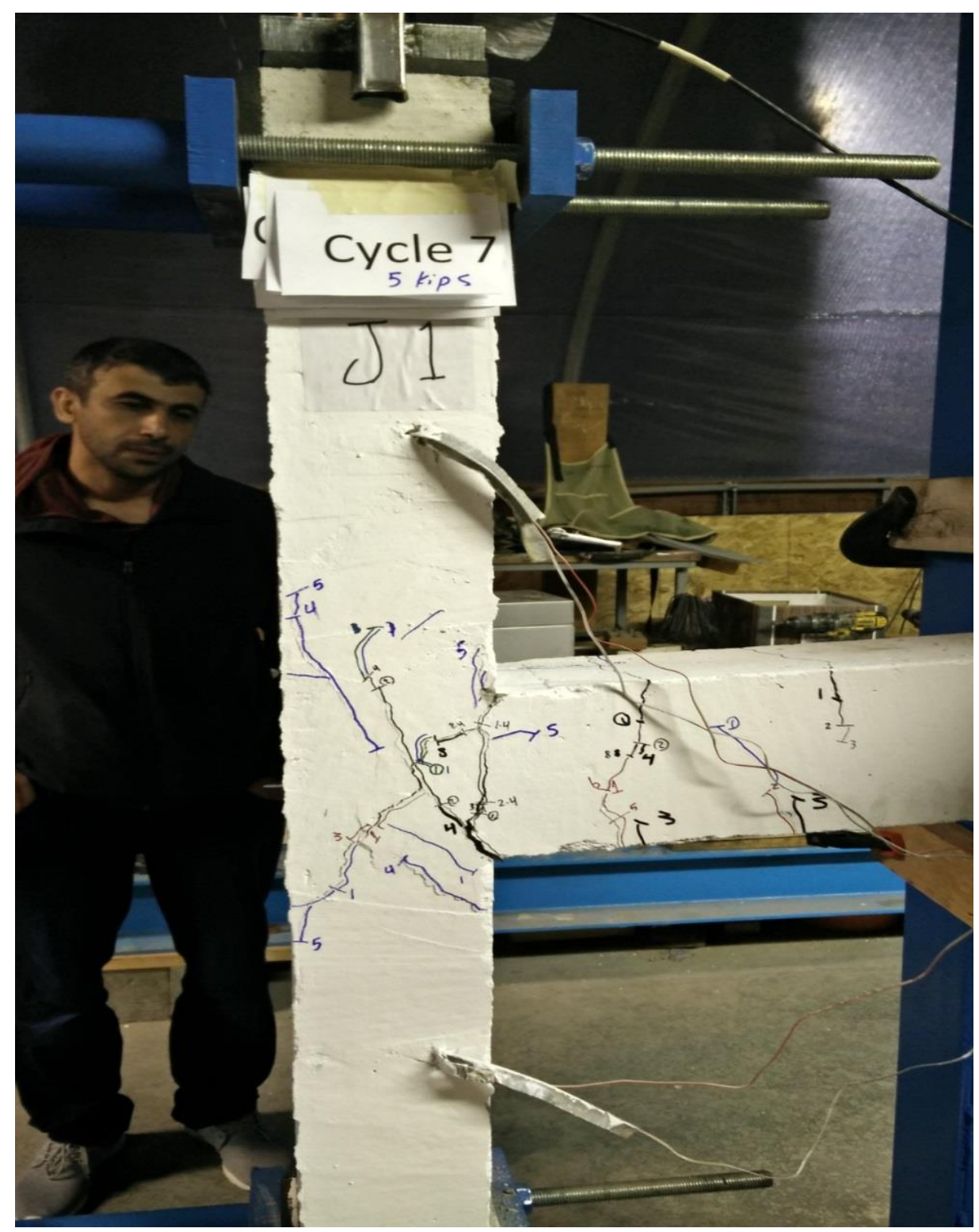

Figure 4-7 Concrete Cover Splitting, J1 
This specimen showed very good ductility. There was no degradation of the strength recorded through this set of cycles. After nineteen cycles in strain control, the jack stroke maxed out and this was the only reason why the test was stopped. At this point, the back side of the column was still intact with no crack. Figure 4-8 shows the final crack pattern of ductile specimen $\mathrm{J} 1$.
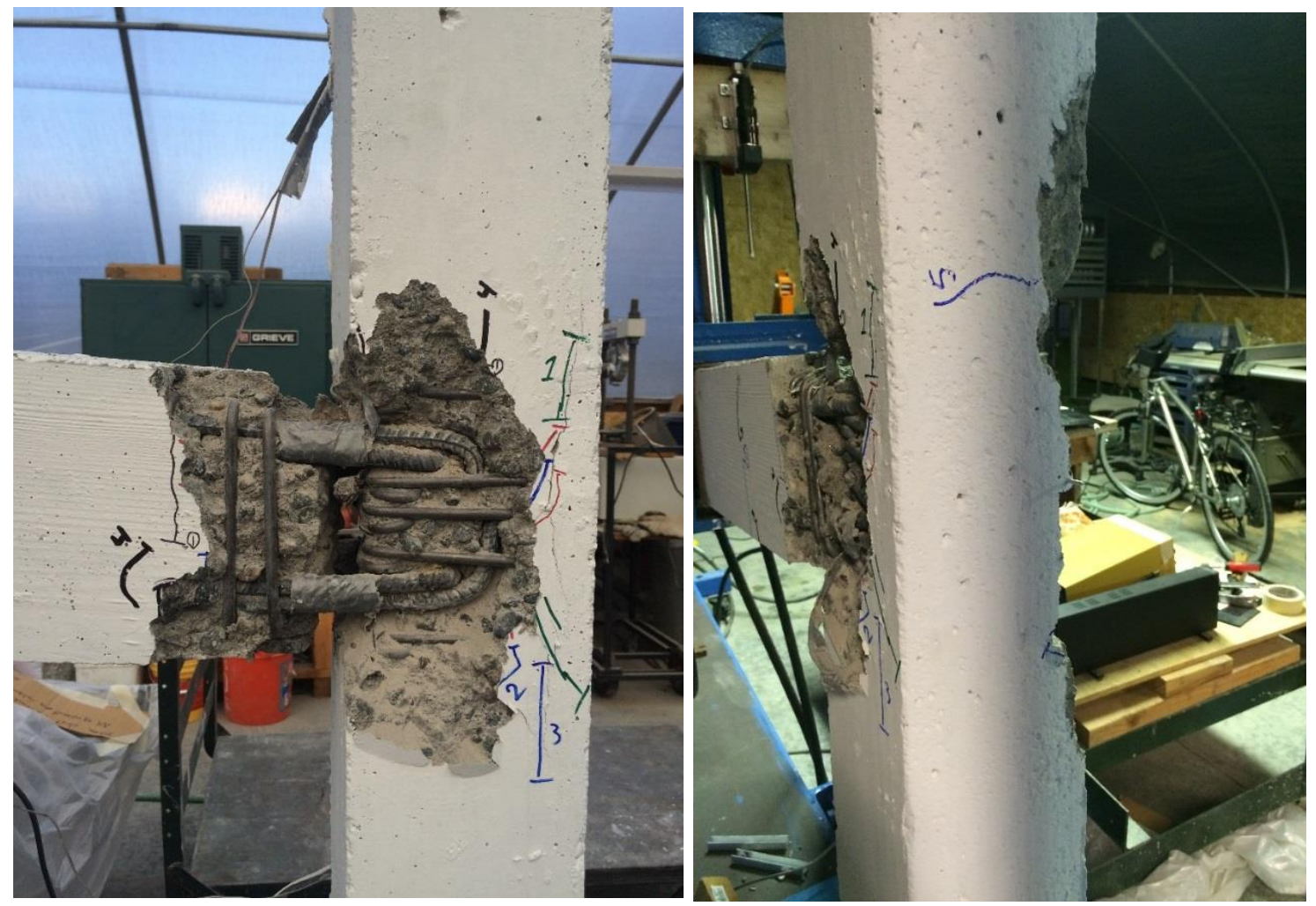

Figure 4-8 Specimen J1 (final crack pattern)

The applied load versus displacement was recorded and plotted in Figure 4-9. This figure shows that this beam-column joint was subjected to thirty-nine loading cycles.

Table 4-1 shows the values of the loads and displacements at each cycle for the free end of the beam. 


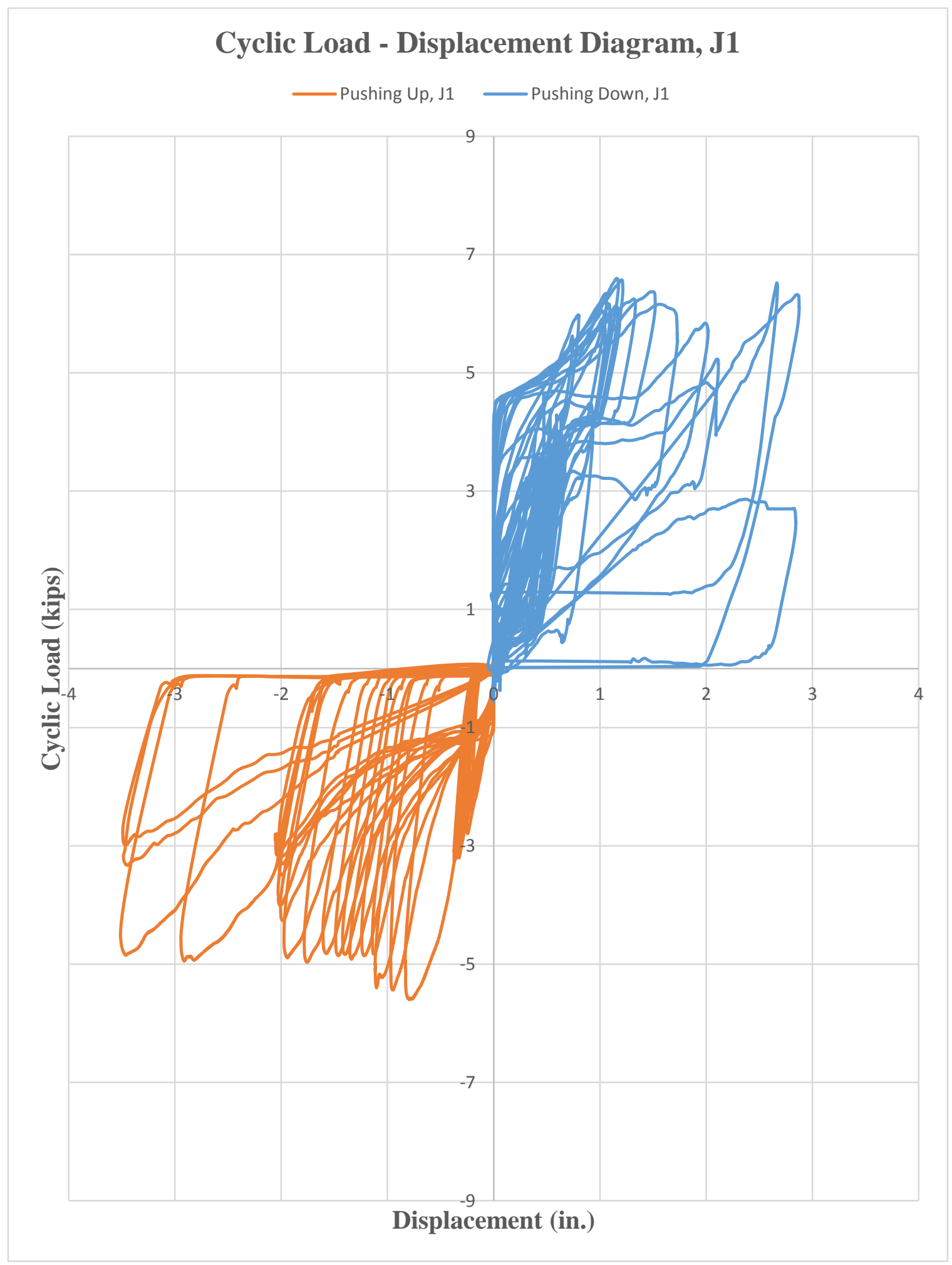

Figure 4-9 Load-Displacement Diagram, JI 
Table 4-1 The Maximum Values of the Loads and Displacements at Each Cycle, J1

\begin{tabular}{|c|c|c|c|c|}
\hline Cycle & Down F. & Disp. & Up F. & Disp. \\
\hline 0 & 0 & 0 & 0 & 0 \\
\hline 1 & 2.6381 & 0.13093 & -2.48314 & -0.11433 \\
\hline 2 & 2.4027 & 0.3225 & -2.49272 & -0.10126 \\
\hline 3 & 2.41088 & 0.32366 & -2.41603 & -0.14237 \\
\hline 4 & 2.4433 & 0.2433 & -2.41603 & -0.13801 \\
\hline 5 & 2.42712 & 0.36504 & -2.55984 & -0.14972 \\
\hline 6 & 2.419003 & 0.37702 & -2.5 & -0.144 \\
\hline 7 & 2.42712 & 0.3770202 & -2.4 & -0.14427 \\
\hline 8 & 2.419 & 0.40369 & -2.42561 & -0.16034 \\
\hline 9 & 2.532 & 0.40369 & -2.4543 & -0.16415 \\
\hline 10 & 2.402768 & 0.35415 & -2.502 & -0.15299 \\
\hline 11 & 2.83 & 0.44 & -2.78993 & -0.18048 \\
\hline 12 & 2.808 & 0.45868 & -2.88581 & -0.2009 \\
\hline 13 & 2.8 & 0.46059 & -2.809 & -0.2322 \\
\hline 14 & 2.7924 & 0.4265 & -2.857 & -0.23737 \\
\hline 15 & 2.784 & 0.4976 & -2.742 & -0.19872 \\
\hline 16 & 2.8086 & 0.4023 & -2.83787 & -0.24445 \\
\hline 17 & 2.8411 & 0.453 & -2.8858 & -0.2256 \\
\hline 18 & 2.83299 & 0.48971 & -2.78035 & -0.21723 \\
\hline 19 & 2.84111 & 0.4927 & -2.80911 & -0.2417 \\
\hline 20 & 2.8248 & 0.5267 & -2.972 & -0.23928 \\
\hline 21 & 3.027 & 0.7932 & -5.762 & -0.67238 \\
\hline 22 & 4.9 & 0.60296 & -5.666 & -0.86157 \\
\hline 23 & 4.96 & 0.63862 & -5.1196 & -0.89723 \\
\hline 24 & 4.919 & 0.8623 & -4.9758 & -1.0227 \\
\hline 25 & 5 & 0.95466 & -5.04297 & -1.1493 \\
\hline 26 & 5.154 & 0.94949 & -5.1196 & -1.2571 \\
\hline 27 & 5.235 & 0.91628 & -5.0142 & -1.3229 \\
\hline 28 & 5.77 & 1.0191 & -5.1005 & -1.39429 \\
\hline 29 & 5.787 & 1.054 & -5.0429 & -1.4988 \\
\hline 30 & 5.178 & 1.01319 & -5.167 & -1.68911 \\
\hline 31 & 5.138 & 0.9944 & -5.09091 & -1.876 \\
\hline 32 & 5.024 & 1.033 & -4.525 & -1.91 \\
\hline 33 & 5.43 & 1.1283 & -4.1321 & -1.91341 \\
\hline 34 & 5.609 & 1.3379 & -3.662 & -1.9175 \\
\hline 35 & 5.527 & 1.5459 & -3.3843 & -1.91477 \\
\hline 36 & 4.45 & 2.018 & -3.288 & -2.018 \\
\hline & & & & \\
\hline 24 & & & \\
\hline 13 & & & & \\
\hline & & & &
\end{tabular}




\begin{tabular}{|l|c|c|c|c|}
37 & 4.36 & 2.09 & -3.25972 & -2.046 \\
\hline 38 & 5.55 & 2.6603 & -5.04297 & -3.48 \\
\hline 39 & 2.037 & 2.4926 & -3.02 & -3.55 \\
\hline
\end{tabular}

Figure 4-9 showed the load versus displacement. Unfortunately during the test, two problems occurred: (1) One of the pressure sensors that was recording the load from the pushing hydraulic line, and this caused an erratic response in this part of the figure. (2) In the second phase of loading (strain control phase), some displacement data were not recorded because the tip of the beam moved away from the LVDT plunger. In these cases, data were not recorded, hence the plot shows no displacement for the earlier portion of loading in this phase. Based on the pushing up part in the Figure 4-9 above, specimen J1 showed that the load and displacement changed in a linear manner within the first twenty load cycles. After first cycles, flexural cracks at the interface between the column and the beam were created where the plastic hinge was supposed to form according to the design. The cracks' width at this plane increased as the load progressed in the cycles. Meanwhile, some diagonal cracks developed within the joint region as well. As expected, at the start of the strain control phase of the load sequence, the specimen was still healthy, and not losing any strength especially in the first load cycle. The maximum load that the specimen was subjected to was at this cycle. At cycle 39 which represented last cycle in this test, the cyclic load dropped to about half compared with the maximum load. This could be a sign that the strength was beginning to deteriorate. 


\subsubsection{Non-Ductile Specimen J2}

The general behavior of the non-seismic joint specimen $\mathrm{J} 2$ represented the behavior of the control specimen of non-ductile concrete beam-column joint, similar to those designed before modern seismic codes. This specimen was prepared and cast at Greenhouse Lab at Portland State University. After two and a half months, this specimen was tested by using the Blue Frame. Figure 4-10 shows how the specimen was placed in the frame and set for the test.

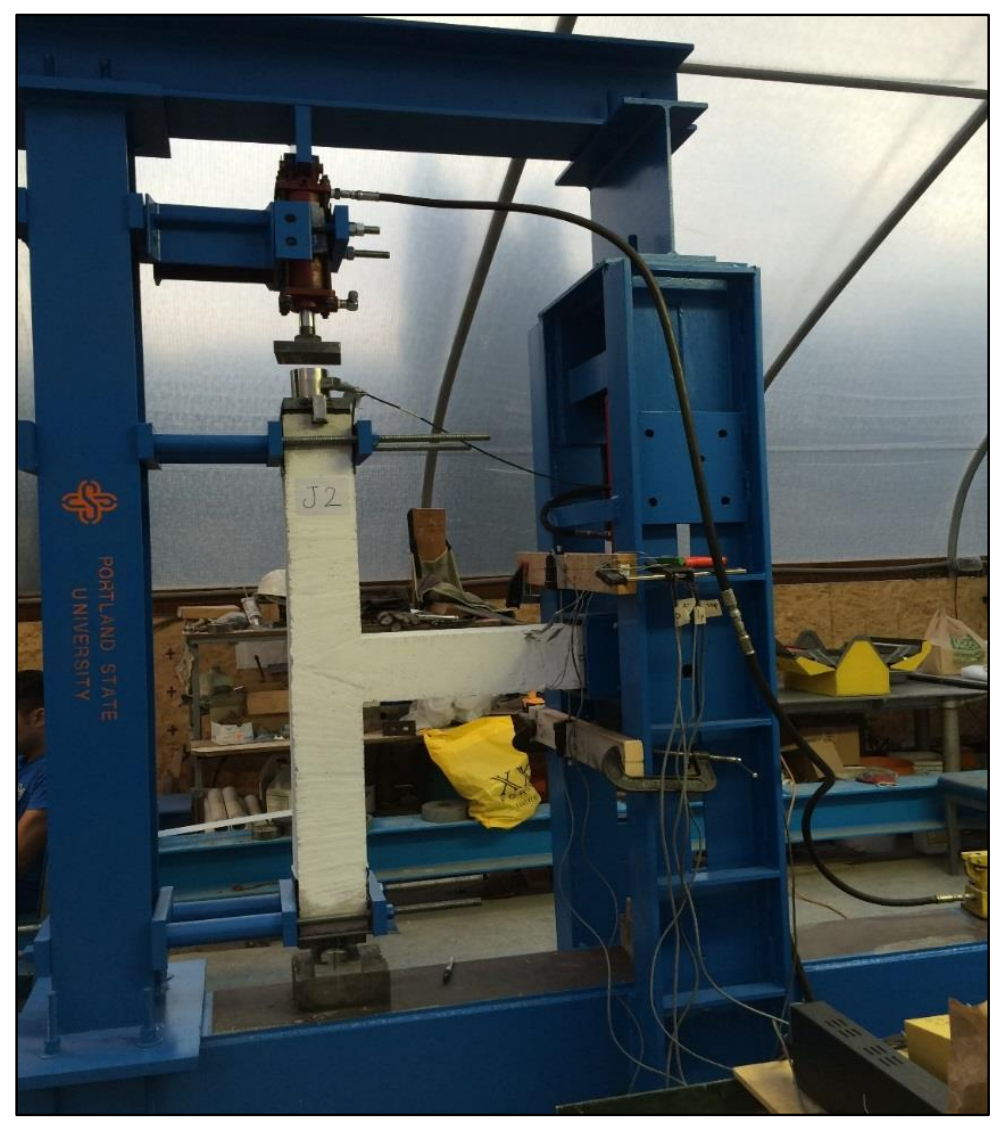

Figure 4-10 Test Setup of Specimen J2

After the four strain gauges of the specimen were connected to the data logger, the specimen was ready to test. The test was started by applying a 15 kip axial directly onto 
the column followed by the cyclic load on the free end of the beam. Each cycle load consisted of pushing the free end of the concrete beam downward and then releasing it, followed by pushing the beam up. The first ten cycles of the load were applied by using $75 \%$ of the maximum theoretical capacity of the beam section, which was equal to 2.4 kips. When the first cycle was applied, a single hairline crack started to develop from the upper corner of the specimen, between the beam and column, to the middle of the beam width vertically as shown in Figure 4-11. When the load was applied, the crack width measured $0.2 \mathrm{~mm}$, and after the load was released the crack closed completely.

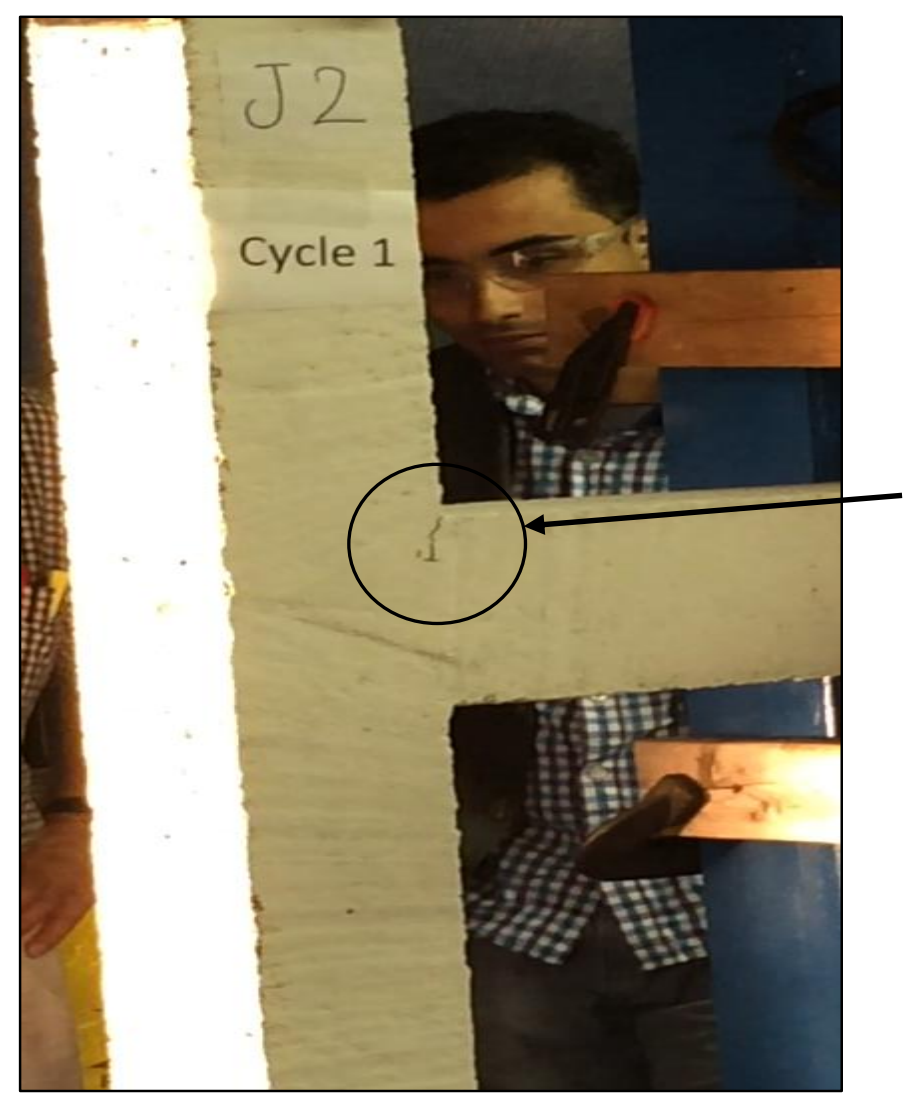

First crack at the first cycle

Figure 4-11 The Development of the First Crack, J2 
During the first cycle, when the pushing up force was applied, the same type of crack developed at the lower corner of the joint in opposite direction. The only difference between these cracks was the crack length. The lower crack was longer than the upper crack. Figure 4-12 shows these cracks at the end of cycle one. After the release of all loads at the end of cycle one, the crack closed completely. This meant that no permanent deformation happened in this cycle.

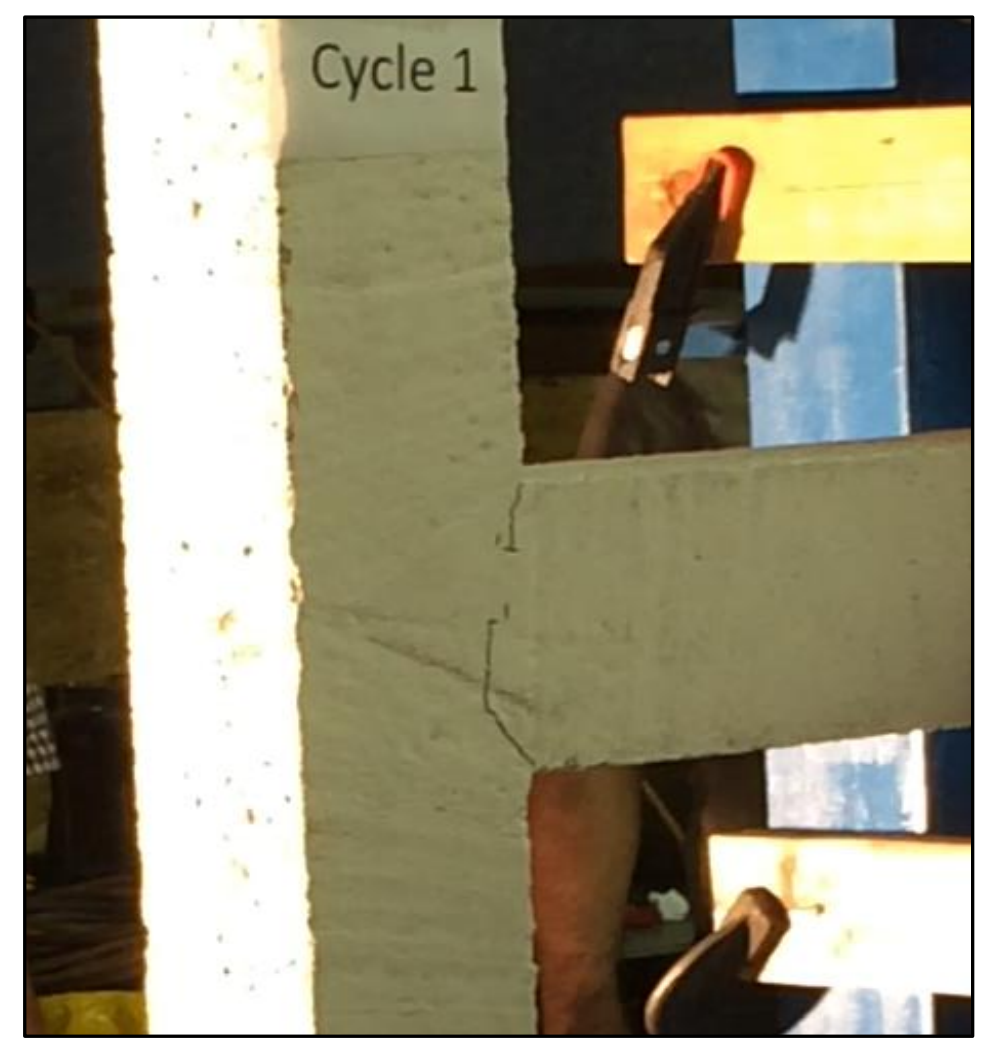

Figure 4-12 The Cracks of Joint J2 at the End of Cycle 1

When the second cycle was applied, both the upper and lower cracks elongated until they connected with each other. Moreover, the cracks' width increased. The upper crack width changed from $0.2 \mathrm{~mm}$ to $0.3 \mathrm{~mm}$, whereas the lower crack width changed from $0.2 \mathrm{~mm}$ to 
$0.25 \mathrm{~mm}$. Figures 4-13 and 4-14 show the cracks in joint $\mathrm{J} 2$ at the second cycle on both sides of the specimen.

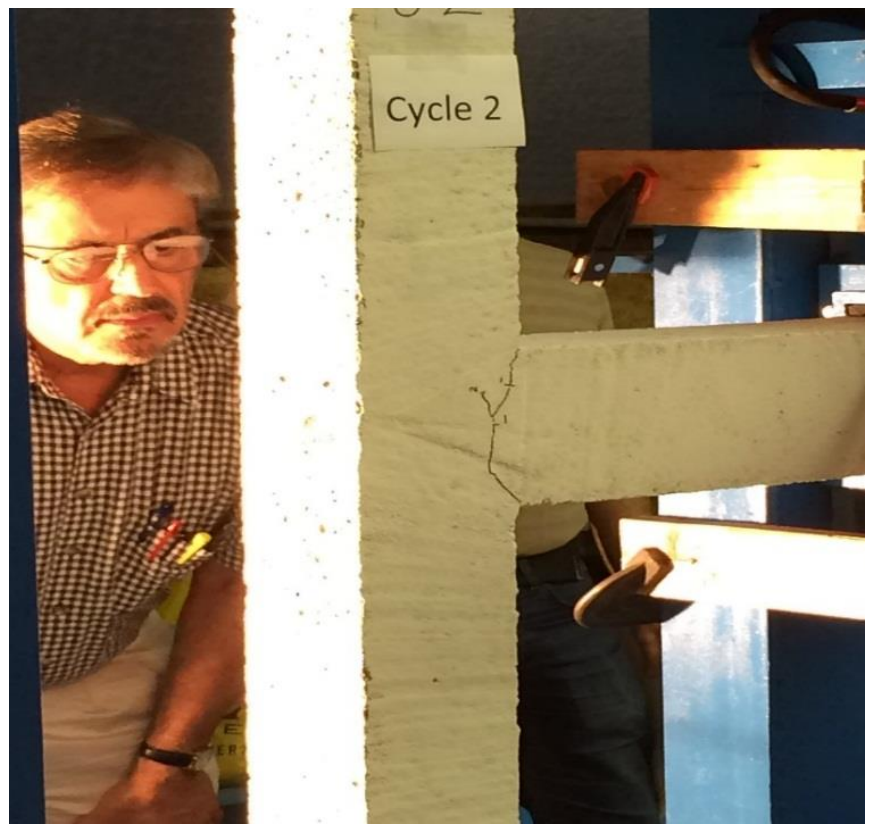

Figure 4-13 The Cracks of Joint J2 at the End of Cycle 2

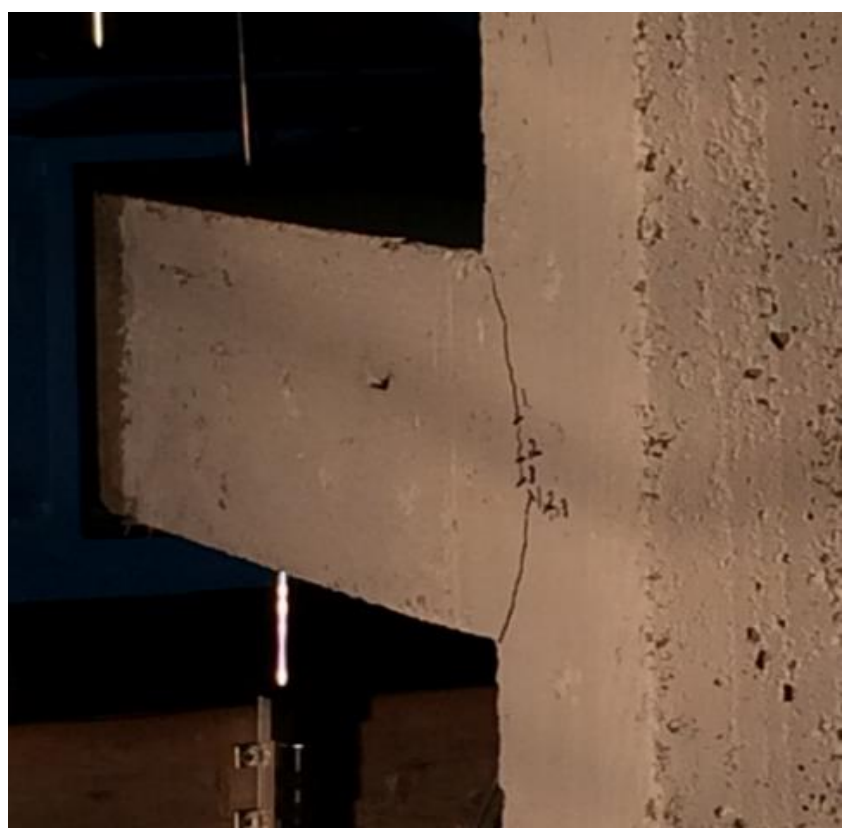

Figure 4-14 The Backside of Joint J2 at the End of Cycle 2 
Within the first ten cycles, when the maximum applied load was 2.4 kips, and after the third cycle, no cracks formed except at fourth cycle. Two 2-in. vertical cracks appeared within the joint area on one side of the specimen, as shown in Figure 4-15. The rest of the cycles caused an increase in the width of cracks. The crack width was $0.2 \mathrm{~mm}$ at cycle one, and increased to $0.58 \mathrm{~mm}$ and $0.4 \mathrm{~mm}$ at tenth cycle for the upper and lower cracks, respectively. All cracks closed at the end of all cycles, and this gave an indication that no permanent deformation had occurred.

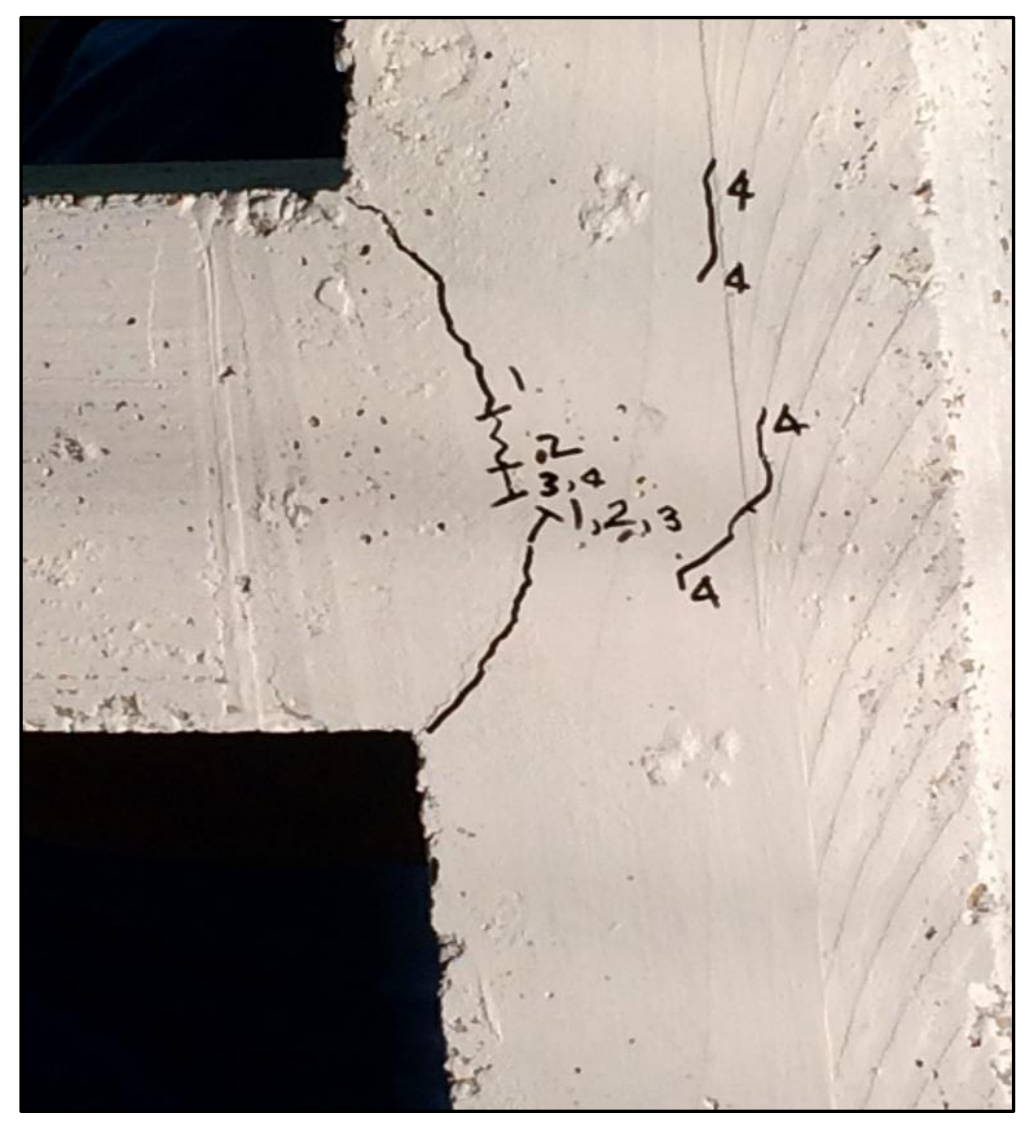

Figure 4-15 Developed Cracks at Cycle No. 4, J2 
For the next ten cycles, the load value was increased to represent $90 \%$ of the maximum theoretical beam capacity. The maximum applied load was 2.8 kips at each cycle of this set (from cycle 11 to cycle 20). The method used to apply the cyclic load was the same as described for the first ten cycles, and all of the cracks in these ten cycles were marked by a red marker. In the first phase of cycle eleven, a small 2-in. crack developed at $45^{\circ}$ within the joint region because the shear force that acted on the joint region. Figure 4-16 shows first shear crack that appeared on the joint.

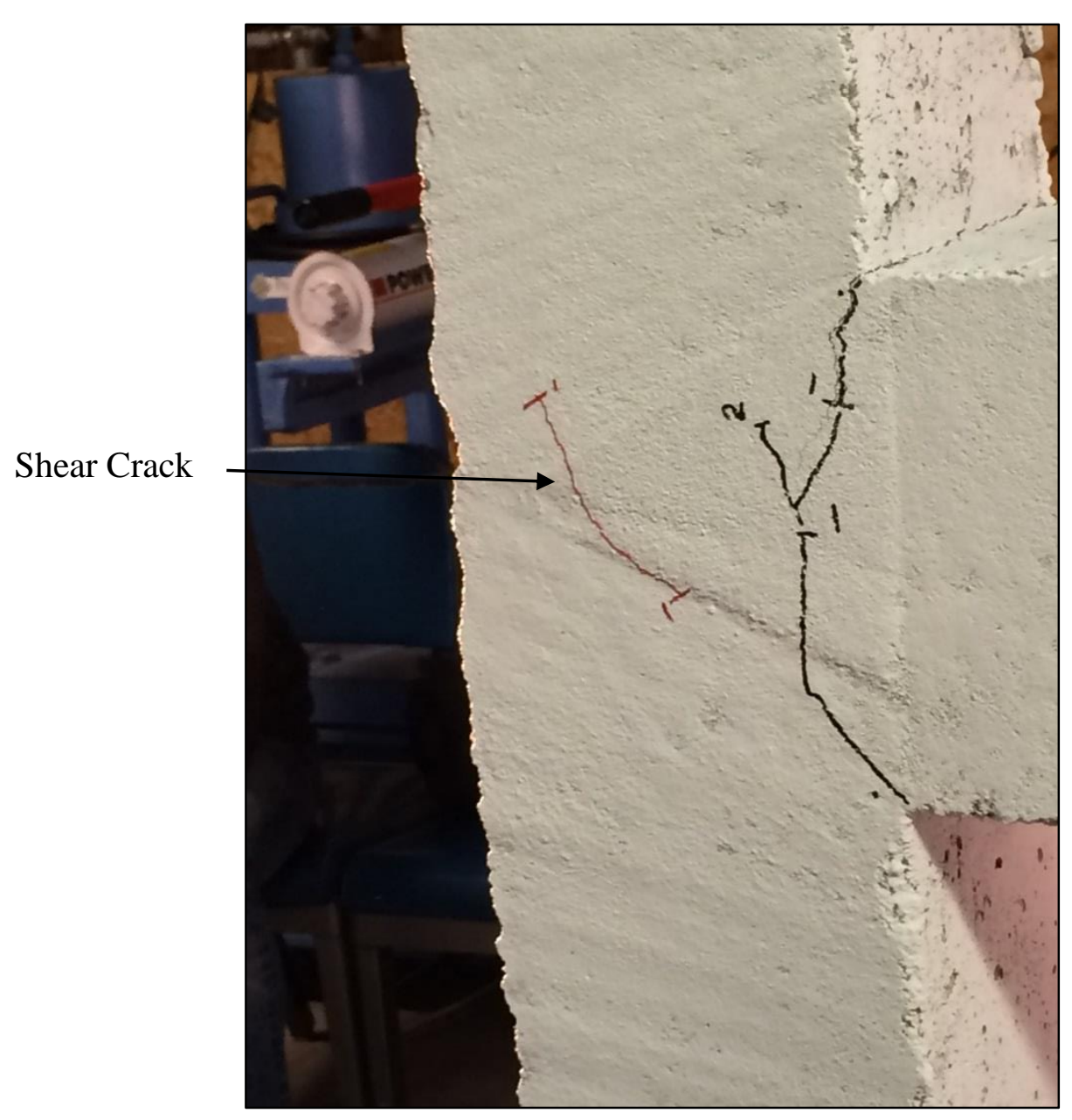

Figure 4-16 Cycle 21, J2 
By the end of the first cycle, two diagonal cracks in opposite directions developed, and formed a "X" shape at the center of the joint, as shown in Figure 4-17.
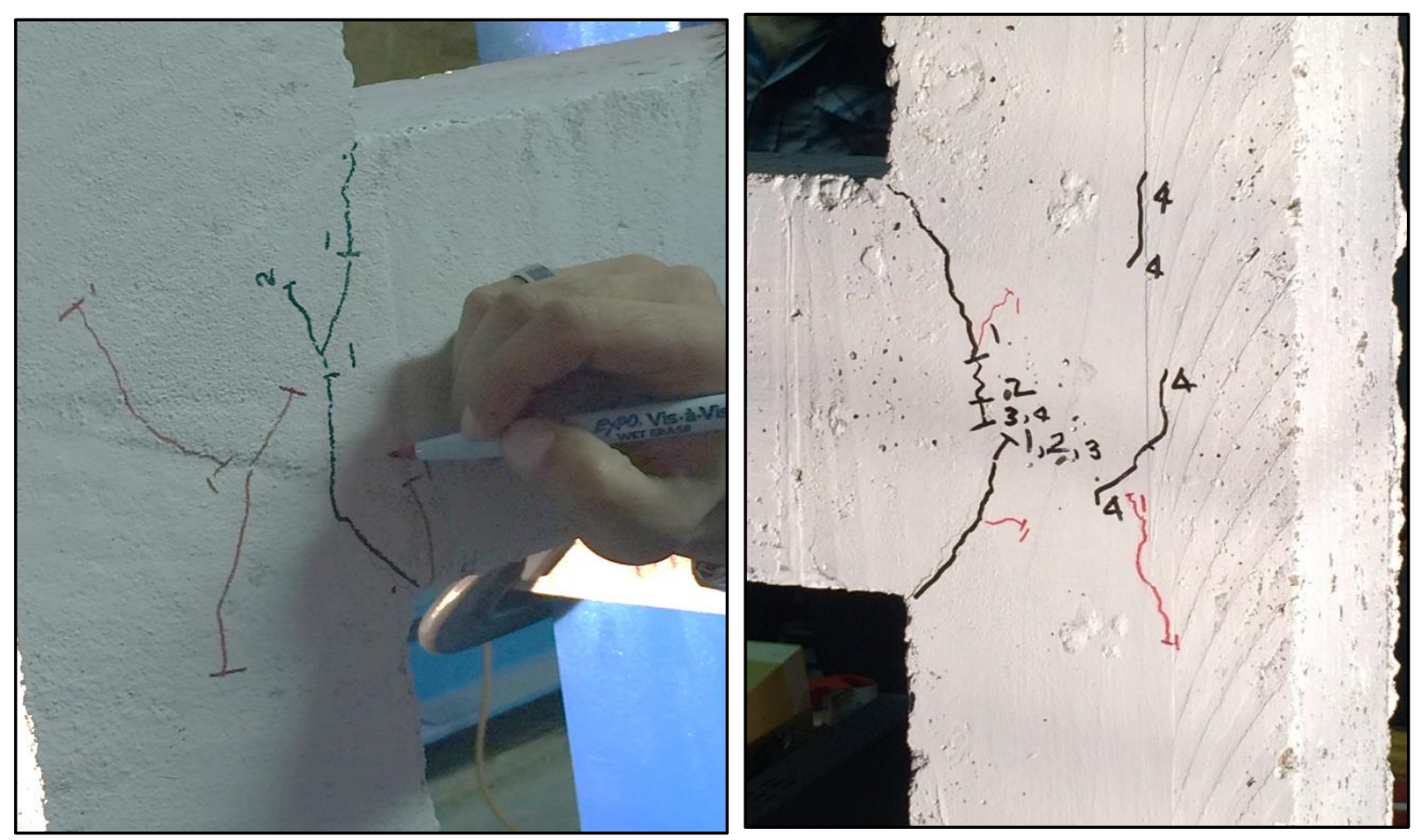

Figure 4-17 First Shear Cracks, J2

Moreover, a small flexural crack developed at the interface between the beam and column because the applied load was very close to the maximum design load. With regard to the previous cracks that developed in the first ten cycles, the cracks widths were $0.7 \mathrm{~mm}$ and $0.35 \mathrm{~mm}$ for the upper and lower cracks, respectively, when the cyclic load was applied, and $0.4 \mathrm{~mm}$ and $0.1 \mathrm{~mm}$ when the loads were released because the steel bars passed the elastic range and started in the plastic stage.

For the following cycles at the same applied load rate, there were no additional cracks formed in the joint region, but all old cracks progressed through the joint region on both sides. Meanwhile the cracks widths increased gradually beside flexural cracks in a "U" 
shape form on the top and bottom of the beam because the peak applied load of these ten cycles was very close to the maximum theoretical beam capacity. The crack widths ended at $1.2 \mathrm{~mm}$ and $0.6 \mathrm{~mm}$ under the load and $0.6 \mathrm{~mm}$ and $0.2 \mathrm{~mm}$ when the loads were released. Figure 4-18 shows the development of the cracks by the end of cycle twenty.

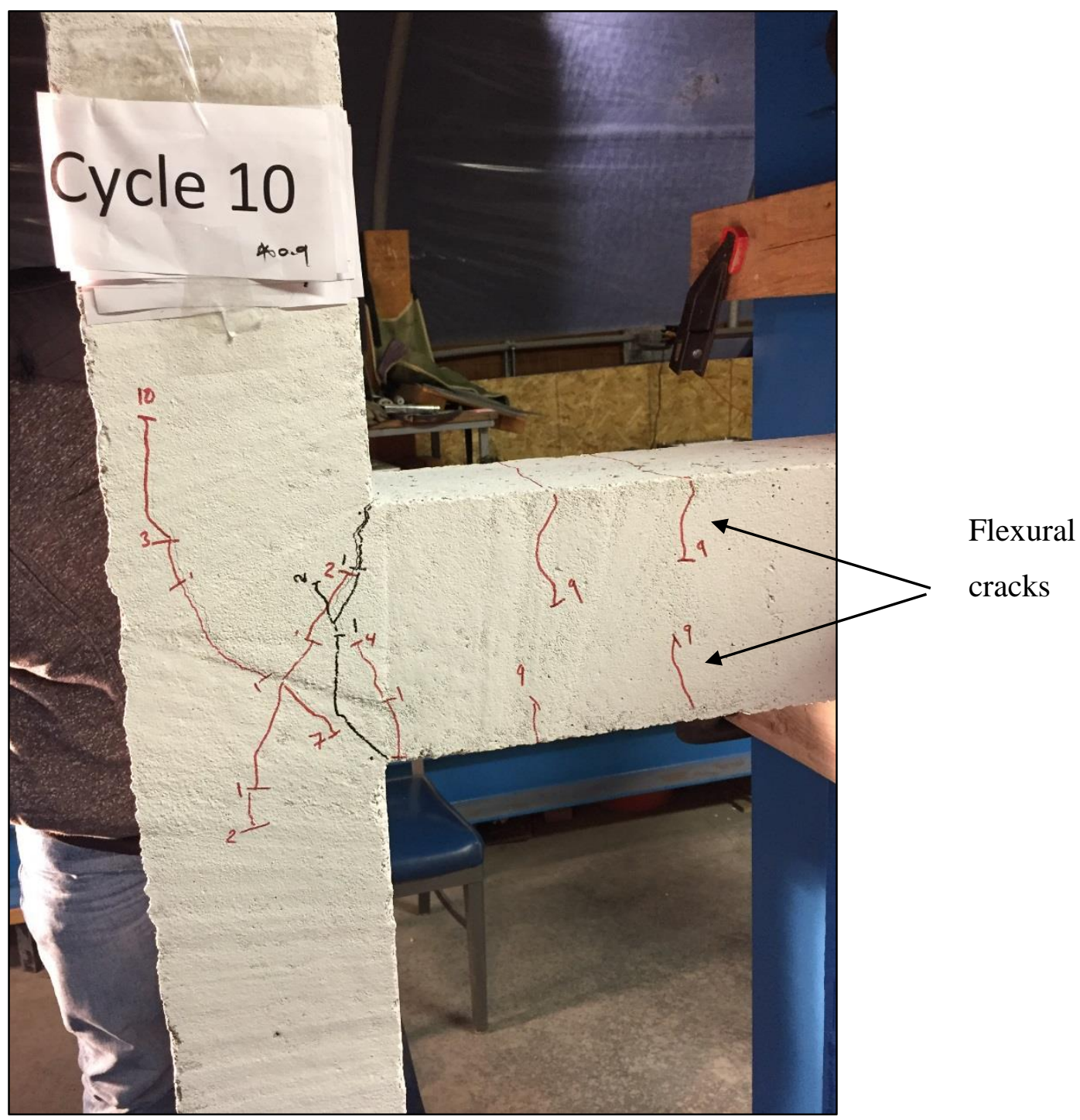

Figure 4-18 Developed Cracks within the Load Control Phase, J2 
The second ten cycles represented a moderate earthquake. Based on the loads and cracks patterns, such non-ductile concrete beam-column joints could have survived this kind of seismic effect. At this stage of the test, the load control phase was over and second phase (strain control) was started. In this stage, the joint would exhibit its behavior under a severe earthquake. The load cycle was applied in each direction until the strain in the beam longitudinal bars reached 0.004 , which represented two times the yield strain of the steel bar. At the first cycle, the free end of the beam pushed down until the strain in the upper beam steel bars reached 0.004 as planned. The specimen showed the highest strength and ductility during the test. The maximum applied load was 4.55 kips, which represented more than $1.4 \%$ of the theoretical design strength of the concrete beam section, whereas the deflection was 0.5 in. Once the load released, deflection decreased to zero. During the next four cycles, this specimen showed significant degradation in the strength of the joint where the specimen lost load capacity. It also experienced a large deflection under low loads. The test was ended when the strain reached $0.1 \%$ (indicating a steel stress of half yield capacity), and the maximum deflection was $1.25 \mathrm{in}$. The degradation in the strength was 50\%. Figure 4-19 shows the deformation of the joint at the end of the joint. The increase in crack widths, the slippage of reinforcement, and the loss of the concrete cover caused severe strength degradation. 

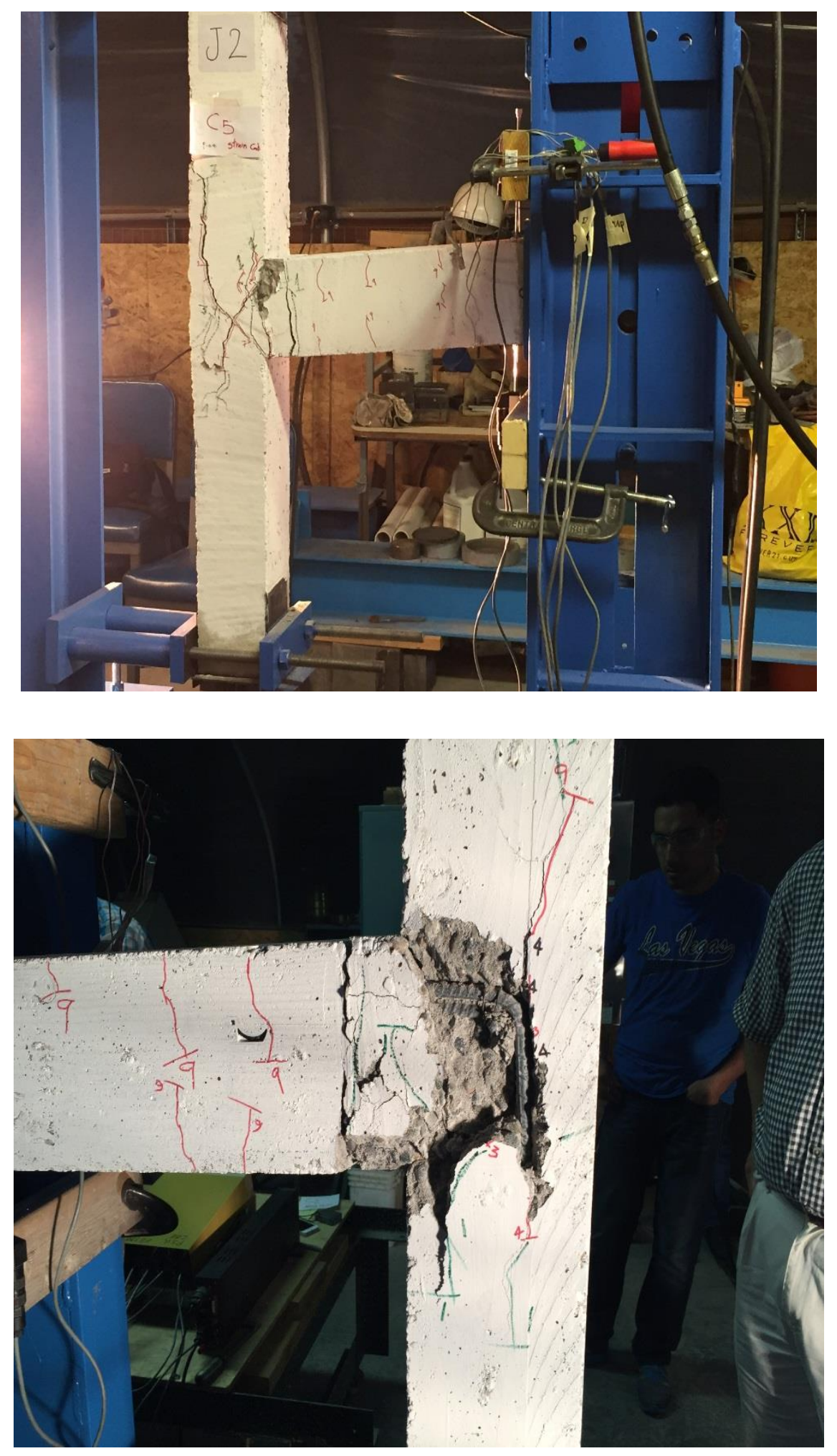

Figure 4-19 The Failure Pattern of Specimen J2 
The applied load versus displacement was recorded and plotted in Figure 4-20. This figure shows that this beam-column joint was subjected to twenty five loading cycles.

Table 4-2 shows the maximum values of the loads and displacements at each cycle.

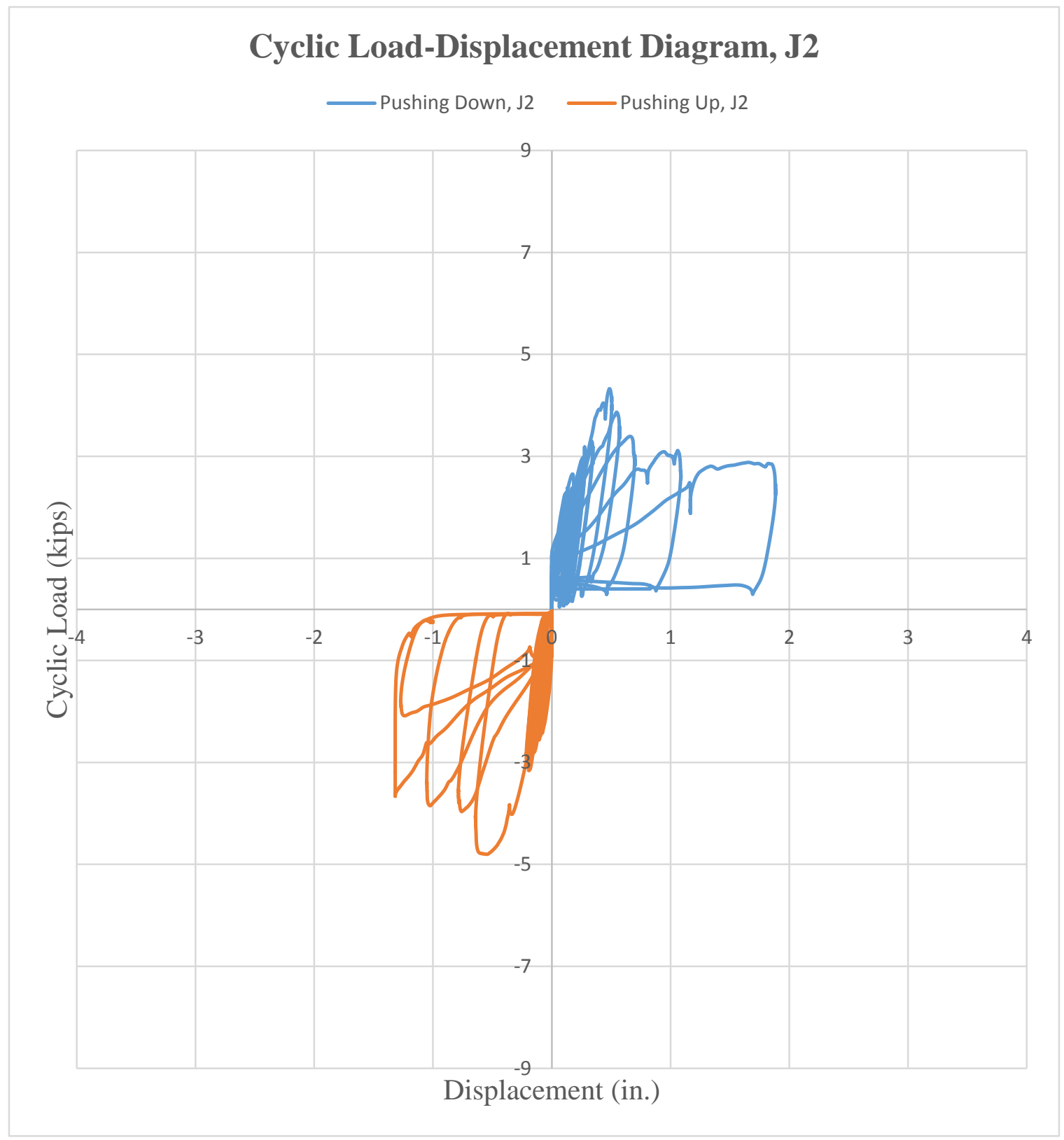

Figure 4-20 Load - Displacement Diagram, J2 
Table 4-2 The Values of the Loads and Displacements at Each Cycle, J2

\begin{tabular}{|c|c|c|c|c|}
\hline Cycle & Down F. & Disp. & Up F. & Disp. \\
\hline 0 & 0 & 0 & 0 & 0 \\
\hline 1 & 2.4064 & 0.12152 & -2.4064 & -0.0684 \\
\hline 2 & 2.4064 & 0.11803 & -2.416 & -0.07205 \\
\hline 3 & 2.433 & 0.1276 & -2.41602 & -0.0857 \\
\hline 4 & 2.444 & 0.1563 & -2.4352 & -0.08467 \\
\hline 5 & 2.4256 & 0.1718 & -2.4735 & -0.08832 \\
\hline 6 & 2.4064 & 0.188 & -2.4352 & -0.095 \\
\hline 7 & 2.4064 & 0.197 & -2.4064 & -0.1 \\
\hline 8 & 2.416 & 0.18411 & -2.416 & -0.106 \\
\hline 9 & 2.4064 & 0.1876 & -2.416 & -0.101 \\
\hline 10 & 2.4064 & 0.182 & -2.4064 & -0.107 \\
\hline 11 & 2.8091 & 0.2158 & -2.8091 & -0.143 \\
\hline 12 & 2.8282 & 0.2274 & -2.8474 & -0.14925 \\
\hline 13 & 2.81869 & 0.208 & -2.857 & -0.172 \\
\hline 14 & 2.8 & 0.2591 & -2.8186 & -0.178 \\
\hline 15 & 2.828 & 0.2199 & -2.8187 & -0.18195 \\
\hline 16 & 2.8 & 0.251 & -2.847 & -0.19225 \\
\hline 17 & 2.847 & 0.23175 & -2.818 & -0.2 \\
\hline 18 & 2.8 & 0.2355 & -2.876 & -0.1932 \\
\hline 19 & 2.924 & 0.2621 & -2.81869 & -0.2017 \\
\hline 20 & 2.9816 & 0.271 & -2.8 & -0.204 \\
\hline 21 & 4.544 & 0.4998 & -4.995 & -0.548 \\
\hline 22 & 4.065 & 0.555 & -4.1225 & -0.77 \\
\hline 23 & 3.882 & 0.6541 & -4.026 & -1.0371 \\
\hline 24 & 3.202 & 1.0611 & -3.8157 & -1.318 \\
\hline 25 & 2.75 & 1.1674 & -2.29139 & -1.25 \\
\hline
\end{tabular}

Figure 4-20 shows the load versus displacement. First the cracks started within the joint region, and then flexural cracks appeared along the beam. Since first cycles when the load was represented by $75 \%$ and $90 \%$ of the maximum theoretical beam capacity, the joint showed strength against the applied cyclic load in the load control phase. It was clear based on the J2's behavior that non- ductile specimens designed for gravity load 
could only survive light earthquakes. Once the strain control phase started, the degradation of the strength was clear. But the slip of the longitudinal flexural bar within the joint region on the last two cycles occurred where the maximum strain was $0.1 \%$ (about half yield strain) meant the steel stopped working effectively.

\subsubsection{Retrofitted Specimen J3}

The general behavior of strengthened joint $\mathrm{J} 3$ represented the behavior of the non-ductile concrete beam-column joint which was designed according to the pre-seismic codes. This specimen was retrofitted by using one layer of CFRP sheet. The way the specimen was retrofitted has been described in previous chapters. Figure 4-21 shows how the specimen was placed in the frame and set for the test.

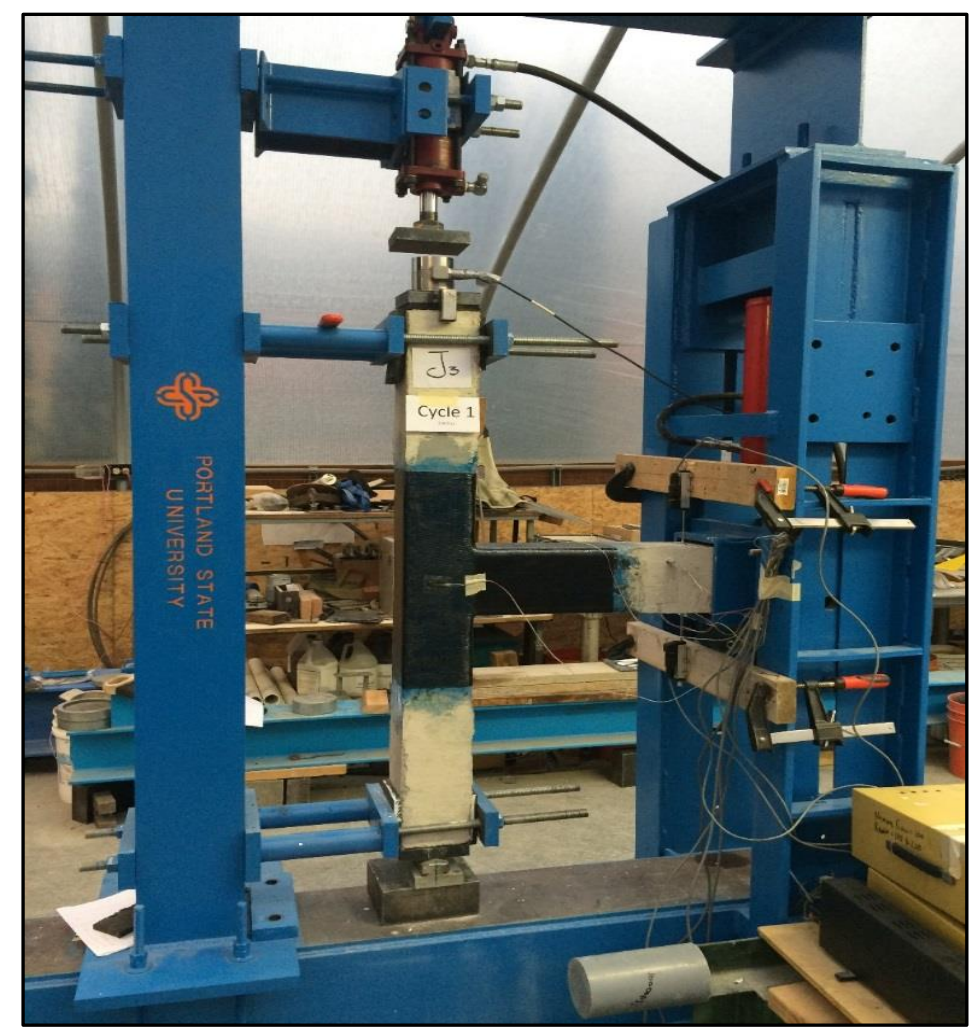

Figure 4-21 Test Setup of Specimen J3 
Two additional strain gages were used in this test on either sides of the joint at the middle of the joint region in order to measure the strain would develop in the CFRP sheets before the start of the test. The same load sequences were followed where the test started by applying the axial column load, then the cyclic loads on the beam. Because the joint and surrounding areas were wrapped with CFRP sheets, it was not possible to track the cracks. In the first two sets (twenty cycles) of the cyclic loads (phase 1), which represented $75 \% \mathrm{P}$ and $90 \% \mathrm{P}$, there was no deterioration in the specimen's strength. Figure 4-22 shows the specimen $\mathrm{J} 3$ at the end of cycle twenty.

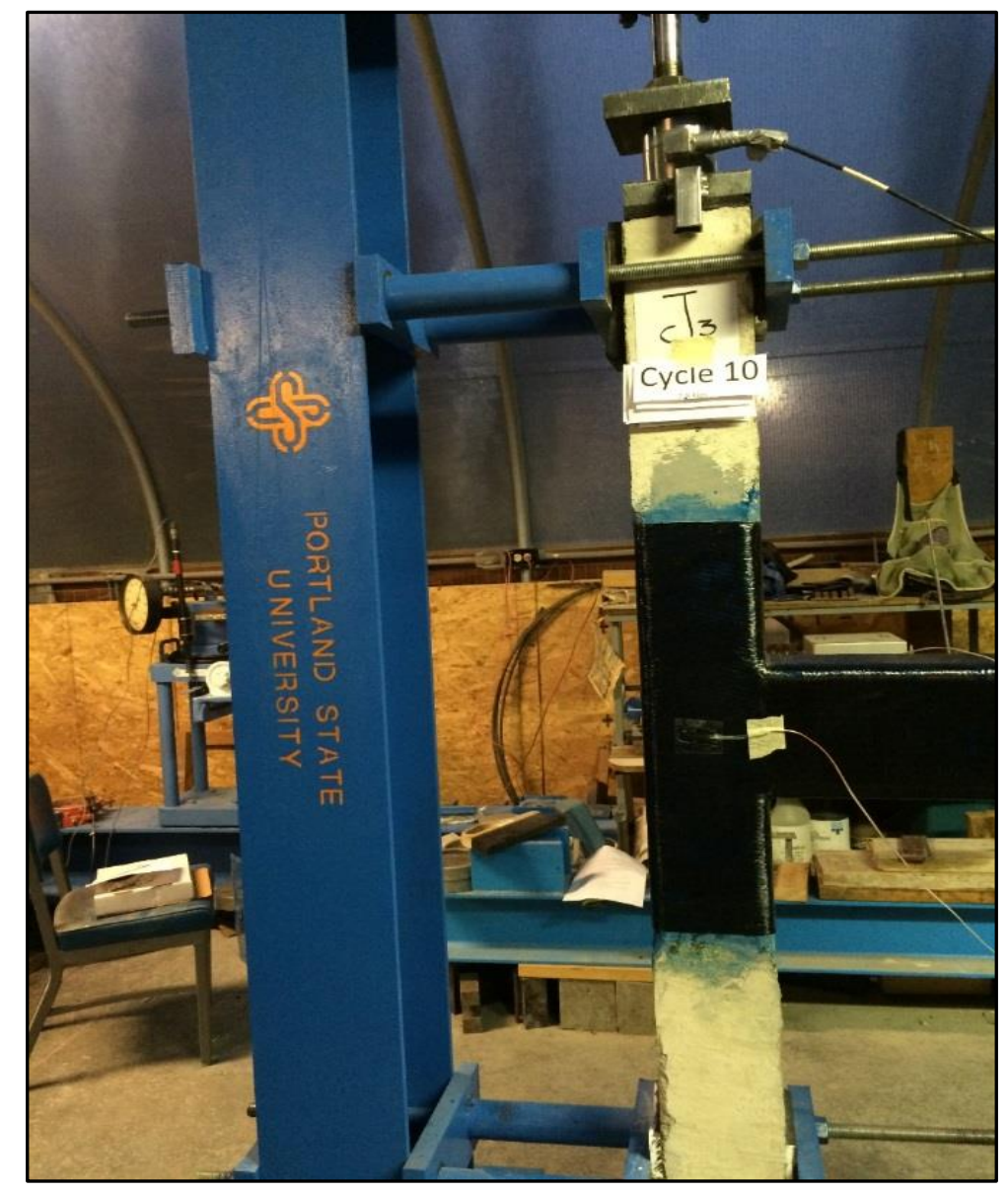

Figure 4-22 Specimen J3 at the End of cycle 20 
At this point, the strain control stage started, where the cyclic load was applied until the strain in the beam flexural bars reached $0.4 \%$. Twenty load cycles were applied on the free end of the beam. During these cycles the CFRP sheets showed a small fold that appeared at both corners, but without rupture failure. The maximum strain that developed in the CFRP sheets was around 0.4\%. Figure 4-23 shows the joint J3 at the end of the first 20 cycles in the strain control phase.

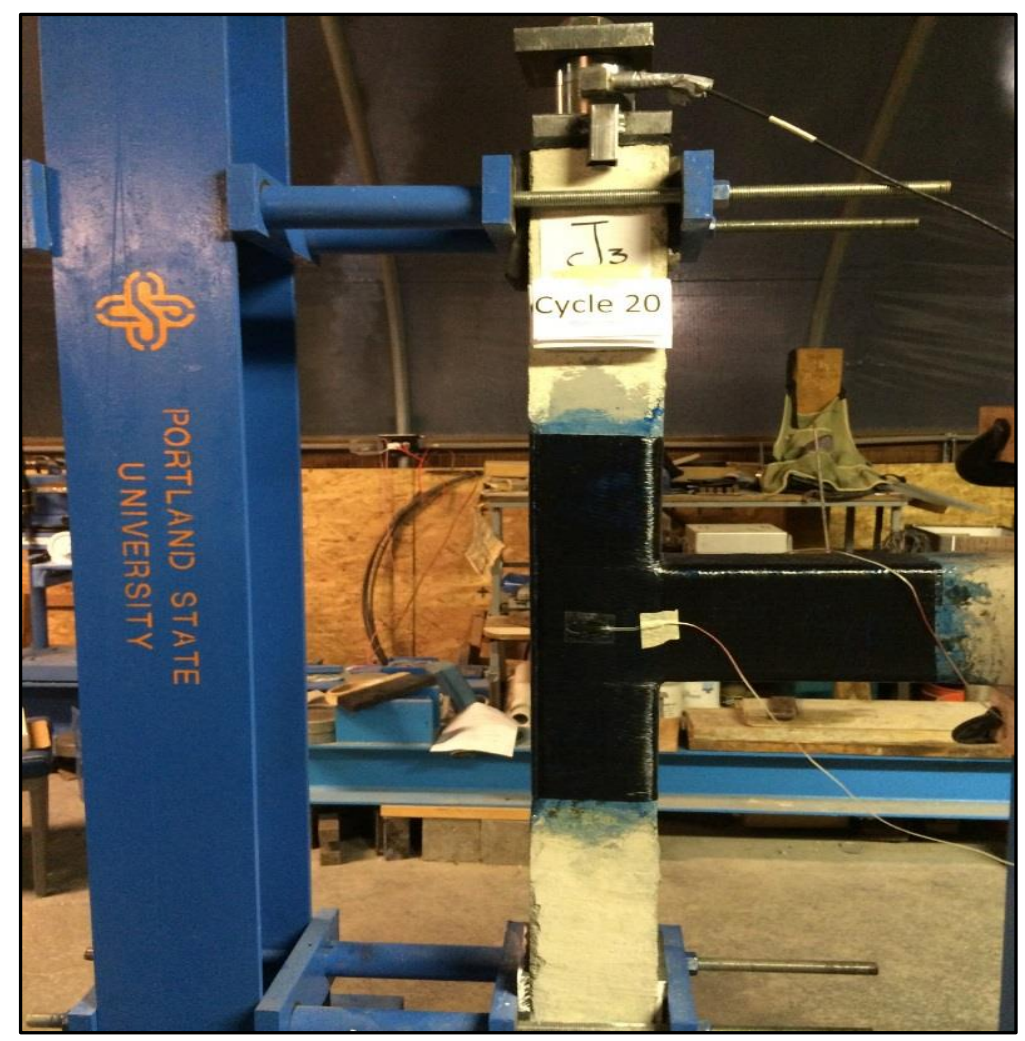

Figure 4-23 Specimen J3 at the End of Cycle 20, Strain Control Phase

The specimen showed no sign of failure or deterioration in the strength. The second stage of the strain control was based on developing a $0.6 \%$ strain in the beam flexural bars. During the first cycle within this set, the joint showed adequate strength in terms of the applied load, but the CFRP sheets ruptured at 45 degree angles (X-shape) between the beam and column. With the advance of the cycles at the same strain level, the CFRP 
sheets started to rupture and gave a clear sign that the failure was close. After five cycles within this stage of loading, the CFRP sheet in the joint region ruptured completely. The concrete covers on both sides were taken off when the maximum strain that developed on the CFRP sheets was around $0.6 \%$. On the other hand, the beam and the wrapped areas around the column above and below the joint were still intact. Consequently, it was observed that the general behavior of the wrapped specimen J3 was improved significantly over the control specimen J2. Figure 4-24 shows specimen J3 at failure.

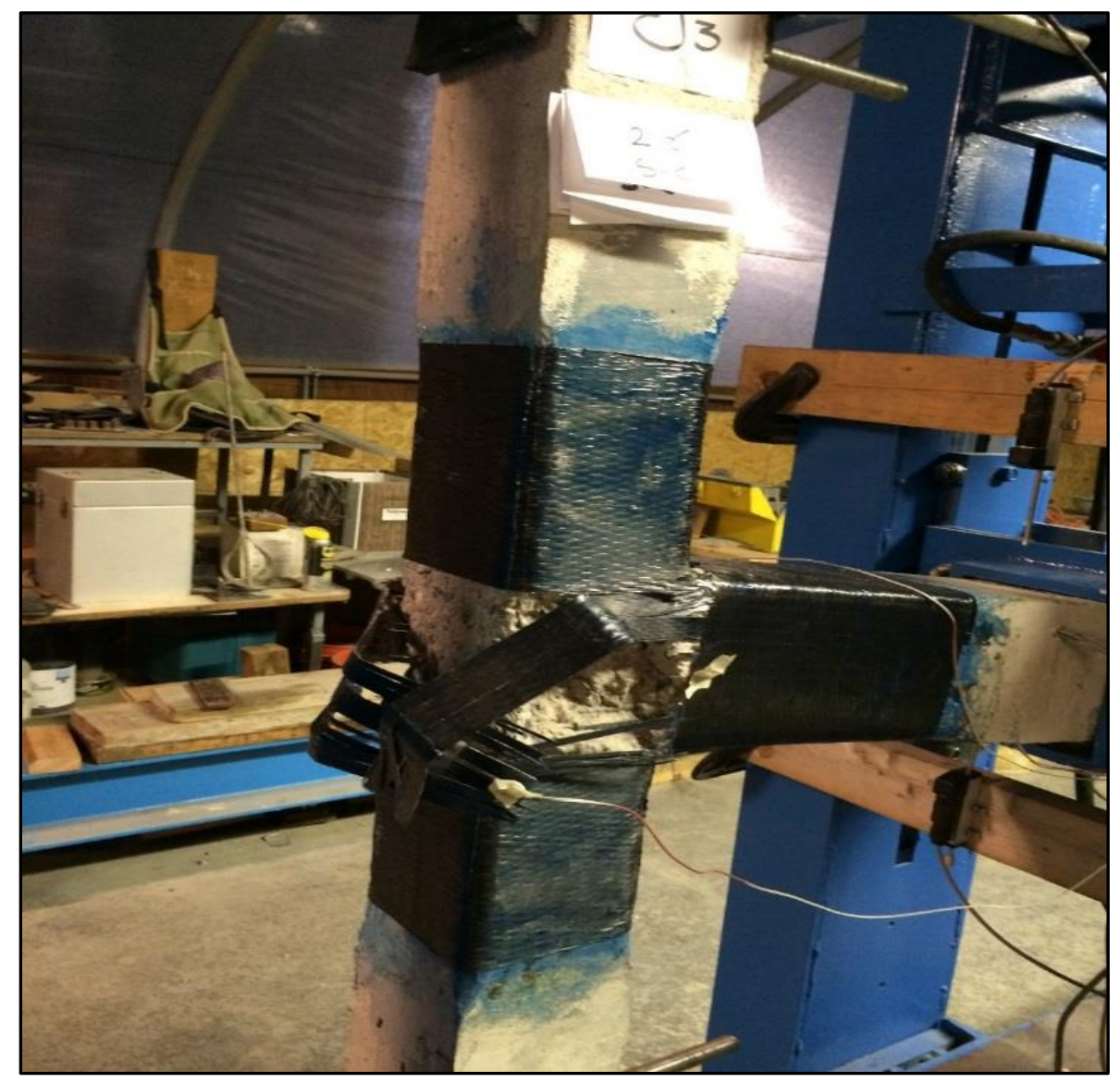

Figure 4-24 Specimen J3 at the Failure 
The applied cyclic load versus displacement of the free end of the beam was recorded and plotted in Figure 4-25. This figure shows that this beam-column joint was subjected to forty five loading cycles. Table 4-3 shows the values of the loads and displacements at each cycle.

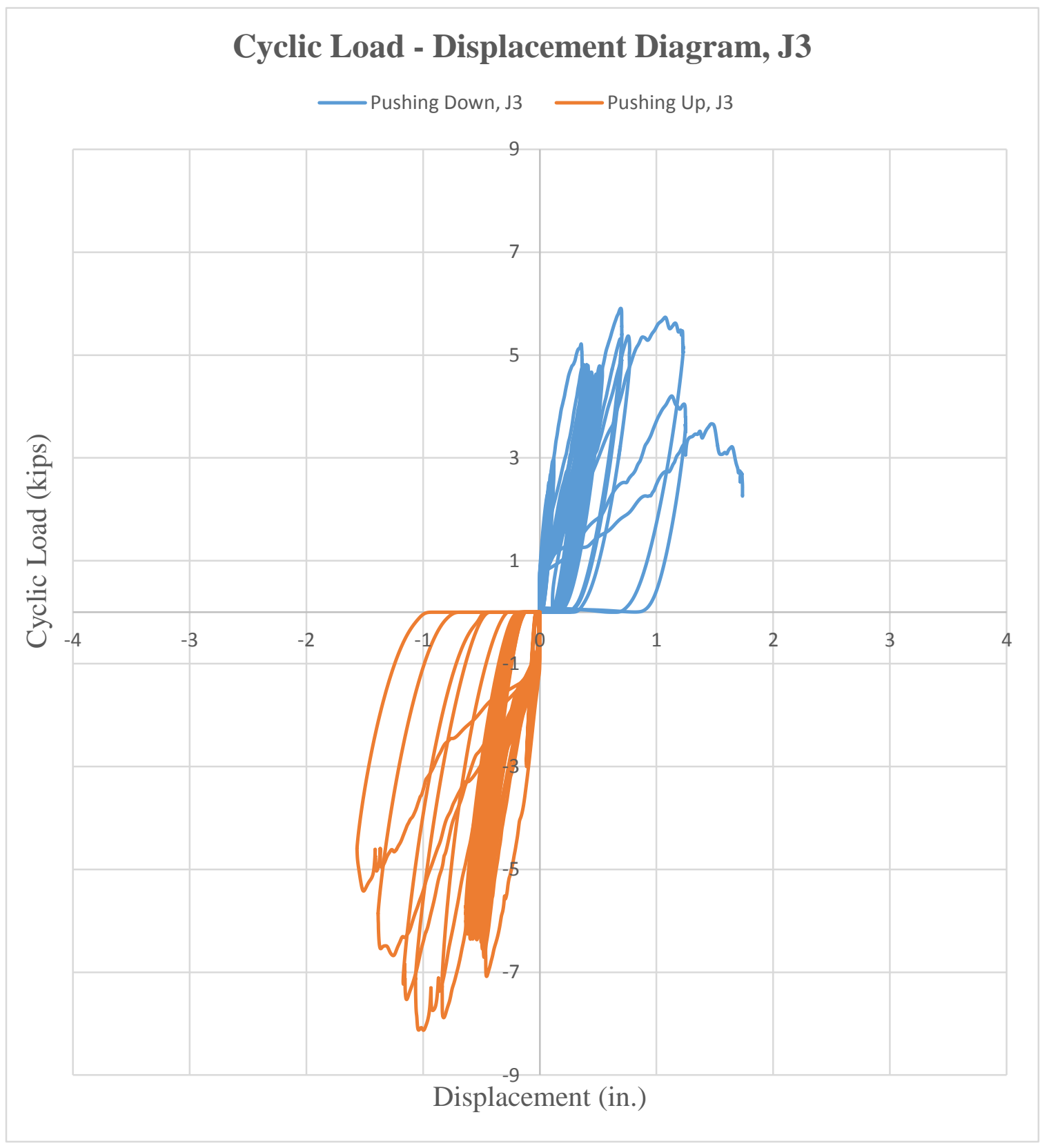

Figure 4-25 Load-Displacement Diagram, J3 
Table 4-3 The Values of the Loads and Displacements at Each Cycle, J3

\begin{tabular}{|c|c|c|c|c|}
\hline cycle & Down F. & Disp. & Up F. & Disp. \\
\hline 0 & 0 & 0 & 0 & 0 \\
\hline 1 & 2.483 & 0.0718 & -2.4831 & -0.0722 \\
\hline 2 & 2.444 & 0.075 & -2.416 & -0.082 \\
\hline 3 & 2.4543 & 0.074 & -2.406 & -0.0896 \\
\hline 4 & 2.4352 & 0.0702 & -2.435 & -0.085 \\
\hline 5 & 2.4064 & 0.0751 & -2.444 & -0.0907 \\
\hline 6 & 2.4064 & 0.0737 & -2.40644 & -0.09046 \\
\hline 7 & 2.4064 & 0.0789 & -2.4256 & -0.09019 \\
\hline 8 & 2.4064 & 0.0745 & -2.40644 & -0.091 \\
\hline 9 & 2.416025 & 0.0819 & -2.444 & -0.09019 \\
\hline 10 & 2.406 & 0.0811 & -2.425 & -0.091 \\
\hline 11 & 2.8091 & 0.102 & -2.837 & -0.0975 \\
\hline 12 & 2.8091 & 0.102 & -2.828 & -0.0953 \\
\hline 13 & 2.837 & 0.105 & -2.8378 & -0.09944 \\
\hline 14 & 2.818 & 0.1091 & -2.828 & -0.1005 \\
\hline 15 & 2.837 & 0.1107 & -2.8187 & -0.0953 \\
\hline 16 & 2.8186 & 0.1121 & -2.8378 & -0.10216 \\
\hline 17 & 2.8474 & 0.1146 & -2.8187 & -0.10325 \\
\hline 18 & 2.8378 & 0.11514 & -2.857 & -0.113 \\
\hline 19 & 2.8091 & 0.12059 & -2.80911 & -0.1038 \\
\hline 20 & 2.8091 & 0.12059 & -2.80911 & -0.1038 \\
\hline 21 & 5.3977 & 0.3555 & -7.133 & -0.4555 \\
\hline 22 & 4.956 & 0.3786 & -6.854 & -0.471 \\
\hline 23 & 4.91833 & 0.3996 & -6.7878 & -0.49089 \\
\hline 24 & 4.8895 & 0.4099 & -6.586 & -0.5017 \\
\hline 25 & 4.7361 & 0.41839 & -6.5386 & -0.51239 \\
\hline
\end{tabular}




\begin{tabular}{|c|c|c|c|c|}
\hline 26 & 4.6978 & 0.42683 & -6.4139 & -0.52 \\
\hline 27 & 4.7457 & 0.4317 & -6.4235 & -0.53091 \\
\hline 28 & 4.745 & 0.4374 & -6.4139 & -0.54125 \\
\hline 29 & 4.4581 & 0.4431 & -6.2893 & -0.54588 \\
\hline 30 & 4.7553 & 0.4483 & -6.327 & -0.5496 \\
\hline 31 & 4.619 & 0.4497 & -6.394 & -0.5589 \\
\hline 32 & 4.4677 & 0.457052 & -6.366 & -0.5619 \\
\hline 33 & 4.448 & 0.46 & -6.327 & -0.5717 \\
\hline 34 & 4.5348 & 0.4668 & -6.327 & -0.57528 \\
\hline 35 & 4.69782 & 0.4769 & -6.337 & -0.5829 \\
\hline 36 & 4.6307 & 0.4864 & -6.3276 & -0.59106 \\
\hline 37 & 4.76 & 0.5 & -6.2 & -0.5992 \\
\hline 38 & 4.7553 & 0.5117 & -6.327 & -0.6087 \\
\hline 39 & 4.7553 & 0.5172 & -6.327 & -0.6158 \\
\hline 40 & 4.7553 & 0.528647 & -6.289 & -0.6204 \\
\hline 41 & 5.8674 & 0.6829 & -7.89 & -0.82272 \\
\hline 42 & 5.5511 & 0.693 & -7.928 & -0.92 \\
\hline 43 & 5.3114 & 0.7526 & -7.775 & -1.14911 \\
\hline 44 & 5.1676 & 0.8242 & -6.728 & -1.355 \\
\hline 45 & 3.624 & 1.25 & -------- & --------- \\
\hline
\end{tabular}

Based on the load- displacement diagram for specimen J3, it is clear that until the final failure there was no deterioration in the strength along the load sequence. The maximum load was about 8 kips whereas the maximum theoretical capacity of the beam strength was 3 kips. This improvement in the strength of the specimen J3 was due to the confinement provided by the CFRP sheet. 


\subsubsection{Retrofitted Specimen J4}

The general behavior of retrofitted joint J4 represents the behavior of the non-ductile concrete beam-column joint, which was designed according to the earlier codes used before the development of modern seismic code. This specimen was retrofitted using two layers of the carbon fiber reinforced polymer sheet. This specimen was prepared and cast at Greenhouse Lab at Portland State University. After three months, this specimen was tested using the Blue Frame in the lab. Figure 4-26 shows how the specimen was placed in the frame and set for the test.

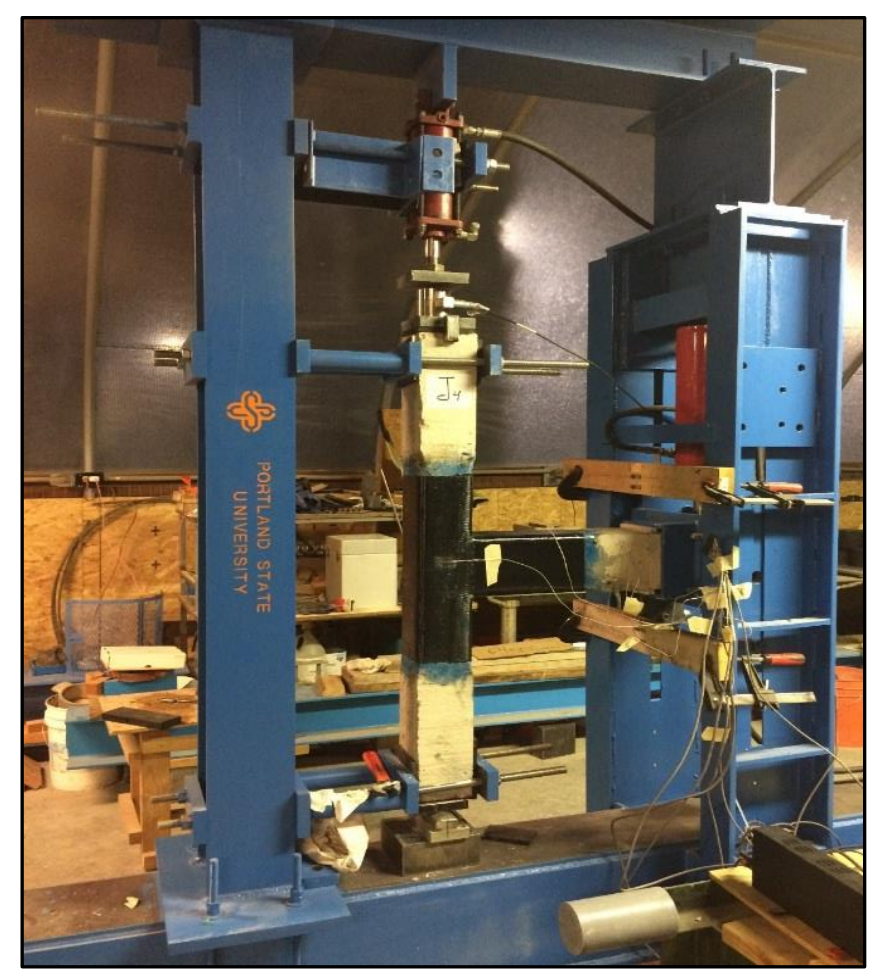

Figure 4-26 Test Setup of Specimen J4

Two additional strain gages were used in this test, as well on either sides of the joint at the middle of the joint region in order to measure the strain that developed in the CFRP 
sheets before starting the test. The same load sequences were followed where the test started by applying the axil load, and then the cyclic loads as usual. Because the joint and surrounding areas were wrapped in CFRP sheets, it was not possible to observe the cracks. In the first two sets (twenty cycles) of the cyclic loads at $75 \%$ and $90 \%$ of the beam capacity, there was no deterioration in the specimen's strength. Figure 4-27 shows the specimen $\mathrm{J} 4$ at the end of twentieth cycle.

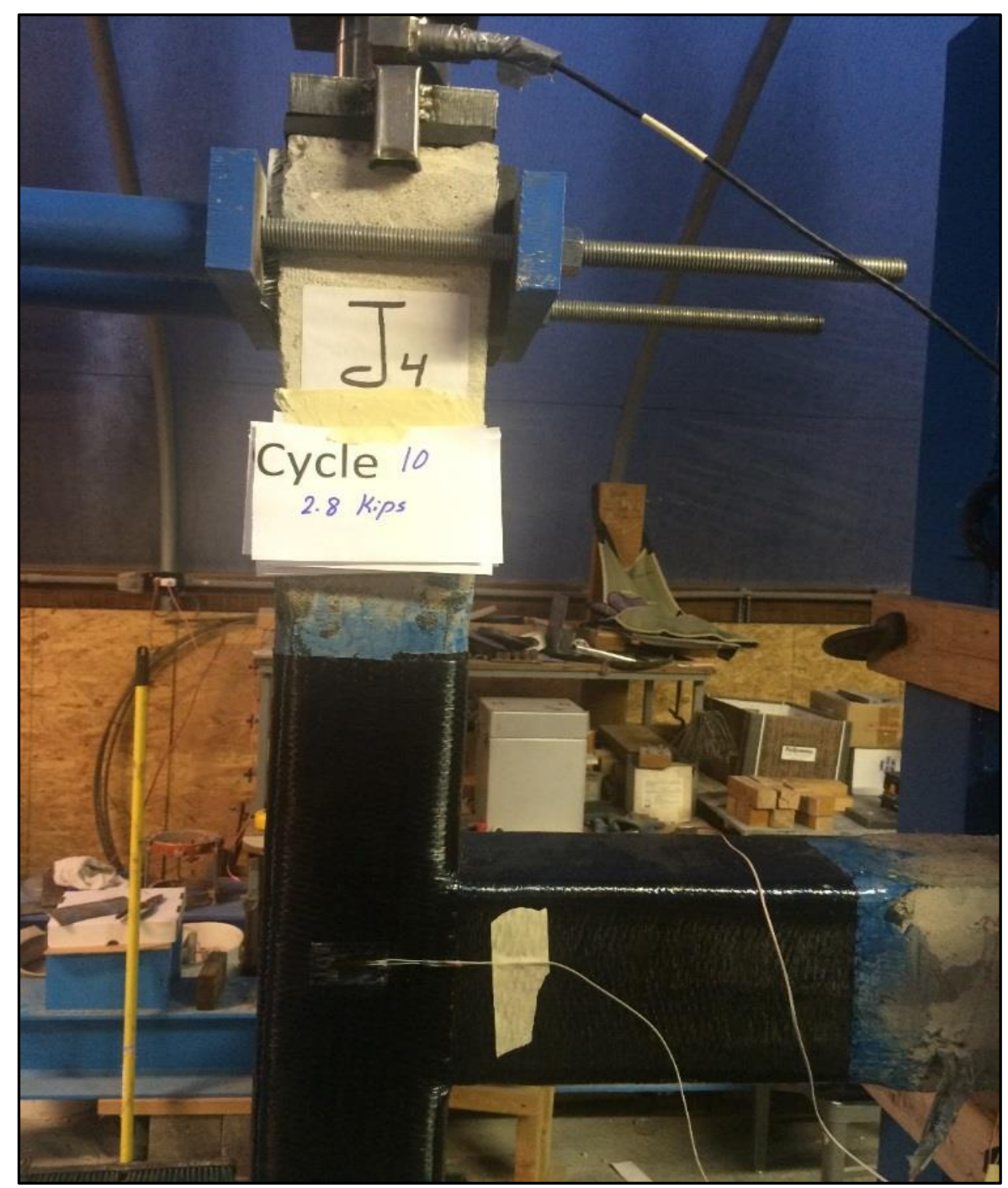

Figure 4-27 Specimen J4 at the End of Load Control 
The specimen did not show any sign of failure or strength deterioration during the load control stage. When the second stage of the load sequence started, the load was supposed to be applied until the strain in the flexural reinforcement reached $0.4 \%$. But, the beam failed near the free end in the unwrapped section. The maximum push down load was 8 kips, and the maximum steel strain at the interface between the beam and the column was $0.334 \%$. Shear failure in the beam near the free end occurred when the applied moment at the beam-column intersection reached its ultimate theoretical moment. The load then dropped rapidly to 5 kips, the steel bars buckled and the concrete broke to small pieces. Figure 4-28 shows the free end failure of the specimen.

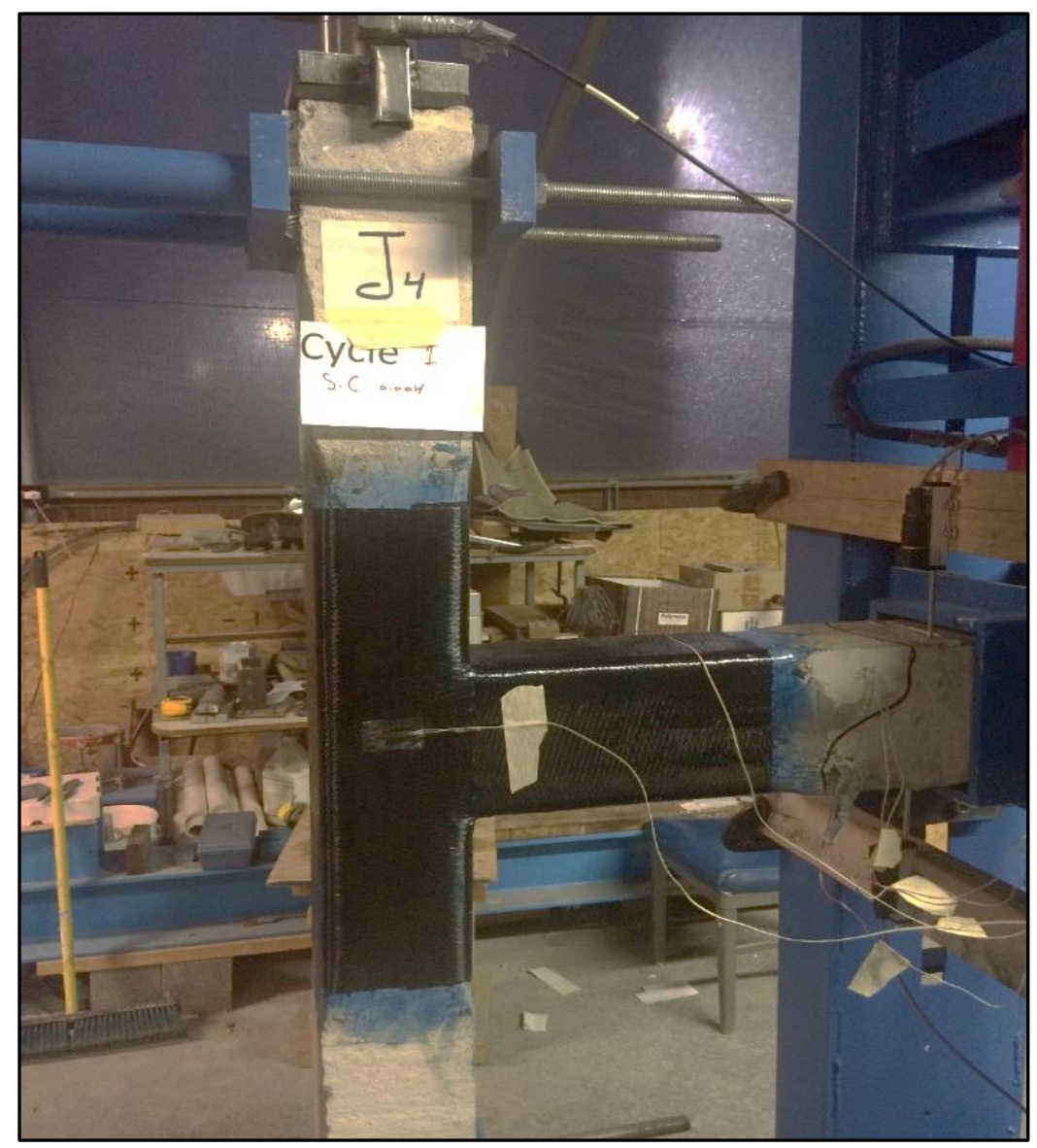

Figure 4-28 Specimen J4 at the Failure 
In summary of this test, the final failure occurred away from the confinement (wrapped) regions of both beam and column, which was the main goal of using the CFRP sheets. The CFRP sheets kept the joint intact during the test and after beam failure. When the test was terminated, the CFRP sheets were removed in order to visually check the members. No crack was evident under the CFRP sheets. This was contrary to the previous cases where a lot of cracks were formed and concentrated, especially at the joint area. Figure 4-29 shows the concrete status under the CFRP sheets after the test. In the left photo, the upper CFRP layer of the beam was peeled away to expose the concrete surface under the CFRP sheet
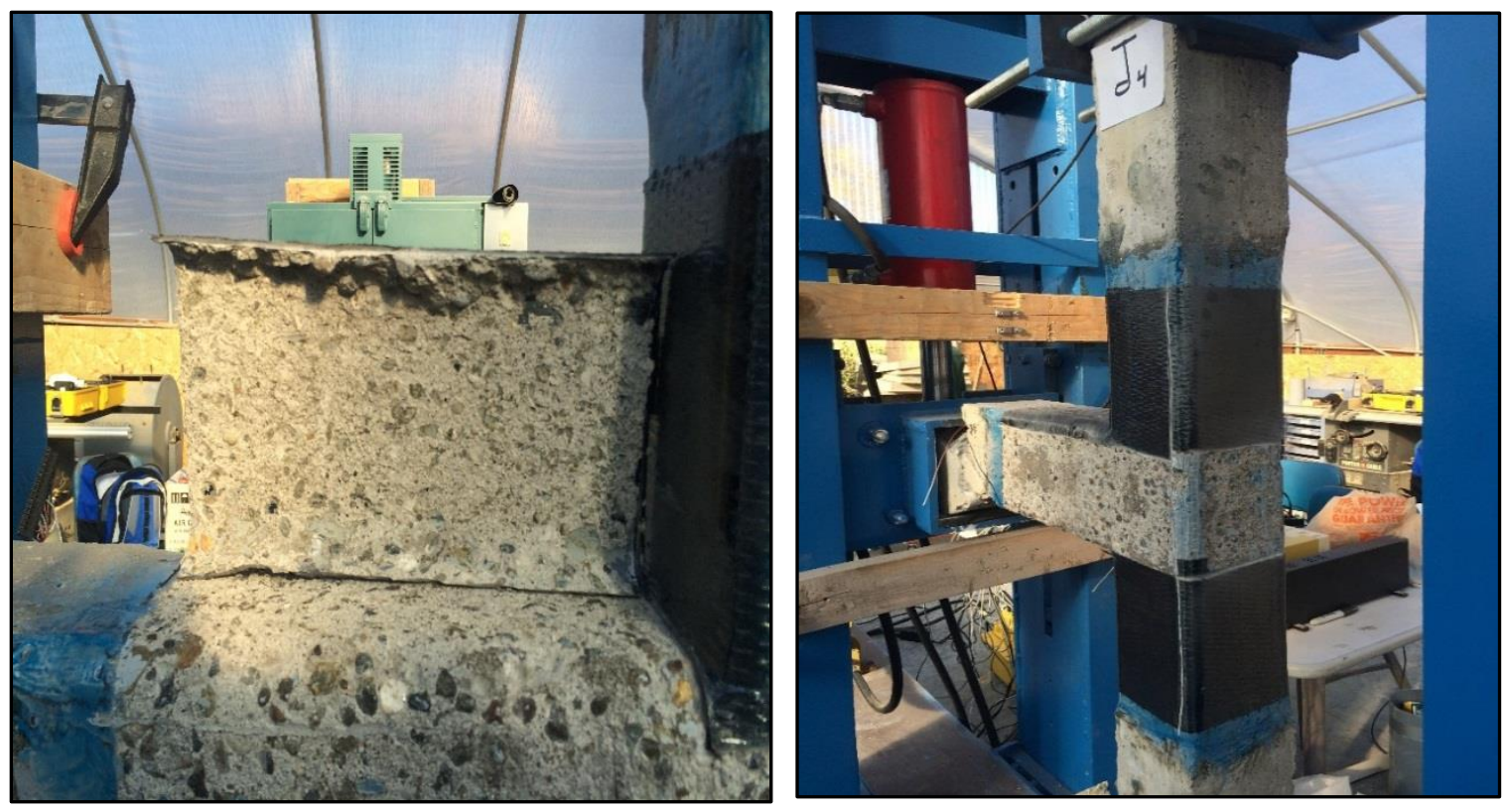

Figure 4-29 Areas under CFRP Sheets at the End of the Test, Specimen J4

The applied cyclic load versus the displacement of the free end of the beam was recorded and plotted in Figure 4-30. This figure shows that this beam-column joint was subjected 
to twenty-three loading cycles. Table 4-4 shows the values of the loads and displacements at each cycle.

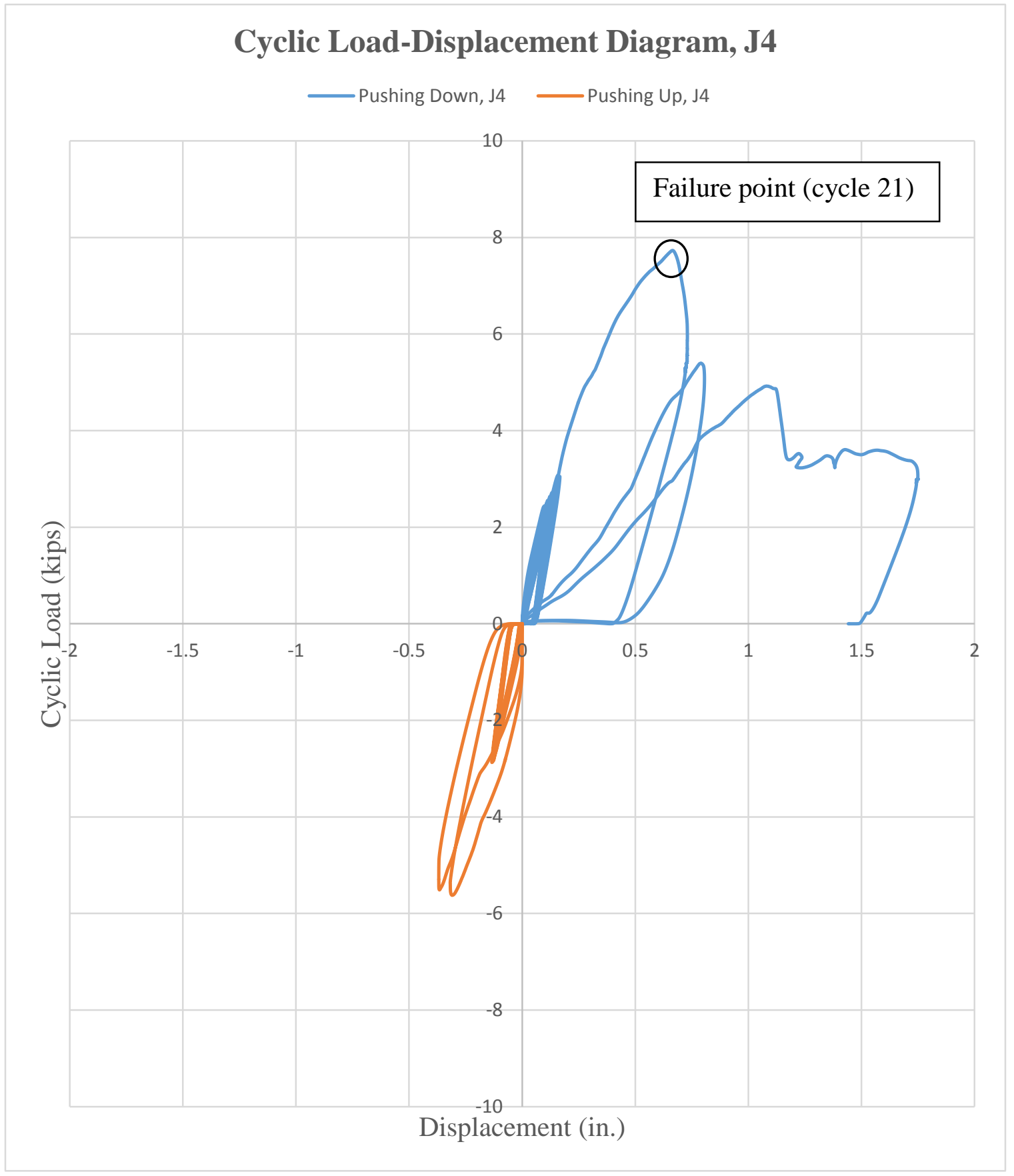

Figure 4-30 Load versus Displacement, J4 
Table 4-4 The Values of the Loads and Displacements at Each Cycle, Specimen J4

\begin{tabular}{|c|c|c|c|c|}
\hline Cycle & Down F. & Disp. & Up F. & Disp. \\
\hline 0 & 0 & 0 & 0 & 0 \\
\hline 1 & 2.406 & 0.0944 & -2.483 & -0.106 \\
\hline 2 & 2.4352 & 0.101265 & -2.463 & -0.105 \\
\hline 3 & 2.4352 & 0.107253 & -2.435 & -0.116 \\
\hline 4 & 2.521487 & 0.113242 & -2.5 & -0.125 \\
\hline 5 & 2.406438 & 0.110792 & -2.406 & -0.109 \\
\hline 6 & 2.387263 & 0.100176 & -2.483 & -0.12 \\
\hline 7 & 2.607773 & 0.107798 & -2.483 & -0.099 \\
\hline 8 & 2.492725 & 0.10317 & -2.492 & -0.098 \\
\hline 9 & 2.444788 & 0.10562 & -2.454 & -0.103 \\
\hline 10 & 2.339326 & 0.092281 & -2.4352 & -0.102 \\
\hline 11 & 2.99127 & 0.159791 & -2.82828 & -0.12107 \\
\hline 12 & 2.828284 & 0.154619 & -2.82828 & -0.12433 \\
\hline 13 & 2.828284 & 0.15135 & -2.82828 & -0.12651 \\
\hline 14 & 2.809109 & 0.15135 & -2.82828 & -0.12787 \\
\hline 15 & 2.799521 & 0.150264 & -2.8187 & -0.12733 \\
\hline 16 & 2.809109 & 0.152441 & -2.83787 & -0.13032 \\
\hline 17 & 2.828284 & 0.151353 & -2.8187 & -0.13005 \\
\hline 18 & 2.99127 & 0.166052 & -2.83787 & -0.13141 \\
\hline 19 & 2.837871 & 0.160063 & -2.83787 & -0.13468 \\
\hline 20 & 2.837871 & 0.156525 & -2.83787 & -0.13413 \\
\hline 21 & 7.938369 & 0.678092 & -5.3536 & -0.31851 \\
\hline 22 & 5.378533 & 0.811206 & -5.35936 & -0.36851 \\
\hline 23 & 5.06214 & 1.1297 & --------- & -------- \\
\hline & & & & \\
\hline
\end{tabular}

In Figure 4-30, the load versus displacement shows that in the first twenty cycles, the load and displacement changed in a linear manner because the specimen was within the elastic range. Once the load passed the theoretical capacity of the beam, the load displacement curve started to lose stiffness. This meant that the beam started to deform out of the elastic range, and moved to failure. When the beam section in the weakest region of the beam (at $7 \mathrm{in.}$ from the free end of the beam) reached the maximum strength 
during cycle twenty-one in the strain control stage, the load dropped. The load cycles after that represented the post crack cycles where the beam lost strength gradually until most of the concrete spalled, and the steel bars buckled. Figure 4-31 shows more details about this failure.
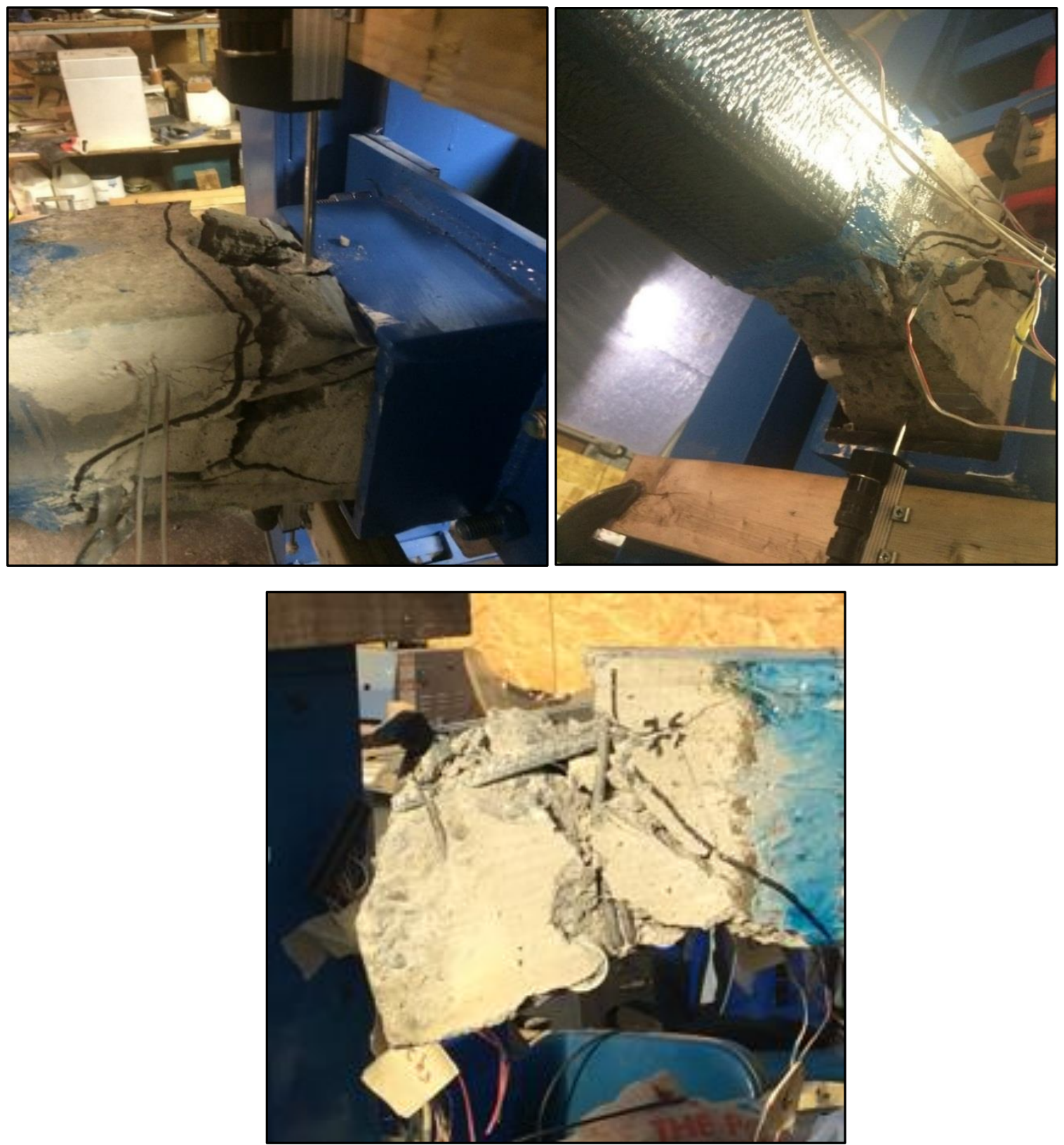

Figure 4-31 Failure of Specimen J4 


\subsubsection{Retrofitted Specimen J5 and J6}

The behavior of specimens J5 and J6 was almost as same as the behavior of specimens J3 and $\mathrm{J} 4$, respectively, despite the fact that the axial load applied on the column is different. The axial force applied on the specimens J3 and $\mathrm{J} 4$ represented $20 \%$ of the load capacity index ( $\mathrm{f}^{\prime} \mathrm{c} \mathrm{Ag}$ ) of the column, whereas in $\mathrm{J} 5$ and $\mathrm{J} 6$ represented $40 \%$ of the load capacity index. The reason to test specimens J5 and J6 under a higher axial load was to investigate how the proposed technique would be affected by a higher level of gravity load that represents joints in a building with a larger number of stories. Figure 4- 32 and 4-33 show load versus displacement for specimens J5 and J6, respectively. 


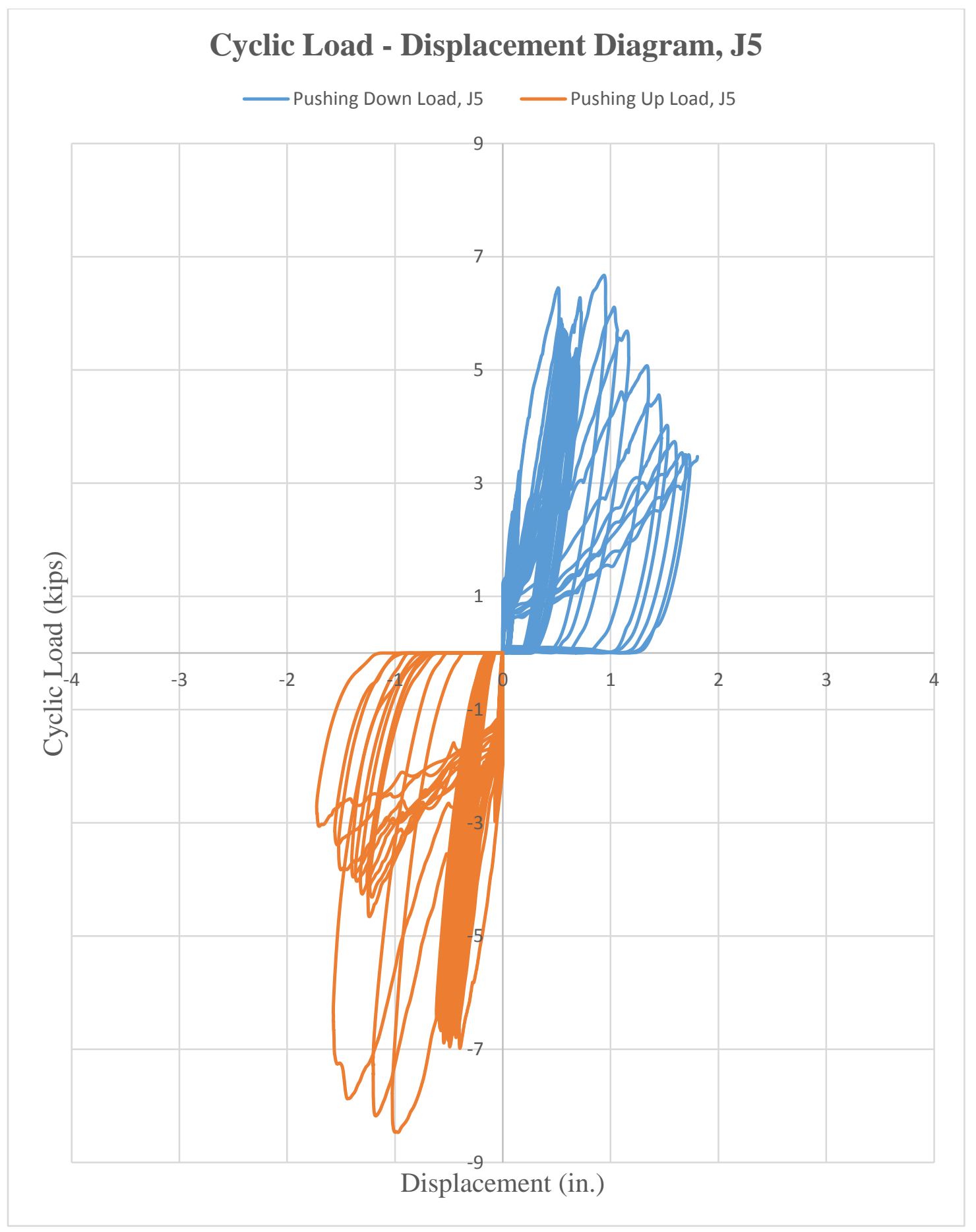

Figure 4-32 Load-Displacement Diagram, J5 


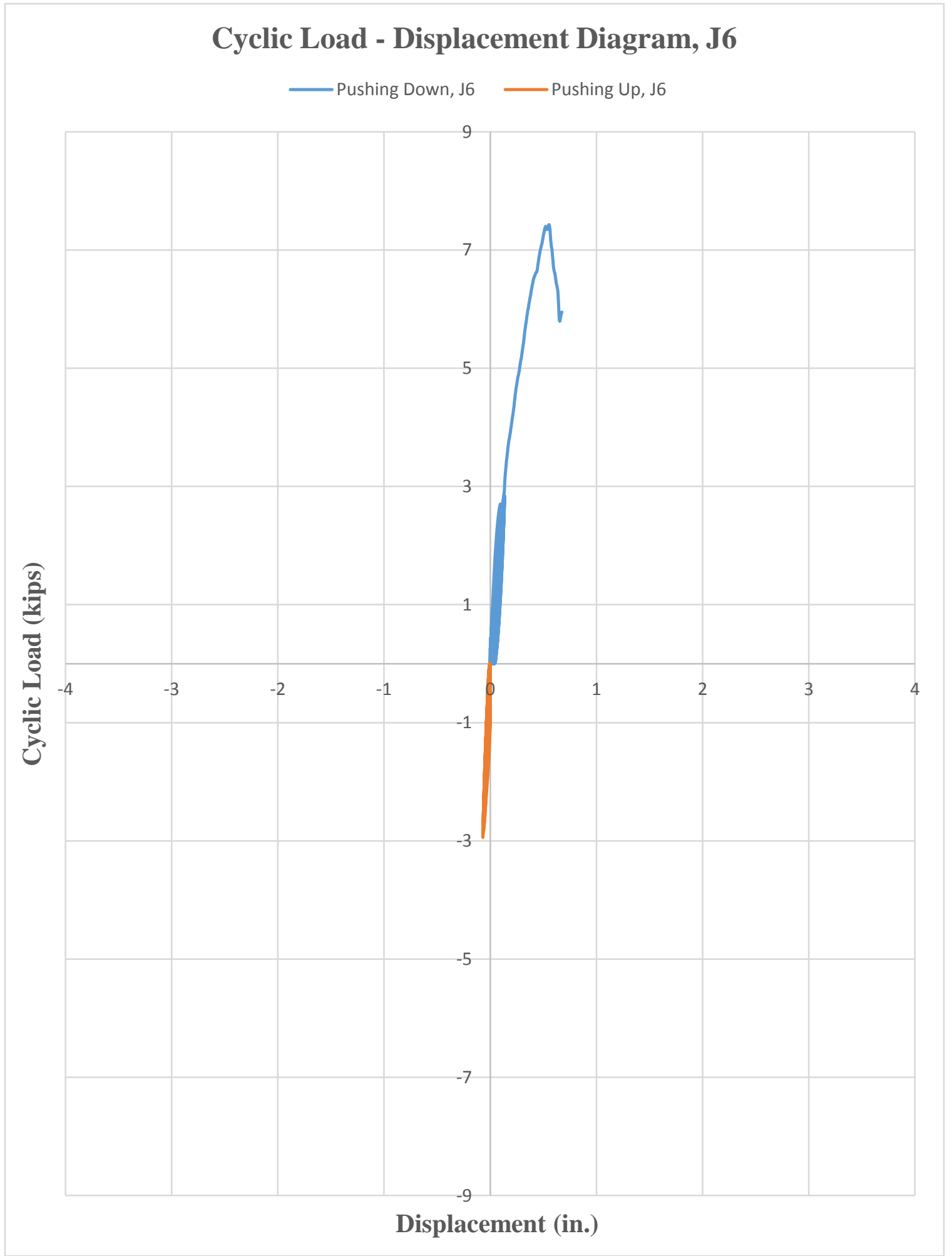

Figure 4-33 Cyclic Load-Displacement, J6 
Tables 4-5 and 4-6 show the load values and displacement for specimens J5 and J6 at each cycle.

Table 4-5 Values of Loads and Displacements at Each Cycle, J5

\begin{tabular}{|c|c|c|c|c|}
\hline Cycle & Down F. & Down Disp. & Up. F & Up Disp. \\
\hline 0 & 0 & 0 & 0 & 0 \\
\hline 1 & 2.416 & 0.083 & -2.531 & -0.0552 \\
\hline 2 & 2.4352 & 0.089 & -2.444 & -0.0506 \\
\hline 3 & 2.4064 & 0.089 & -2.483 & -0.05009 \\
\hline 4 & 2.4831 & 0.0873 & -2.4 & -0.05172 \\
\hline 5 & 2.435 & 0.089 & -2.377 & -0.05281 \\
\hline 6 & 2.4064 & 0.102 & -2.52149 & -0.0588 \\
\hline 7 & 2.444 & 0.103 & -2.56 & -0.05036 \\
\hline 8 & 2.4064 & 0.1064 & -2.41603 & -0.054 \\
\hline 9 & 2.4064 & 0.10344 & -2.4639 & -0.056 \\
\hline 10 & 2.416 & 0.1064 & -2.49272 & -0.05335 \\
\hline 11 & 2.8666 & 0.12467 & -2.8378 & -0.0634 \\
\hline 12 & 2.828 & 0.12658 & -2.99127 & -0.062 \\
\hline 13 & 2.809 & 0.118124 & -2.828 & -0.0658 \\
\hline 14 & 2.8666 & 0.1298 & -2.8282 & -0.06724 \\
\hline 15 & 2.7899 & 0.1249 & -2.83787 & -0.0677 \\
\hline 16 & 2.8 & 0.1325 & -2.83787 & -0.072 \\
\hline 17 & 2.828 & 0.1412 & -2.8282 & -0.06751 \\
\hline 18 & 2.8666 & 0.147 & -2.8278 & -0.07214 \\
\hline 19 & 2.8474 & 0.1464 & -2.8378 & -0.068 \\
\hline 20 & 2.8378 & 0.1437 & -2.8378 & -0.07187 \\
\hline 21 & 6.366 & 0.5172 & -7.133 & -0.4 \\
\hline 22 & 6.078 & 0.54 & -6.77 & -0.4124 \\
\hline
\end{tabular}




\begin{tabular}{|c|c|c|c|c|}
\hline 23 & 5.934 & 0.55 & -6.99 & -0.4352 \\
\hline 24 & 5.69 & 0.56 & -6.97 & -0.455 \\
\hline 25 & 5.8 & 0.574 & -6.96 & -0.467 \\
\hline 26 & 5.55 & 0.586 & -7.08 & -0.4807 \\
\hline 27 & 5.74 & 0.5964 & -6.97 & -0.4965 \\
\hline 28 & 5.56 & 0.605 & -6.97 & -0.504 \\
\hline 29 & 5.234 & 0.605 & -6.787 & -0.512 \\
\hline 30 & 5.53 & 0.621 & -6.8 & -0.524 \\
\hline 31 & 5.215 & 0.6489 & -6.89 & -0.5335 \\
\hline 32 & 5.09 & 0.6576 & -6.672 & -0.54498 \\
\hline 33 & 5.215 & 0.6631 & -6.7399 & -0.5534 \\
\hline 34 & 5.388 & 0.666 & -6.922 & -0.561 \\
\hline 35 & 5.3114 & 0.672 & -6.739 & -0.565 \\
\hline 36 & 5.1484 & 0.6786 & -6.67 & -0.574 \\
\hline 37 & 5.119 & 0.683 & -6.55 & -0.586 \\
\hline 38 & 5.01 & 0.682 & -6.55 & -0.59 \\
\hline 39 & 5.119 & 0.69 & -6.51 & -0.59 \\
\hline 40 & 5.06 & 0.694 & -6.596 & -0.602 \\
\hline 41 & 6.797 & 0.9429 & -8.57 & -1.0164 \\
\hline 42 & 6.346 & 1.04 & -8.273 & -1.18 \\
\hline 43 & 5.56 & 1.156 & -7.09 & -1.167 \\
\hline 44 & 5.186 & 1.3428 & -4.486 & -1.1988 \\
\hline 45 & 4.678 & 1.448 & -4.266 & -1.215 \\
\hline 46 & 4.084 & 1.523 & -4.103 & -1.244 \\
\hline 47 & 3.806 & 1.5919 & -4.44 & -1.31 \\
\hline 48 & 3.56 & 1.678 & -4.1 & -1.353 \\
\hline 49 & 3.652 & 1.73 & -4.01 & -1.379 \\
\hline 50 & ------- & -------- & -3.88 & -1.497 \\
\hline
\end{tabular}




\begin{tabular}{|c|c|c|c|c|}
\hline 51 & ------- & ------ & -3.49 & -1.529 \\
\hline 52 & ------- & ------- & -3.096 & -1.696 \\
\hline
\end{tabular}

Table 4-6 Values of Loads and Displacements at Each Cycle, J6

\begin{tabular}{|c|c|c|c|c|}
\hline Cycle & Down F. & Down Disp. & Up F. & Up Disp. \\
\hline 0 & 0 & 0 & 0 & 0 \\
\hline 1 & 2.4064 & 0.0658 & -2.3776 & -0.0345 \\
\hline 2 & 2.444 & 0.08629 & -2.4165 & -0.0416 \\
\hline 3 & 2.4927 & 0.0832 & -2.49272 & -0.0528 \\
\hline 4 & 2.42561 & 0.0941 & -2.45438 & -0.05172 \\
\hline 5 & 2.4352 & 0.091737 & -2.49272 & -0.0579 \\
\hline 6 & 2.4927 & 0.09364 & -2.41603 & -0.0528 \\
\hline 7 & 2.4352 & 0.09255 & -2.41603 & -0.05281 \\
\hline 8 & 2.4064 & 0.09255 & -2.49272 & -0.0539 \\
\hline 9 & 2.41602 & 0.092554 & -2.47355 & -0.049 \\
\hline 10 & 2.5502 & 0.11242 & -2.4064 & -0.05009 \\
\hline 11 & 2.8282 & 0.1219 & -2.80911 & -0.06479 \\
\hline 12 & 2.8282 & 0.1214 & -2.837 & -0.06697 \\
\hline 13 & 2.83787 & 0.1249 & -2.8378 & -0.06479 \\
\hline 14 & 2.81869 & 0.126036 & -2.822 & -0.0637 \\
\hline 15 & 2.8282 & 0.12522 & -2.8282 & -0.06261 \\
\hline 16 & 2.81869 & 0.12875 & -2.8378 & -0.06452 \\
\hline 17 & 2.8858 & 0.1347 & -2.80911 & -0.0637 \\
\hline 18 & 2.8953 & 0.135 & -2.8378 & -0.068 \\
\hline 19 & 2.818 & 0.13012 & -2.8378 & -0.0664 \\
\hline 20 & 2.8282 & 0.131208 & -2.83787 & -0.06424 \\
\hline 21 & 7.62 & 0.629 & -------- & ---------- \\
\hline
\end{tabular}


Figures 4-34 and 4-35 show the failure patterns of specimens J5 and J6.

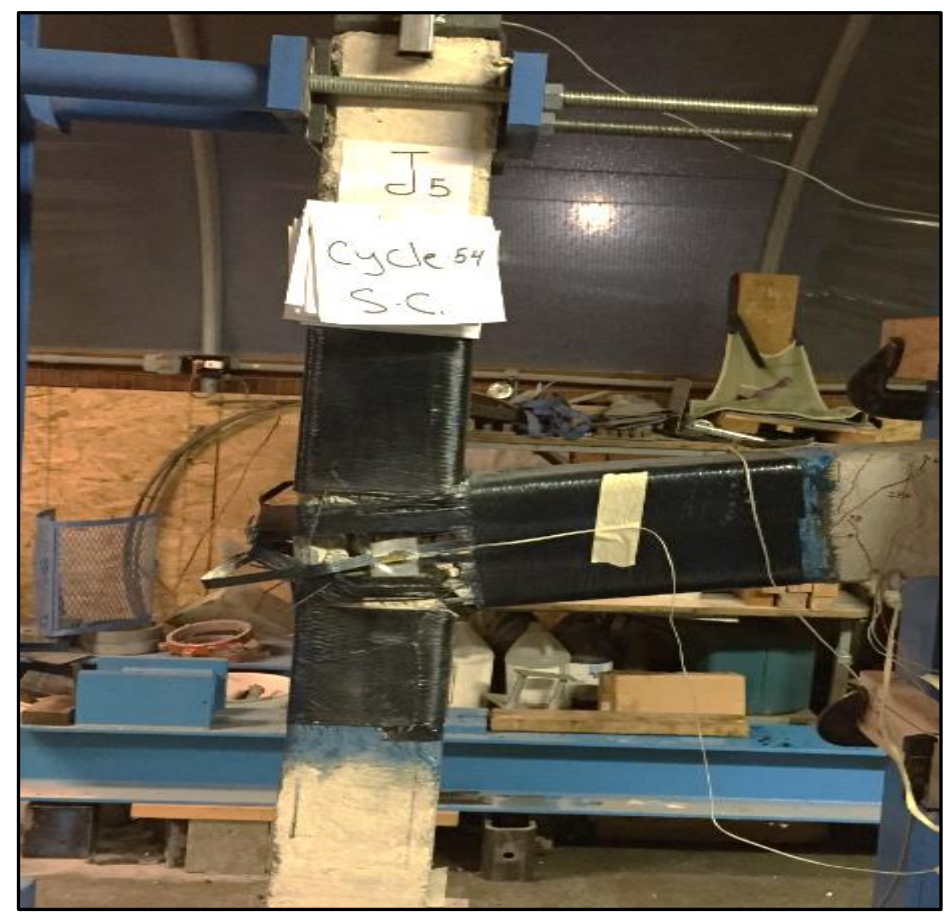

Figure 4-34 Failure of Specimen J5

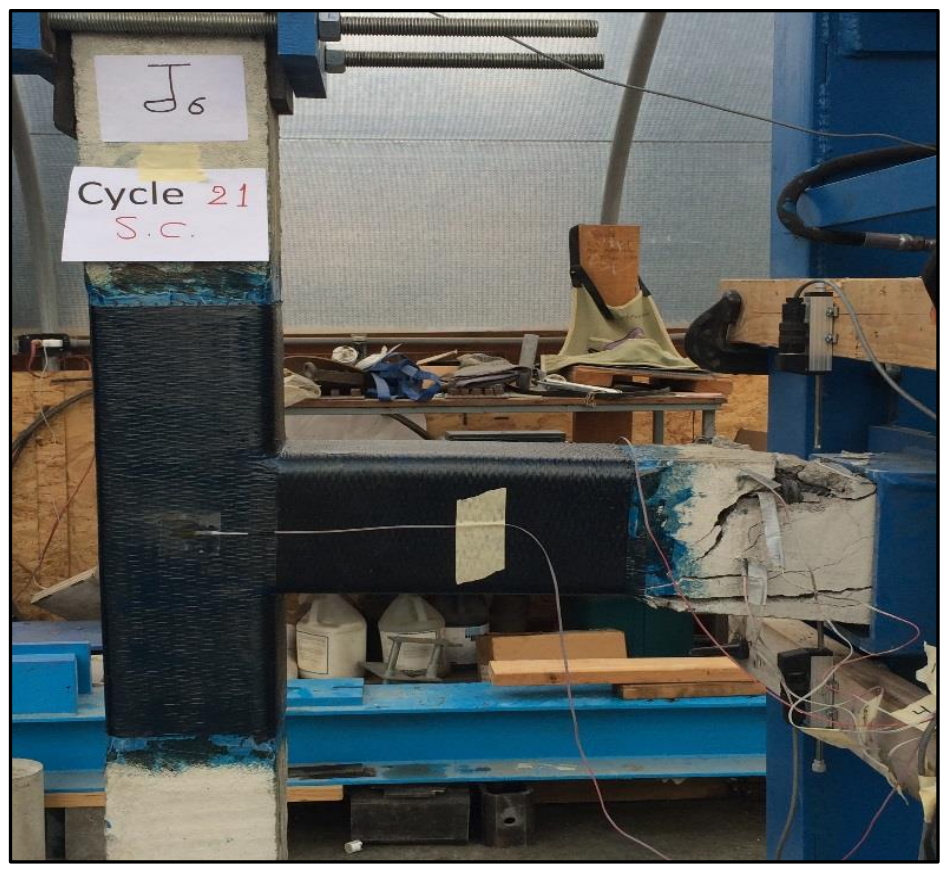

Figure 4-35 Failure of Specimen J6 


\subsection{Effect of Carbon Fiber Reinforced Polymer (CFRP) Sheets on Joint's Strength}

All joints were tested up to failure under the axial and cyclic load at the same time. The maximum cyclic load that each specimen carried, and the cycle number regarding to load sequence are summarized in Table 4-7 and Figure 4-36.

Table 4-7 Summary of the Test Results

\begin{tabular}{|c|c|c|c|c|c|c|}
\hline Specimen & Property & $\begin{array}{c}\text { Maximum } \\
\text { Pushing } \\
\text { Down load } \\
\text { (kips) }\end{array}$ & $\begin{array}{c}\text { Cycle } \\
\text { number }\end{array}$ & $\begin{array}{c}\text { Maximum } \\
\text { Pushing Up } \\
\text { load } \\
\text { (Kips) }\end{array}$ & $\begin{array}{c}\text { Cycle } \\
\text { Number }\end{array}$ & $\begin{array}{c}\text { Load sequence } \\
\text { Phase at failure }\end{array}$ \\
\hline J1 & $\begin{array}{c}\text { Control } \\
\text { Ductile }\end{array}$ & 5.7 & 39 & 5.7 & 39 & $\begin{array}{c}\text { Strain control } \\
(0.4 \%)\end{array}$ \\
\hline J2 & $\begin{array}{c}\text { Control } \\
\text { Non-ductile }\end{array}$ & 4.5 & 25 & 5 & 25 & $\begin{array}{c}\text { Strain control } \\
(0.4 \%)\end{array}$ \\
\hline J3 & $\begin{array}{c}\text { One CFRP } \\
\text { Layer }\end{array}$ & 5.8 & 45 & 7.9 & 44 & $\begin{array}{c}\text { Strain control } \\
(0.6 \%)\end{array}$ \\
\hline J4 & $\begin{array}{c}\text { Two CFRP } \\
\text { Layers }\end{array}$ & 8 & 21 & N/A & 20 & $\begin{array}{c}\text { Strain Control } \\
(0.4 \%)\end{array}$ \\
\hline J5 & $\begin{array}{c}\text { One CFRP } \\
\text { Layer }\end{array}$ & 6.8 & 49 & 8.6 & 52 & $\begin{array}{c}\text { Strain Control } \\
(0.6 \%)\end{array}$ \\
\hline J6 & $\begin{array}{c}\text { Two CFRP } \\
\text { Layers }\end{array}$ & 7.6 & 21 & N/A & 20 & $\begin{array}{c}\text { Strain Control } \\
(0.4 \%)\end{array}$ \\
\hline
\end{tabular}




\section{Maximum Moment Generated by Pushing Down Load}

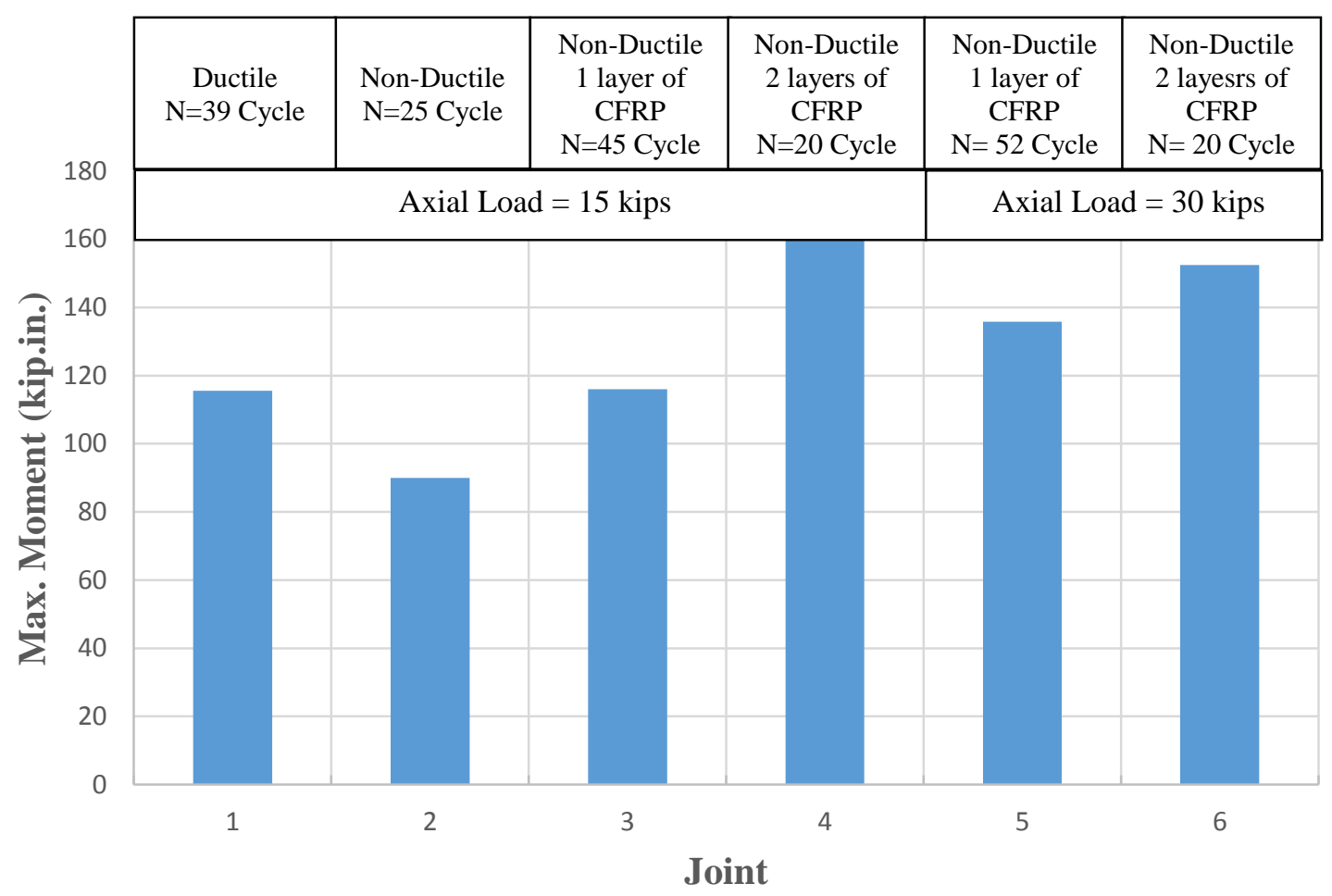

Figure 4-36 Maximum Moment at Face of the Column, Pushing Down Case

As shown in Table 4-7 and Figure 4-36, the maximum strength for all joints wrapped by CFRP were larger than the control specimens because the weakest joint area of all retrofitted specimens was confined by CFRP sheets, so that the failure either transferred to the beam or occurred at larger load. In terms of the comparison with the ductile and non-ductile specimens, specimens J4 and J6 that were retrofitted by using two CFRP layers had changed the non-ductile one (J2) from weak column-strong beam to strong column-weak beam. The desirable goal was achieved by keeping the joint area of the specimens intact during the test. Regarding the specimens J3 and J5 that were wrapped 
by one layer of the CFRP sheet, the improvement of the general behavior is shown in Table 4-7, as well. The specimens J3 and J5 were the only once that reached the last stage of the load sequence, and showed high strength. In comparison with specimen J2, the increases in the strength of joints J3 and J5 were $28 \%$ and $50 \%$, respectively. In comparison with specimen $\mathrm{J} 1$, the increases in the strengths were about $2 \%$ and $20 \%$, respectively. Moreover, the use of CFRP for confinement gave joints the ability to survive a larger number of loading cycles within the strain control phase of the load sequence. It was clear that the CFRP sheets had a significant impact on the general behavior. Specimen J2 failed after the first five cycles in the strain control phase of the load sequence.

In comparison with specimen $\mathrm{J} 2$, the incremental increases in the strength of joints $\mathrm{J} 4$ and J6 were $77 \%$ and $69 \%$, respectively. In comparison with specimen J1, the incremental increase in the strengths of joints J4 and J6 were $40 \%$ and 32\%, respectively. The increase in J6 capacity was limited by the failure of the unconfined section of the beam. 


\subsection{Load versus Displacement}

The load vs the vertical displacement of the free end of the beam at each cycle in both upward and downward directions during the loading sequences for all specimens are shown in Figures 4-37 to 4-42.

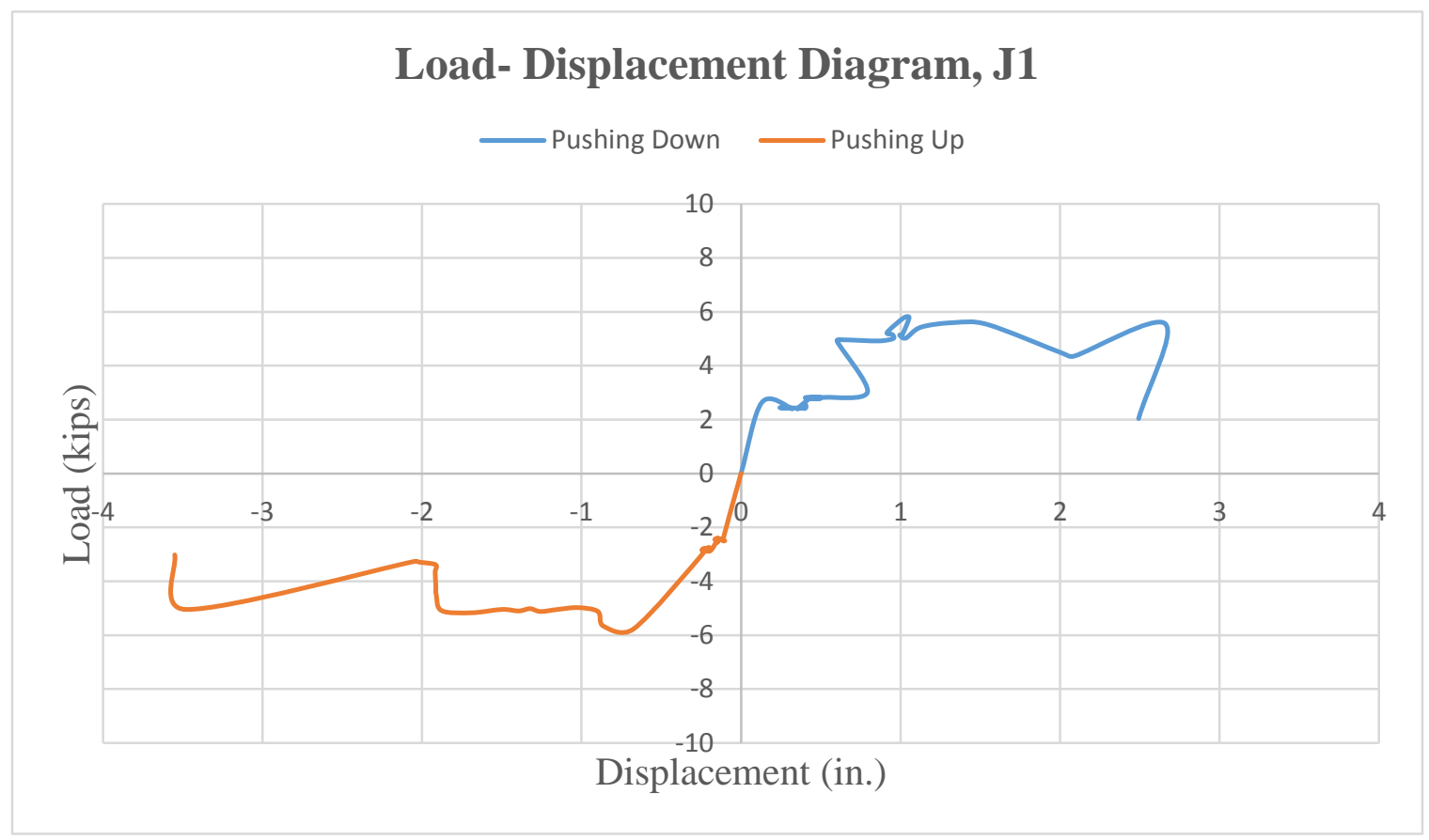

Figure 4-37 Envelop Cyclic Load-Vertical Displacement of the Ductile Specimen, J1 


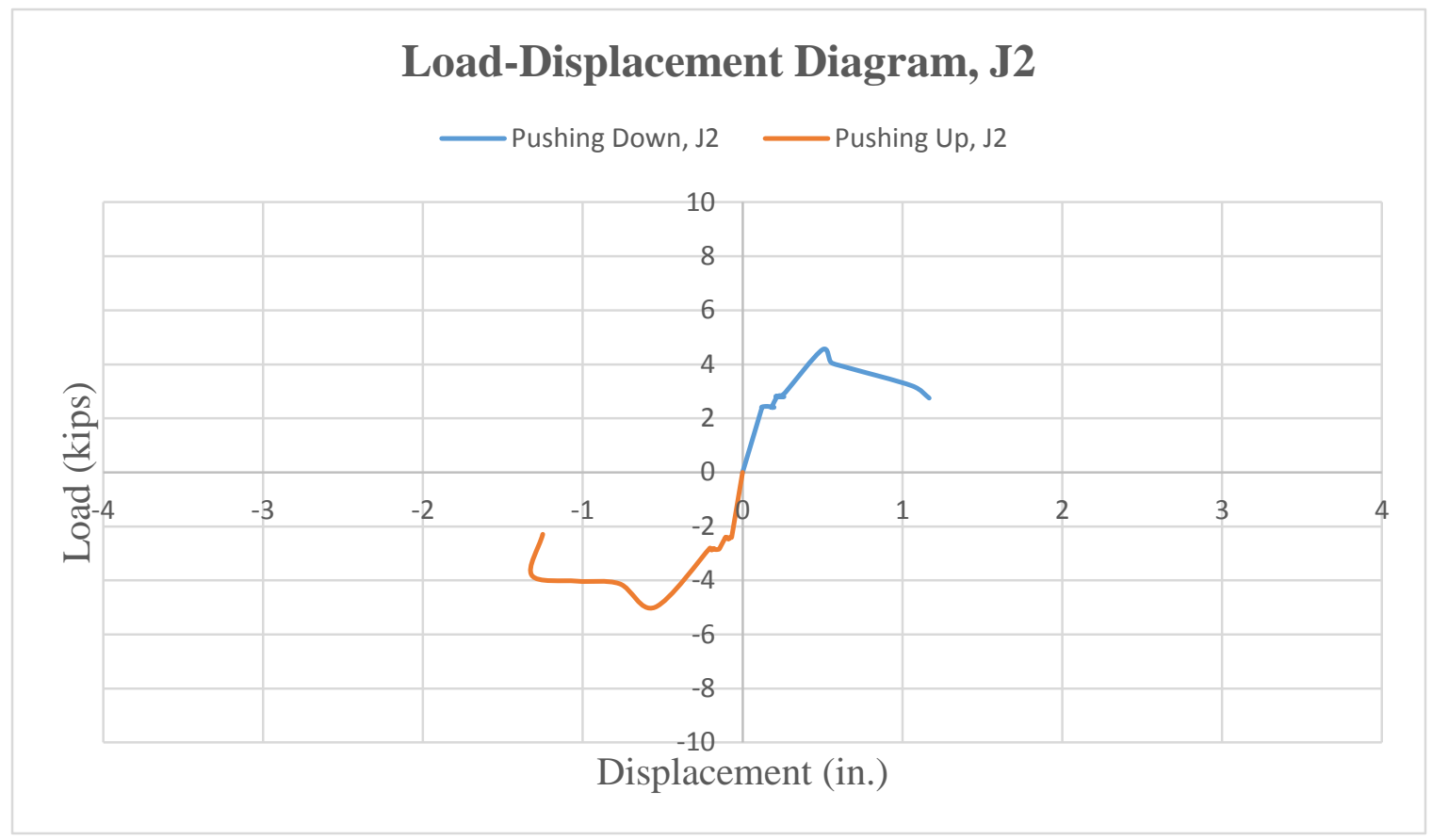

Figure 4-38 Envelop Cyclic Load-Vertical Displacement of the Non-Ductile Specimen, J2

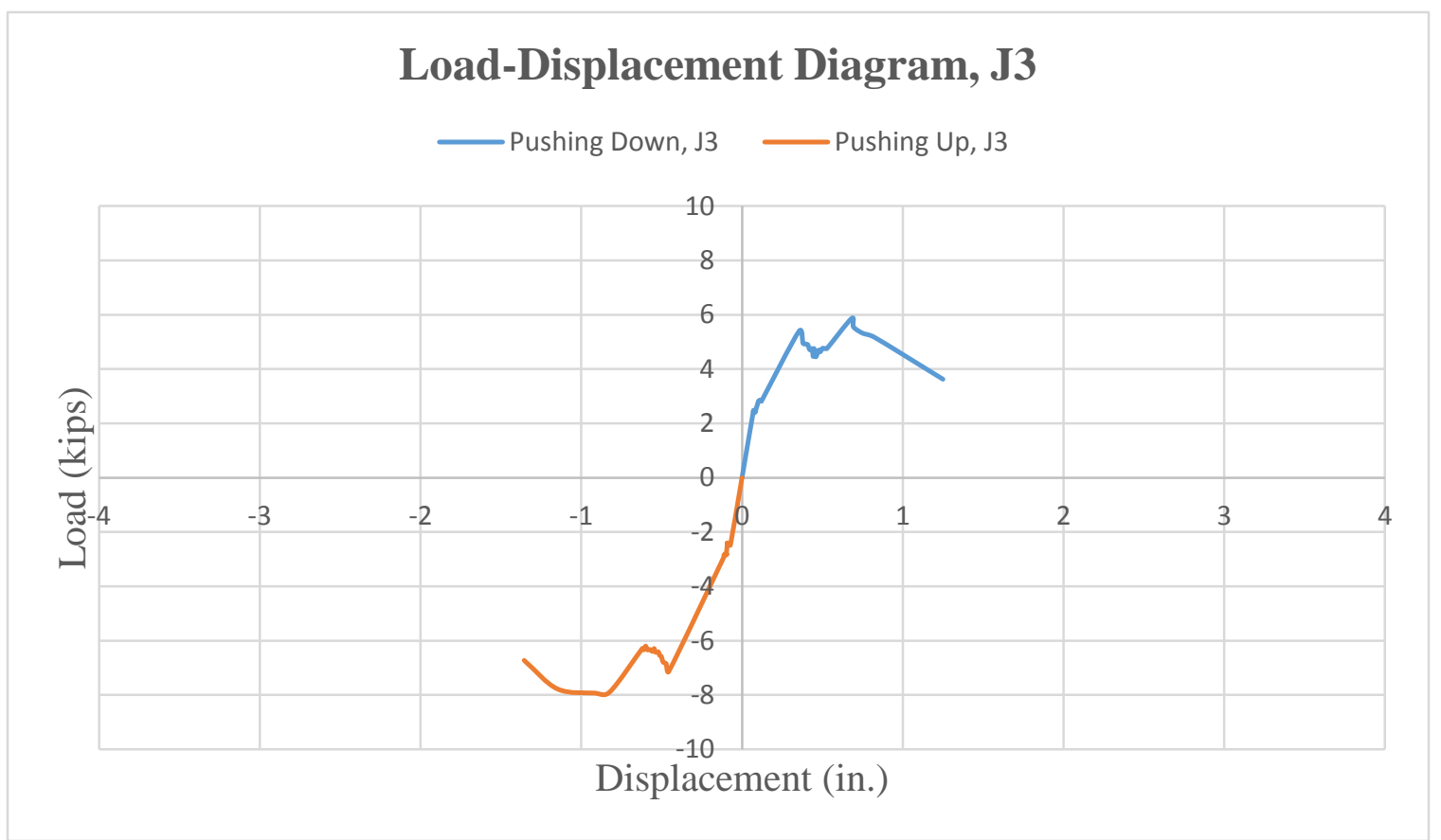

Figure 4-39 Envelop Cyclic Load-Vertical Displacement, Specimen J3 


\section{Load- Displacement Diagram, J4}

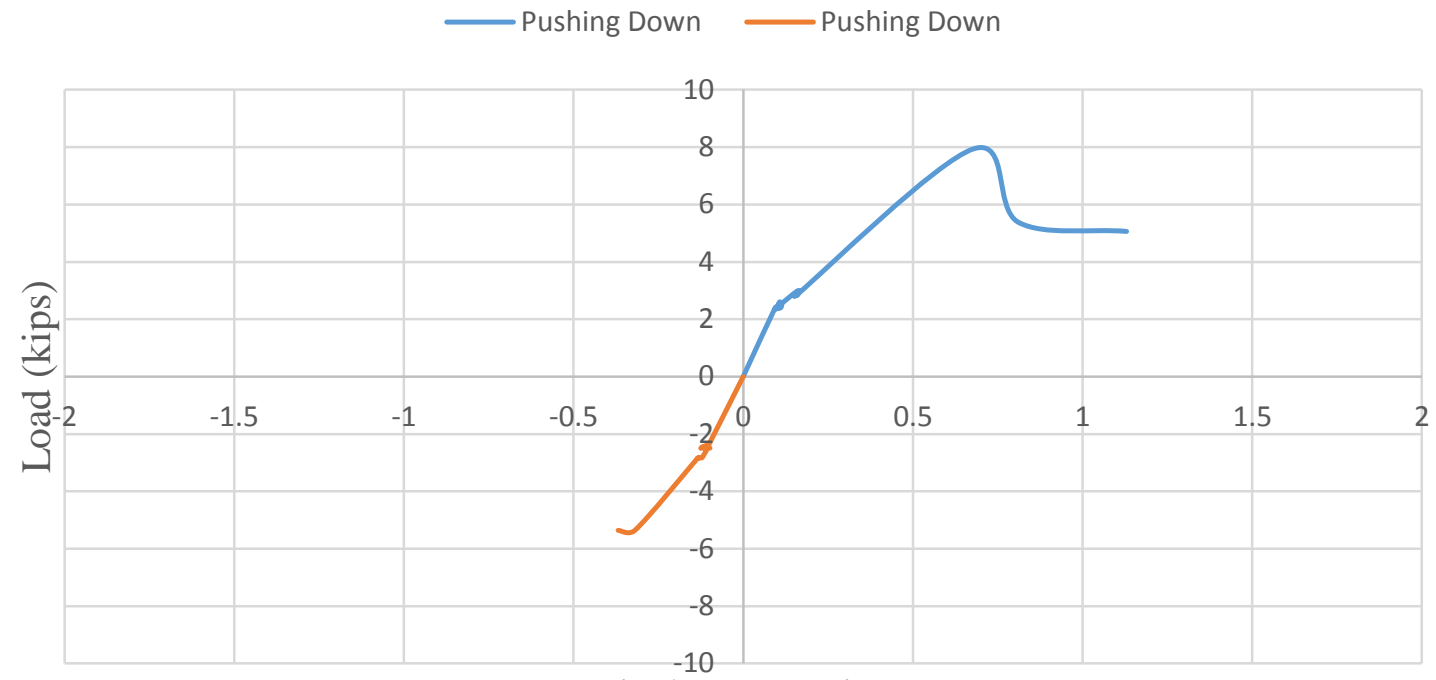

Displacement (in.)

Figure 4-40 Envelop Cyclic Load-Vertical Displacement of the Specimen, J4

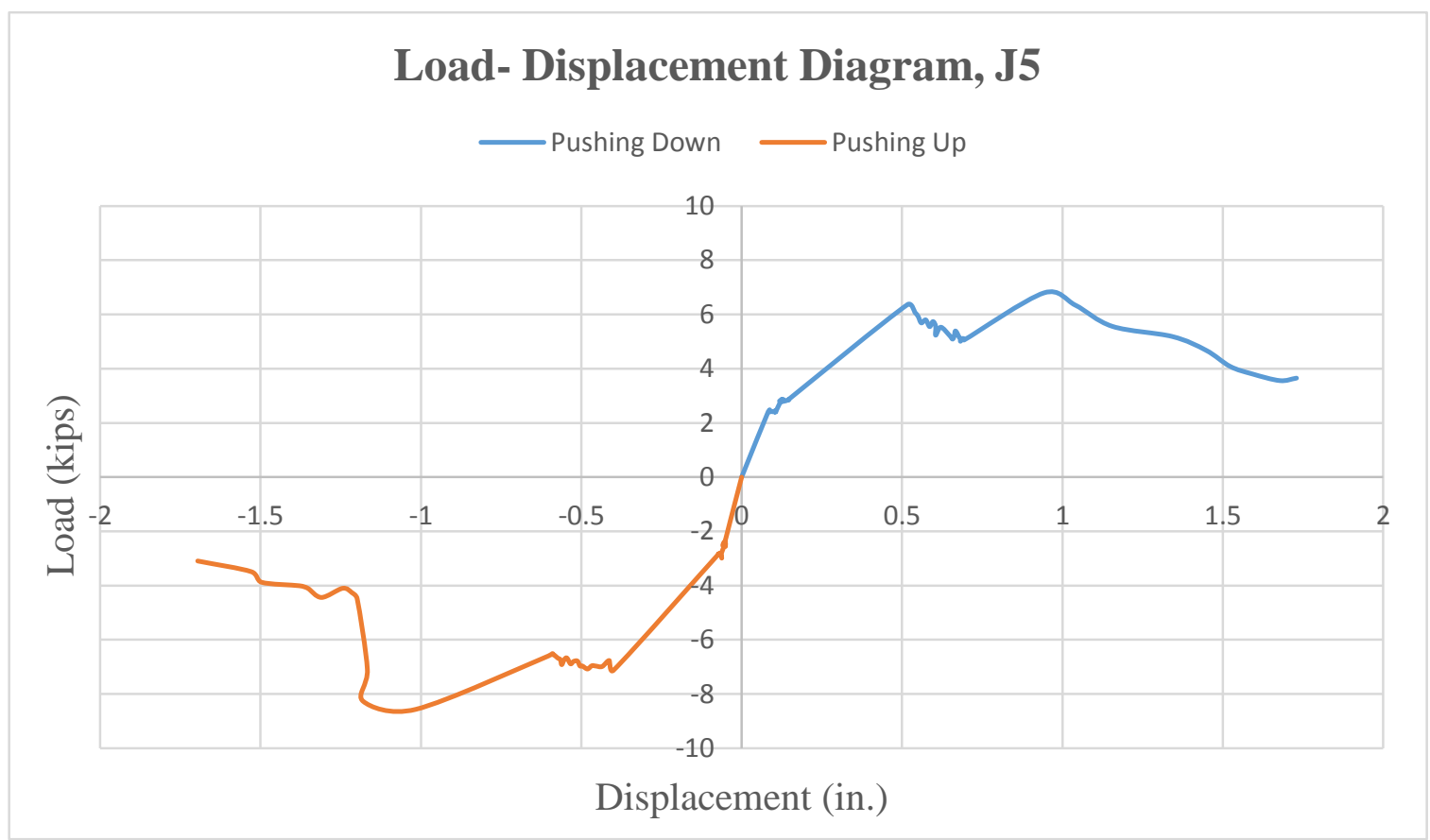

Figure 4-41 Envelop Cyclic Load-Vertical Displacement of the Specimen, J5 


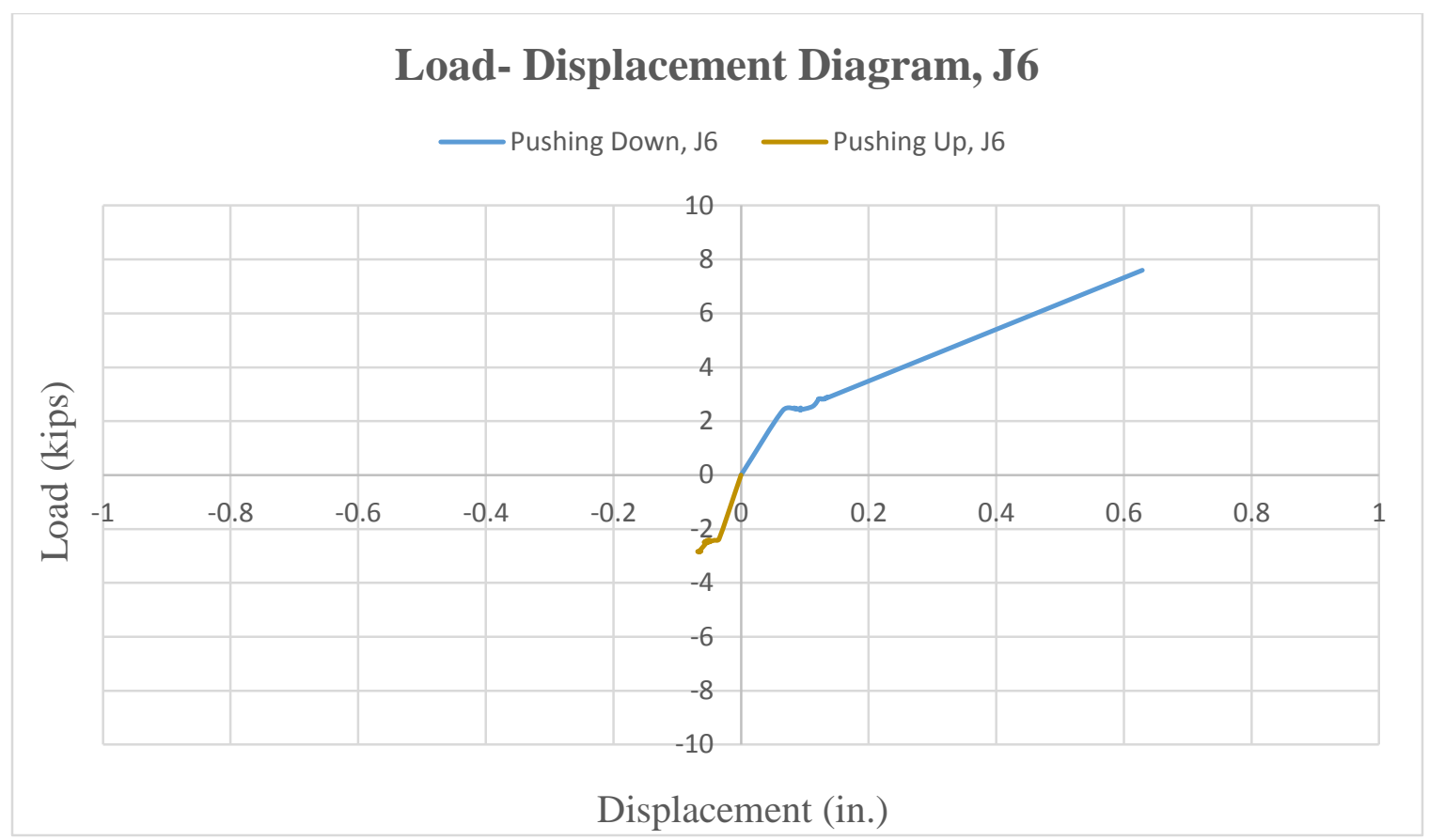

Figure 4-42Envelop Cyclic Load-Vertical Displacement of the Specimen, J6 
A comparison of the specimens in terms of the vertical displacement of all specimens is shown in Figure 4-43.

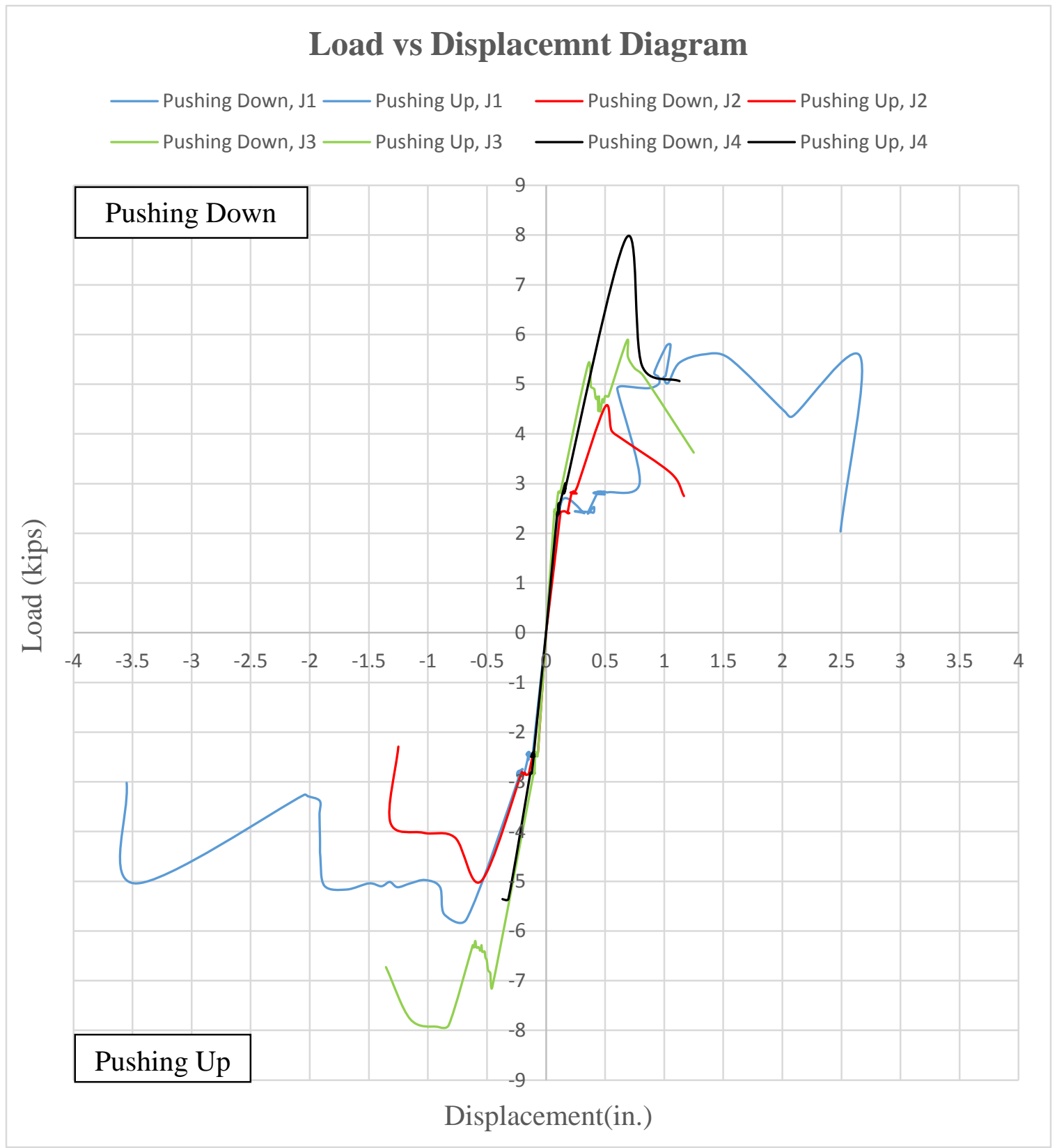

Figure 4-43 Cyclic Load-Vertical Displacement Relationship of All Specimens Tested Under Same Axial Loads (20\% of the Column Capacity) 
For specimens J1, J2, J3, and J4 as shown in Figure 4-43, at the first load stage of the load sequence when the load was $75 \%$ of the maximum theoretical beam capacity, all of the curves are identical because only the concrete and the steel bars carried the applied load. For the stage of the load sequence that represented $90 \%$ of the maximum theoretical beam capacity, the difference between the retrofitted specimens and the control specimens started to clearly apparent. The non-retrofitted specimens developed more displacement than strengthened specimens. The reason was that the applied cyclic load was very close to the maximum beam capacity, and this led to a development of extensive tensile stresses in the joint region for the non-ductile specimen as represented by J2. The lack of transverse reinforcement caused many diagonal cracks and severe deterioration in the joint strength. With regard to the ductile specimen represented by $\mathrm{J} 1$, at these load cycles, the plastic hinge started to form right on the face of column. In spite of this, all of the specimens were able to survive during the first phase of the load sequence, but the non-ductile specimen $\mathrm{J} 2$ developed severe diagonal cracks within the joint region. This specimens failed after the first five cycles within the strain control phase of the load sequence. This is an evidence of the weakness in these kinds of joints that were designed and constructed prior to modern seismic codes. From Figure 4-43 above that $\mathrm{J} 1$, during the strain control stage of the load sequence, at strain of $0.4 \%$, the specimen $\mathrm{J} 1$ showed great flexibility, and showed no deterioration in the strength despite the gradual increase in the displacement. With regard to specimens $\mathrm{J} 3$ and $\mathrm{J} 4$, their behaviors were also identical even at the strain control stage of the load sequence. The retrofitted specimens showed very high level of strength in comparison to the non- 
retrofitted specimens (control specimens). The reason was that the confinement provided by attaching the CFRP sheets to these specimens, and a change in the tension load path, were the main causes to develop the ultimate moment capacity of the beam section. In terms of the maximum strength, the maximum load that both of the retrofitted specimens developed was 8 kip where specimen J3 was not able to maintain this load, and this led to joint failure because the "L" shapes of the CFRP were not able to handle the large amount of tension. Whereas specimen J4 was able handle the load since two layers of CFRP sheets were used, and the failure occurred out of the confinement region.

In order to judge the effects of the axial load on the column, a comparison between retrofitted specimens was required. Figures 4-44 and 4-45 show how the axial load affected the behavior of these specimens in terms of load-displacement behavior.

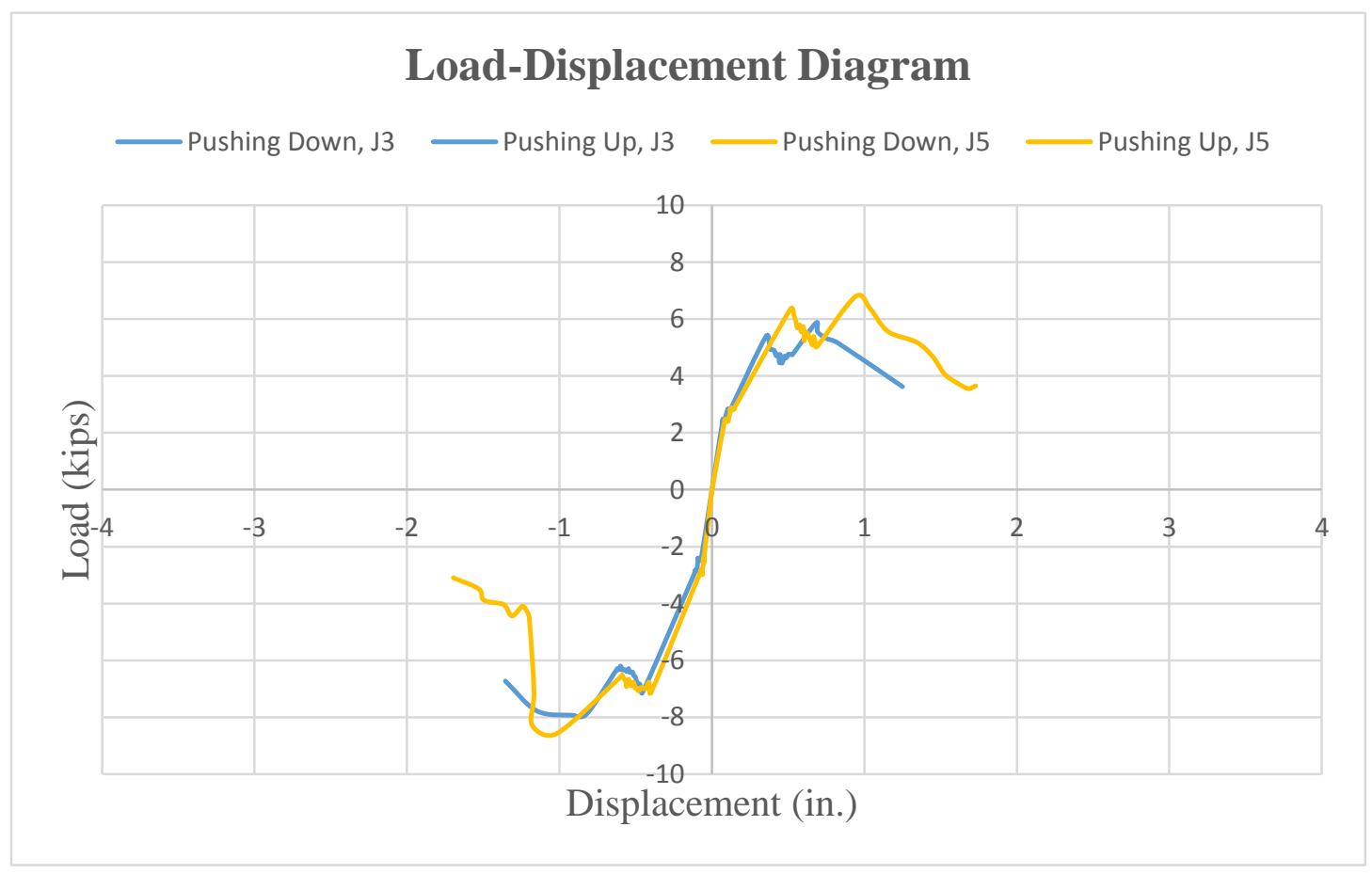

Figure 4-44 Cyclic Load-Vertical Displacement Relationship of Specimens (J3 and J5) Tested under a Different Axial Load (20\% and $40 \%$ of the Column Capacity) 


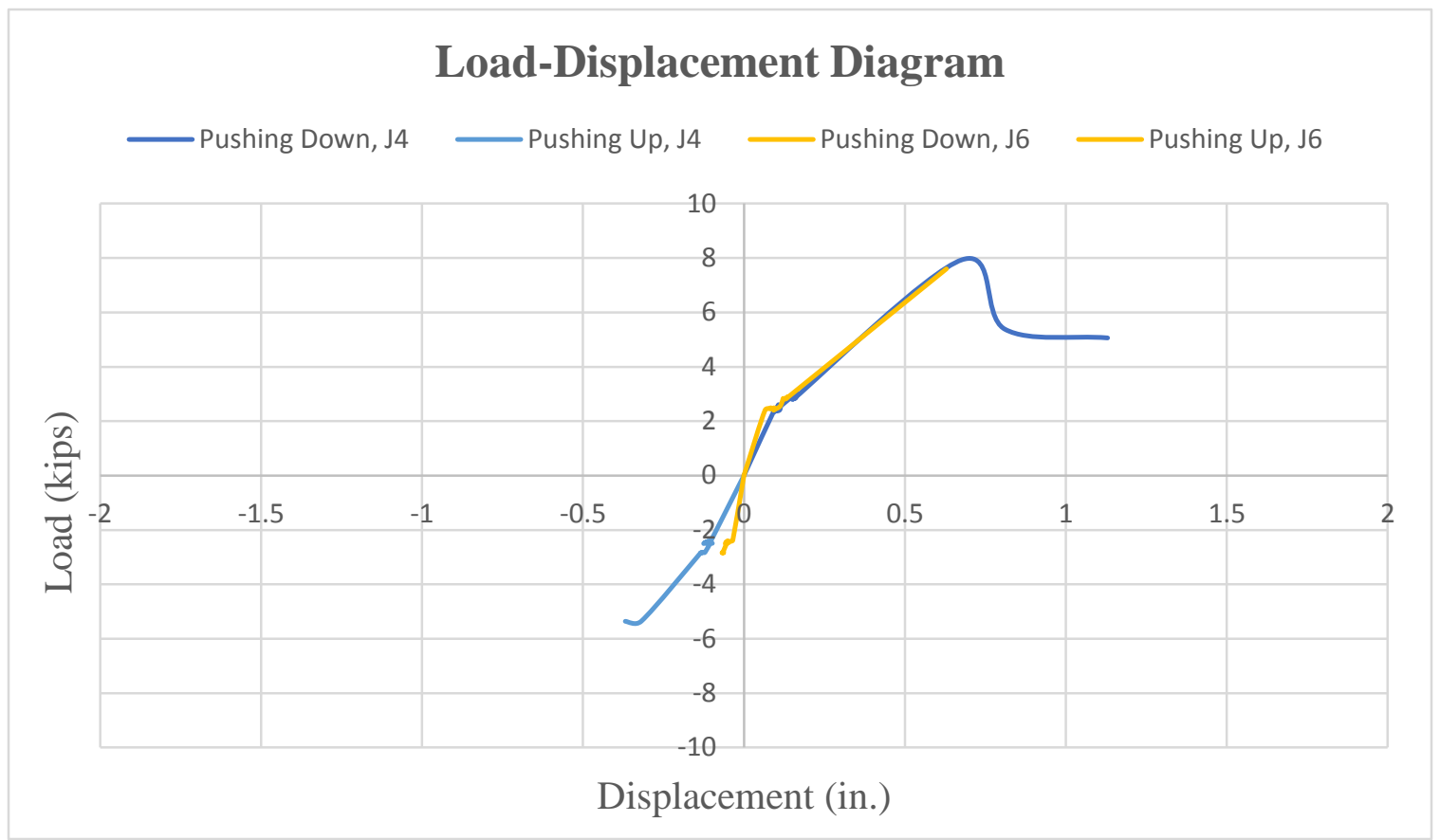

Figure 4-45 Cyclic Load-Vertical Displacement Relationship of Specimens (J4 and J6) Tested under a Different Axial Load (20\% and $40 \%$ of the Column Capacity)

It is important to mention that any increase in the axial load on the column will cause it to improve the concrete strength against the shear in the joint region as stated in the ACI 318-14 Code, Chapter 10 (shear strength provided by concrete for nonprestressed members). Because of the increase in compression load, and the consequent increase in the shear capacity, there were two items of improvement in J5 as compared to J3.

As shown in Figure 4-44, there was a slight improvement (about 8\%) in the J5 within the strain control phase of the load sequence, as compared with J3. The number of cycles for $\mathrm{J} 5$ also increased to 52 cycles, as compared to $\mathrm{J} 3$ which was 45 cycles. 
For specimens $\mathrm{J} 4$ and $\mathrm{J} 6$, the confinement provided by the two layers of CFRP sheets was enough to make the joint area stronger than the beam outside the confinement region. The behavior of both J4 and J6 were similar. The failure of each frame was in the strain control phase (first cycle) and was caused by failure of the un-wrapped portion of the beam. After failure, the joints were inspected and there were no cracks.

\subsection{Carbon Fiber Reinforced Polymer (CFRP) Sheet Strain}

As described in Chapter Three, two strain gages were used and installed in the middle of the joint region of all retrofitted specimens in order to measure the average strain within the joint that would develop during loading. Figures 4-46 to 4-49 show the CFRP sheets strain at the different load levels.

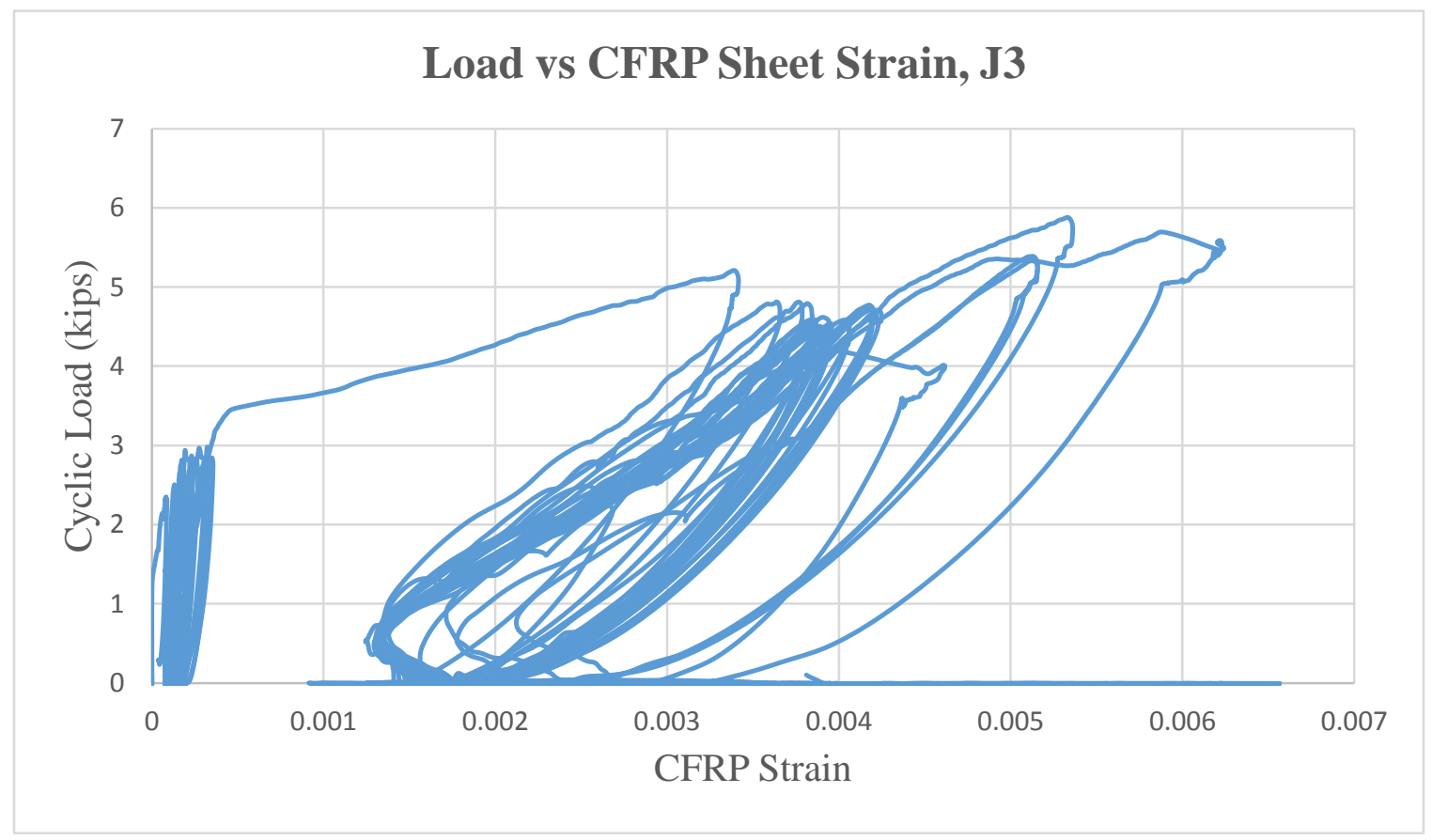

Figure 4-46 CFRP Joint Strain versus Load for Specimen J3 


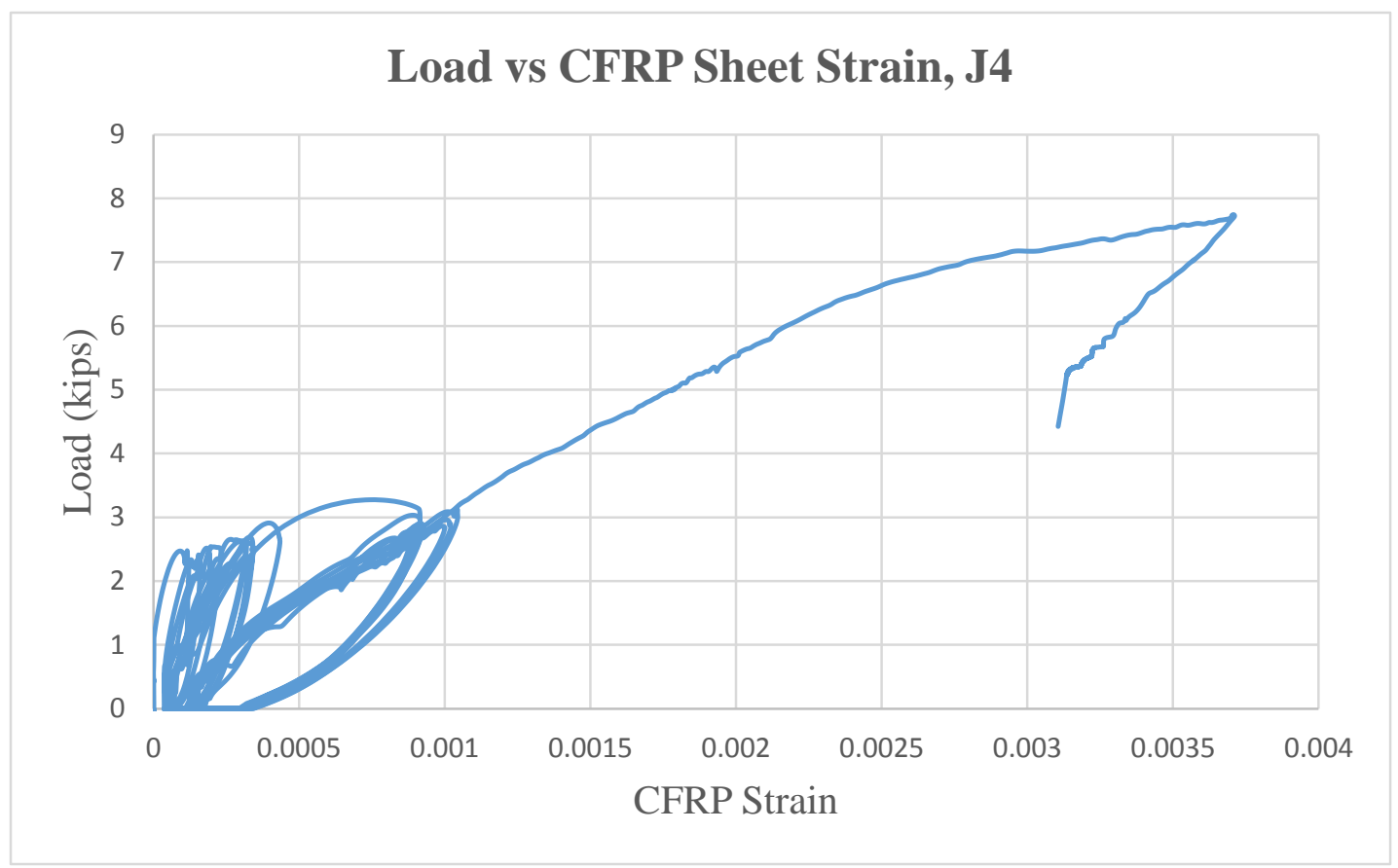

Figure 4-47 CFRP Joint Strain versus Cyclic Load for Specimen J4

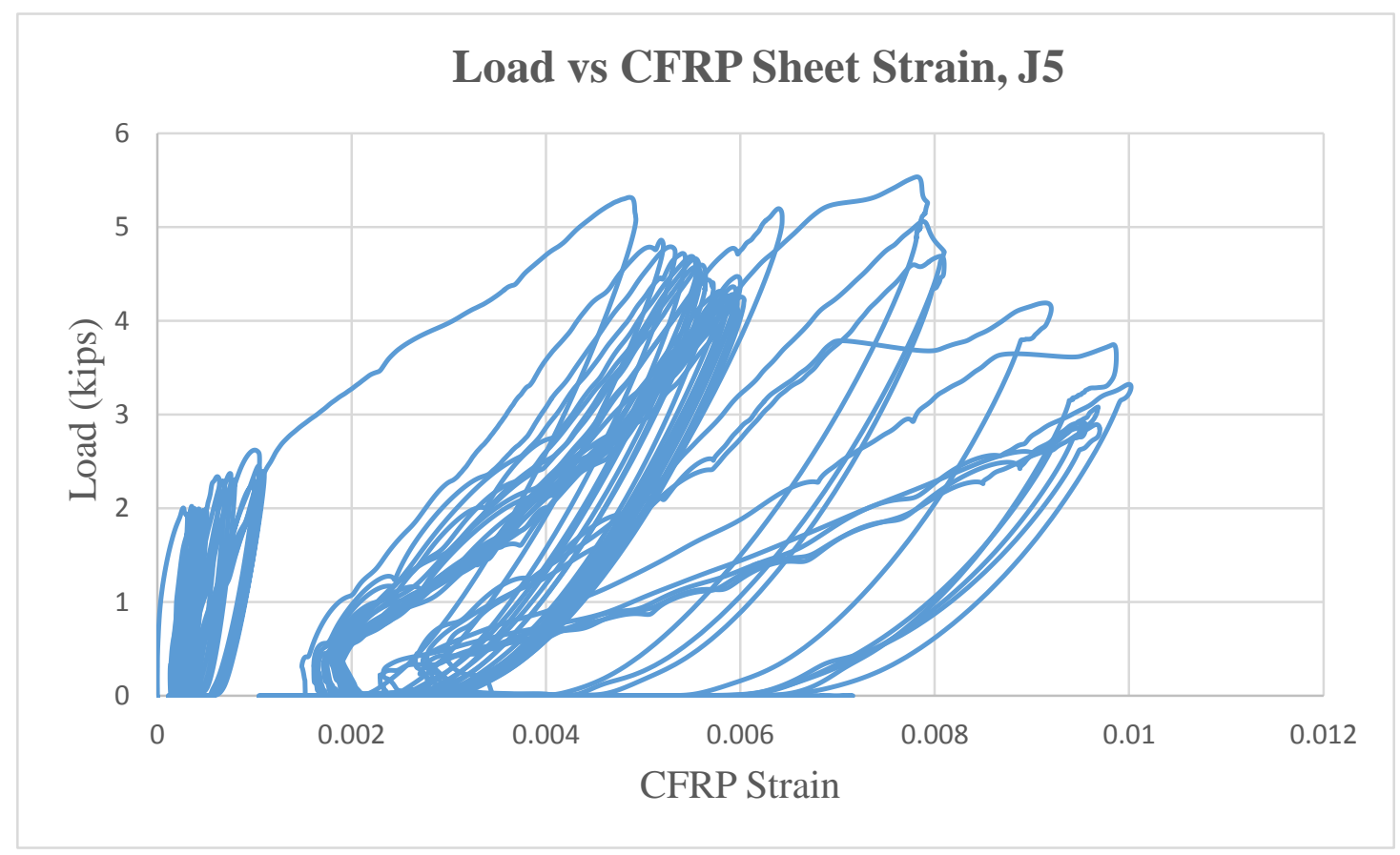

Figure 4-48 CFRP Joint Strain versus Cyclic Load for Specimen J5 


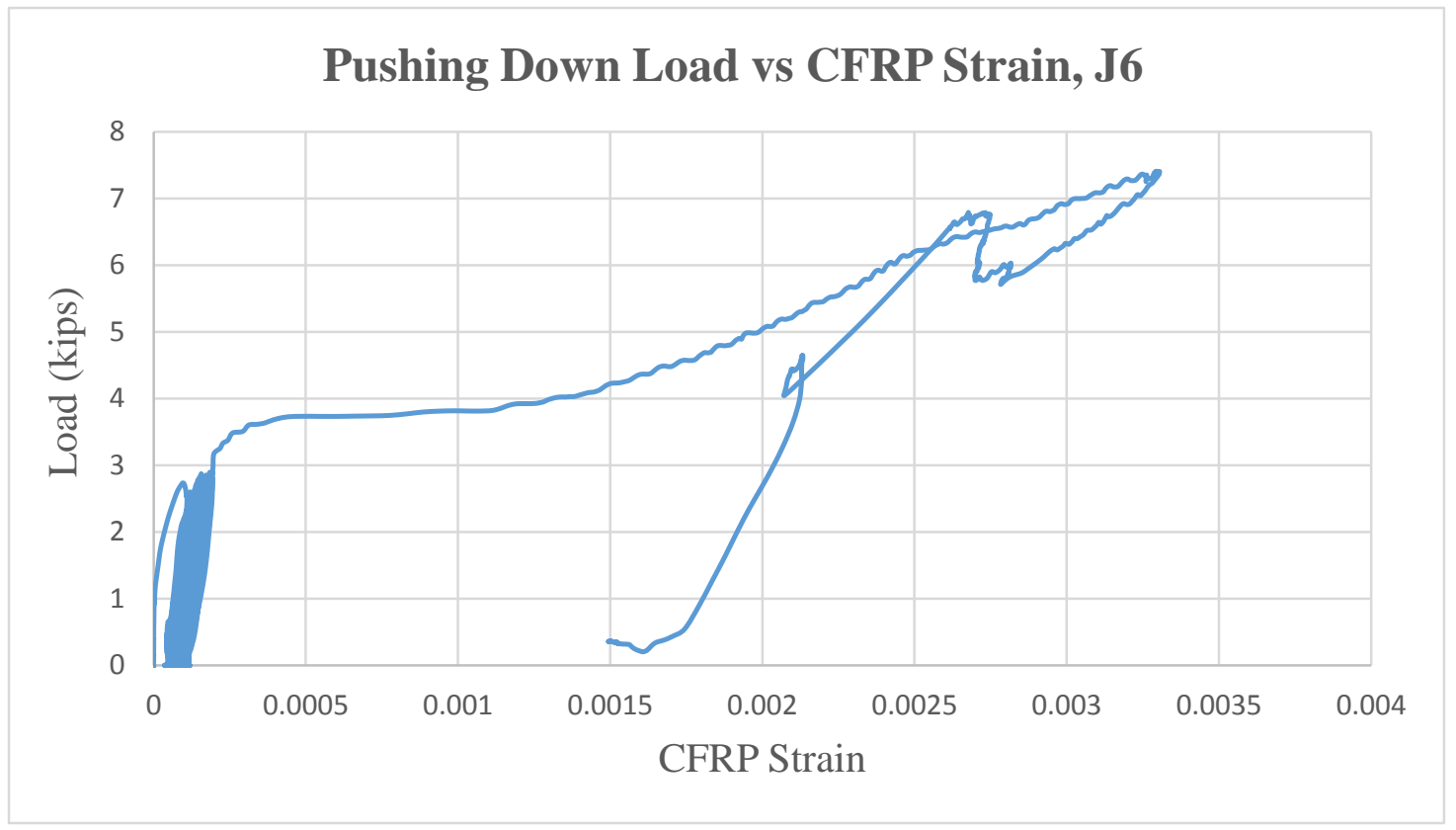

Figure 4-49 CFRP Joint Strain versus Cyclic Load for Specimen J6

Figures 4-46 and 4-48, show specimens J3 and J5, within the load control. The strain was very small, and it started and ended at the same strain values. By starting the strain control phase of the load sequence, the strain started and ended close to $0.15 \%$ and this indicated that the confinement was not enough to keep the concrete under the CFRP sheets without cracks. On the other hand, with regard to specimens J4 and J6 during the load sequence of the test, the strain of the beam flexural reinforcement matched the strain at the joint region. This meant that all confinement regions worked as one unit. The figures show that there was no permanent deformation in the CFRP sheets and the concrete under them where the strains start from zero and this return to the same value at each cycle. This is confirmed when the CFRP sheets were removed from the concrete, there were no cracks. The maximum stress that developed in the CFRP sheet of each retrofitted specimen is summarized in Table 4-8. 
Table 4-8 Maximum Stress Developed in the CFRP Sheet

\begin{tabular}{|c|c|c|}
\hline Specimen & Maximum Strain & Maximum Stress (ksi) \\
\hline J3 & 0.0066 & 216 \\
\hline J4 & 0.0037 & 122 \\
\hline J5 & 0.0100 & 330 \\
\hline J6 & 0.0033 & 109 \\
\hline
\end{tabular}

\subsection{Energy Dissipation}

The absorption of energy is the most important feature of the concrete structures that are subject to earthquakes where the ability of the structure to survive during the earthquakes depends on its ability to absorb energy. In this test, the closed area of cyclic load versus displacement represented the energy dissipation of each cycle. Figures 4-50 to 4-55 show the cumulative energy dissipation of all specimens. 


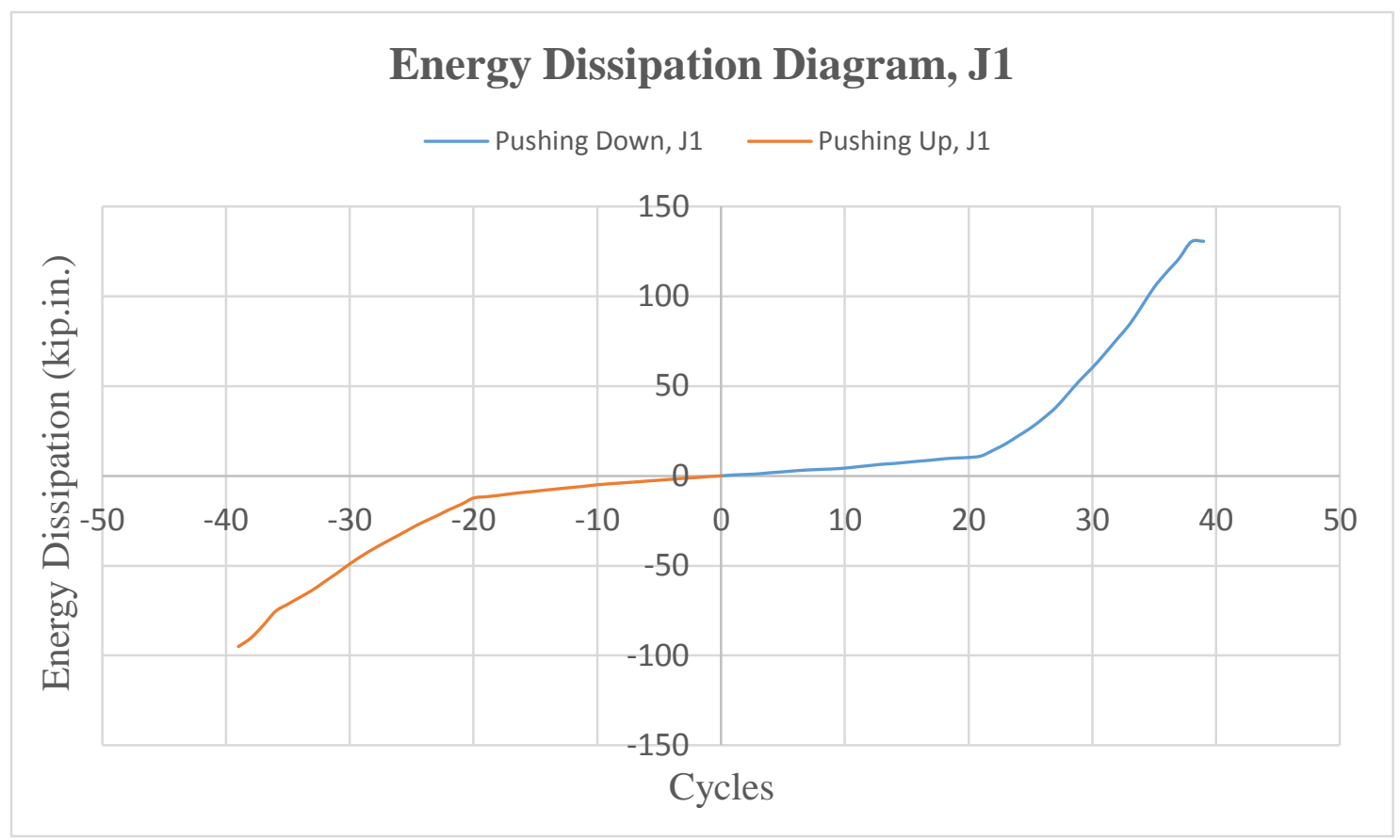

Figure 4-50 The Cumulative Energy Dissipation of Specimen J1

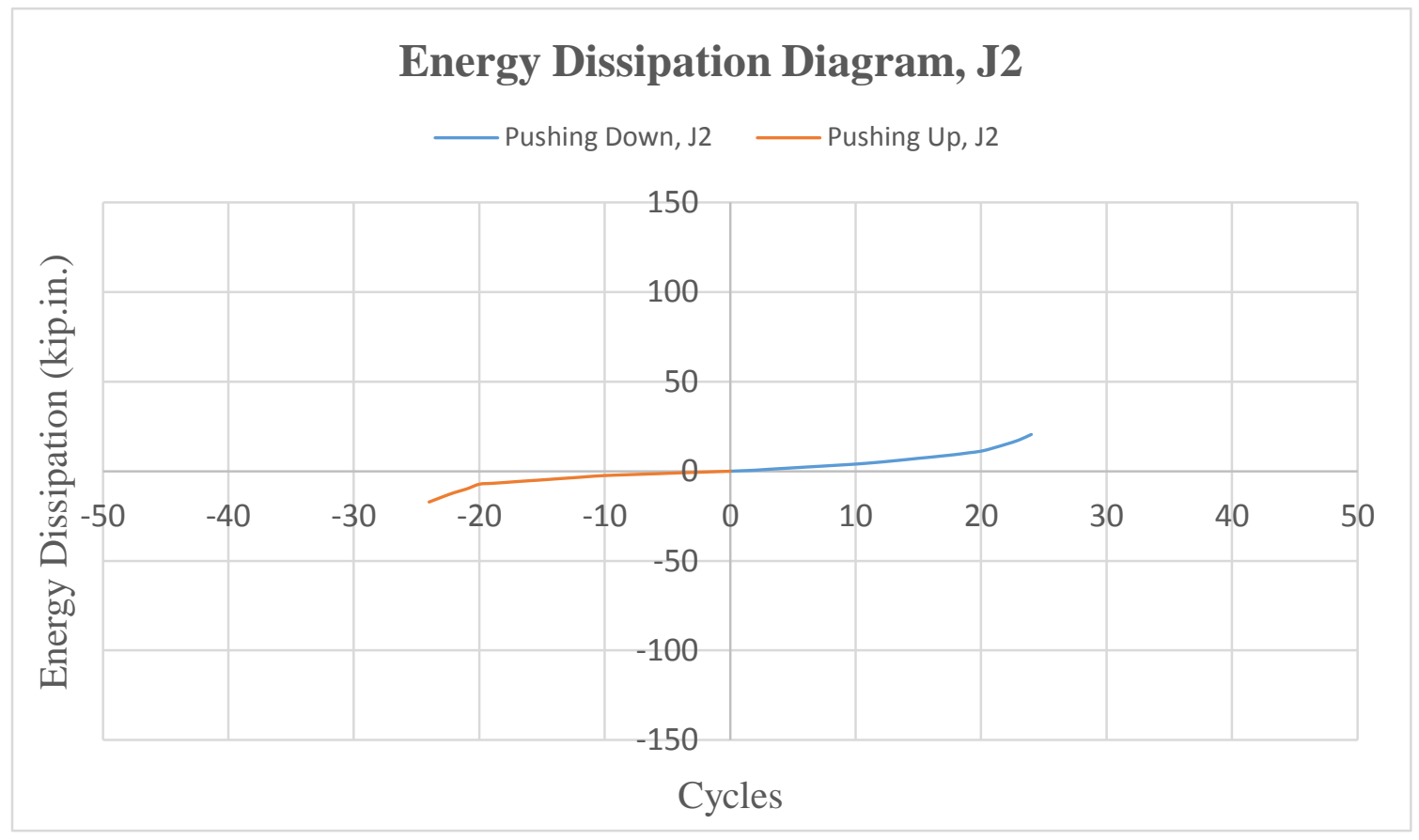

Figure 4-51 The Cumulative Energy Dissipation of Specimen J2 


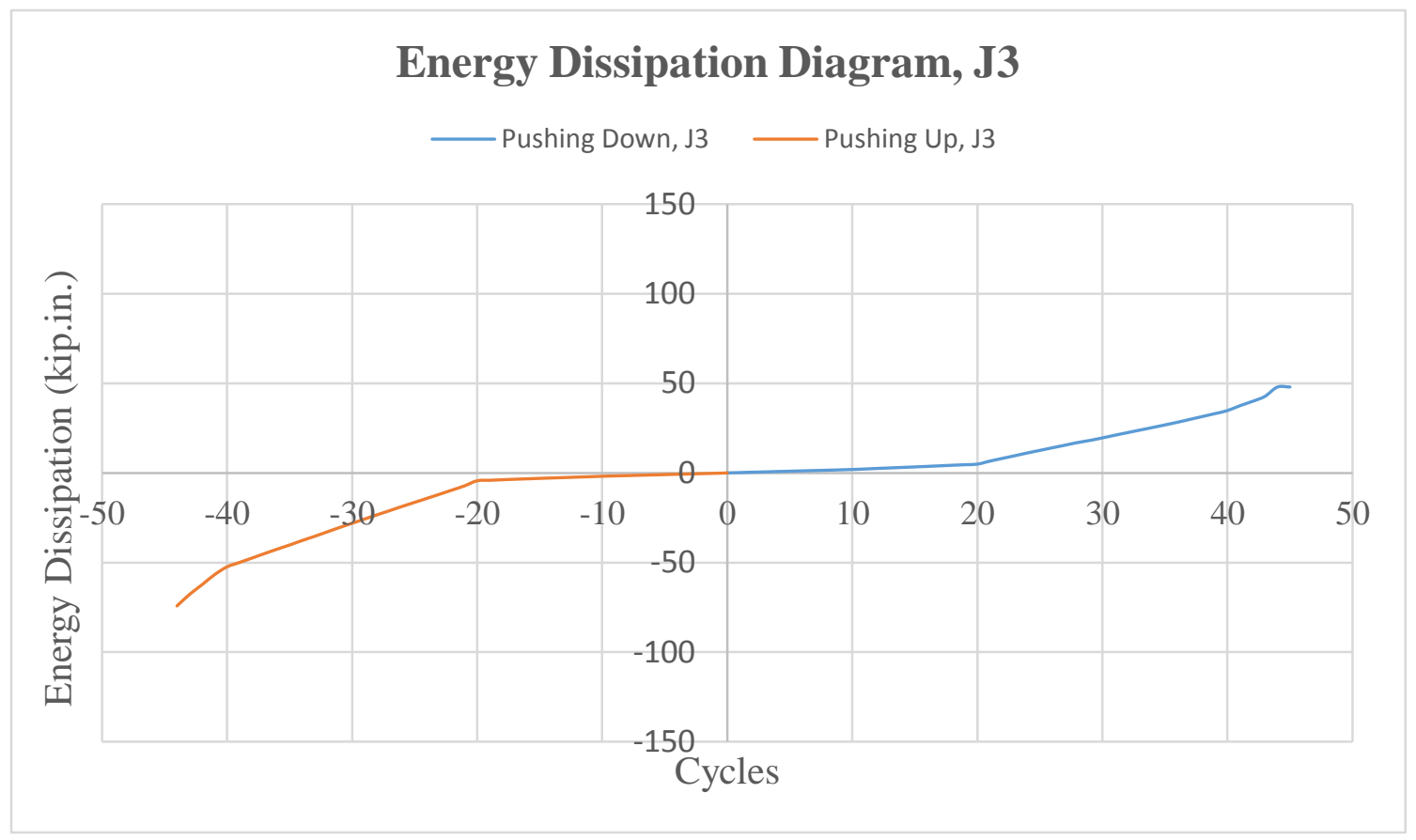

Figure 4-52 The Cumulative Energy Dissipation of Specimen J3

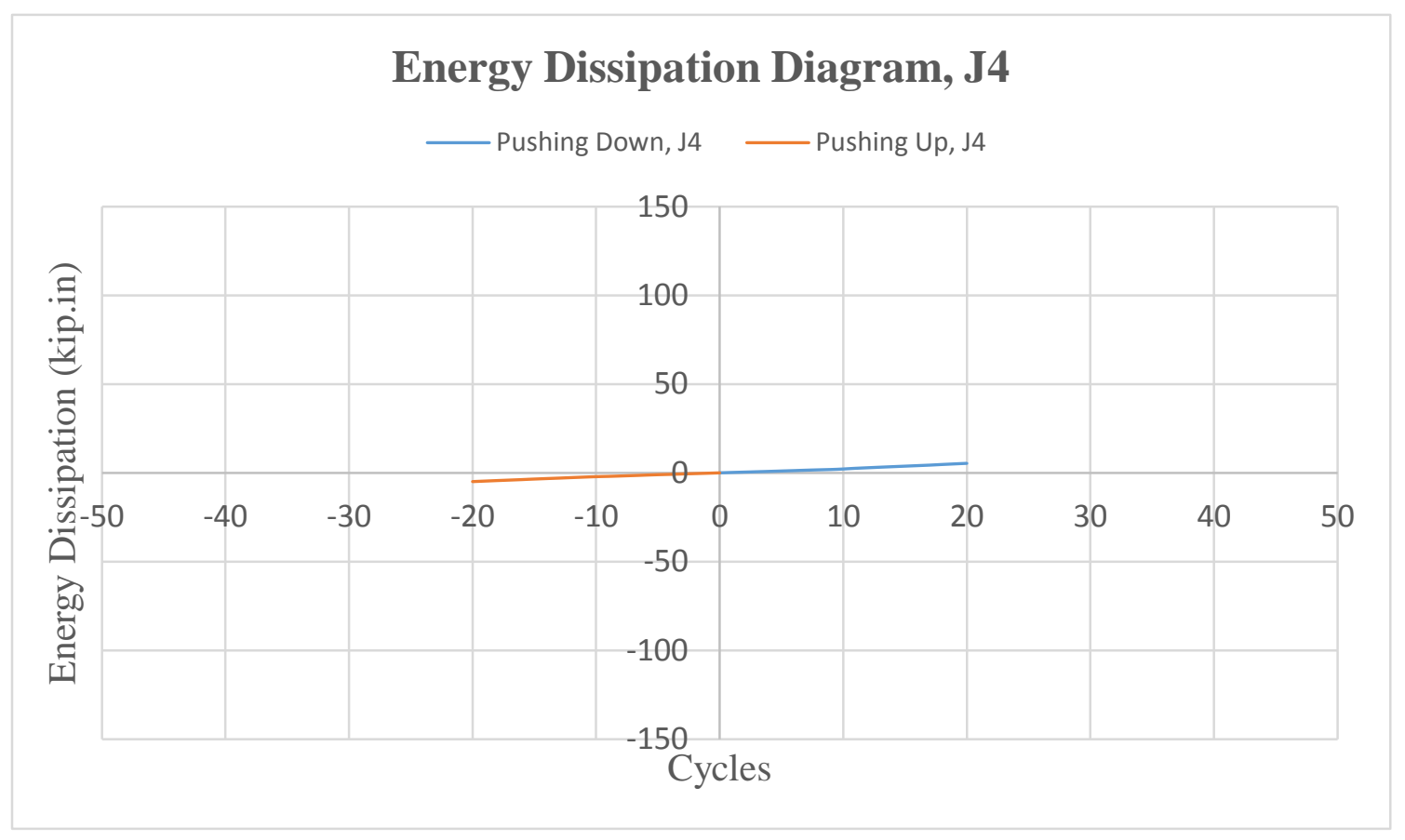

Figure 4-53 The Cumulative Energy Dissipation of Specimen J4 


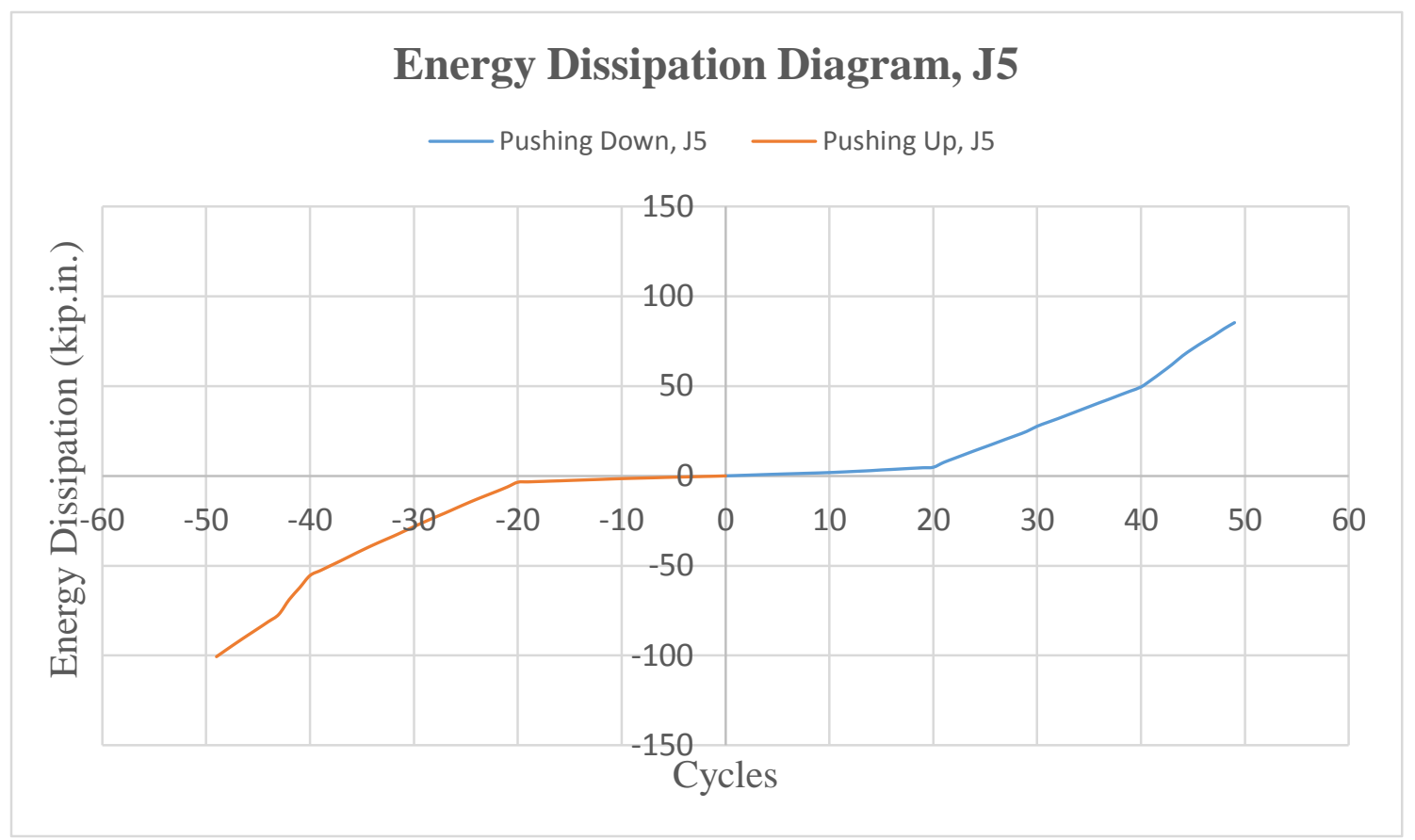

Figure 4-54 The Cumulative Energy Dissipation of Specimen J5

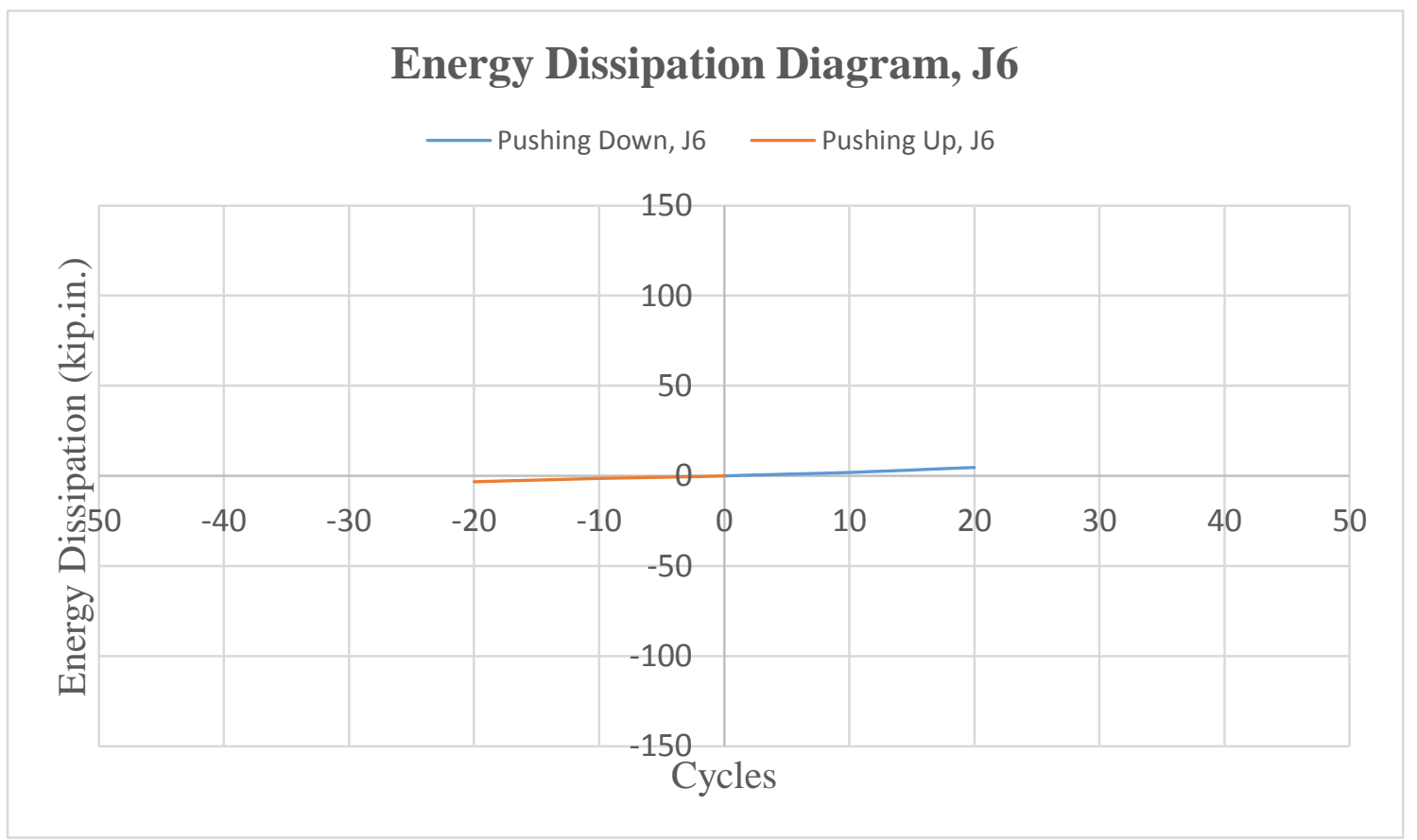

Figure 4-55 The Cumulative Energy Dissipation of Specimen J6 
Figure 4-56 shows a comparison of all specimens J1, J2, J3, and J4 tested under same load conditions in terms of the cumulative half cycle energy dissipation.

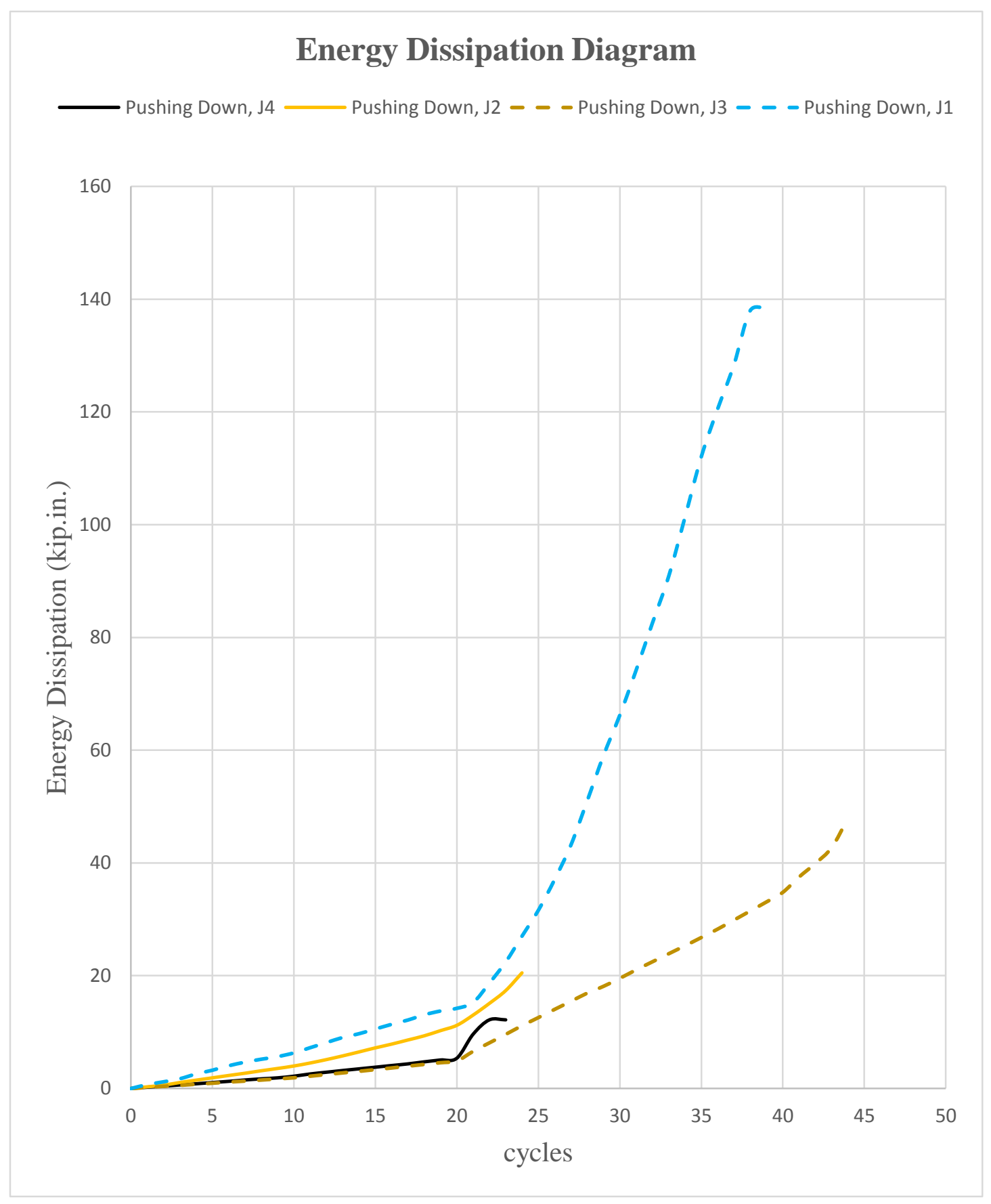

Figure 4-56 The Cumulative Half Cycle Energy Dissipation of Specimens J1, J2, J3, and $\mathrm{J} 4$ 
Within the load control phase of the load sequence, specimens J1 and J2 showed that the absorbed energy of the control specimens was more than retrofitted specimens J3 and J4. The behaviors of specimens J3 and J4 was identical. It was clear that the energy dissipation was increasing consistently and regularly from cycle number one until cycle twenty. This meant that all of the cycles for each specimen were almost equal, and the behavior was result of the absence of a sudden deterioration in the resistance to the specimens. The difference in the behavior of specimens $\mathrm{J} 1$ and $\mathrm{J} 2$ was because specimen $\mathrm{J} 1$ started forming the plastic hinge within the ductile zone since the first cycle and consequently the absorbed energy increased comparing with specimen $\mathrm{J} 2$ that started forming diagonal cracks within the joint region. In general the behavior of the control specimens represented the behavior of the concrete and steel only. On the other hand, the similarity in the behavior of specimens J3 and J4 was because CFRP sheets affected the cyclic behavior of the retrofitted specimens and caused to increase the strength of these specimens and reduced their deflections in both directions. In general, specimen J1 showed very high level of energy dissipation because it was designed with high ductility according to the current ACI Code. Moreover, specimen J2 also showed good ductility as compared to retrofitted specimens $\mathrm{J} 3$ and $\mathrm{J} 4$, because the CFRP sheets remained within the elastic range until failure. This reduced the ability of the retrofitted joints to dissipate the energy. Overall, specimen J2 performed poorly in terms of energy dissipation because of the rapid failure according to the deficiency of the transverse reinforcement at the joint region. This led to a very brittle shear failure and slip of the longitudinal reinforcement beam bars. The energy dissipation of $\mathrm{J} 1$ was about 7 times larger than $\mathrm{J} 2$. Using one layer 
the CFRP improved the behavior of the joint. The energy dissipation of J3 was about 2.5 times larger than J2. Figures 4-57 and 4-58 show effects of the change in the axial applied load on the retrofitted specimens in terms of the cumulative energy dissipation.

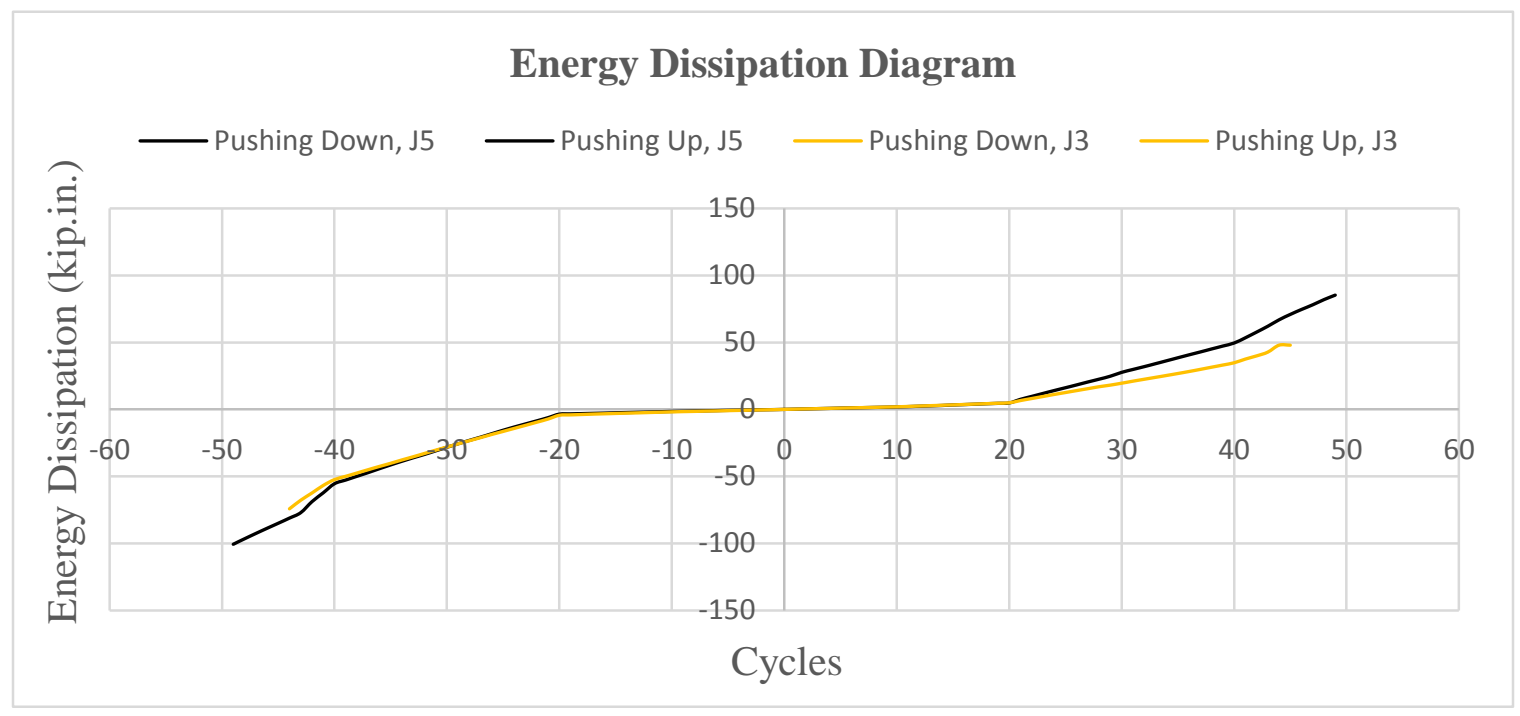

Figure 4-57 Compare between the Cumulative Energy Dissipation for Specimens J3 and J5

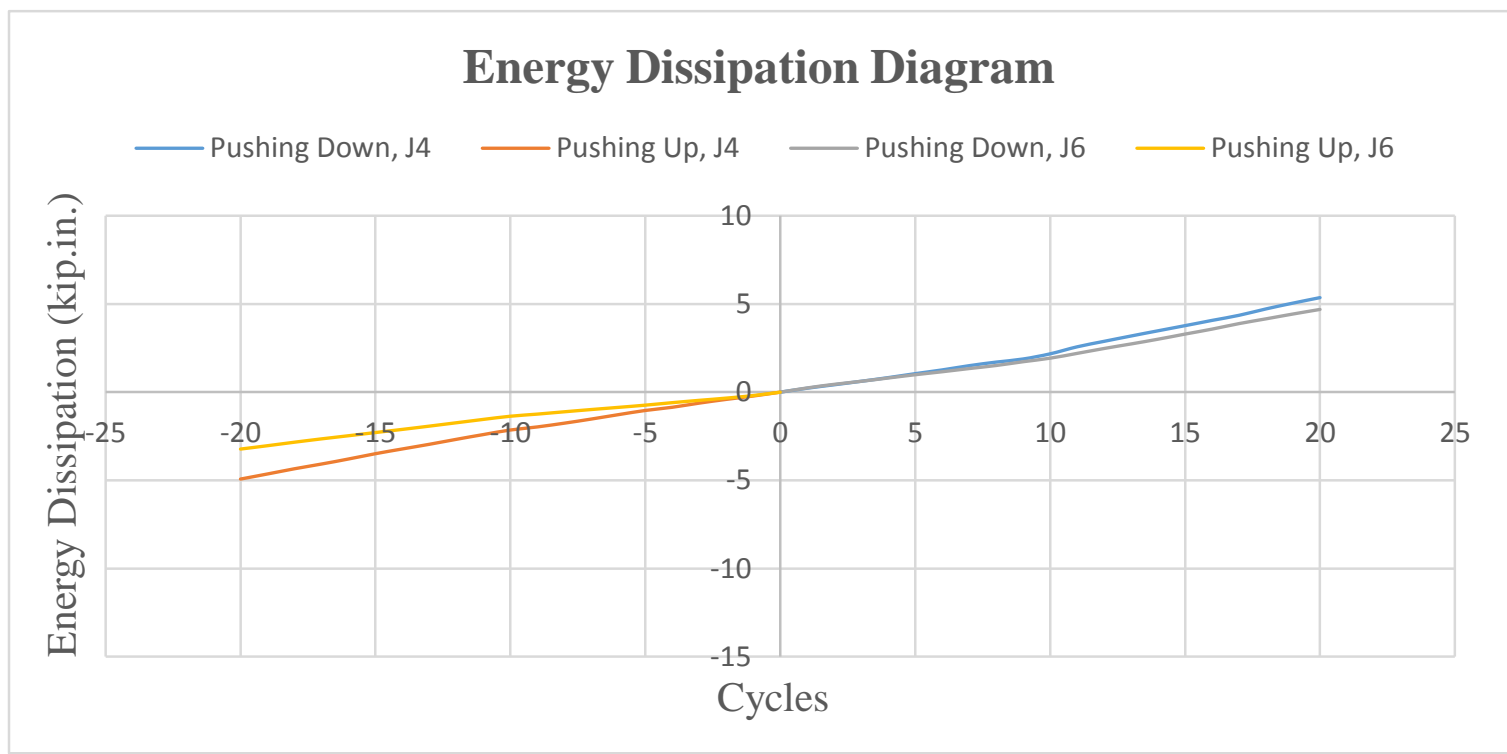

Figure 4-58 Compare between the Cumulative Energy Dissipation for Specimens J4 and J6 
The dissipation ability of the energy for specimen J5 increased, as shown in Figure 4-57, by about $70 \%$ as compared to specimen $\mathrm{J} 3$ because the increase in the axial load on the column helped to improve the shear strength of the concrete for the joint region. Due to this, the development of cracks was delayed, and this helped specimen J5 to go through more loading cycles before the failure. Figure 4-58 shows the opposite situation, where the cumulative energy dissipation of specimen $\mathrm{J} 4$ was larger than the cumulative energy dissipation in specimen J6. This was due to the increase in the concrete shear strength, and provided the proper confinement for the joint region helped to reduce the initial displacement for the free end of the beam. This made the energy dissipation for the specimen J6 less than the energy dissipation for the specimen J4.

\subsection{Ductility Factor}

As Revathi, R. et al. (2014) stated, the ductility factor is the ability of the element to deform beyond the yield point without losing a lot of the resisting strength. If the ductility factor is very large, this means the structure could show a sufficient deformation beyond the yield point. The ductility factor is actually expressed as a ratio between the displacements at each cycle with respect to the displacement at the yield of the beam longitudinal reinforcement. Table 4-9 shows the maximum ductility factor of each specimen that developed during this experimental work. 
In the pushing down instance:

\begin{tabular}{|c|c|c|c|}
\hline Specimen (J) & Max. Disp.(in.) & Yield Disp.(in.) & Max. Ductility Factor \\
\hline 1 & 2.49 & 0.307 & 8.1 \\
\hline 2 & 1.16 & 0.170 & 6.8 \\
\hline 3 & 1.25 & 0.173 & 7.2 \\
\hline 4 & 1.12 & 0.288 & 3.9 \\
\hline 5 & 1.73 & 0.241 & 7.2 \\
\hline 6 & 0.62 & 0.261 & 2.4 \\
\hline
\end{tabular}

In the pushing up instance:

\begin{tabular}{|c|c|c|c|}
\hline Specimen (J) & Max. Disp.(in.) & Yield Disp.(in.) & Max. Ductility Factor \\
\hline 1 & -3.55 & 0.379 & -9.4 \\
\hline 2 & -1.25 & 0.245 & -5.1 \\
\hline 3 & -1.35 & 0.239 & -5.6 \\
\hline 4 & -0.37 & N/A & N/A \\
\hline 5 & -1.70 & -0.181 & -9.4 \\
\hline 6 & -0.06 & N/A & N/A \\
\hline
\end{tabular}


Figures 4-59 to 4-64 show more details about the ductility (half cycle) of each specimen with respect to the cycle number.

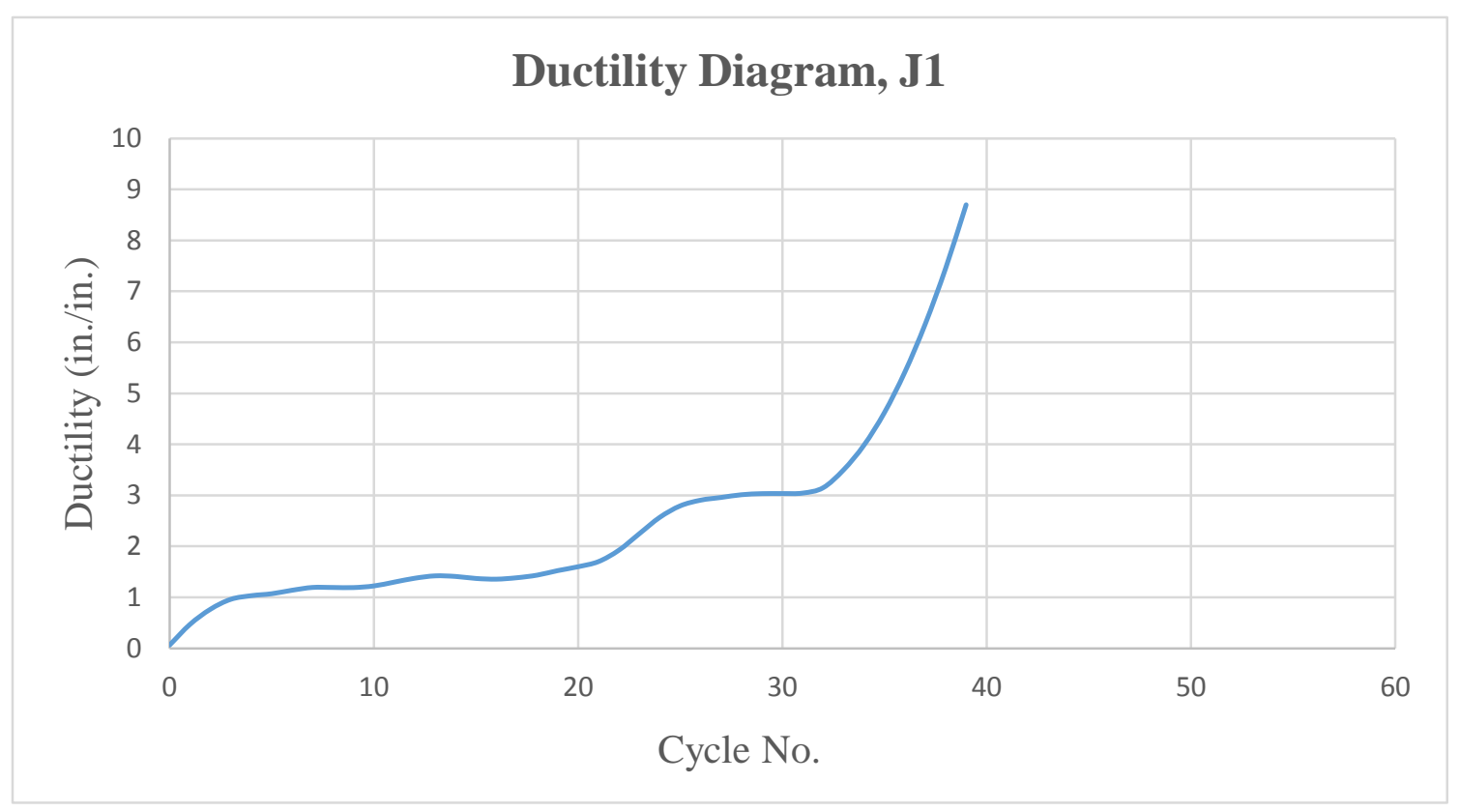

Figure 4-59 Ductility Factor Diagram (Half Cycle) of Specimen, J1

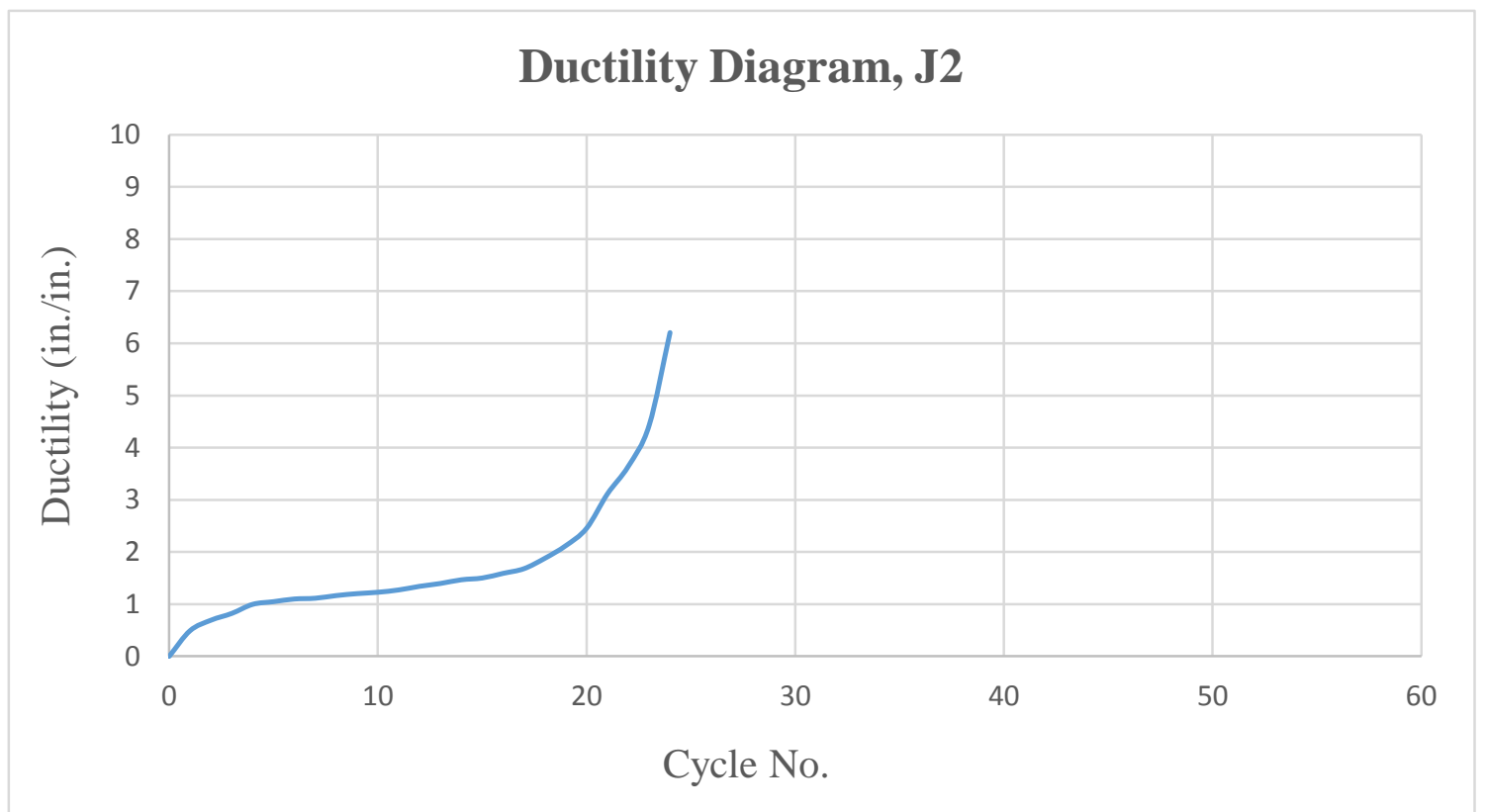

Figure 4-60 Ductility Factor Diagram (Half Cycle) of Specimen, J2 


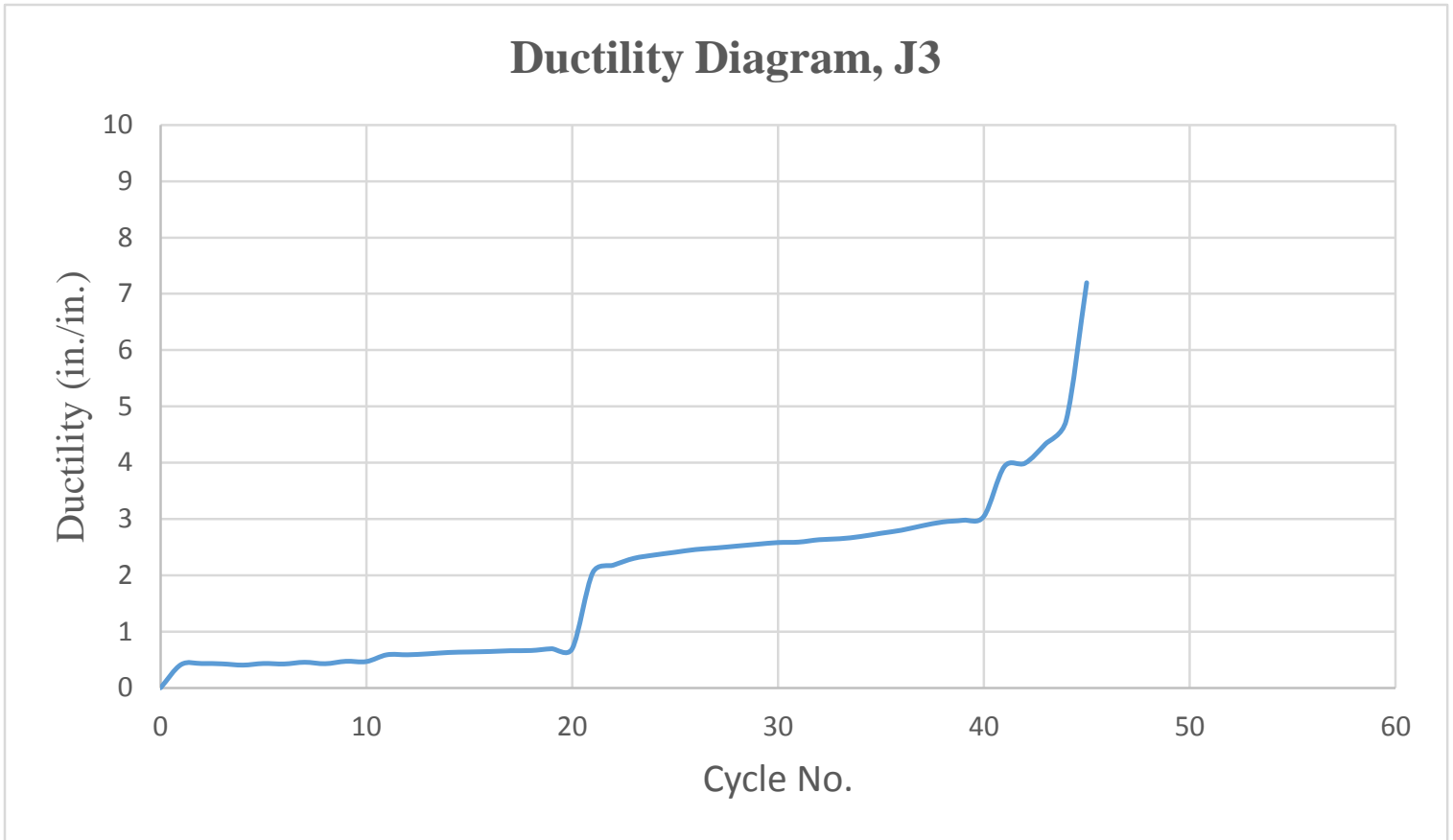

Figure 4-61 Ductility Factor Diagram (Half Cycle) of Specimen, J3

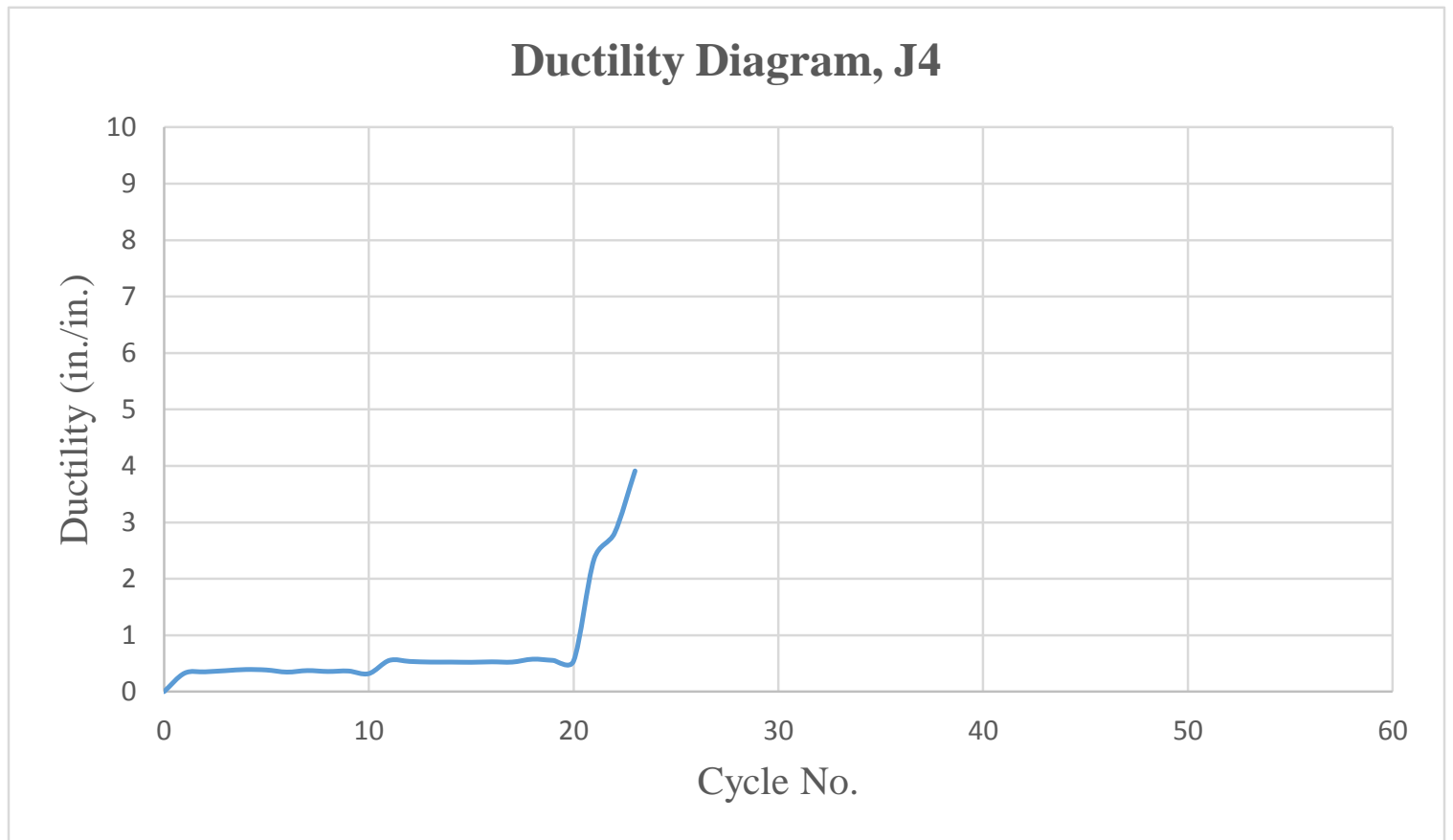

Figure 4-62 Ductility Factor Diagram (Half Cycle) of Specimen, J4 


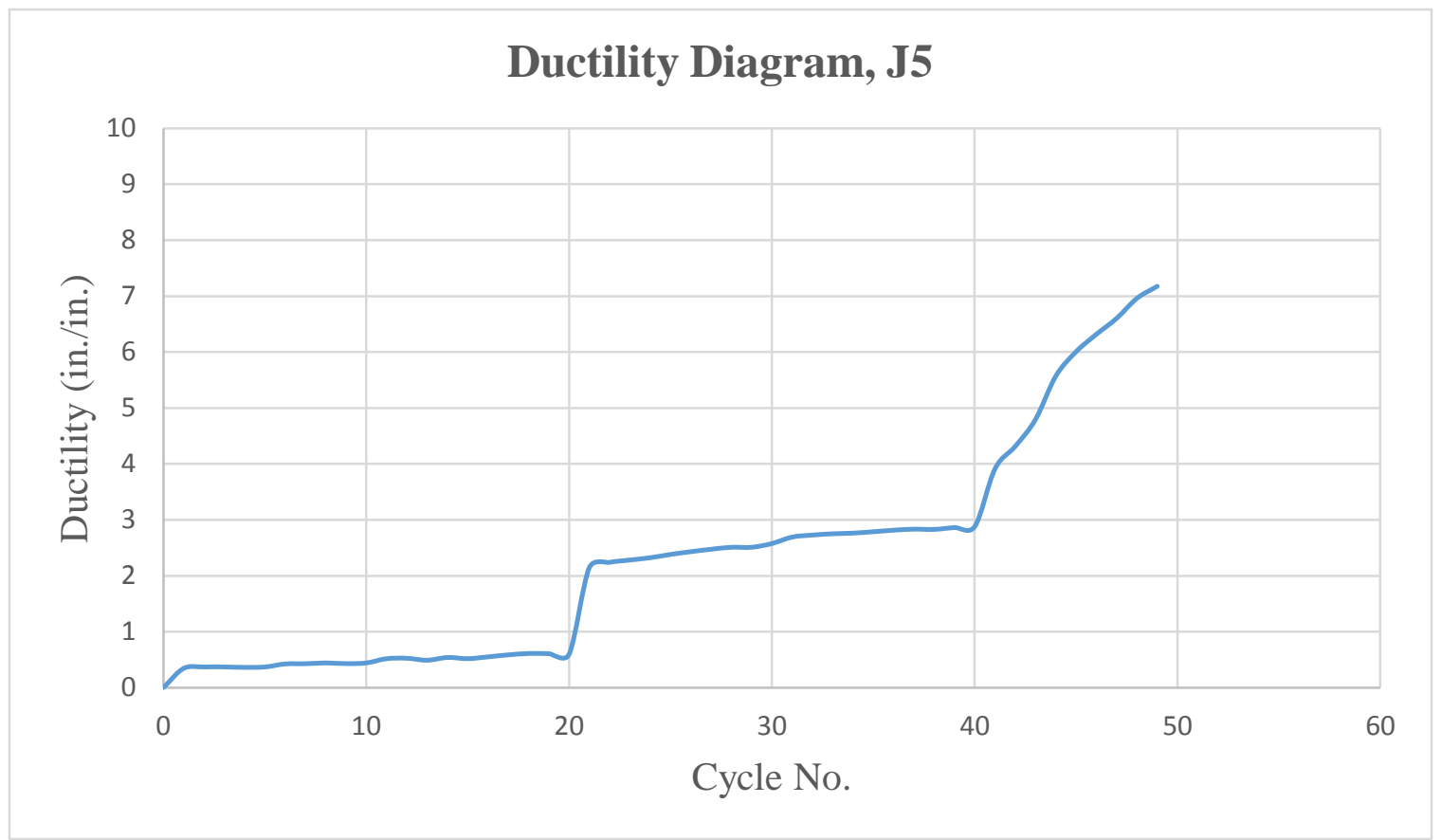

Figure 4-63 Ductility Factor Diagram (Half Cycle) of Specimen, J5

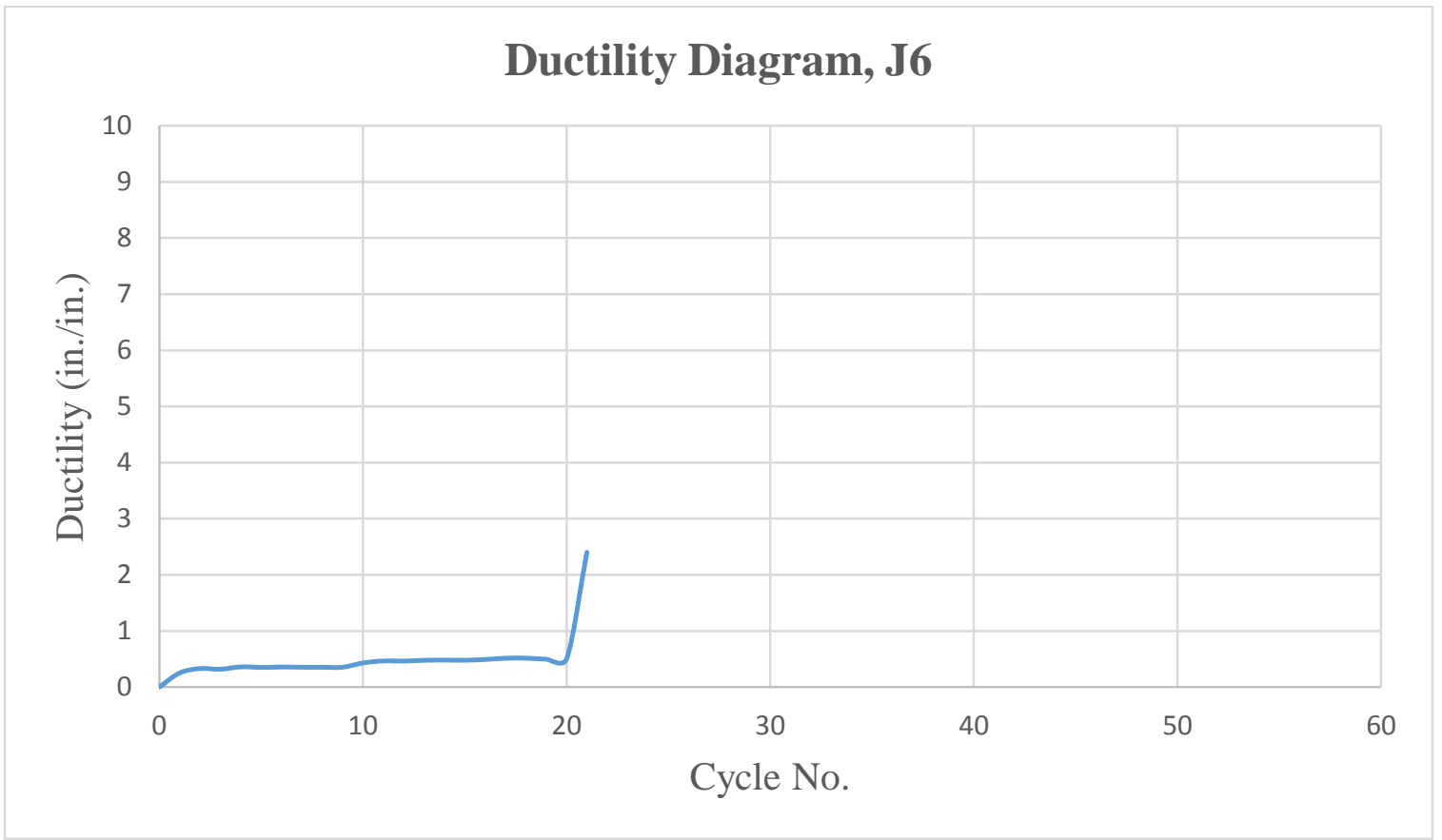

Figure 4-64 Ductility Factor Diagram (Half Cycle) of Specimen, J6 
Figure 4-65 shows the comparison of specimens J1, J2, J3, and J4, which were subjected to the same load condition.

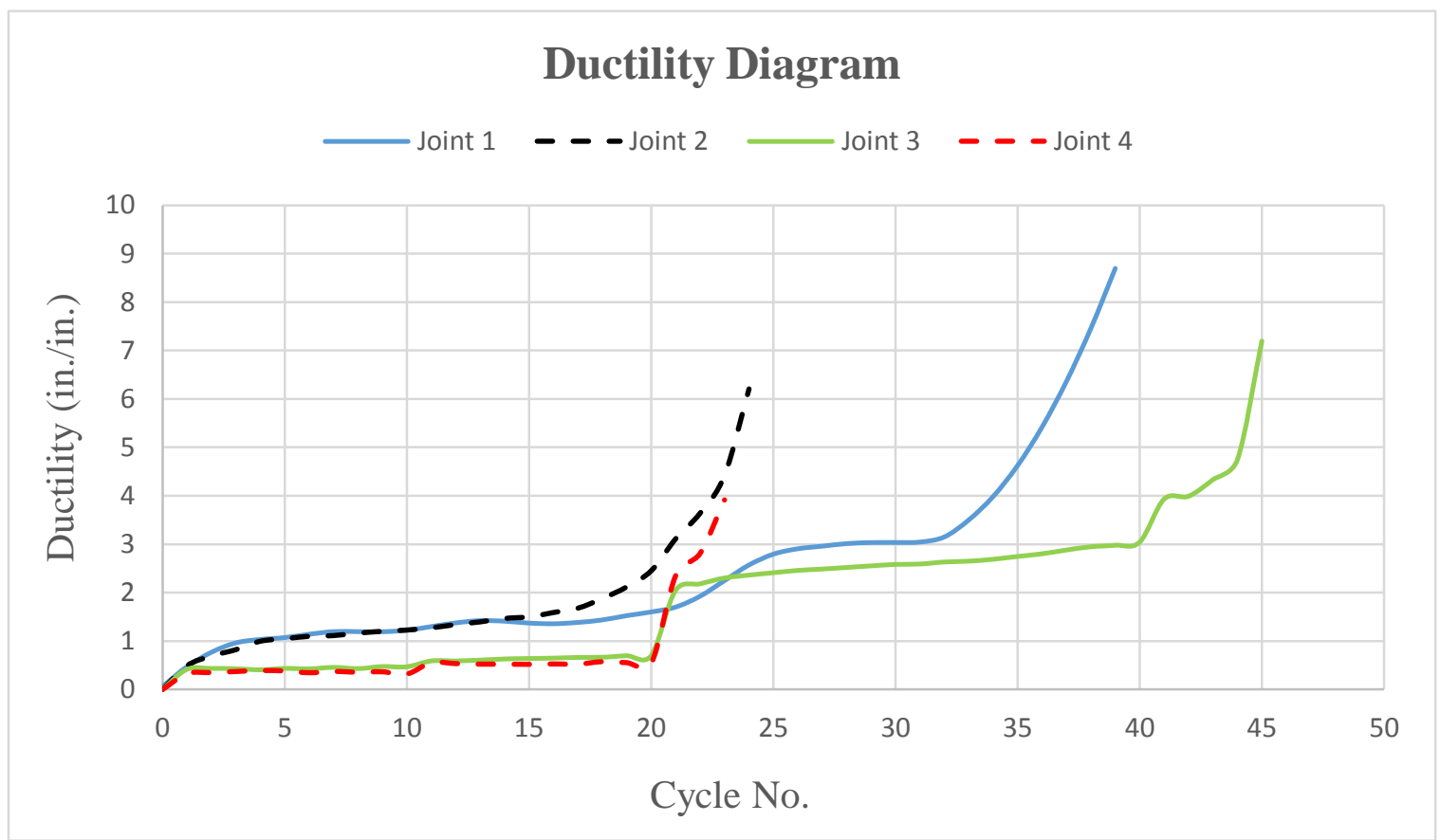

Figure 4-65 Compare of Ductility (Half Cycle) for Specimens J1, J2, J3, and J4

From the Figure 4-65 above, it is clear that specimen J1 showed the highest ductility as compared to the other specimens despite the fact it reached the yield point during the first cycles when the applied cyclic load was lower than the maximum capacity of the beam. The behavior of specimen $\mathrm{J} 2$ was identical to the behavior of specimen J1 within the first twenty cycles, but the lack of transverse reinforcement within the joint region caused loss of strength in the joint. This forced the test to be terminated at the early cycles of the strain control phase. The ductility factor in the last three cycles for the specimen J2 cannot be trusted because severe cracks developed in the joint beside the slip in the flexural beam reinforcement. The specimens that were wrapped in CFRP sheets behaved 
identically as well. They showed a low ductility within the load control phase of the load sequence because the composite system increased the overall strength of the specimen, and this led to a reduction in the displacement under the same load sequence. No yield was reached within the load control, as shown the figures. Specimen J3, which was strengthened with one layer of the CFRP sheet, increased the final ductility to about $40 \%$ as compared to the non-ductile specimen $\mathrm{J} 2$. The specimen reached the final ductility at the strain control phase of the load sequence after fortieth cycle where the strain in the longitudinal was $0.6 \%$. Specimen J4 developed a low ductility within the load control phase, as well. Once the strain control phase started, the beam member crashed because the beam was weakest than the column and the joint.

Figures 4-66 and 4-67 show the effect of an increase in the axial load on the column by comparing specimens $\mathrm{J} 5$ and $\mathrm{J} 6$ with specimens $\mathrm{J} 3$ and $\mathrm{J} 4$. The figures also take into consideration the CFRP layers, and show that the specimens behaved identically under different axial loads. As known, shear strength of the concrete subjected to the compression will increase and this will improve the behavior of the specimen. Since the ductility factor is actually an expression as a ratio between the displacements at each cycle with respect to the displacement at the yield, any increase in the joint rejoin strength will affect both the displacement at each cycle and the displacement at yield. This was the reason for the similarity between the specimens under different axial loads. 


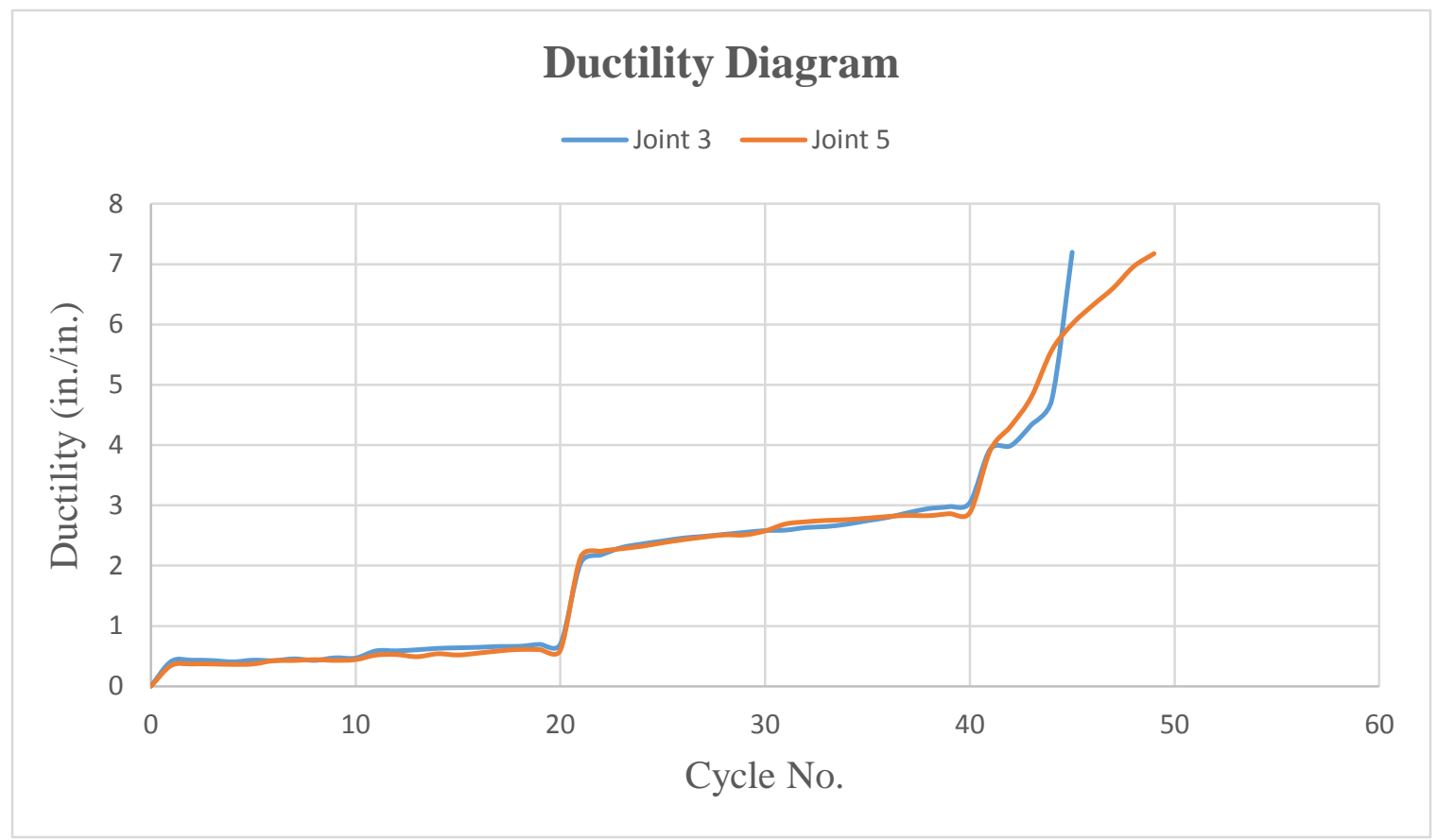

Figure 4-66 Comparison of Ductility for Specimens J3 and J5

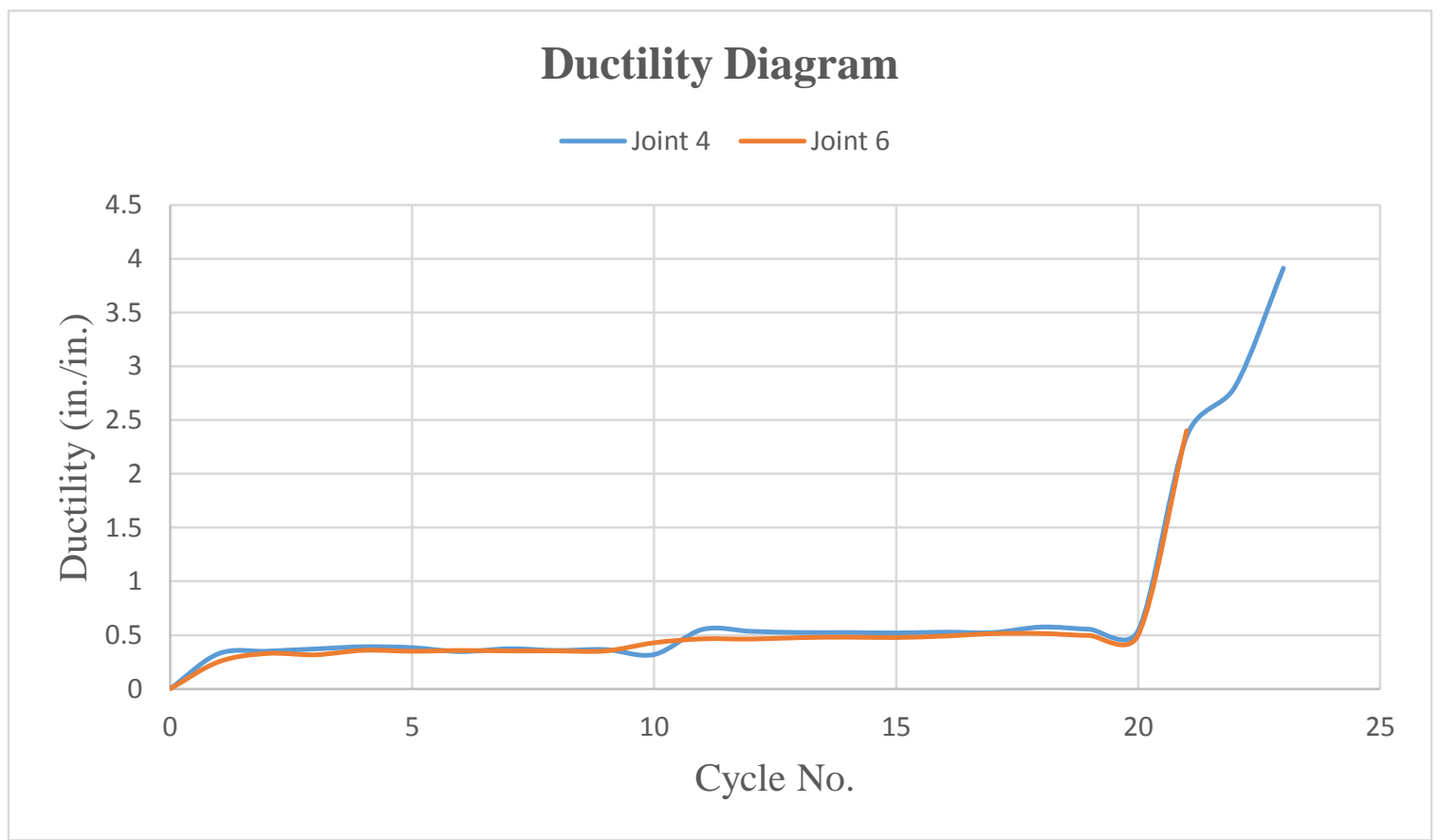

Figure 4-67 Comparison of Ductility for Specimens J4 and J6 


\section{Chapter 5.}

\subsection{Summary:}

This experimental work was conducted in order to evaluate a proposed technique by using CFRP sheets to retrofit non-ductile joints constructed prior to the modern codes. Six specimens were tested; two were tested as control specimens (specimen J1 and specimen J2) and the rest were retrofitted by using CFRP sheets. The variable factors in this research were the number of CFRP layers and the level of applied axial force in the column. Two specimens were wrapped with one layer, and two with two layers. Based on the experimental results, the following conclusions are drawn:

\subsection{Conclusion:}

1- The non-ductile specimen J2, which was designed based on older codes, was structurally deficient to resist the lateral loads due to the lack in the transverse reinforcement at the joint region. This caused to a brittle shear failure in the joint.

2- The ductile specimen J1, which was designed based on the current codes (ACI 318-14), was structurally sufficient to eliminate the failure in the joint region and resulting in formatting of the plastic hinge within the beam instead of the joint region.

3- Retrofitting the specimens with CFRP sheets improved the behavior of nonductile joints by increasing the joint capacity, and changed the final failure mode.

4- For the specimens that were retrofitted by only one layer of CFRP, failure was mainly by the CFRP rupture at the joint, however, without de-bonding. 
5- The general behaviors of retrofitted specimens were similar in terms of shear strength, ductility, and energy dissipation.

6- Using an "L" shape technique at the intersection corners between the beam and column appeared effective to strengthen the joints.

7- The proposed CFRP wrapping technique was successful to change the weak column- strong beam to the strong column- weak beam situation, and to push the failure out of the confining area.

8- Since the measured strain of the longitudinal bars at the interface between the adjoining members and CFRP sheets at the center of the joint panel were nearly identical (specimens J4 and J6), the composite system appeared to act as fully composite.

9- Based on the test results, the proposed technique could be used for joints in lowrise and medium-rise buildings. 


\subsection{Recommendations:}

The following recommendations are suggested for further research:

1- Investigate the validation of the proposed technique with the internal beamcolumn joints.

2- Investigate the performance of the proposed technique on the joints in the presence of the concrete slab.

3- Investigate by using bidirectional CFRP sheets.

4- Investigate the validation of the proposed technique to repair the damaged joints.

5- Further investigation is needed for the circular column- rectangular beam joints.

6- Create an analytical FEM model to predict the performance of joints retrofitted with CFRP sheets.

7- Since the ACI 440.2R-08 "Guide for the Design and Construction of Externally Bonded FRP Systems for Strengthening Concrete Structures” is not included a specific procedure to retrofit the beam-column joint by using FRP, a theoretical and an experimental work to develop a specific procedure to retrofit the existing joints is still an open area for further studies. 


\section{References}

ACI Committee 440. (2008). Guide for the Design and Construction of Externally Bonded FRP Systems for Strengthening Concrete Structures. American Concrete Institute.

ACI Commiitee 318-14. (2014). Building Code Requirements for Structural Concrete. Farmington Hills: American Concrete nstitute.

Alobaidi, S. (2015). Behavior of Reinforced Concrete Beams Retrofitted in Flexure Using CFRP-NSM Technique. Portland.

ASTM 39/39M. (2008). Standard Test Method for Compressive Strength of Cylinderical Concrete Specimens. ANNUAL BOOK OF ASTM STANDARDS.

ASTM C 469. (2008). Standard test method for Static Modulus of Elasticity and Poisson's Ratio of concrete in Compression. ANNUAL BOOK OF ASTM STANDARDS.

ASTM C 496/C 496M. (2008). Standerd Test Method for Splitting Tensile Strength of Cylindrical Concrete Specimens. ANNUAL BOOK OF ASTM STANDARDS.

ASTM C 78. (2008). Standard Test for Flexural Strength of Concrete (Using Simple Beam with Third-point Loading). ANNUAL BOOK OF ASTM STANDARDS.

ASTM D 3039/ 3039M. (1995). Standerd Test Mathod for Tesnsile Properties of Polymer Matrix Composite Materials. ANNUAL BOOK OF STANDARDS. 
Ghobarah, A., \& El-Amoury, T. (2005). Siesmic Rehabilitation of Deficient Exterior Concrete Frame Joints. journal of composites for construction, 408-416.

GHOBARAH, A., \& SAID, A. (2001). Seismic Rehabilitation of Beam-Column Joint Using FRP Laminates. Journal of Earthquake Engineering, 5, 113-129.

Ghobarah, A., \& Said, A. (2002). Shear Strengthening of beam-column joint. Engineering Structures, 881-888.

Hakuto, S., Park, R., \& Tanaka, H. (2000). Seismic Load Tests on Interior and Exterior Beam-column Joints with Substanderd Reinfocing Details. ACI STRUCTURAL JOURNAL, 97(1), 11-25.

Mukherjee, A., \& Joshi, M. (2005). FRPC reinforced concrete beam-column joints under cyclic excitation. science and direct, 185-199.

Murate, E., Lawrence, K. F., \& Abdul-Hamid, Z. (2005). Repair and Strengthening of Reinforced Concrete Beam-Column Joints: State of Art. ACI STRUCTURAL JOURNAL, 102 .

park, R., \& Paulay, T. (1973). BEHAVIOR OF REINFORCED CONCRETE EXTERNAL BEAM-COLUMN JOINTS UNDER CYCLIC LOADING. 772781.

Pinkham, C. W. (1985). Rocomendations for design of beam-column joints in monolithic reinforced concrete structures. Journal of American Concrete INstitute, 82, 266283. 
Prota, A., Nanni, A., Manfredi, G., \& Cosenza, E. (2000). Seismic Upgrade of BeamColumn joints with FRP reinforcement. Indsutria del Cemento, 1-17.

REVATHI R., S. V. (2014). Flexural Behavior of Corner Beam-Column Joint with and without Slab. International Journal of, 3.

Xinbao, Y., Antonio, N., Stephen, H., \& Chung Leung, S. (2002). Strength and Modulus Degradtion of Carbon Fiber-Reinforced Ploymer Laminates from Fiber Misalignment. MATERIALS IN CIVIL ENGINEERING, 14(4). 


\section{APPENDIX A}

\section{JOINT DESIGN}

\section{Beam-Column Joint Design According to ACI 318-14 Code}

\section{Beam flexural strength:}

$f^{\prime}{ }_{c}=3000 \mathrm{psi}$

$A_{s}=0.22 \mathrm{in}^{2}$ Tensile reinforcement in the section (\#3 bar size)

$\rho=\frac{A_{s}}{b . d}=\frac{0.22}{5.25 * 5}=8.38 * 10^{-3}$

$\rho_{\text {min }}=$ the largest of $\frac{3 * \sqrt{f^{\prime}}{ }_{c}}{f_{y}}=\frac{3 * \sqrt{3000}}{60000}=2.74 * 10^{-3}$ or $\frac{200}{f_{y}}=\frac{200}{60000}=3.3 * 10^{-3}($ control $)<\rho \quad O . K$

$\mathrm{B}_{1}=0.85$

$$
\begin{gathered}
\rho_{b}=0.85 * B_{1} * \frac{f^{\prime}{ }_{c}}{f_{y}} *\left[\frac{87000}{87000+f_{y}}\right]=0.85 * 0.85 * \frac{3000}{60000} *\left[\frac{87000}{87000+60000}\right] \\
=0.0214
\end{gathered}
$$

$\rho_{\max .}=0.75 \rho_{b}=0.75 * 0.0214=0.016$

$\rho_{\max .}>\rho \rightarrow O . K$

$a=\frac{A_{s} * f_{y}}{0.85 * f^{\prime}{ }_{c}^{* b}}=\frac{0.22 * 60000}{0.85 * 3000 * 5}=1.035$ 
$c=\frac{a}{B 1}=\frac{1.035}{0.85}=1.217$

Check:

$$
\begin{aligned}
& \frac{c}{d_{t}}=\frac{1.217}{5.25}=0.232<0.375 \quad \text { O.K } \\
& M_{n}=A_{s} * f_{y}\left(d-\frac{a}{2}\right)=0.22 * 60\left(5.25-\frac{1.035}{2}\right) \cong 62.5 \text { kips } * \text { inch }
\end{aligned}
$$

\section{Shear reinforcement beam design:}

Let's assume that this beam will fail at a concentrated load $(\mathrm{P})=1.25 * 3.125=4$ kips

Use $\mathrm{Vu}=4$ kips

Form shear force diagram of the cantilever

$$
\begin{aligned}
& V_{u}=P=4 \text { kips } \\
& \emptyset V_{c}=0.75 * 2 * \frac{\sqrt{f^{\prime}}}{1000} * b * d=0.75 * 2 * \frac{\sqrt{3000}}{1000} * 5 * 5.25=2.15 \text { Kips } \\
& V_{u}>\emptyset V_{c} \quad \rightarrow \text { use shear reinforcemnt }, \text { use wire, diameter }=0.25 \text { in } \\
& f_{y}=38 \mathrm{Ksi}
\end{aligned}
$$

Bar diameter $=0.25$ in

$$
\begin{aligned}
& A_{b}=0.049 \mathrm{in}^{2} \\
& A_{v}=0.098 \mathrm{in}^{2}
\end{aligned}
$$


Check:

$$
\begin{aligned}
& \emptyset V_{s}=V_{u}-\emptyset V_{c}=4-2.15=1.85 \text { kips } \\
& 8 * \emptyset * \frac{\sqrt{f^{\prime}} \cdot 1}{1000} * b * d=8 * 0.75 * \frac{\sqrt{3000}}{1000} * 5 * 5.25=8.626 \text { kips } \gg \emptyset V_{s}=1.85 \text { kips } \\
& \rightarrow O . K \\
& S_{\text {required }}=\frac{\emptyset * A_{v} * f_{y} * d}{V_{u}-\emptyset V_{c}}=\frac{0.75 * 0.098 * 38 * 5.25}{4-2.15}=8 \text { in } \\
& S=8 \leq d / 2=\frac{5.25}{42}=2.625 \text { in (control) or } 24 \text { in }
\end{aligned}
$$

\section{Use Wire 0.25 in. Diameter (\#2 bar) @ 2.5 in. O.C.}

\section{Beam seismic requirement details:}

18.6.4. Over lengths equal to twice the member depth on both sides of a sections where the flexural yielding is likely to occur in connection with inelastic displacement of frame.

$$
2 d=2 * 5.25=10.5 \text { inch }
$$

First hoop is within (2 in.) from the face of the column

Spacing between hoops is the smallest of:

$$
\begin{aligned}
& >\frac{d}{4}=\frac{5.25}{4}=1.3 \text { inch } \quad(\text { control }) \\
& >6 * d_{b}=6 * 0.375=2.25 \text { inch } \\
& >6 \text { inch }
\end{aligned}
$$


18.6.4.6. Where hoops are not required, stirrups with seismic hooks at both ends shall be spaced at distance not more than $(\mathrm{d} / 2)$ through the length of the member.

$\frac{d}{2}=\frac{5.25}{2}=2.625 \mathrm{inch}$

\section{Column design:}

Assume: $M_{n \text { column }}=\frac{1}{2} M_{n \text { beam }}=\frac{1}{2} * 62=31$ kips . in

Assume $\rho=0.03$ and the longtuidinal reinforcemnt bar size is \#4

$A_{\text {s required }}=\rho * A_{g}=0.03 * 25=0.75 \mathrm{in}^{2}$

$A_{\text {s bar }}=0.2(\# 4$ bar $)$

Number of required bars $=0.75 / 0.2=3.75 \approx 4$ bars

$A_{\text {s provided }}=4 * 0.2=0.8 \mathrm{in}^{2}$

Wire diameter $=0.25$ in $\quad$ (tie diameter)

$\gamma h=5-05 * 2 * 0.25 * 2-0.5=3$ in,$h=5$ in

$\gamma=\frac{3}{5}=0.6$

Based on chart R4-60-60

$\frac{\emptyset M_{n}}{A_{g} * h}=\frac{0.7 * 31}{25 * 5}=0.174 \& \rho=0.03$ 
$\frac{\emptyset P_{n}}{A_{g}}=2.4$ from intraction diagram $\rightarrow P_{n}=85 \mathrm{kips}$

\section{Tie design in column}

The wire bar that is used (diameter 0.25 in.)

25.7.2: Vertical spacing of ties shall not exceed:

$16 *$ longitudinal bar diameter $=16^{*}(0.5 \mathrm{in})=8$ in

$48 *$ lie bar or wire $=48 * 0.25=12$ in

Least dimension of column $=5$ in (control)

\section{Column Seismic requirement details:}

Column confinement

$l_{o}=$ the largest of

$>$ Distance equal to the larger dimension of column $=5 \mathrm{in}$.

$1 / 6$ of the clear $\operatorname{span}=1 / 6 * 40$ in. $\approx 7$ in

18 in (control)

18.7.5.3: Spacing of transverse reinforcement shall not exceed:

$>1 / 4$ min dimension of column section $=1 / 4 * 5=1.25$ in (control)

$6^{*}$ longitudinal bar diameter $=6^{*} 0.5=3$ in

$>$ c $-6 \geq S_{o}=4+\left(\frac{14-h_{x}}{3}\right) \geq 4, h_{x}=3.75$ in 


$$
\begin{aligned}
& 6 \leq S_{o}=4+\left(\frac{14-h_{x}}{3}\right) \geq 4 \quad S_{o}=7.41 \text { in }>6 \text { in } \\
& \rightarrow S_{o}=6 \text { in }
\end{aligned}
$$

The total cross section area:

$$
\begin{aligned}
& A_{s h}=0.3 * \frac{s * b_{c} * f^{\prime}{ }_{c}}{f_{y t}}\left[\frac{A_{g}}{A_{c h}}-1\right]=0.3 * \frac{1.25 * 3.75 * 3}{38} *\left[\frac{25}{3.75^{2}}-1\right] \\
& =0.0863 \mathrm{in}^{2} \text { (control) } \\
& A_{s h}=0.09 * \frac{s * b_{c} * f^{\prime}{ }_{c}}{f_{y t}}=0.3 * \frac{1.25 * 3.85 * 3}{38}=0.034 \mathrm{in}^{2} \\
& A_{s}=2 * \frac{\pi}{4} *\left(d_{b}\right)^{2}=2 * \frac{\pi}{4} *(0.25)^{2}=0.098 \mathrm{in}^{2}>A_{s h}=0.0863 \mathrm{in}^{2}
\end{aligned}
$$

18.7.5.5: Beyond the confinement length $\left(l_{0}\right)$, the column shall contain spiral or hoop reinforcement with center-to-center spacing $(\mathrm{S})$ not exceeding the smaller of six times the diameter of the smallest longitudinal column bars and 6 in.

$6 * 0.5=3$ in. (control) or 6 in. 


\section{Column shear strength (check for seismic requirements)}

$$
\begin{aligned}
& A_{s}=2 * \frac{\pi}{4} d^{2}=2 * \frac{\pi}{4}(0.375)^{2}=0.22 \mathrm{in}^{2} \\
& T=A_{s} *\left(1.25 f_{y}\right)=0.22 * 1.25 * 60=16.5 \text { kips } \\
& a=\frac{A_{s} *\left(1.25 f_{y}\right)}{0.85 * f^{\prime}{ }_{c} * b}=\frac{16.5}{0.85 * 3 * 5}=1.3 \mathrm{in} \\
& M_{p r}=T *\left(d-\frac{a}{2}\right)=16.5 *\left(5.25-\frac{1.3}{2}\right)=75.9 \text { kips } * \text { in }
\end{aligned}
$$

Approxmate column shear :

$$
V_{n}=\frac{M_{p r}}{\frac{L_{\text {above }}+L_{\text {bellow }}}{2}}=\frac{75.9}{40}=1.9 \mathrm{kip}
$$

Joint:

$V_{u}=T-V_{n}=16.5-1.9=14.6$ kips

max. allowed $\varnothing V_{c}=0.75 * 12 * \frac{\sqrt{f_{c}^{\prime}}}{1000} A_{j}$ other cases

$$
\begin{aligned}
& A_{j}=5 * 5=25 \mathrm{in}^{2} \\
& \varnothing V_{c}=12 * \frac{\sqrt{3000}}{1000} * 25=16.43 \text { kips }>V_{u}=14.6 \mathrm{kip} \text { o.k }
\end{aligned}
$$




\section{APENDIX B}

Tensile Test Results for the CFRP Specimens

Seven tests were carried out in accordance with the ASTM D 3039/ D 3039M at the Portland State University Lab in order to verify the tensile properties provided by manufacturer of this material and the test results represented by the stress-strain diagram are summarized in figures below:
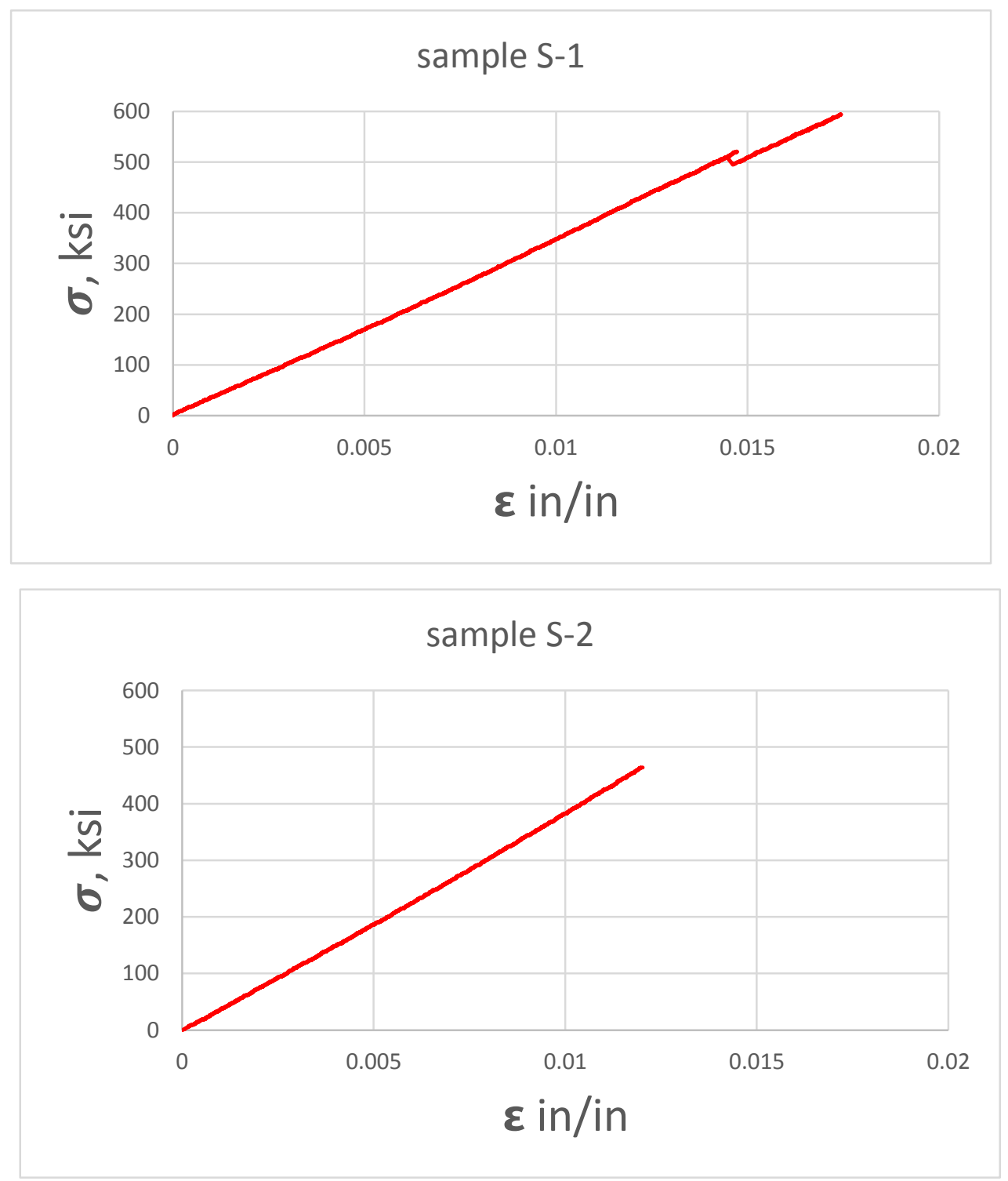

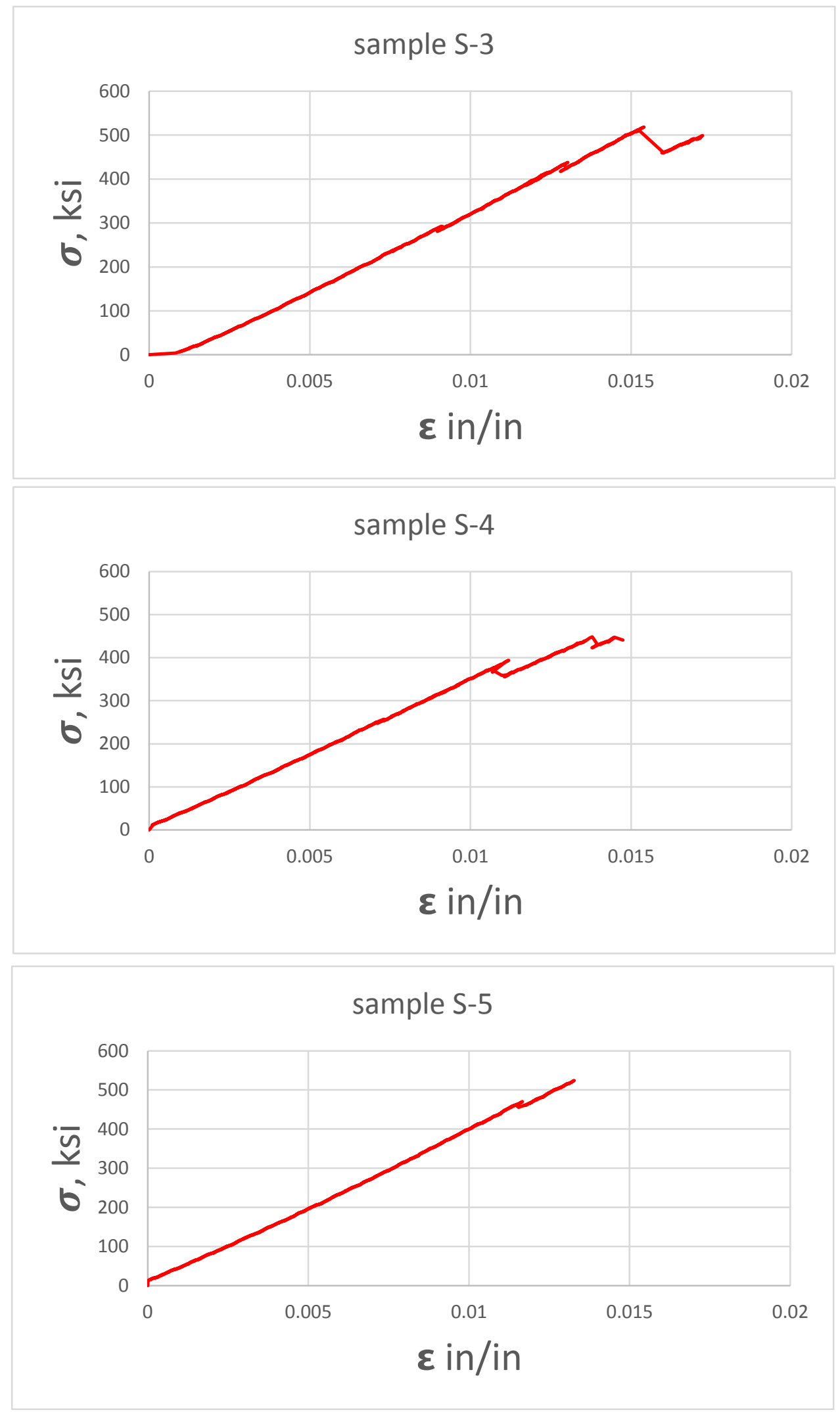

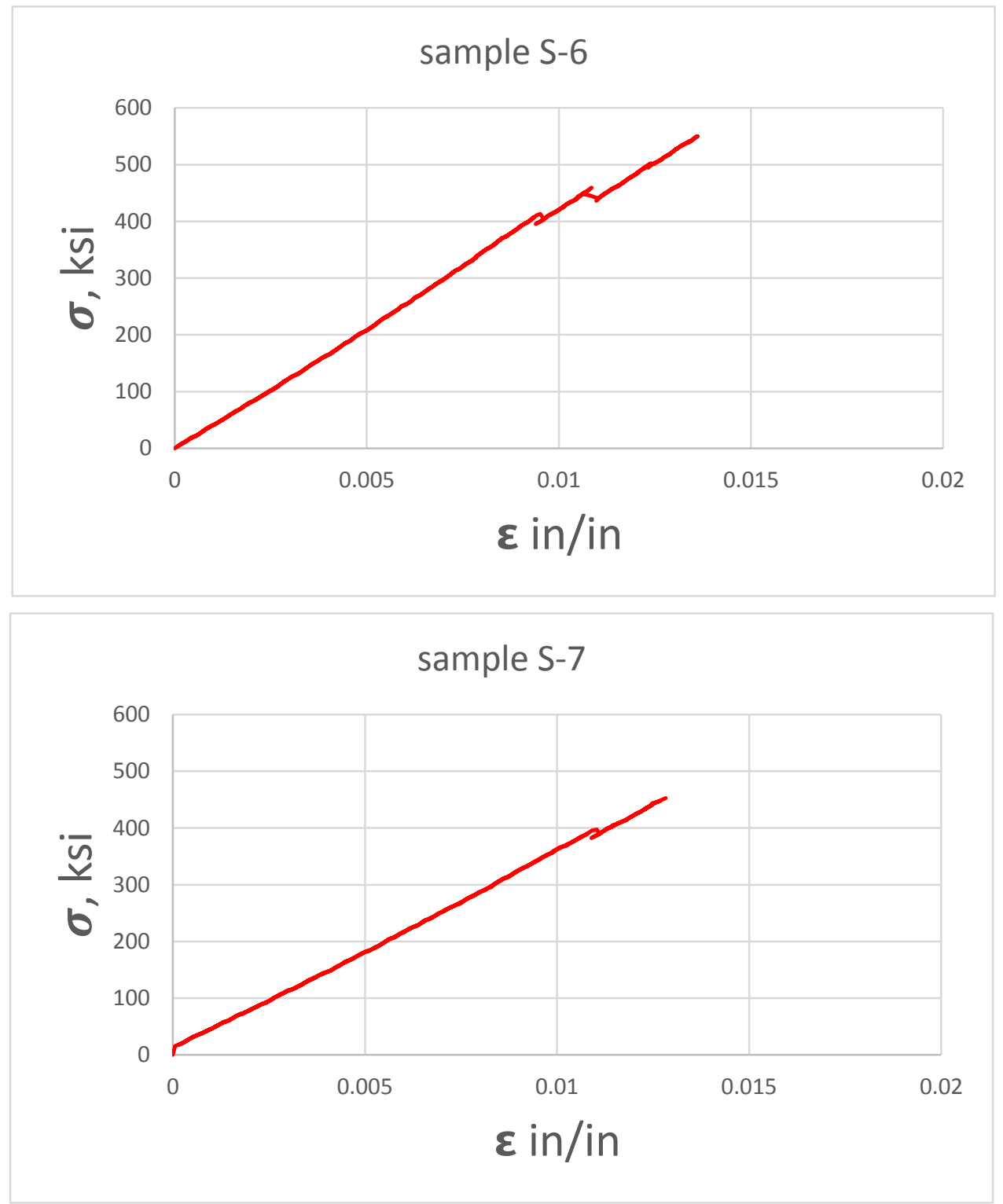

As shown in the stress-strain diagrams of all specimens, the only specimen that matched the manufacturer properties was specimen (S-1) where the failure for this specimen had occurred at the middle of the strip. Regarding to the rest of the specimens, all of the results were a little less than the manufacturer criteria. The reason for this was because the ruptures of the strips occurred close to the grips, and the strain gages were placed at the middle of the models. 